Luciano Reis Coutinho

\title{
Interoperabilidade Organizacional em Sistemas Multiagentes Abertos baseada em Engenharia Dirigida por Modelos
}

Tese apresentada à Escola Politécnica da Universidade de São Paulo para obtenção do Título de Doutor em Engenharia Elétrica. 
Luciano Reis Coutinho

\section{Interoperabilidade Organizacional em Sistemas Multiagentes Abertos baseada em Engenharia Dirigida por Modelos}

Tese apresentada à Escola Politécnica da Universidade de São Paulo para obtenção do Título de Doutor em Engenharia Elétrica.

Área de concentração:

Sistemas Digitais

Orientador:

Prof. Dr. Jaime Simão Sichman 
Este exemplar foi revisado e alterado em relação à versão original, sob responsabilidade única do autor e com a anuência de seu orientador.

São Paulo, 05 de outubro de 2009.

Assinatura do autor

Assinatura do orientador

\section{Ficha Catalográfica}

Coutinho, Luciano Reis

Interoperabilidade Organizacional em Sistemas Multiagentes Abertos baseada em Engenharia Dirigida por Modelos. - ed. rev. - São Paulo, 2009. 233 p.

Tese (Doutorado) - Escola Politécnica da Universidade de São Paulo. Departamento de Engenharia de Computação e Sistemas Digitais.

1. Sistemas multiagentes. 2. Agentes inteligentes. 3. Engenharia de Software. I. Universidade de São Paulo. Escola Politécnica. Departamento de Engenharia de Computação e Sistemas Digitais. II. Título. 
A meus pais.

A Isabel e Alan. 


\section{Agradecimentos}

É com grande satisfação que gostaria de registrar meus sinceros agradecimentos a todos que contribuíram para que este trabalho pudesse ser realizado.

Ao Prof. Jaime S. Sichman por ter sido o meu orientador. A ele sou muito grato por ter depositado confiança em minhas idéias, e ter me mostrado que elas nem sempre são claras como eu imagino. Sou grato também pela boa vontade, compreensão e empenho que demonstrou na reta final de minha pesquisa, estimulando-me decisivamente a terminar a escrita da tese.

Ao Prof. Olivier Boissier e a sua família pela calorosa recepção que eu e minha família tivemos em Saint-Etienne. Na École Nationale Supériere des Mines de Saint-Etienne fiz um estágio de seis meses sob a supervisão do Prof. Olivier. Com ele e com seus alunos tive a oportunidade de discutir e refinar boa parte das idéias apresentadas neste trabalho.

Ao Jomi por gentilmente ter me ajudado a implementar a infraestrutura MAORI e a aplicação Write Paper.

Aos amigos e amigas do LTI, Antônio, Diana, Valdinei, Valguima, André, Rodrigo, Anna, Anarosa, Gustavo, Inácio, com os quais convivi e muito aprendi durante a primeira metade do doutorado.

À FAPEMA pela bolsa de doutorado (processo 127/04) e à CAPES pela bolsa para estágio no exterior (processo 1511/06-8). Sem o apoio financeiro destas instituições, a realização deste trabalho não teria sido possível.

Aos amigos Klauber, João de Deus e Naila pela agradável acolhida em São Paulo, quando de minhas idas e vindas entre São Luís e esta cidade.

Por fim, agradeço a toda minha família pela compreensão e apoio que sempre recebi durante todo o processo. Em especial, a Isabel por me encorajar a lutar pelos meus sonhos. 


\section{Resumo}

Nesta tese, propõe-se integrar, de modo sistemático, modelos organizacionais para prover interoperabilidade organizacional em sistemas multiagentes abertos. A interoperabilidade organizacional consiste em permitir que, em uma mesma organização de agentes, coexistam agentes desenvolvidos a partir de modelos organizacionais distintos. Para realizar tal intuito, aplica-se uma abordagem baseada em técnicas da Engenharia Dirigida por Modelos. A abordagem proposta dividese em três etapas principais: (1) representar a estrutura conceitual de modelos organizacionais através de metamodelos; (2) identificar correspondências entre as estruturas conceituais dos modelos organizacionais utilizando como heurística a idéia de dimensões e padrões de modelagem organizacional; e (3) combinar os metamodelos dos modelos organizacionais seguindo um algoritmo de junção de modelos baseado em grafos e articulações de grafos. Utilizando a abordagem proposta, quatro modelos organizacionais existentes são integrados: os modelos AGR, STEAM, MOISE+ e ISLANDER. Para ilustrar o uso da integração de metamodelos no problema de interoperabilidade organizacional, especifica-se e implementa-se uma infraestrutura de interoperabilidade organizacional chamada MAORI (Model-driven Architecture for Organizational Interoperability). A infraestrutura MAORI é estruturada em duas camadas: (1) a camada M2M, na qual a integração de modelos realizada é utilizada para traduzir especificações e estados organizacionais, e (2) a camada ORI, na qual infraestruturas organizacionais são interconectadas. Para testar e validar toda a proposta, a infraestrutura MAORI foi implementada para as infraestruturas organizacionais S-MOISE+ e MADKIT, e uma aplicação denominada WritePaper foi desenvolvida. A partir das implementações, alguns experimentos foram realizados. Os resultados obtidos demonstram que a integração de modelos organizacionais proposta, realizada na infraestrutura de interoperabilidade MAORI, efetivamente interconecta infraestruturas organizacionais distintas e permite que, em uma mesma organização de agentes, coexistam agentes desenvolvidos a partir de modelos organizacionais distintos. 


\section{Abstract}

This thesis proposes to integrate systematically organizational models for providing organizational interoperability in open multiagent systems. Organizational interoperability consists in enabling the participation, in the same agent organization, of agents developed with different organizational models. For this purpose, it is applied an approach based on techniques from Model-driven Engineering. The appoach is divided in three main steps: (1) to represent the conceptual structure of organizational models by means of metamodels; (2) to identify correspondences among the conceptual structures of the organizational models using as heuristics the idea of organizational modeling dimensions and patterns; (3) to combine the metamodels of the organizational models by following a merge algorithm based on graphs and graph articulations. Using the proposed approach, four existing organizational models are integrated: AGR, STEAM, MOISE+ and ISLANDER. To illustrate the use of the integration, an organizational interoperability infrastructure called MAORI (Model-driven Architecture for Organizational Interoperability) is specified and implemented. The MAORI infrastructure is structured in two layers: (1) the M2M layer, in which the integration of models is used to translate the organizational specifications and states, and (2) the ORI layer, in which the organizational infrastructures are interconnected. To test and validate the approach, MAORI infrastructure was implemented for the organizational infrastructures S-MOISE + and MADKIT, and an application called Write Paper was developed. Using the implementations, some experiments were done. The results show that the organizational model integration, implemented in the MAORI infrastructure, effectively interconnects distinct organizational infrastructures and enables the participation, in the same agent organization, of agents developed with different organizational models. 


\section{Sumário}

1 Introdução 1

1.1 Motivação . . . . . . . . . . . . . . . . . . . 1

1.1.1 Organização de Agentes . . . . . . . . . . . . . . 2

1.1.2 Interoperabilidade Organizacional . . . . . . . . . . . 4

1.1.3 Soluções de Interoperabilidade . . . . . . . . . . . . . . 8

1.1.4 Questões Centrais ................. 12

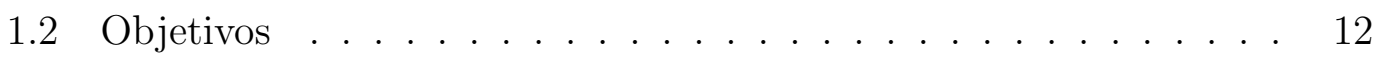

1.3 Abordagem ........................... 13

1.4 Estrutura do Texto . . . . . . . . . . . . . . . . . 15

I Conceitos Básicos $\quad 17$

2 Sistemas Multiagentes centrados na Organização 18

2.1 Agentes Autônomos . . . . . . . . . . . . . . . . 19

2.1.1 Agentes Reativos e Deliberativos . . . . . . . . . . 21

2.1.2 Agentes Sócio-Organizacionais . . . . . . . . . . . 21

2.2 Sistemas Multiagentes . . . . . . . . . . . . . . . . 23

2.2 .1 Interação entre Agentes . . . . . . . . . . . . . . . . . 23

2.2.2 Ordem Social . . . . . . . . . . . . . . . . . 25

2.3 Organizações de Agentes . . . . . . . . . . . . . . . . . . . . . . . 27

2.3.1 Conceito de Organização . . . . . . . . . . . . . . . . . . 27

2.3.2 Modelos Organizacionais . . . . . . . . . . . . . 30

2.3.3 Infraestruturas Organizacionais . . . . . . . . . . 33 
2.3.4 Arquitetura Genérica . . . . . . . . . . . . . . . 38

2.4 Resumo . . . . . . . . . . . . . . . . . . . . . . 39

3 Engenharia Dirigida por Modelos $\quad 41$

3.1 Modelos e Metamodelos . . . . . . . . . . . . . . . . . . 41

3.1 .1 Noção de Modelo . . . . . . . . . . . . . . . . . . . . . . 41

3.1 .2 Noção de Metamodelo . . . . . . . . . . . . . . . . . 44

3.1.3 Metamodelos Ecore . . . . . . . . . . . . . . . . 48

3.2 Integração de (Meta)Modelos . . . . . . . . . . . . . . . 52

3.2 .1 Integração Conceitual . . . . . . . . . . . . . . . . . 52

3.2 .2 Identificação de Correspondências . . . . . . . . . . . . . . 54

3.2.3 Junção de Metamodelos . . . . . . . . . . . . . . . . . . 58

3.3 Resumo . . . . . . . . . . . . . . . . . . . . 68

$\begin{array}{lll}\text { II Integração de Modelos Organizacionais } & 71\end{array}$

4 Modelagem de Organizações de Agentes $\quad 72$

4.1 Dimensões de Modelagem . . . . . . . . . . . . . . . . . . . 72

4.1 .1 Dimensões Primárias . . . . . . . . . . . . . . . . . 74

4.1 .2 Dimensões Secundárias . . . . . . . . . . . . . . . . . 77

4.2 Modelos Organizacionais . . . . . . . . . . . . . . . . . . . . 79

4.2 .1 TAEMS .............................. 81

$4.2 .2 \quad \mathrm{AGR} \ldots \ldots \ldots \ldots \ldots \ldots$

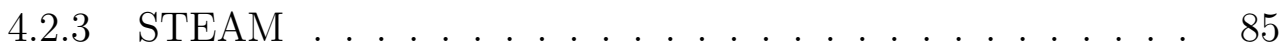

4.2.4 MOISE $+\ldots \ldots \ldots$. . . . . . . . . . . . . . . 90

4.2 .5 ISLANDER . . . . . . . . . . . . . . . . . . 94

4.2 .6 OPERA . . . . . . . . . . . . . . . . . . . 98

4.2 .7 Outros Modelos . . . . . . . . . . . . . . . . 103

4.3 Considerações Finais . . . . . . . . . . . . . . . . . . 104 
5.1 Dimensão Funcional . . . . . . . . . . . . . . . . . 106

5.1 .1 Padrão Conceitual . . . . . . . . . . . . . . 107

5.1 .2 Particularidades . . . . . . . . . . . . . . . . . 109

5.2 Dimensão Estrutural . . . . . . . . . . . . . . . . . . . . . . 112

5.2 .1 Padrão Conceitual . . . . . . . . . . . . . . . . . . . 112

5.2 .2 Particularidades . . . . . . . . . . . . . . . . 113

5.3 Dimensão Dialógica . . . . . . . . . . . . . . . . . . . . 117

5.3.1 Padrão Conceitual . . . . . . . . . . . . . . . . 117

5.3.2 Particularidades . . . . . . . . . . . . . . . . . 118

5.4 Dimensão Normativa . . . . . . . . . . . . . . . . . . . . . . . 123

5.4.1 Padrão Conceitual . . . . . . . . . . . . . . . . 123

5.4 .2 Particularidades . . . . . . . . . . . . . . . . . . 123

5.5 Considerações Finais . . . . . . . . . . . . . . . . . 125

$\begin{array}{lll}6 & \text { Modelo Organizacional Integrado } & 127\end{array}$

6.1 Método de Integração . . . . . . . . . . . . . . . . . . . . . . . . 127

6.2 Aplicação do Método . . . . . . . . . . . . . . . . . . . . . . 130

6.2 .1 Primeira Iteração . . . . . . . . . . . . . . . . . . . 130

6.2 .2 Segunda Iteração . . . . . . . . . . . . . . . . . . . . 140

6.2 .3 Terceira Iteração . . . . . . . . . . . . . . . . . . . 156

6.3 Resultado Final . . . . . . . . . . . . . . . . . . . . 162

\section{Interoperabilidade Organizacional 164}

$\begin{array}{llr}7 & \text { Infraestrutura MAORI } & 165\end{array}$

7.1 Visão Geral . . . . . . . . . . . . . . . . . . . . . 166

7.2 Estrutura Interna . . . . . . . . . . . . . . . . . . . 168

7.2.1 Camada de Integração de Modelos . . . . . . . . . . . . . 168 
7.2.2 Camada de Interoperabilidade Organizacional . . . . . . . 170

7.3 Funcionamento . . . . . . . . . . . . . . . . 173

7.3.1 Conexão entre Provedor e Adaptadores . . . . . . . . . . . 174

7.3.2 Propagação de Eventos Organizacionais . . . . . . . . . . 175

7.3.3 Roteamento de Mensagens entre Agentes . . . . . . . . . 177

7.4 Considerações Finais . . . . . . . . . . . . . . . . . 179

8 Implementação e Testes 181

8.1 Implementação de MAORI . . . . . . . . . . . . . . . . . . . . 181

8.1.1 Camada de Integração de Modelos . . . . . . . . . . . . . 181

8.1.2 Camada de Interoperabilidade Organizacional . . . . . . . 185

8.2 Aplicação Write Paper . . . . . . . . . . . . . . . . . . . . . 189

8.2.1 Descrição da Aplicação . . . . . . . . . . . . . . . . . 189

8.2 .2 Experimento $1 \ldots \ldots \ldots \ldots$

8.2.3 Experimento $2 \ldots \ldots \ldots \ldots$

8.2.4 Experimento $3 \ldots \ldots \ldots . \ldots \ldots$

8.2.5 Experimento $4 \ldots \ldots \ldots \ldots$

8.3 Considerações Finais . . . . . . . . . . . . . . . . . 200

9 Conclusões $\quad 204$

9.1 Contribuições . . . . . . . . . . . . . . . . . . . . . 204

9.2 Trabalhos Futuros . . . . . . . . . . . . . . . . . 208

Apêndice A - Meta-metamodelo de Ecore 210

$\begin{array}{ll}\text { Anexo A - Metamodelos do Capítulo } 4 & 218\end{array}$

Anexo B - Metamodelos do Capítulo 6 219

Anexo C - Implementação do Capítulo 8 220 


\section{Lista de Figuras}

2.1 Agente autônomo. . . . . . . . . . . . . . . . 20

2.2 Modelos genéricos de agentes reativos e deliberativos. . . . . . . . 22

2.3 Abordagens para o problema da ordem social. . . . . . . . . . . . 26

2.4 Conceito de Organização. . . . . . . . . . . . . . . . . . . . 30

2.5 Arquitetura da plataforma MADKIT (GUTKNECHT; FERBER, 2000). 34

2.6 Arquitetura da infra-estrutura TEAMCORE (TAMBE; PYNADATH, 2001). . . . . . . . . . . . . . . . 35

2.7 Componentes de S-MOISE+ (HüBNER; SICHMAN; BOISSIER, 2005). 36

2.8 Arquitetura de uma e-instituição (ESTEVA et al., 2004). . . . . . . 38

2.9 Arquitetura genérica de SMA-COs. . . . . . . . . . . . . . . . . . 39

3.1 Modelos organizacionais e a noção de modelo. . . . . . . . . . . . 44

3.2 Metamodelo da mLE escrito em Ecore/OCL. . . . . . . . . . . . 50

3.3 Modelo criado conforme o metamodelo Ecore da mLE. . . . . . . 52

3.4 Metamodelo Ecore da mLE'. . . . . . . . . . . . . . . . . 55

3.5 Identificação de correspondências entre metamodelos. . . . . . . . 56

3.6 Metamodelo Ecore como grafo. . . . . . . . . . . . . . . 61

3.7 Correspondências como articulação entre grafos. . . . . . . . . . . 62

3.8 Junção dos metamodelos mLE e mLE'. . . . . . . . . . . . . . . . 69

4.1 Dimensões de modelagem organizacional. . . . . . . . . . . . . . . 74

4.2 Exemplo de modelagem TAEMS. . . . . . . . . . . . . . 82

4.3 Metamodelo TAEMS. . . . . . . . . . . . . . . . . 83

4.4 Metamodelo AGR. . . . . . . . . . . . . . . . 85

4.5 Exemplo de modelagem AGR. . . . . . . . . . . . . . 86

4.6 Exemplo de modelagem STEAM. . . . . . . . . . . . . . . 88 
4.7 Metamodelo STEAM. . . . . . . . . . . . . . . . . . 89

4.8 Exemplo de modelagem MOISE $+\ldots \ldots$. . . . . . . . . . . . 91

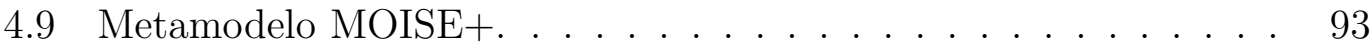

4.10 Exemplo de modelagem ISLANDER. . . . . . . . . . . . . . . 95

4.11 Metamodelo ISLANDER. . . . . . . . . . . . . . . . . 97

4.12 Metamodelo OPERA. . . . . . . . . . . . . . . . . . 101

4.13 Exemplo de modelagem OPERA. . . . . . . . . . . . . . . . 102

5.1 Exemplo de uma especificação funcional em TAEMS, STEAM, MOISE+ e OPERA. . . . . . . . . . . . . . . . . . 108

5.2 Exemplo de uma especificação estrutural em STEAM, AGR, MOISE+, ISLANDER e OPERA. . . . . . . . . . . . . . . . . . . . . . 114

5.3 Exemplo de uma especificação dialógica em ISLANDER e OPERA. 119

5.4 Modelo Organizacional Abstrato. . . . . . . . . . . . . . 126

6.1 Método geral de integração. . . . . . . . . . . . . . . . . . . . . . 128

6.2 Comparação entre as especificações estruturais de AGR e STEAM. 131

6.3 Elementos derivados na especificação estrutural de STEAM. . . . 134

6.4 Comparação entre as estados organizacionais de AGR e STEAM. 136

6.5 Articulação entre metamodelos de AGR e STEAM. . . . . . . . . 138

$6.6 M M_{\# 1}^{\text {int }}-$ metamodelo integrado da primeira iteração. . . . . . . . 140

6.7 Comparação entre o metamodelo de MOISE+ e $M M_{\# 1}^{\text {int }}$ quanto à dimensão estrutural. . . . . . . . . . . . . . . . . . . . . . . 142

6.8 Comparação entre o metamodelo de MOISE+ e $M M_{\# 1}^{\text {int }}$ quanto à dimensão funcional. . . . . . . . . . . . . . . . . . . . . . . . . . 148

6.9 Comparação entre o metamodelo de MOISE+ e $M M_{\# 1}^{\text {int }}$ quanto à dimensão normativa. . . . . . . . . . . . . . . . . 153

$6.10 M M_{\# 2}^{\text {int }}-$ metamodelo integrado da segunda iteração. . . . . . . . 155

6.11 Comparação entre o metamodelo de ISLANDER e $M M_{\# 2}^{\text {int }}$ quanto à dimensão estrutural. . . . . . . . . . . . . . . . . . . . . . . . . 158

$6.12 M M_{\# 3}^{\text {int }}$ - metamodelo integrado da terceira iteração (parte 1). . . 161 
$6.13 M M_{\# 3}^{\text {int }}$ - metamodelo integrado da terceira iteração (parte 2). . . 162

7.1 Interoperabilidade organizacional. . . . . . . . . . . . . . 167

7.2 infraestrutura MAORI. . . . . . . . . . . . . . . . . 169

7.3 Sociedade de interoperabilidade organizacional ORISOC. . . . . . 171

7.4 Especificação organizacional da camada ORI, em MOISE+. . . . . 172

7.5 Conexão entre provedor e adaptadores por meio de S-MOISE +. 173

7.6 Protocolo de conexão entre provedor e adaptadores. . . . . . . . . 174

7.7 Protocolos de propagação de eventos organizacionais. . . . . . . . 176

7.8 Protocolos de roteamento de mensagens entre agentes. . . . . . . 178

8.1 Implementação dos metamodelos da camada M2M. . . . . . . . . 182

8.2 Implementação das transformações da camada M2M. . . . . . . . . 184

8.3 Implementação especificação organizacional da camada ORI utilizando S-MOISE.$+ \ldots \ldots \ldots$. . . . . . . . . . . 186

8.4 Implementações do provedor S-MOISE+ e do adaptador MADKIT. 187

8.5 Implementações do provedor MADKIT e do adaptador S-MOISE+. 188

8.6 Especificação da organização $w p$-org. . . . . . . . . . . . . . . . . 190

8.7 Implementação da organização wp-org na infraestrutura S-MOISE+.192

8.8 Implementação da organização wp-org na infraestrutura MADKIT. 193

8.9 Especificação da atividade conjunta dos agentes que compõem a organização wp-org. . . . . . . . . . . . . . . . . . . . . . . . 194

8.10 Experimento 1 - Provedor S-MOISE+ e adaptador MADKIT; Eric e Carol em S-MOISE+; e Joel, Greg e Mark em MADKIT. . . . . 196

8.11 Experimento 2 - Provedor S-MOISE+ e adaptador MADKIT; Joel, Greg e Mark em S-MOISE+; e Eric e Carol em MADKIT. . . . . 199

8.12 Experimento 3 - Provedor MADKIT e adaptador S-MOISE+; Eric e Carol em MADKIT; e Joel, Greg e Mark em S-MOISE+. . . . . 201

8.13 Experimento 4 - Provedor MADKIT e adaptador S-MOISE+; Joel, Greg e Mark em MADKIT; e Eric e Carol em S-MOISE+. . . . . 202

A.1 Estrutura conceitual da linguagem de meta-modelagem Ecore. . . 211 
A.2 Conformidade entre (meta)modelos e (meta-)metamodelos. . . . . 217 


\section{Lista de Tabelas}

4.1 Quadro comparativo dos modelos organizacionais analisados. . . . 105

5.1 Padrão de especificação funcional: descrição das classes. . . . . . . 110

5.2 Padrão de especificação funcional: restrições contextuais. . . . . . 111

5.3 Padrão de modelagem estrutural. . . . . . . . . . . . . . . . 115

5.4 Padrão de modelagem dialógica: descrição das classes. . . . . . . . 120

5.5 Padrão de especificação dialógica: restrições contextuais. . . . . . 121

5.6 Padrão de modelagem normativa. . . . . . . . . . . . . . . . . . . 124 


\section{Lista de Abreviaturas}

AGR Agent, Group, Role

AGRE Agent, Group, Role, Environment

AMELI Agent-based Middleware for ELectronic Institutions

API Application Programming Interface

ATL ATLAS Transformation Language

AUML Agent UML

BNF Backus-Naur Form

DFD Data Flow Diagram

DSpec Dialogical Specification

DTD Document Type Definition

Ecore EMF core

EDM Engenharia Dirigida por Modelos

EMF Eclipse Modeling Framework

FIPA Foundation for Intelligent Physical Agents

FIPA-ACL FIPA Agent Communication Language

FSpec Functional Specification

GOPPRR Graph-Object-Property-Port-Role-Relationship

HIPO Hierarchical Input Process Output

IDEF0 Integrated Definition for Functional Modeling

KARMA Knowledgeable Agent Resources Manager Assistant

KM3 Kernel Meta Meta Model 
KQML Knowledge Query and Manipulation Language

LCR Logic for Contract Representation

LMED Linguagem de Modelagem Específica de Domínio

M2M Integração de Metamodelos, camada

MAS-ML MAS Modeling Language

MAORI Model-driven Architecture for ORganization Interoperability

mLE mini Linguagem para modelagem de Empresas

MML Meta-Modeling Language

MOF Meta Object Facility

MOISE+ Model of Organization for multI-agent SystEms

MT4MDE Mapping Tool for Model-Driven Engineering

NSpec Normative Specification

OCL Object Constraint Language

ODML Organization Design Modeling Language

OPERA Organizations per Agents

ORI Interoperabilidade ORganizacional, camada

ORISOC ORganizational Interoperability SOCiety

OSpec Organizational Specification

SACI Simple Agent Communication Infrastructure

SMA Sistema Multiagentes

SMA-CA SMA Centrado no Agente

SMA-CO SMA Centrado na Organização

S-MOISE+ SACI/MOISE+

SSpec Structural Specification

STEAM Shell for TEAMwork 
TAEMS Task Analysis, Environment Modeling, and Simulation TOPI Team Oriented Programming Interface

UML Unified Modeling Language

XMF eXtensible Modeling Facility

XML eXtensible Markup Language

XSD XML Schema Definition 


\section{Lista de Símbolos}

Seguindo a notação tradicional da teoria de conjuntos, $A \cup B, A \cap B, A-B, A \times B$ e $m: A \rightarrow B$ representam respectivamente a união, a interseção, a diferença, o produto cartesiano e uma função (mapeamento) entre um conjunto $A$ e um conjunto $B$. Além da notação tradicional da teoria de conjuntos, empregam-se os seguintes símbolos especiais ao longo do texto:

\begin{tabular}{|c|c|}
\hline símbolo & descrição \\
\hline$a \mapsto b$ & par ordenado $(a, b) \in m: A \rightarrow B$; i.e., $m(a)=b$; \\
\hline$C_{1} \uplus C_{2}$ & união disjunta entre os conjuntos $C_{1}$ e $C_{2}$; \\
\hline$C_{1} \oplus_{\left\langle C, m_{1}, m_{2}\right\rangle} C_{2}$ & $\begin{array}{l}\text { soma amalgamada dos conjuntos } C_{1} \text { e } C_{2} \text {, módulo } \\
\text { mapeamentos } m_{1}: C \rightarrow C_{1} \text { e } m_{2}: C \rightarrow C_{2} \text {; }\end{array}$ \\
\hline$O M_{i}, O M_{j}$ & modelos organizacionais $i$ e $j$ \\
\hline$M M_{i}, M M_{j}$ & $\begin{array}{l}\text { metamodelos (grafos) que representam os modelos } \\
\text { organizacionais } i \text { e } j \text {, respectivamente; }\end{array}$ \\
\hline$G^{\text {art }}$ & $\begin{array}{l}\text { grafo de articulação entre dois metamodelos (gra- } \\
\text { fos) } M M_{i} \text { e } M M_{j}\end{array}$ \\
\hline$m_{\text {art }, i}: G^{a r t} \rightarrow M M_{i}$ & $\begin{array}{l}\text { morfismo entre o grafo de articulação } G^{\text {art }} \text { e o me- } \\
\text { tamodelo (grafo) } M M_{i}\end{array}$ \\
\hline$m_{a r t, j}: G^{a r t} \rightarrow M M_{j}$ & $\begin{array}{l}\text { morfismo entre o grafo de articulação } G^{a r t} \text { e o me- } \\
\text { tamodelo (grafo) } M M_{j} \text {; }\end{array}$ \\
\hline $\operatorname{art}\left(M M_{i}, M M_{j}\right)$ & $\begin{array}{l}\text { articulação }\left\langle G^{a r t}, m_{\text {art }, i}, m_{\text {art }, j}\right\rangle \text { entre dois metamo- } \\
\text { delos (grafos) } M M_{i} \text { e } M M_{j}\end{array}$ \\
\hline$M M_{i} \oplus_{\operatorname{art}\left(M M_{i}, M M_{j}\right)} M M_{j}$ & $\begin{array}{l}\text { soma amalgamada dos metamodelos (grafos) } M M_{i} \\
\text { e } M M_{j} \text {, módulo } \operatorname{art}\left(M M_{i}, M M_{j}\right)\end{array}$ \\
\hline$M M_{\# n}^{i n t}$ & metamodelo integrado após $n$ iterações; \\
\hline $\begin{array}{l}\operatorname{transf}\left(f: M M_{i}\right): M M^{i n t} \\
\operatorname{conv}_{i j}\left(f: M M_{i}\right): M M_{j}\end{array}$ & $\begin{array}{l}\text { transformação de } M M_{i} \text { para } M M^{i n t} \\
\left.\text { conversão } \operatorname{transf(} \operatorname{transf}\left(f: M M_{i}\right): M M^{i n t}\right) \text { : } \\
M M_{j} ;\end{array}$ \\
\hline$A g_{i}$ & agente $i$ \\
\hline
\end{tabular}




\section{Introdução}

Nesta tese, aborda-se o problema de como prover interoperabilidade organizacional entre agentes de software e organizações de agentes que são heterogêneos do ponto de vista de seus modelos e infraestruturas organizacionais subjacentes. Como principais contribuições, mostra-se como integrar as estruturas conceituais de modelos organizacionais existentes e como utilizar essa integração na especificação de uma infraestrutura de software cuja meta é interconectar infraestruturas organizacionais heterogêneas e permitir que, em uma mesma organização de agentes, coexistam agentes desenvolvidos a partir de modelos organizacionais distintos.

\subsection{Motivação}

Sistemas Multiagentes (SMAs) são sistemas de software que têm por base a noção de agente. Na pesquisa e desenvolvimento de tais sistemas, um dos problemas centrais é como garantir que um sistema composto por agentes venha a apresentar um comportamento global desejável de modo estável e eficiente (CASTELFRANCHI, 2000). Este problema surge a partir da própria definição de agente que, dentre outras características (FRANKLIN; GRAESSER, 1997), é concebido como um componente orientado a objetivos e com capacidade de decisão própria (autonomia).

Nos últimos anos, com a crescente demanda por sistemas abertos (ZAMBONELLI; PARUNAK, 2004; LUCK; MCBURNEY; PREIST, 2004; JENNINGS, 2001), esse problema tornou-se ainda mais desafiador. De maneira geral, um sistema aberto pode ser caracterizado como um sistema no qual se espera poder conectar ou desconectar componentes já na fase de produção. Mais importante, esses novos componentes podem ser heterogêneos, i.e., não precisam necessariamente ser fornecidos pelo projetista original do sistema, ter uma arquitetura interna específica, ou até mesmo serem implementados utilizando uma dada tecnologia.

$\mathrm{Na}$ nova realidade de sistemas abertos, percebem-se dois agravantes com 
relação ao problema de desenvolver SMAs:

- agentes heterogêneos irão apresentar interesses diversos que não necessariamente estarão de acordo com os interesses do sistema como um todo;

- agentes heterogêneos podem não ser capazes de interoperar entre si, isto é, trocar mensagens entre si ou compartilhar serviços devido a possíveis diferenças no modo pelo qual foram projetados.

Uma possível abordagem para superar tais problemas é a definição de organização de agentes.

\subsubsection{Organização de Agentes}

No contexto de SMAs abertos, uma abordagem que tem se mostrado promissora e bastante pesquisada é projetar o sistema sob um enfoque organizacional (BOISSIER; HüBNER; SICHMAN, 2007; FERBER; GUTKNECHT; MICHEL, 2004; GASSER, 2001; ZAMBONELLI; JENNINGS; WOOLDRIDGE, 2001; LEMAîTRE; EXCELENTE, 1998). Nesta abordagem, o sistema é concebido e implementado utilizando-se como metáfora as organizações humanas.

As organizações humanas, cujo exemplo típico são as empresas, são coletivos heterogêneos e dinâmicos que se formam tendo em vista uma finalidade e uma área de atuação bem definidas (SCOTT, 1998). Nesse caso, heterogeneidade e dinamismo, de modo geral, significam respectivamente que organizações tanto agregam pessoas que possam ter interesses próprios conflitantes quanto permitem a entrada ou saída de indivíduos ao longo do tempo. Dados estes fatores e tendo em vista uma dada finalidade, a atividade conjunta em uma organização tende a ser formalmente estruturada e padronizada, além de controlada explicitamente. Assim, dentro de uma organização há uma divisão e padronização de trabalho na forma de estruturas de papéis, grupos, procedimentos, protocolos, normas, etc., que:

- não surgem espontaneamente, mas, ao contrário, são planejadas e descritas objetivamente de modo independente dos indivíduos que a constituem em um dado momento por meio de documentos formais, tais como estatutos, organogramas, manuais, etc.;

- são explicitamente impostas aos membros da organização por meio de centros de gerenciamento e controle, que agem a partir do que foi planejado 
e descrito formalmente; indivíduos que não seguem as "regras do jogo" ficam sujeito a restrições e sanções que, em último caso, podem resultar na expulsão do indivíduo pela organização.

Com isso, uma organização busca garantir que, apesar de mudanças de pessoal e interesses diversos, a atividade conjunta de seus membros seja estável, predizível e eficiente ao longo do tempo, tendo em vista um objetivo maior que deve ser atingido.

Guardando-se as devidas proporções, nota-se que o desafio básico de desenvolver SMAs abertos, i.e., o problema de como garantir um comportamento global desejável de modo estável e eficiente a despeito da autonomia e da possível heterogeneidade dos agentes, é um problema comparável ao problema que empresas e outras organizações humanas enfrentam em face da variação e heterogeneidade de seus membros. Então, por analogia, vários pesquisadores têm argumentado, e mostrado através da construção de modelos e arquiteturas computacionais (HüBNER; SICHMAN; BOISSIER, 2005; HüBNER; SICHMAN; BOISSIER, 2002; HORLING; LESSER, 2004; DECKER, 1996; FERBER; GUTKNECHT; MICHEL, 2004; GUTKNECHT; FERBER, 2000; DIGNUM et al., 2002; ESTEVA; PADGET; SIERRA, 2002; ESTEVA et al., 2004; TAMBE et al., 1999; TAMBE; PYNADATH, 2001), que uma solução viável e vantajosa para desenvolver SMAs abertos é projetá-los em torno de organizações de agentes; ou seja, projetá-lo a partir de similares computacionais das organizações humanas.

Desta maneira, definem-se os SMAs centrados em organizações (SMA-COs) (FERBER; GUTKNECHT; MICHEL, 2004): SMAs que se caracterizam por apresentar, além de agentes, organizações de agentes como subsistemas do SMA. Tais organizações são especificadas formalmente, abstraindo-se características e estados internos dos agentes membros, e podem ser implementadas objetivamente, utilizando-se uma arquitetura computacional externa aos agentes membros de modo a desempenhar um papel similar ao que os documentos formais (organogramas, manuais, etc.) e os centros de gerenciamento e controle desempenham nas organizações humanas, conforme descrito acima.

Operando como um sistema aberto, as organizações de agentes admitem agentes heterogêneos. Como requisito básico, exige-se entretanto que todos os agentes que venham a entrar, participar e, ao final sair da organização, devem estar de acordo e se comprometer a proceder conforme a especificação formal da organização. Com isso, a grande vantagem é que o projetista passa a ter garantias sobre a atividade conjunta de agentes, tanto no que diz respeito à sua 
eficácia quanto à sua eficiência. Sendo eficazes, atingem um resultado esperado de modo estável. Já sendo eficientes, ao encontrarem estruturas organizacionais pré-estabelecidas, os agentes ficam livres de ter de deliberar uns com os outros a respeito de como proceder, tornando assim o funcionamento do SMA potencialmente mais otimizado. Como ponto negativo, no entanto, observa-se que quanto mais detalhado e restritivo for a especificação da organização, mais os agentes irão perder em autonomia, que vem a ser uma de suas características mais básicas. Como consequência, o SMA como um todo pode perder em flexibilidade de operação, deixando de ser capaz de reagir a eventos ou mudanças não previstas na especificação da organização.

Nota-se ainda que a exigência de proceder conforme uma especificação organizacional, requisito básico para um agente poder participar de uma organização de agentes, tem por base uma suposição arquitetural implícita sobre o projeto dos agentes. De maneira implícita, supõe-se que os agentes devem ter sido projetados para trabalhar em conjunto conforme um dado modelo organizacional que foi utilizado para especificar a organização de agentes. Assim, observa-se que os agentes participantes de uma organização podem ser heterogêneos, mas até certo ponto. Esta observação, que relativiza e restringe a concepção de SMAs abertos, está na base da problemática mais específica que motiva a investigação conduzida nesta tese, descrita a seguir.

\subsubsection{Interoperabilidade Organizacional}

Em geral, organizações de agentes são especificadas utilizando-se um modelo organizacional. Sob uma perspectiva de desenvolvimento de software, modelos organizacionais podem ser vistos como linguagens de modelagem específicas de domínio - LMEDs (Kelly; TOlVAnen, 2008; SCHMidt, 2006). Conforme esta visão, modelos organizacionais são linguagens que fornecem uma coleção de conceitos de modelagem (e.g., papel, grupo, tarefa, interações, obrigação, etc.), e regras de combinação de conceitos, que são propostos especificamente para representar o domínio de organizações de agentes. Desta maneira, modelos organizacionais determinam como organizações de agentes podem ser especificadas ${ }^{1}$.

No estado atual da pesquisa e desenvolvimento, há à disposição vários modelos organizacionais (HORLING; LESSER, 2004; FERBER; GUTKNECHT; MICHEL, 2004; HüBNER; SICHMAN; BOISSIER, 2002; DIGNUM et al., 2002; ESTEVA; PADGET;

\footnotetext{
${ }^{1} \mathrm{~A}$ associação de modelos organizacionais ao conceito de LMEDs é uma das idéias fundamentais na qual se assenta toda pesquisa desenvolvida no âmbito desta tese. Desta forma, essa idéia será rediscutida a seguir na seção 1.3, e detalhada nos capítulo 2 e 3.
} 
SIERRA, 2002; TAMBE et al., 1999; DECKER, 1996). Alguns destes modelos estão associados a infraestruturas organizacionais para a implementação explícita de organização de agentes (KITIO et al., 2008; HüBNER; SICHMAN; BOISSIER, 2005; LESSER et al., 2004; ESTEVA et al., 2004; TAMBE; PYNADATH, 2001; GUTKNECHT; FERBER, 2000).

De modo geral, as infraestruturas organizacionais existentes consistem em arquiteturas de software genéricas que são capazes de interpretar uma especificação organizacional feita em um dado modelo e, como resultado, funcionar como um subsistema explícito e independente que monitora e controla a atividade conjunta dos agentes de modo a implementar a organização de agentes especificada.

Por um lado, a existência de vários modelos organizacionais favorece o desenvolvimento de organizações de agentes uma vez que, com várias propostas, acumulam-se experiência e melhores práticas. Por outro lado, uma grande variedade de modelos organizacionais introduz heterogeneidade ao desenvolvimento de organizações de agentes. Como consequência direta dessa heterogeneidade, no caso de organizações que devem operar como sistemas abertos, um novo e importante problema de interoperabilidade surge. Em linhas geral, o problema pode ser enunciado da seguinte forma:

Caso não possuam uma arquitetura flexivel o suficiente, ou não sejam providos mecanismos explícitos de interoperabilidade, os agentes feitos para operar em organizações de agentes especificadas a partir de determinado modelo organizacional provavelmente não serão capazes de funcionar em organizações de agentes que utilizam um modelo organizacional diferente.

No contexto desta tese, esse problema será denominado de problema de interoperabilidade organizacional.

De maneira mais ampla, a noção de interoperabilidade organizacional pode ser definida como a capacidade de um agente poder participar de uma organização, independentemente de ter sido projetado a partir de um modelo organizacional diferente daquele utilizado na concepção da organização. Alternativamente, pode-se também dizer que interoperabilidade organizacional é uma das condições necessárias para que uma dada organização de agentes possa vir a ser formada por agentes que são heterogêneos do ponto de vista dos modelos organizacionais subjacentes às suas arquiteturas internas.

Tendo como motivação básica aumentar o grau de heterogeneidade permitido 
em organizações de agentes que operam como sistemas abertos, investigam-se nesta tese soluções para algumas das questões básicas envolvidas na problemática de como prover interoperabilidade organizacional.

\section{Cenários de Aplicação}

Para ilustrar concretamente o problema de interoperabilidade organizacional, a sua importância e os seus desafios, a seguir, apresentam-se dois cenários onde se pode perceber tanto a aplicação das organizações de agentes quanto a necessidade de haver interoperabilidade organizacional. Os cenários são: comércio eletrônico e gerenciamento de conferências.

Comércio Eletrônico O comércio eletrônico através da Internet é uma das principais áreas de aplicação para agentes e SMAs (SIERRA, 2004; KURBEL; LOUTCHKO, 2003) $)^{2}$. Com o advento da Internet, tanto clientes quanto empresas que fornecem produtos e serviços ampliaram seus horizontes. Hoje em dia, comprar pela Internet, participar de leilões virtuais, contratar serviços, abrir lojas virtuais são tarefas bastante comuns. Uma extensão natural deste cenário que envolve apenas pessoas é introduzir agentes autônomos que possam comprar ou vender produtos representando pessoas ou empresas em mercados virtuais espalhados pela Internet. Alguém que quisesse comprar um dado produto, por exemplo um computador portátil, poderia encarregar um agente para procurar por ofertas de computadores na Internet e dependendo das ofertas, fazer a compra do produto. Este agente poderia de forma simples visitar sites de lojas especializadas, ou de forma mais sofisticada visitar vários mercados virtuais onde vários fornecedores disputam para vender seus produtos.

Neste cenário, os mercados virtuais seriam em essência organizações de agentes abertas. Um mercado virtual seria desenvolvido por um projetista e os agentes externos que o visitam por outros. Um requisito básico para um agente participar de um mercado virtual seria ele ser capaz de "compreender" e adequar seu comportamento à especificação organizacional a partir da qual o mercado virtual foi concebido e implementado.

Neste ponto, surgem as importantes questões: como projetar um agente capaz de visitar vários mercados virtuais? Se os mercados virtuais compartilham

\footnotetext{
${ }^{2}$ Há até uma uma competição anual iniciada em 2000, chamada Trading Agent Competition (TAC), cujo objetivo é utilizar cenários de compra e venda de produtos em um ambiente aberto, para promover a pesquisa em Inteligência Artificial, SMAs e comércio eletrônico (WELLMAN et al., 2001).
} 
um modelo organizacional comum, o problema é fácil de ser resolvido. Mas, e se os mercados virtuais tiverem sido projetados de acordo com modelos organizacionais diferentes, cada um com uma visão particular sobre que elementos e mecanismos devem compor uma organização institucionalizada? É possível reaproveitar um agente já existente, feito para funcionar em mercados virtuais que seguem dado modelo organizacional, em mercados virtuais que seguem outros modelos organizacionais? É possível construir um agente que seja capaz de participar de mercados virtuais heterogêneos de um ponto de vista organizacional? Em suma, como prover interoperabilidade organizacional entre agentes externos e mercados virtuais, concebidos como organizações de agentes?

Gerenciamento de Conferências Neste segundo exemplo, imagina-se um cenário onde os sistemas de gerenciamento de conferência são desenvolvidos como SMAs abertos (DIGNUM, 2004; ZAMBONELLI; JENNINGS; WOOLDRIDGE, 2001). Um sistema de gerenciamento de conferências típico seria uma organização de agentes que ajuda na coordenação de vários indivíduos e grupos. Para uma conferência, há geralmente quatro fases distintas: submissão de artigos, revisão, aceitação e versão final. Os detalhes de cada fase irão variar de conferência para conferência. No entanto, o padrão geral que é comum a todas é o seguinte: $(i)$ autores submetem artigos durante a fase de submissão; $(i i)$ na fase de revisão, revisores são contactados e recebem artigos para revisar; (iii) na fase de aceitação, alguns artigos são aceitos, outros rejeitados, e os autores informados; ( $i v)$ na fase de versão final, cada autor que teve um artigo aceito submete a versão final do seu artigo.

Sendo o sistema de gerenciamento de conferências uma organização de agentes, cada um dos possíveis usuários a principio pode desenvolver seu próprio agente. Na prática, deve haver agentes já desenvolvidos por terceiros que possam ser utilizados pelos usuários. Suponhamos que um dado pesquisador, bastante conhecido e solicitado, freqüentemente participa como revisor de várias conferências ao mesmo tempo. Para cada conferência, ele irá precisar de um agente autônomo que gerencie aspectos burocráticos de sua participação no evento como revisor. Tarefas tais como gerenciamento de datas e negociação com outros revisores sobre que artigos revisar segundo seus interesses, carga atual de trabalho, etc., podem ficar a cargo do agente autônomo. Uma solução interessante para este pesquisador seria ter um único agente que fosse capaz de interoperar com as várias organizações de agentes das conferências das quais ele participa. Adicionalmente, caso o pesquisador fosse convidado para uma nova conferência, o agente deveria 
também poder interoperar com a organização de agentes da nova conferência. Assim, com apenas um agente, o pesquisador não teria o problema de configurar vários agentes para tratar de seus interesses nas várias conferências, tampouco teria o problema de se lembrar e gerenciar vários agentes espalhados pelas várias conferências e teria ainda a possibilidade de gerenciar de forma mais centralizada sua carga de trabalho como revisor de várias conferências.

A mesma linha de raciocínio pode ser aplicada aos autores de artigos. Cada autor poderia ter seu agente que cuidasse de datas, preenchimento de formulários, etc.

Dado que os sistemas de gerenciamento de conferências concebidos como organizações de agentes podem ser heterogêneos quanto ao modelo organizacional utilizado, novamente surge a questão: como garantir interoperabilidade organizacional entre agentes e organizações de agentes heterogêneos?

\subsubsection{Soluções de Interoperabilidade}

Observando-se alguns dos trabalhos de pesquisa relativos a questões de interoperabilidade em SMAs abertos, identificam-se pelo menos quatro tipos de abordagens para o problema de prover interoperabilidade organizacional entre agentes e organizações. São eles: a padronização, a delegação do raciocínio organizacional, a criação de arquiteturas de agentes ou infraestruturas organizacionais universais, e a definição de adaptadores entre agentes e organizações de agentes heterogêneas.

\section{Padronização}

A abordagem tradicional para problemas de interoperabilidade em geral é a criação e uso de padrões. Nessa abordagem, o que se busca é resolver os problemas de interoperabilidade eliminando-se a diversidade, i.e., eliminando a causa dos problemas. Ao invés de diversos modelos organizacionais, a idéia é ter um único modelo padronizado que é aceito e utilizado por todos os desenvolvedores de infraestruturas organizacionais e arquiteturas de agentes.

No entanto, a curto prazo, esta abordagem não é considerada como factível para prover interoperabilidade organizacional. O desenvolvimento de padrões depende em larga escala da consolidação e consenso da pesquisa, desenvolvimento e interesses comerciais em uma área. Ao contrário disso, a área de SMA-COs ainda se encontra em fase de amadurecimento quanto a modelos organizacionais: 
distribuído tem levado a muitos tipos de sistemas multiagentes que são ilhas de funcionalidade - agentes em diferentes tipos de plataforma que são incapazes de interoperar entre si. ... O processo de padronização ajuda a mudar a ênfase do desenvolvimento de infraestrutura para o uso de infraestrutura. ... Padrões necessitam ser desenvolvidos no tempo certo. ... A padronização precoce, antes da pesquisa ter se consolidado pode levar a padrões ruins e imaturos ..."

[Traduzido de (POSLAD; CHARLTON, 2001, p. 105)]

Além desse impedimento, um outro problema com a padronização é o fato de que padrões só valem para agentes e organizações desenvolvidos após, e conformes com, o esforço de padronização, deixando de fora sistemas já desenvolvidos, ou sistemas que não concordam com a padronização.

\section{Delegação}

Uma segunda abordagem para interoperabilidade organizacional, que se encontra implementada em algumas infraestruturas organizacionais, é a idéia de delegar o "raciocínio organizacional" de agentes que entram em uma organização a componentes especiais. Assim, todo agente que entra em uma organização será representado por um delegado. Este delegado se encarrega de "entender" a especificação da organização e de se coordenar com outros delegados, requisitando ao agente externo, quando necessário, a realização de tarefas específicas à posição do agente na organização. Desta maneira, os agentes não têm de se preocupar com aspectos organizacionais e podem participar de várias organizações, ainda que estas tenham sido concebidas e implementadas de modo heterogêneo. Isso acontece, por exemplo, na infraestrutura organizacional TEAMCORE (TAMBE; PYNADATH, 2001), onde os delegados são chamados de proxies. Ocorre também, em parte, na infraestrutura AMELI (ESTEVA et al., 2004), na forma de governors $^{3}$.

O principal ponto negativo dessa abordagem de delegação é que os agentes perdem a sua autonomia organizacional. Os agentes externos não "entendem" a estrutura e funcionamento da organização e passam a simplesmente reagir às requisições provindas dos delegados. Neste sentido, levando em conta que a autonomia é uma das características centrais da noção de agentes, a organização deixa de ser aberta e passa a ser vista como uma sociedade semi-fechada (no caso da infraestrutura TEAMCORE) ou semi-aberta (no caso da infraestrutura ISLANDER), nas quais os agentes indiretamente fazem parte (DAVIDSSON, 2001).

\footnotetext{
${ }^{3}$ Tanto a infraestrutura organizacional TEAMCORE quanto a AMELI serão descritas em mais detalhes no próximo capítulo, seção 2.3.3.
} 


\section{Universalidade}

Uma outra abordagem, aventada em (MAGNIN et al., 2002) é a idéia de criar arquiteturas de agentes ou infraestruturas organizacionais universais. Tal abordagem foi concebida no contexto de mobilidade entre agentes e plataformas de agentes, mas pode ser pensada como solução para questões de interoperabilidade organizacional. Nesta idéia desenvolve-se uma arquitetura de agente, ou infraestrutura organizacional, compatível com vários modelos organizacionais.

Esta é uma abordagem ambiciosa e tecnicamente desafiadora. Além de uma visão integrada da estrutura conceitual de vários modelos organizacionais, ela requer o desenvolvimento de arquiteturas de agentes, ou infraestruturas organizacionais, flexíveis o suficiente para adequar-se aos vários modelos organizacionais. Como no caso da padronização, será uma abordagem que deixa de fora agentes e infraestruturas organizacionais já desenvolvidos.

\section{Adaptação}

Por fim, uma quarta categoria de solução que se pode observar para problemas de interoperabilidade é a criação de adaptadores (GIAMPAPA; PAOLUCCI; SYCARA, 2000; WEGNER, 1996). Este tipo de solução, aplicada ao problema de interoperabilidade organizacional, tem por base a possibilidade de se definirem mapeamentos entre as estruturas conceituais de modelos organizacionais heterogêneos. A partir dos mapeamentos, cria-se um adaptador que é uma camada de software intermediária que busca converter a especificação de uma organização de agentes para representações equivalentes, só que expressas na visão organizacional do agente externo que deseja participar da organização.

Com relação às abordagens anteriores, a adaptação apresenta algumas vantagens importantes. No caso do problema de interoperabilidade organizacional, ela permite reaproveitar agentes e infraestruturas organizacionais pré-existentes, e garantir que autonomia organizacional dos agentes seja preservada. Por outro lado, há também alguns pontos problemáticos. O principal deles é que para a adaptação ser útil, as estruturas conceituais dos modelos organizacionais têm de apresentar um determinado grau de compatibilidade, permitindo a definição de mapeamentos que habilitem agentes externos a "entender" e saber como proceder dentro de uma organização heterogênea.

Um outro ponto problemático na adaptação é que, havendo $n$ modelos diferentes, uma solução completa irá requerer $O\left(n^{2}\right)$ mapeamentos, pois no pior 
caso quando os modelos são mapeados dois a dois são necessários $n \times(n-1) / 2$ mapeamentos. Uma alternativa para reduzir esta complexidade pode ser a definição de mapeamentos indiretos através de uma visão integrada dos modelos organizacionais. Assim, o número de mapeamentos reduz-se a $O(n)$.

\section{Discussão}

Dadas as vantagens e desvantagens das possíveis soluções levantadas, conclui-se que três características desejáveis em uma solução ideal de interoperabilidade organizacional são:

- permitir que os agentes ao entrar nas organizações possam ainda ter, caso desejem, autonomia organizacional;

- permitir que agentes e organizações heterogêneos já desenvolvidos (ou os que serão desenvolvidos sem pressupor a solução) possam interoperar, e não apenas os que foram feitos utilizando-se diretamente a solução;

- ser modular e escalável, i.e., permitir que novos modelos e infraestruturas organizacionais sejam incorporados à solução sem grandes problemas.

Conquanto desejáveis, estas características são difíceis de conciliar. A padronização satisfaz o primeiro item, mas deixa de satisfazer o segundo e elimina o terceiro item, além de requerer consenso político e técnico. A delegação não satisfaz o primeiro item, e deixa de satisfazer o segundo quando organizações são desenvolvidas utilizando-se uma infraestrutura organizacional que não fornece suporte a delegados que isolam completamente os agentes do raciocínio organizacional. A criação de agentes ou infraestruturas universais também não atendem ao segundo item, e podem deixar de atender o terceiro. Por fim, a adaptação satisfaz ao primeiro item, mas pode deixar de atender ao segundo item quando há grandes incompatibilidades conceituais e de interface entre agentes e organizações, e também ao terceiro item quando muitos mapeamentos são necessários para incorporar novos modelos e infraestruturas organizacionais.

Após analisar possíveis soluções para o problema de interoperabilidade organizacional, uma outra conclusão a que se chega é a seguinte:

As soluções de interoperabilidade organizacional levantadas, com exceção da delegação, pressupõem um entendimento integrado dos modelos organizacionais utilizados para especificar e implementar organizações de agentes. 
De fato, definir padrões de interoperabilidade, criar agentes ou infraestruturas universais, ou fazer adaptação por meio de mapeamentos, todas são soluções que, antes de tudo, requerem uma compreensão global das propostas de modelagem organizacional existentes. Esta conclusão conduz diretamente às questões centrais e aos objetivos do trabalho de pesquisa relatado neste texto.

\subsubsection{Questões Centrais}

Tendo como motivação o problema de interoperabilidade organizacional, e a partir da constatação de que soluções de interoperabilidade organizacional naturalmente pressupõem um conhecimento integrado dos modelos organizacionais utilizados na concepção de organizações de agentes, formulam-se a seguir algumas questões importantes que norteiam o trabalho de pesquisa empreendido nesta tese:

- Como a estrutura conceitual dos modelos organizacionais existentes se relacionam? Há similaridades significativas ou todos apresentam uma visão radicalmente diferente e incompatível de como especificar organizações de agentes?

- Na hipótese de haver similaridades significativas, quais os conceitos de modelagem recorrentes nos modelos organizacionais?

- Levando em conta tanto os conceitos recorrentes quanto os conceitos particulares, é possível integrar os modelos organizacionais em um superconjunto consistente de conceitos, englobando a estrutura conceitual dos vários modelos organizacionais? Como metódica e tecnicamente realizar uma tal integração?

- Na hipótese de se ter à disposição uma integração de modelos organizacionais, como efetivamente utilizá-la em uma solução de interoperabilidade organizacional?

Em linhas gerais, nesta tese, busca-se apresentar respostas a estas questões.

\subsection{Objetivos}

Partindo da hipótese de que é possível integrar de modo consistente os modelos organizacionais, o objetivo principal desta tese é propor uma abordagem sistemática para realizar tal integração. Além disso, busca-se mostrar como o resultado da 
aplicação da abordagem proposta pode ser utilizado de modo efetivo em uma solução de interoperabilidade organizacional.

Para atingir este objetivo, traçam-se as seguintes metas mais específicas:

1. Realizar um estudo comparativo da estrutura conceitual de vários modelos organizacionais existentes;

2. A partir do estudo comparativo realizado, descrever de modo geral os conceitos de modelagem recorrentes nos modelos organizacionais analisados;

3. Definir um método geral para integração de modelos organizacionais, levando em consideração conceitos recorrentes e particularidades que venham a existir entre os modelos organizacionais;

4. Aplicar o método definido e realizar a integração de alguns modelos organizacionais atualmente existentes;

5. Definir uma infraestrutura de software que utilize a integração de modelos organizacionais feita e que seja capaz de prover interoperabilidade organizacional;

6. Implementar a infraestrutura de interoperabilidade organizacional proposta, e desenvolver uma aplicação que mostre o funcionamento da infraestrutura e sua efetividade em prover interoperabilidade organizacional.

Observa-se ainda que, até onde se pode pesquisar, não há na literatura nenhum trabalho similar ao que se propõe nesta tese. Há vários modelos e infraestruturas organizacionais propostos, mas nenhuma abordagem que busque integrar modelos organizacionais e promover interoperabilidade organizacional.

\subsection{Abordagem}

Na consecução das metas traçadas acima, adota-se uma abordagem baseada na Engenharia Dirigida por Modelos - EDM (SCHMIDT, 2006; MELLOR; CLARK; FUTAGAMI, 2003).

A EDM é uma área recente da Engenharia de Software que enfoca o uso de modelos como artefatos finais do desenvolvimento de software, ao invés de código. Neste sentido, a EDM é caracterizada pelo uso combinado de: 
- Linguagens de modelagem específicas de domínio (LMEDs) cujas primitivas de modelagem formalizam a estrutura e funcionamento de aplicações em um domínio de aplicação particular (KELLY; TOLVANEN, 2008);

- Transformações de modelos e geração automática de código que analisam modelos criados a partir de LMEDs e então sintetizam vários tipos de artefatos, tais como modelos escritos em LMEDs alternativas, modelos dependentes de uma plataforma de implementação, código fonte e arquivos de configuração da aplicação expressa pelo modelo, etc.

Na EDM, as primitivas de modelagem de LMEDs são descritas utilizando metamodelos. Metamodelos consistem em representações dos conceitos e dos relacionamentos e restrições entre conceitos característicos em um domínio de aplicação (KLEPPE, 2008; GUIZZARDI, 2007; KüHNE, 2006; CLARK; EVANS; KENT, 2002).

Adotando uma abordagem baseada na EDM, a idéia básica é utilizar metamodelos para representar a estrutura conceitual de modelos organizacionais. Neste sentido, modelos organizacionais são tratados como LMEDs, como já mencionado anteriormente. Assim, comparar e integrar modelos organizacionais passa a significar comparar e integrar metamodelos que representam a estrutura conceitual dos modelos organizacionais.

Há dois motivos principais que justificam o idéia de usar metamodelos para comparar e integrar modelos organizacionais:

- O primeiro e mais básico é que os modelos organizacionais são de fato LMEDs. Utilizando modelos organizacionais projetistas de SMA-COs "escrevem" especificações de organizações de agente. Logo, tem-se uma linguagem cujo domínio específico de aplicação é a modelagem de organizações de agentes.

- O segundo motivo é que há disponível algumas ferramentas livres para implementação de interpretadores e tradutores para LMEDs a partir de metamodelos (STEINBERG et al., 2008; SELIC, 2003; KARAGIANNIS; KüHN, 2002). Assim, na prática, estas ferramentas podem ser utilizadas para implementar facilmente a proposta de integração de modelos organizacionais desenvolvida nesta tese.

Por fim, observa-se que uma abordagem alternativa para representar, comparar e integrar modelos organizacionais seria o uso da tecnologia de ontologias 
(NOY, 2004; KAlFOGLOU; SCHORLEMmeR, 2003; KLEIN, 2001). Tanto metamodelos como ontologias consistem em representações de estruturas conceituais (PARREIRAS; STAAB; WINTER, 2007; GUIZZARDI, 2007; GOGUEN, 2005). No entanto, metamodelos diferem de ontologias em um aspecto importante: enquanto metamodelos são utilizados para representar a estrutura conceitual de linguagens de modelagem, ontologias funcionam como esquemas de bases de conhecimento. Como modelos organizacionais são melhor caracterizados como linguagens de modelagem do que como bases de conhecimento, na visão expressa neste trabalho, opta-se pelo uso de metamodelos.

\subsection{Estrutura do Texto}

O texto a seguir encontra-se estruturado em três partes principais. Na Parte I, são discutidos os conceitos e tecnologias básicas nos quais se fundamenta o trabalho. Em seguida, na Parte II, apresenta-se a proposta de integração de modelos organizacionais defendida nesta tese. Finalmente, na Parte III, mostra-se a utilização da proposta de integração apresentada em um solução de interoperabilidade organizacional.

A Parte I é composta pelos capítulos 2 e 3. No capítulo 2, são discutidos em mais detalhes os conceitos de agente, sistema multiagentes, organização de agentes, modelo organizacional e infraestrutura organizacional relacionados à noção de SMA-CO. No capítulo 3, discutem-se os conceitos de modelo, metamodelo e integração de (meta) modelos ligados à EDM. Também são apresentados exemplos de metamodelos escritos nas linguagens de meta-modelagem Ecore (STEINBERG et al., 2008) e OCL (OMG, 2006b) e um algoritmo para a junção de metamodelos (SABETZADEH; EASTERBROOK, 2006; DISKIN; DINGEL; LIANG, 2006). As linguagens Ecore e OCL, bem como o algoritmo de junção apresentado, são utilizadas na Parte II para a representação e integração de modelos organizacionais.

A Parte II é composta pelos capítulos 4, 5 e 6 . No capítulo 4, apresenta-se um estudo comparativo de vários modelos organizacionais existentes. A comparação de modelos organizacionais é realizada tendo por base a idéia de dimensões de modelagem organizacional (COUTINHO; SICHMAN; BOISSIER, 2009). A partir do estudo comparativo realizado, no capítulo 5 descreve-se de modo geral os conceitos de modelagem recorrentes nos modelos organizacionais analisados. Cada dimensão de modelagem é caracterizada por um padrão de modelagem descrito em Ecore/OCL. No capítulo 6, define-se um método geral para integração de modelos organizacionais. O método tem por base a representação de modelos or- 
ganizacionais em Ecore, as dimensões e padrões de modelagem organizacional, e o algoritmo de junção apresentado no capítulo 3. Em seguida, o método é aplicado em quatro modelos organizacionais que foram descritos no capítulo 4, gerando ao final um metamodelo organizacional integrado (COUTINHO et al., 2008). O metamodelo integrado resultante é então aplicado na Parte III como componente de uma infraestrutura de interoperabilidade organizacional.

A Parte III é composta pelos capítulos 7 e 8 . No capítulo 7, descreve-se a infraestrutura MAORI - Model-driven Architecture for ORganizational Interoperability (COUTINHO et al., 2009). MAORI foi desenvolvida para interconectar infraestruturas organizacionais heterogêneas e prover interoperabilidade organizacional. MAORI segue a abordagem de adaptação (seção 1.1.3), utilizando a integração de modelos proposta nesta tese para a realização de mapeamentos entre modelos organizacionais distintos. No capítulo 8, apresenta-se uma implementação de MAORI e um estudo de caso. Através do estudo de caso, apresentam-se alguns experimentos feitos com o propósito de demonstrar a validade e viabilidade da solução de interoperabilidade organizacional proposta nesta tese.

Por fim, no capítulo 9, apresentam-se as principais conclusões, contribuições, e os trabalhos futuros decorrentes do trabalho de pesquisa realizado.

Além desses capítulos, o documento apresenta um apêndice, e três anexos em CD. No apêndice A, apresenta-se de forma resumida as primitivas de modelagem da linguagem Ecore. Nos anexos A e B, encontram-se os arquivos fonte dos metamodelos Ecore apresentados nos capítulos 4 e 6, respectivamente. Finalmente, no anexo $\mathrm{C}$, têm-se a implementação da infraestrutura MAORI e estudo de caso discutidos no capítulo 8. 


\section{Parte I}

Conceitos Básicos 


\section{Sistemas Multiagentes centrados na Organização}

Agentes autônomos e sistemas multiagentes são conceitos que inicialmente surgiram no âmbito da pesquisa em Inteligência Artificial Distribuída (CHAIB-DRAA; MANDIAU; MILLOT, 1992). Nos últimos anos, no entanto, com a percepção de que a tecnologia de agentes "oferece uma nova e geralmente mais apropriada rota para o desenvolvimento de sistemas complexos, especialmente em ambientes abertos e dinâmicos" (LUCK; MCBURNEY; PREIST, 2004, p. 204), esses conceitos foram incorporados por outras comunidades de pesquisa, notadamente pela Engenharia de Software (ZAMBONELLI; OMICINI, 2004; JENnINGS, 2000). Alguns pesquisadores chegam mesmo a afirmar que agentes e SMAs constituem uma "mudança de paradigma na Ciência da Computação e Engenharia de Software" que promete ampliar a nossa capacidade de conceber, projetar e implementar sistemas computacionais complexos (ZAMBONELLI; PARUNAK, 2004).

Neste capítulo, os conceitos básicos de agentes autônomos (seção 2.1) e sistemas multiagentes (seção 2.2) são discutidos tendo como propósito último caracterizar de forma mais detalhada a noção de sistema multiagente centrado na organização (SMA-CO) (seções 2.2.2 e 2.3).

Conforme assinalado na Introdução, a questão de como prover interoperabilidade organizacional, investigada nas partes II e III deste documento, ocorre no contexto dos SMA-COs. Assim, este capítulo tem como justificativa definir os conceitos básicos necessários à completa formulação do problema que é objeto de pesquisa neste trabalho.

A seção 2.4 apresenta um resumo dos principais conceitos discutidos no capítulo. 


\subsection{Agentes Autônomos}

Na literatura encontram-se inúmeras definições para o termo "agente" ${ }^{1}$. A definição adotada neste trabalho segue uma linha de desenvolvimento de software. Do ponto de vista do desenvolvimento de software, um agente pode ser definido como:

um programa de computador autônomo, situado em um ambiente que ele é capaz de perceber e sobre o qual ele é capaz de agir (BOISSIER, 2001, p. 71); a um agente se atribui uma certa missão que ele é capaz de cumprir de maneira autônoma e possivelmente (não necessariamente) em coordenação com outros agentes (BRIOT; DEMAZEAU, 2001, p. 18).

Se substituirmos "programa de computador" por "entidade" - o que será feito algumas vezes ao longo do texto - tem-se uma definição mais geral de agente. Neste caso, além de programas de computador, pessoas, animais, robôs, dentre outros, podem ser considerados agentes (FRANKLIN; GRAESSER, 1997). Tal generalização é importante e válida quando nosso interesse for construir sistemas computacionais que envolvem ou que se assemelham a vários desses elementos. Na figura 2.1, ilustra-se a definição de agente apresentada.

A principal característica de um agente, aquela que em geral o distingue de programas de computador tradicionais, é a autonomia. O termo "autonomia", por sua vez, também admite várias acepções (COVRIGARU; LINDSAY, 1991; SICHMAN; DEMAZEAU, 1996; LUCK; D'INVERNO, 2001; CARABELEA; BOISSIER; FLOREA, 2004). No âmbito deste trabalho, considera-se autonomia como sendo a capacidade de um agente de auto-comandar seu mecanismo interno de funcionamento, i.e., de poder controlar sua atividade e estado internos. Assim, um agente em princípio deve ser capaz de decidir por ele mesmo o que fazer, quando fazer, que ações realizar no ambiente, tendo em vista uma missão que deve cumprir e as suas percepções do ambiente ${ }^{2}$.

De forma simples, o ambiente é conceituado como uma coleção de elementos, materiais ou de software, da qual o agente faz parte. O agente age no ambiente,

\footnotetext{
${ }^{1}$ Um estudo comparativo de várias definições de "agente" encontra-se reportado em (FRANKLIN; GRAESSER, 1997).

${ }^{2}$ É ilustrativo comparar a idéia de agente autônomo com a noção de objeto, oriunda do desenvolvimento tradicional de software. Um objeto representa um elemento de sistema com identidade e que encapsula estado e realização de comportamentos (BOOCH, 1994). Objetos tradicionalmente não são considerados elementos autônomos. Em sua definição original, apesar de encapsularem realização de comportamento, objetos não encapsulam o controle de ativação de comportamentos ou escolha de ações. Assim, qualquer objeto pode fazer uma chamada a qualquer um dos métodos públicos de um outro objeto a qualquer tempo. Uma vez feita a chamada, a execução do método se segue. Neste sentido, objetos são totalmente obedientes uns aos outros e não possuem escolha de ação (JENNINGS, 2000, p. 280).
} 


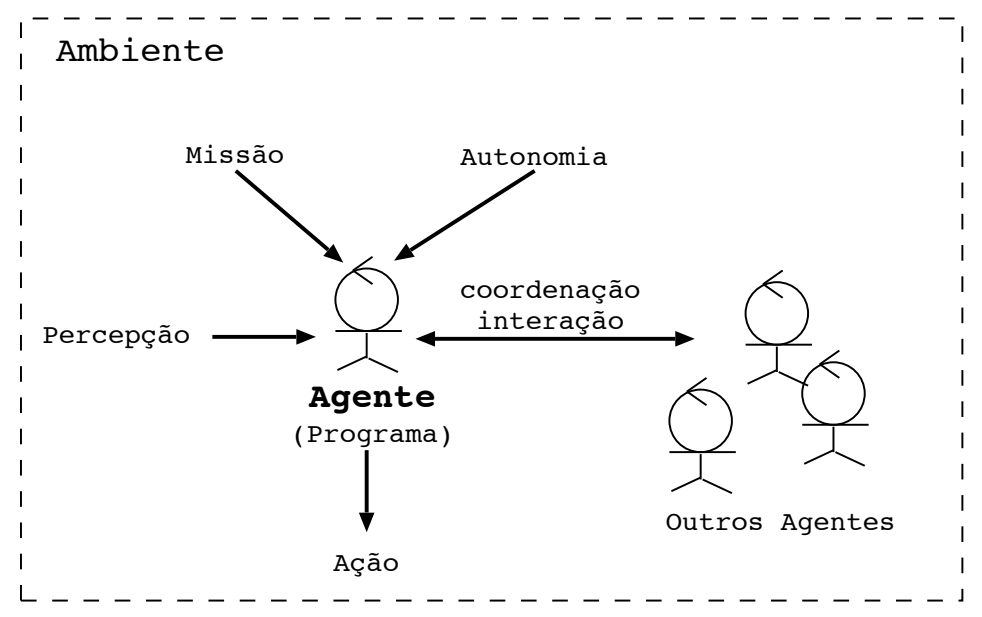

Figura 2.1: Agente autônomo.

modificando alguns de seus elementos, tendo em vista o cumprimento de sua missão. Tomando como exemplo específico o sistema de gerenciamento de conferências discutido no capítulo anterior (seção 1.1.2), artigos, revisões, contas de e-mail, etc. seriam alguns dos elementos que compõem o ambiente de um agente cuja missão é auxiliar o trabalho de um revisor (humano). De forma mais geral, outros exemplos de elementos que poderiam fazer parte do ambiente de agentes são bases de dados, impressoras, infra-estrutura de comunicação, objetos que compõem uma simulação (em jogos), etc.

Conforme definido, e seguindo uma tendência dos trabalhos na área, o termo "ambiente" é utilizado em um sentido estrito de coleção de elementos não-autônomos. Neste sentido, outros agentes não são considerados como parte do ambiente no qual um agente se insere. Uma maneira de estender esta noção de ambiente para englobar outros agentes é definir estes outros agentes como o ambiente social de um agente. A diferença básica entre ambiente e ambiente social está na natureza da interação do agente com tais ambientes. Com o ambiente, o agente interage com elementos sem capacidade de escolha. Quando o agente solicita que um elemento do ambiente mude ou faça algo, este simplesmente o faz; a interação é parecida com a ativação de um método em orientação a objetos (vide nota 2, página 19). Com o ambiente social, o agente interage com entidades autônomas, capazes de decidir por elas mesmas o que fazer e quando fazer. Neste caso, a possibilidade de "ouvir um não" a uma solicitação, a necessidade de ter de "convencer", ter de se coordenar, cooperar, etc., com outros agentes para fazer algo, são fatores que devem ser levados em consideração. 


\subsubsection{Agentes Reativos e Deliberativos}

Tendo em vista o mecanismo interno através do qual o agente decide agir no ambiente, os agentes podem ser classificados em duas grandes categorias recorrentes na literatura: agentes reativos e agentes deliberativos ${ }^{3}$ (BOISSIER, 2001).

Os agentes reativos possuem uma constituição interna simples (figura 2.2(a)). Em geral, agentes reativos não possuem representação explícita do ambiente. Ações são selecionadas unicamente a partir das percepções do ambiente. O mecanismo de seleção de ação consiste em um mapeamento quase que direto entre percepção e ação. Assim, agentes reativos têm o ciclo de percepção-decisão-ação muito rápido.

Os agentes deliberativos, por sua vez, são mais complexos (figura 2.2(b)). Nestes, a tomada de decisão sobre que ação realizar passa por um processo de raciocínio explícito. O agente possui um estado mental. No estado mental do agente podem estar representados conhecimentos, crenças, objetivos, desejos, intenções, histórico de percepção-ação, etc., relacionados ao próprio agente, à missão atribuída ao agente, ou ao ambiente (social) no qual o agente encontra-se imerso $^{4}$. A partir das representações em seu estado mental, bem como da percepção atual do ambiente, o agente infere quais ações são possíveis de realizar e por fim decide qual ação ele irá realizar. Agentes deliberativos podem ter complexos mecanismos de raciocínio e decisão. Assim, geralmente têm um ciclo de percepção-decisão-ação longos quando comparados com os agentes reativos.

\subsubsection{Agentes Sócio-Organizacionais}

Agentes deliberativos que operam em conjunto com outros agentes podem possuir, além da autonomia, uma ou duas capacidades adicionais: (1) a capacidade de trocar mensagens com outros agentes utilizando uma linguagem de comunicação simbólica de alto nível (agentes sociais) e (2) a capacidade de participar de organizações (agentes organizacionais). Estas características, que encontramse ilustradas de forma explícita como módulos no modelo genérico de agente deliberativo da figura 2.2(b), são discutidas nas seções a seguir.

Agentes autônomos sócio-organizacionais são o tipo de agente de interesse central nesta tese.

\footnotetext{
${ }^{3} \mathrm{Um}$ terceiro tipo de agente - o agente híbrido - pode ser definido juntando-se características de agentes reativos e agentes deliberativos.

${ }^{4} \mathrm{O}$ fato de possuir (ou ser concebido como possuindo) um estado mental leva muitos autores a denominar os agentes deliberativos de agentes cognitivos.
} 


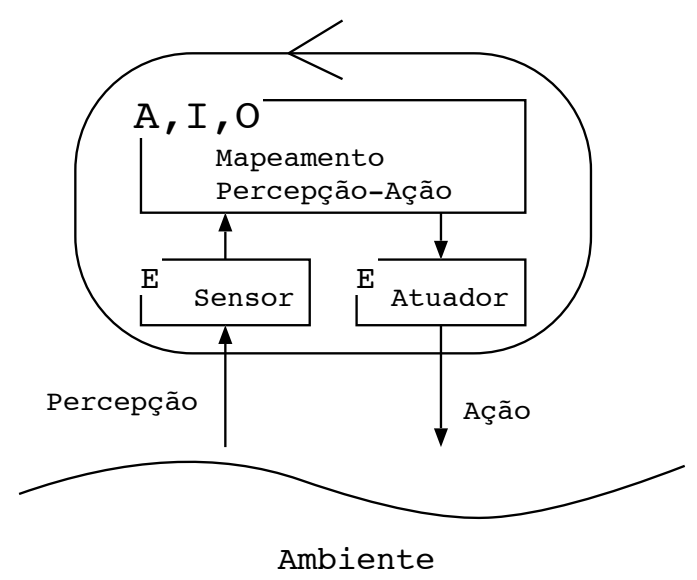

(a) Modelo Genérico de Agente Reativo

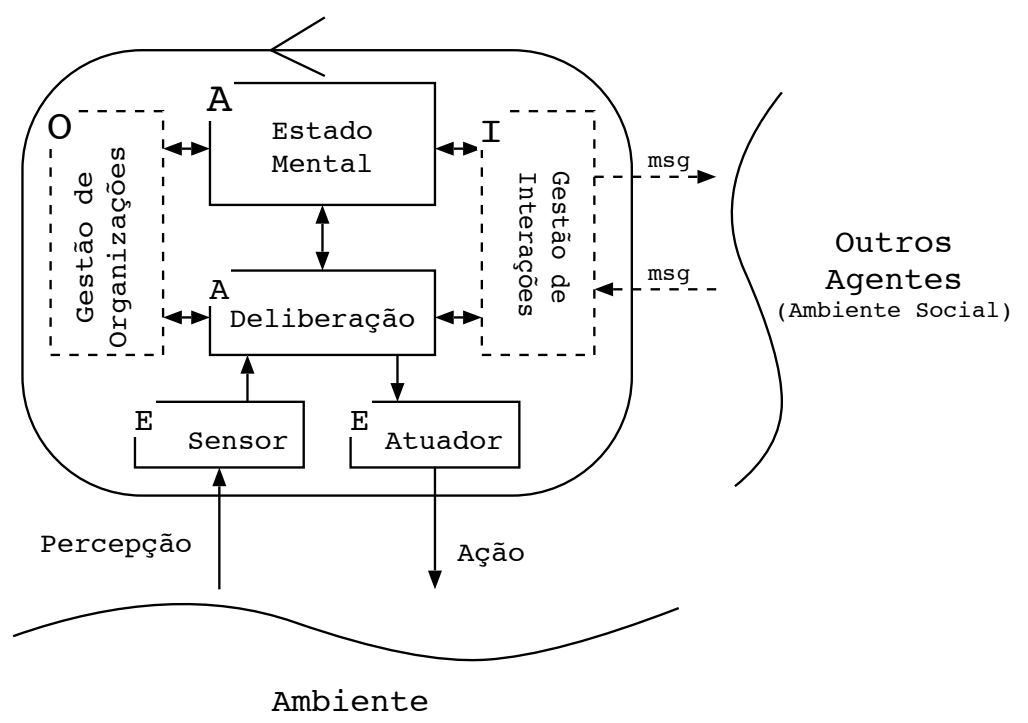

(b) Modelo Genérico de Agente Deliberativo

As letras A, E, I e O, presentes no canto superior esquerdo dos módulos que compõem o agente, se referem a quatro dimensões básicas de modelagem em SMA: agente (A), ambiente (E), interações (I) e organização social (O) (DEMAZEAU, 1995). Assim, uma dessas letras em um módulo significa que este módulo reflete a correspondente dimensão de modelagem no interior do agente. Agentes reativos, por serem mais simples, frequentemente não possuem elementos explícitos em sua arquitetura relativos às dimensões I e O. Além disso, arquiteturas específicas de agentes deliberativos nem sempre contemplam as dimensões I e $\mathrm{O}$, e quando o fazem nem sempre as dimensões A, I e O encontram-se modularizadas explicitamente conforme retratado na figura. O objetivo da figura é mostrar apenas uma visão idealizada de agentes reativos e deliberativos.

Figura 2.2: Modelos genéricos de agentes reativos e deliberativos. 


\subsection{Sistemas Multiagentes}

Em geral, sistemas multiagentes (SMAs) são sistemas nos quais, entre seus componentes, encontram-se dois ou mais agentes que se interrelacionam e interagem tendo em vista uma finalidade global. Em um SMA, os relacionamentos e interações entre os agentes tendem a seguir padrões de atividade conjunta. A padronização é vista como um pré-requisito para que o funcionamento do SMA seja ordenado, não-caótico, e para que a finalidade do SMA seja atingida de modo eficiente.

\subsubsection{Interação entre Agentes}

A interação entre agentes em um SMA pode se dar de duas maneiras:

- de forma indireta, quando a interação ocorre por intermédio do ambiente. Um agente age no ambiente modificando algum aspecto deste último para influenciar na percepção de um outro agente. Em seguida, o outro agente age modificando novamente o ambiente e influenciando na percepção do primeiro agente; e assim por diante.

- de forma direta, quando a interação se processa por meio de comunicação. Um agente envia uma mensagem destinada a um outro agente. A mensagem é escrita em uma linguagem simbólica. O outro agente recebe, interpreta e responde a mensagem; e assim por diante.

Em geral, SMAs onde apenas o primeiro tipo de interação ocorre são formados por agentes reativos. Um exemplo típico de SMA onde ocorre interação indireta e no qual os agentes são considerados reativos é o formigueiro. As formigas cooperam em prol do formigueiro e esta cooperação surge sobretudo de interação por traços e sinais químicos espalhados pelo ambiente. O formigueiro tem sido uma inspiração constante em vários trabalhos de pesquisa que estudam o fenômeno de emergência (JOHNSON, 2003). Nestes estudos um dos temas centrais é compreender como comportamentos simples e locais levam ao surgimento de complexos padrões de interação e organização social (DROGOUL; CORBARA; LALANDE, 1995).

Por sua vez, SMAs onde tanto a primeira quanto a segunda formas de interação podem ocorrer, são formados em geral por agentes deliberativos. Possuindo estado mental explícito, um agente deliberativo está melhor equipado para interagir diretamente com outros agentes, trocando com estes mensagens simbólicas (figura 2.2(b)). 
A linguagem que um agente deliberativo utiliza para interagir com outro é denominada de linguagem de comunicação de agente $^{5}$ (CHAIB-DRAA; DIGNUM, 2002). As linguagens de comunicação de agentes em geral são projetadas tendo por base a teoria filosófica dos atos de fala (SEARLE, 2000). Nesta teoria, uma mensagem enviada de um agente a outro contém dois elementos fundamentais: um ato ilocucionário e um conteúdo proposicional. De forma simples, mas pouco precisa, podemos dizer que o conteúdo proposicional é o que se quer comunicar e o ato ilocucionário é o tipo ou a forma da comunicação. Por exemplo, (pedir "Faça tarefa T1") poderia ser uma mensagem onde pedir é o ato ilocucionário e "Faça tarefa T1" é o conteúdo proposicional. Em uma interação, esta mensagem seria recebida por um agente que se encarregaria de interpretá-la e decidir o que fazer. Exercendo sua autonomia, o agente que recebeu a mensagem poderia decidir não realizar a tarefa cuja execução foi solicitada através de um pedido. Em seguida, esse mesmo agente poderia enviar a mensagem em resposta: (informar "Não farei tarefa T1"), onde informar é o ato ilocucionário e "Não farei tarefa T1" é o conteúdo proposicional. Continuando a interação, o agente cujo pedido foi recusado poderia lançar mão de sua autoridade $^{6}$ e insistir enviando a seguinte mensagem: (ordenar "Faça tarefa T1"), onde temos o mesmo conteúdo proposicional - "Faça tarefa T1" - expresso com um ato ilocucionário diferente - ordenar.

Nesses exemplo, um ponto importante que merece menção é o fato de que para haver interação direta, os agentes devem compartilhar tanto o significado da força ilocucionária quanto o significado do conteúdo proposicional. Em geral, o significado da força ilocucionária pode ser definido de maneira independente de domínio de aplicação por meio de protocolos de interação, tais como o protocolo de redes contratuais (SMITH, 1980), o protocolo hierárquico (DURFEE; MONTGOMERY, 1990), o protocolo de introdução (BERTHET; DEMAZEAU; BOISSIER, 1992), e os protocolos de leilões (SANDHOLM, 1999). Por sua vez, o significado do conteúdo proposicional sempre é dependente de domínio de aplicação e pode ser formalizado por meio de ontologias ou conceitualizações de domínio, i.e., representações computacionais de conceitos, relacionamentos entre conceitos, procedimentos, etc., vigentes em um dado domínio de aplicação (CHANDRASEKARAN; JOSEPHSON; BENJAMINS, 1999; USCHOLD, 1998).

\footnotetext{
${ }^{5}$ Dois exemplos de linguagens de comunicação de agente bastante conhecidos são KQML e FIPA-ACL (LABROU; FININ; PENG, 1999).

${ }^{6}$ Há autoridade, poder, etc. quando a padronização da interação passa ao nível de organização, como discutido nas próximas seções.
} 


\subsubsection{Ordem Social}

Um ponto crucial no desenvolvimento de SMA é como conciliar a autonomia dos agentes com interações que levem a algum comportamento global esperado. Dito de outra maneira, como ordem ou coordenação podem surgir e serem mantidas quando se espera que problemas sejam resolvidos pelo esforço conjunto de entidades que têm em princípio controle sobre sua própria atividade? Inspirado por problemas semelhantes estudados nas Ciências Sociais, este problema pode ser chamado de problema da ordem social: "como obter a partir de projeto e programação locais, e a partir de ações, interesses, e visões locais, algum resultado emergente global desejável e relativamente predizível/estável" (CASTELFRANCHI, 2000, p. 2).

Tendo em vista o problema da ordem social, alguns pesquisadores (FERBER; GUTKNECHT; MICHEL, 2004; LEMAîTRE; EXCELENTE, 1998) dividem as abordagens para o desenvolvimento de SMAs em duas grandes categorias: os SMAs centrados nos agentes e os SMAs centrados na organização.

Nos SMAs centrados nos agentes (SMA-CAs), o foco do desenvolvimento são os agentes. O que se busca é obter ordem social de baixo para cima. Assim, utilizando modelos de agentes sociais, os projetistas concentram seus esforços na criação de agentes que sejam capazes ou estejam dispostos a se auto-organizar tendo em vista uma dada finalidade global. Exemplos desse tipo de abordagem são os trabalhos relacionados a intenções conjuntas (LEVESQUE; COHEN; NUNES, 1990), comprometimento social (CASTELFRANCHI, 1995; CAVEDON; SONENBERG, 1998) e dependência social (CASTELFRANCHI; MICELI; CESTA, 1992; SICHMAN; DEMAZEAU, 2001).

Nos SMAs centrados na organização (SMA-COs), o foco do desenvolvimento deixa de ser o projeto de agentes que se auto-organizam e passa a ser o projeto de organizações de agentes ${ }^{7}$. Neste tipo de abordagem, a ordem social é obtida de cima para baixo. Utilizando um modelo organizacional, o projetista primeiramente define especificações organizacionais nas quais a atividade conjunta dos agentes é prescrita independentemente de uma população específica de agentes. Em seguida, possivelmente utilizando uma infraestrutura organizacional, as especificações organizacionais são explicitamente implementadas, cada uma dando origem a uma organização de agentes distinta.

Os SMA-CAs e SMA-COs são ilustradas na figura 2.3. Por um lado, nos

\footnotetext{
${ }^{7}$ Conforme mencionado na Introdução, os SMA-COs se inspiram em organizações humanas tais como empresas, times, etc.
} 
SMA-CAs, notam-se apenas agentes como componentes básicos. Por outro lado, nos SMA-COs, além dos agentes, encontram-se também uma (ou mais) organização(ões) de agentes figurando como componente(s) do SMA-CO. Agentes externos a uma organização de agentes têm de passar por um processo de entrada para poder interagir com outros agentes no contexto da organização. Para entrar e permanecer em uma organização, exige-se de cada agente que ele se comprometa a agir e interagir, seja por construção ou por deliberação própria, de acordo com a especificação organizacional subjacente à organização de agentes. Casos desviantes podem ser punidos com sanções e, em último caso, com a saída do agente da organização.
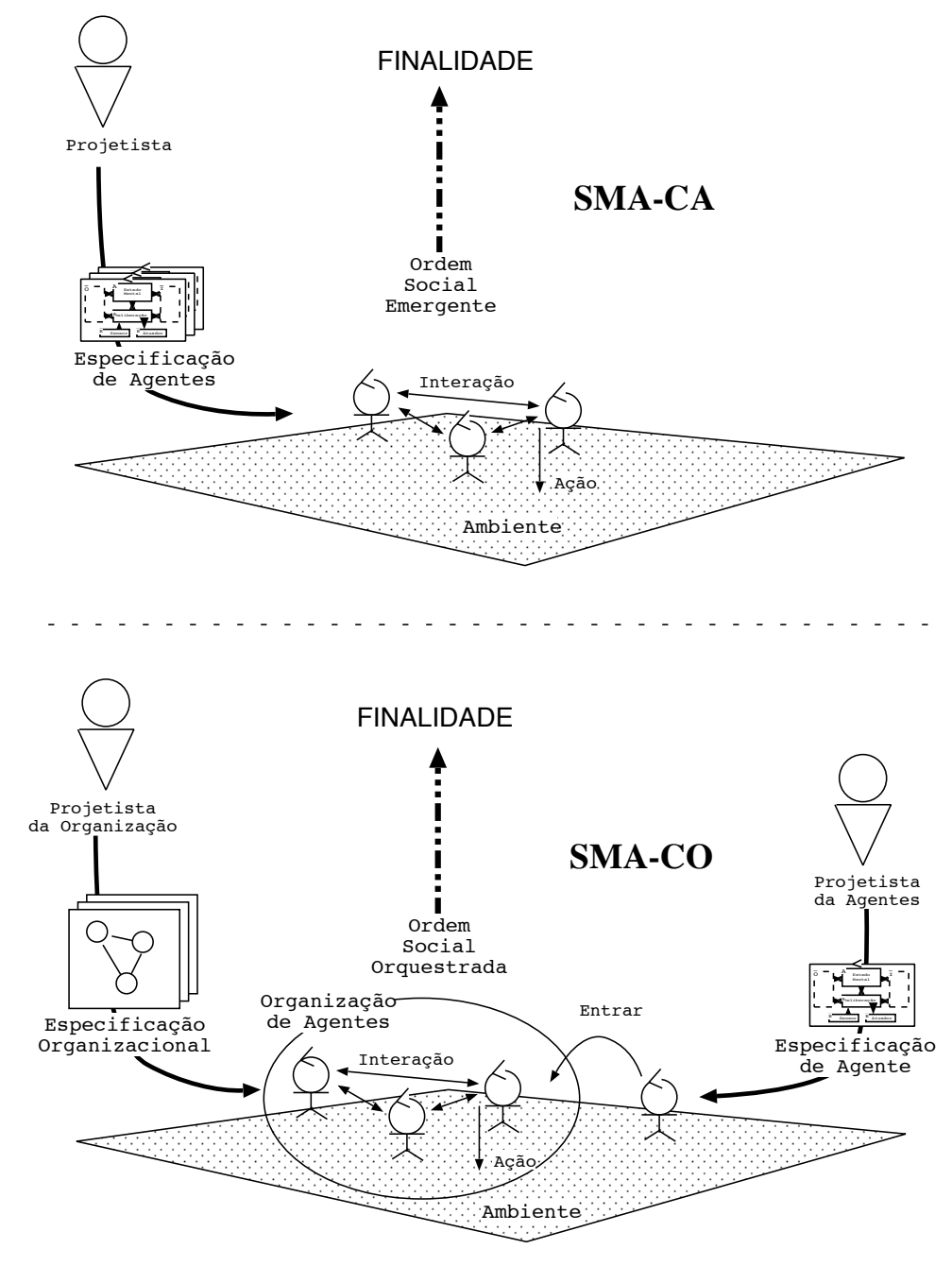

Figura 2.3: Abordagens para o problema da ordem social.

Com o crescente interesse no desenvolvimento de sistemas complexos, especialmente em ambientes abertos e dinâmicos (FEILER et al., 2006; LUCK; MCBURNEY; PREIST, 2004) formados por agentes heterogêneos (criados por diferentes projetistas, utilizando diferentes arquiteturas internas e tendo interesses próprios), a idéia de SMA-COs tem sido apontada por vários pesquisadores como 
sendo uma solução mais adequada do que os SMA-CAs (BOISSIER; HüBNER; SICHMAN, 2007; VáZQUEZ-SALCEDA; DIGNUM; DIGNUM, 2004; HORLING; LESSER, 2004; FERBER; GUTKNECHT; MICHEL, 2004; GASSER, 2001; PITT; MAMDANI; CHARLTON, 2001; ZAMBONELLI; JENNINGS; WOOLDRIDGE, 2001; LEMAîTRE; EXCELENTE, 1998).

Num tal contexto, os SMA-CAs levam a dois problemas em potencial: (1) como não há uma definição explícita em relação ao modo como as tarefas devem ser feitas, novos agentes ao entrar no sistema têm de descobrir por si mesmos como trabalhar em conjunto com os outros agentes e (2) como agentes externos podem ter seus próprios interesses, não há nenhuma garantia a priori de que o SMA como um todo irá apresentar um comportamento ordenado e útil.

Os SMA-COs buscam eliminar esses problemas por meios das organizações de agentes que tanto padronizam quanto controlam explicitamente o comportamento conjunto dos agentes. No entanto, ao participar de uma organização, os agentes necessariamente perdem parte de sua autonomia, não podendo mais agir como e quando quiserem, sob pena de serem penalizados ou excluídos da organização. Assim, em alguns casos, tais como quando o ambiente ou objetivos da organização sofrem mudanças, a perda de autonomia dos agentes pode levar a uma incapacidade da organização a se adequar à nova realidade. Nestes casos, ou ocorre um processo de reorganização e estabelece-se uma nova especificação organizacional, ou então a organização de agentes pode deixar de ser útil (HüBNER, 2003).

Por limitação de escopo, os SMA-CAs não serão tratados em mais detalhes nesta tese. No que segue, a ênfase recai sobre os SMA-COs, nos quais o conceito de organização é essencial.

\subsection{Organizações de Agentes}

Nesta seção, discutem-se os conceitos de organização, modelo organizacional, especificação organizacional e infraestrutura organizacional empregados na definição de SMA-COs.

\subsubsection{Conceito de Organização}

Organização é um conceito fundamental no contexto desta pesquisa. Infelizmente, trata-se de uma noção multifacetada e difícil de circunscrever com uma 
única definição. Nos trabalhos sobre SMA-COs, identificam-se pelo menos duas variações de sentido que são complementares e que convêm serem esclarecidas.

Uma primeira variação é a noção de organização como um coletivo de agentes organizado. Na seção anterior usou-se o termo organização de agentes para designar esta noção. Esta visão de organização surge a partir de um paralelo dos SMAs com o que nas Ciências Sociais se denominam organizações:

"Organizações [humanas] são coletivos orientados a objetivos relativamente específicos e que exibem estruturas sociais com um grau relativamente alto de formalização."

[Traduzido de (SCOTT, 1998, p. 26)]

"Uma estrutura social formal é aquela na qual as posições sociais e relacionamentos entre elas foram explicitamente especificados e são definidos independentemente das características pessoais e relacionamentos dos participantes ocupando estas posições."

[Traduzido de (SCOTT, 1998, p. 19)]

"As organizações [humanas] caracterizam-se por:

1. divisão de trabalho, do poder e das responsabilidades de comunicação, divisão essa que não é obra de casualidade nem obedece a um esquema tradicional, senão que tem sido deliberadamente planejada, para favorecer a realização de fins específicos;

2. presença de um ou mais centros de poder que controlam os esforços concentrados da organização e os dirige até seus fins; estes centros de poder, ademais, revisam continuamente a atuação da organização e remodelam sua estrutura, onde se tornar necessário, para aumentar sua eficiência;

3. substituição de pessoal, isto é, que as pessoas que não satisfazem possam ser dispensadas e suas tarefas atribuídas a outras. A organização pode também mudar seu pessoal através da transferência e promoção."

(CURY, 1990, p. 99)

Usando essa noção de organização humana como inspiração, pesquisadores da área de SMA argumentam que:

"no desenvolvimento de sistemas [SMA] de médio e grande porte, possivelmente imersos em ambientes abertos e dinâmicos, e que devem garantir comportamentos predizíveis e confiáveis, ... a metáfora mais apropriada é a de uma organização humana."

[Traduzido de (ZAMBONELLI; JENNINGS; WOOLDRIDGE, 2003, p. 324)]

"Organizações em Sistemas Multi-Agentes podem ser entendidas como entidades complexas onde uma multiplicidade de 
agentes interagem, dentro de um ambiente estruturado tendo em vista um propósito global."

[Traduzido de (DIGNUM, 2009, p. 4)]

Uma segunda variação de sentido para organização, intimamente ligada à idéia de coletivo organizado, é a noção de organização como um conjunto de padrões regulares e flexíveis que moldam ou restringem a atividade conjunta dentro de um grupo de agentes tendo em vista um propósito comum. Neste sentido, destacam-se as seguintes citações:

"Organizações exibem padrões de atividade e, de fato, uma maneira de descrever organizações tanto teórica quanto fenomenologicamente é como padrões observados de atividade. Esses padrões têm características estáveis (as características estáveis são o que os tornam padrões) e eles têm características flexíveis (duas coleções de atividade organizacional nunca são as mesmas, e de fato flexibilidade de ação é importante em ambientes dinâmicos). Em efeito, então, organizações podem ser vistas como arquiteturas: estruturas restritivas estáveis nas quais um certo grau de atividade flexível é possível. Generalizando a várias dimensões de descrição organizacional, uma outra maneira de dizer isto é que organizações são 'coleções específicas de questões resolvidas (estáveis) e não resolvidas (flexíveis)"' [Traduzido de (GASSER, 2001, p. 6)]

"a organização de um SMA é um conjunto de restrições ao comportamento dos agentes a fim de conduzi-los a uma finalidade comum."

(HüBNER, 2003, p. 23)

A partir dessas duas noções de organização e do que foi discutido na seção anterior, chega-se a seguinte conclusão. Uma organização de agentes, o elemento central nos SMA-COs, é uma entidade coletiva que agrega agentes e que se caracteriza por apresentar uma organização (i.e., padrões regulares e flexíveis de atividade conjunta que moldam ou restrigem a atividade coletiva dado um propósito comum) que é:

- formal - na medida em que é prescrita através de uma especificação organizacional que abstrai as características e relacionamentos individuais dos agentes participantes; e

- explícita - na medida em que existe objetivamente e permanece além dos agentes que populam a organização em um dado momento.

Utiliza-se o termo organização institucionalizada para designar a organização formal e explícita que caracteriza uma organização de agentes (HüBNER, 2003). 
Por fim, menciona-se que além dos SMA-COs, os SMA-CAs podem também ser descritos como possuindo agentes capazes de formar grupos organizados:

"A organização de um sistema multi-agente é a coleção de papéis, relacionamentos, e estruturas de autoridade que governam o seu comportamento global. Todo sistema multi-agente possui algumas ou todas essas características e assim todos têm alguma forma de organização, embora ela possa ser implícita e informal."

[Traduzido de (HORLING; LESSER, 2005, p. 1)]

“... há várias estruturas em qualquer sistema MA ... Cada estrutura afeta tanto a possibilidade quanto o sucesso das ações dos agentes, e restringe (quando conhecida) suas decisões, objetivos e planos. Os agentes não são tão livres para agir como quiserem: eles estão condicionados por suas relações de poder e dependência, seus conhecimentos, suas possibilidades de comunicação, seus papéis e comprometimentos, regras e normas sociais.

Algumas destas estruturas são deliberadamente construídas pelos agentes (pelo menos parcialmente); outras são emergentes em uma maneira objetiva."

[Traduzido de (CASTELFRANCHI, 1998, p. 175)]

Neste caso, a organização (padrões regulares e flexíveis de atividade conjunta) resulta de um processo de auto-organização e se manifesta de modo informal e implícito, não caracterizando desta maneira uma organização de agentes, conforme empregamos o termo ao longo desta tese. Na figura 2.4, ilustram-se as noções de organização discutidas.

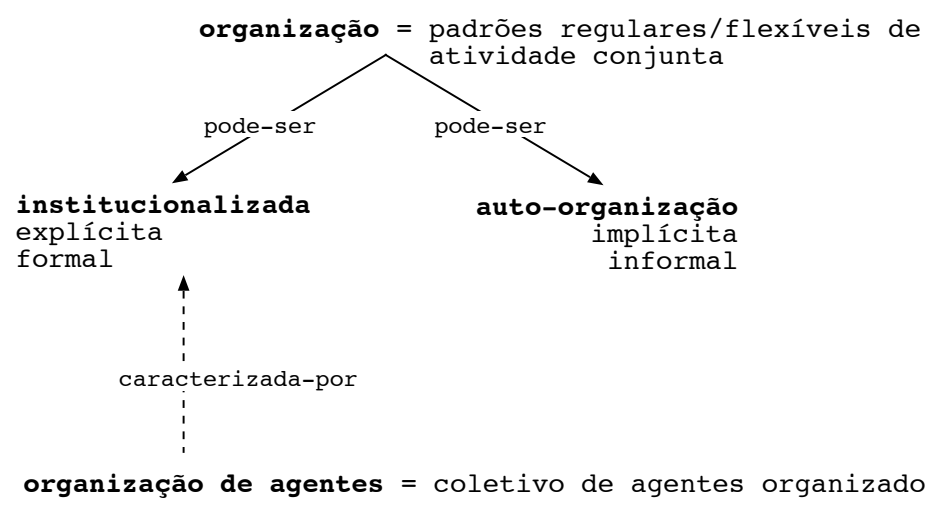

Figura 2.4: Conceito de Organização.

\subsubsection{Modelos Organizacionais}

Um elemento fundamental na etapa de concepção de um SMA-CO é o que convencionalmente se chama de modelo organizacional. Dado que os termos "or- 
ganização" e "modelo" admitem variações de significado, a construção "modelo organizacional" também fica sujeita a diferentes possibilidades de interpretação.

Dentre as interpretações possíveis, um modelo organizacional pode ser entendido de maneira geral como uma linguagem de modelagem ${ }^{8}$ utilizada para se criar especificações de organizações de agentes que irão compor um SMACO. Estas especificações são ditas especificações organizacionais e têm como foco prescrever os padrões de atividade conjunta que irão caracterizar uma dada organização de agentes.

Essa visão de modelo organizacional como linguagem de modelagem pode ser justificada observando-se alguns exemplos de modelos organizacionais presentes na literatura. Para fins de ilustração, no que segue, descrevem-se brevemente quatro modelos organizacionais, que serão convenientemente melhor detalhados na seção 4.2 .

\section{AGR}

No modelo AGR (GUTKNECHT, 2001; FERBER; GUTKNECHT; MICHEL, 2004) encontram-se três conceitos fundamentais: agentes, grupos e papéis. Ao usar AGR, o projetista representa uma dada organização de agentes como uma coleção de grupos nos quais existem papéis que devem ser assumidos por agentes. Para escrever concretamente uma especificação, encontram-se à disposição duas sintaxes. A primeira é uma sintaxe gráfica composta por figuras geométricas e linhas que materializam visualmente agentes, grupos, papéis e seus relacionamentos formando uma especificação organizacional. A segunda é uma sintaxe textual baseada em $\mathrm{XML}^{9}$ utilizada para representar computacionalmente uma especificação organizacional.

\section{STEAM}

No modelo STEAM (TAMBE, 1997), uma organização de agentes é representada em termos de times, sub-times, papéis, objetivos e planos compartilhados. Agentes ao entrar em um time assumem papéis que implicam seguir determinados planos. Da mesma forma que AGR, em STEAM há uma sintaxe gráfica e uma sintaxe

\footnotetext{
${ }^{8}$ Como uma linguagem de modelagem (GUIZZARDI, 2007), um modelo organizacional irá prover aos projetistas um arcabouço conceitual (construtos de modelagem) e uma ou mais sintaxes (símbolos e regras de composição para representar os construtos de modelagem) através das quais uma organização de agentes possa ser representada. No capítulo 3, essas noções de modelos e linguagens de modelagens serão retomadas em mais detalhes.

${ }^{9}$ eXtensible Markup Language (http://www.w3.org/XML/).
} 
XML para escrever especificações organizacionais.

\section{MOISE+}

No modelo MOISE+ (HüBNER; SICHMAN; BOISSIER, 2002; HüBNER, 2003), uma especificação organizacional divide-se em três sub-especificações: uma especificação de grupos e papéis; uma especificação de meta globais, missões, planos e esquemas sociais; e uma especificação deôntica que relaciona papéis a missões. Novamente, MOISE+ também disponibiliza sintaxes XML e gráfica para representar concretamente uma especificação organizacional.

\section{ISLANDER}

No modelo ISLANDER (ESTEVA; CRUZ; SIERRA, 2002), a especificação de uma organização de agentes compõe-se de quatro elementos básicos: uma estrutura de diálogo na qual se descrevem papéis; cenas nas quais se descrevem protocolos de interação; estruturas de atuação na qual as cenas são interrelacionadas; e normas que regulamentam obrigações que os agentes acumulam ao assumir papéis e participar de cenas. Como nos outros modelos, ISLANDER disponibiliza tanto uma sintaxe gráfica quanto uma sintaxe XML.

A partir dessa breve descrição, nota-se que em geral os modelos organizacionais variam com relação aos elementos que irão compor uma especificação organizacional. Apesar disso, é possível identificar vários temas comuns de modelagem nos quais os modelos se sobrepõem. Por exemplo, todos os modelos discutidos acima apresentam a noção de papel como ponto de contato entre a organização e os agentes individuais. Os modelos MOISE+ e STEAM organizam a atividade conjunta dos agentes por meio da decomposição de objetivos em planos. Por outro lado, ISLANDER utiliza a noção de protocolo de interação para moldar a atividade conjunta dos agentes. Esta noção não aparece nos outros modelos apresentados, mas consta em outros modelos tais como o OPERA (DIGNUM, 2004). A análise da estrutura conceitual de modelos organizacionais e a identificação de temas comuns de modelagem constituem um dos objetivos centrais desta tese. Desta maneira, no parte II do texto, os modelos organizacionais que aqui foram apenas esboçados, voltarão a ser tratados mais detidamente.

Com relação à sintaxe dos modelos organizacionais, nota-se que além de prover uma forma gráfica adequada para comunicar visualmente uma especificação 
organizacional, os modelos organizacionais também definem um formato computacional. Em geral, este formato é utilizado como entrada para infraestruturas organizacionais que implementam organização de agentes.

\subsubsection{Infraestruturas Organizacionais}

Para facilitar o trabalho de implementação de uma organização de agentes, alguns dos modelos organizacionais encontram-se associados à arquiteturas de software genéricas que são capazes de gerenciar uma organização de agentes a partir de uma especificação organizacional. Arquiteturas de software genéricas com estas características serão denominadas de infraestruturas organizacionais (BOISSIER; HüBNER; SICHMAN, 2007).

De acordo com (ESTEVA et al., 2004), alguns requisitos básicos que uma infraestrutura organizacional deve satisfazer são:

- ser independente de domínio de aplicação, sendo capaz de interpretar diferentes especificações organizacionais, criadas para diferentes áreas de aplicação;

- facilitar a participação dos agentes enquanto cuida para que as estruturas, padrões e normas estabelecidas pela especificação organizacional sejam cumpridas;

- ser neutra arquiteturalmente, i.e., poder aceitar agentes desenvolvidos com quaisquer arquiteturas internas;

- ser escalável, i.e., ser capaz de lidar com populações de agentes dinâmicas e possivelmente vastas.

Para tornar mais concreta a discussão, apresentam-se a seguir algumas infraestruturas organizacionais que satisfazem aos requisitos arrolados.

\subsubsection{MADKIT}

MADKIT (GUTKNECHT; FERBER, 2000), mais do que simplesmente uma infraestrutura organizacional, é uma plataforma de execução e intercomunicação de agentes construída tendo por base o modelo organizacional AGR. MADKIT encontra-se estruturada em torno de três princípios de projeto:

- Arquitetura baseada em micro-kernel - na base da MADKIT há um microkernel. Este tem por objetivo fornecer três funcionalidades básicas: (1) 


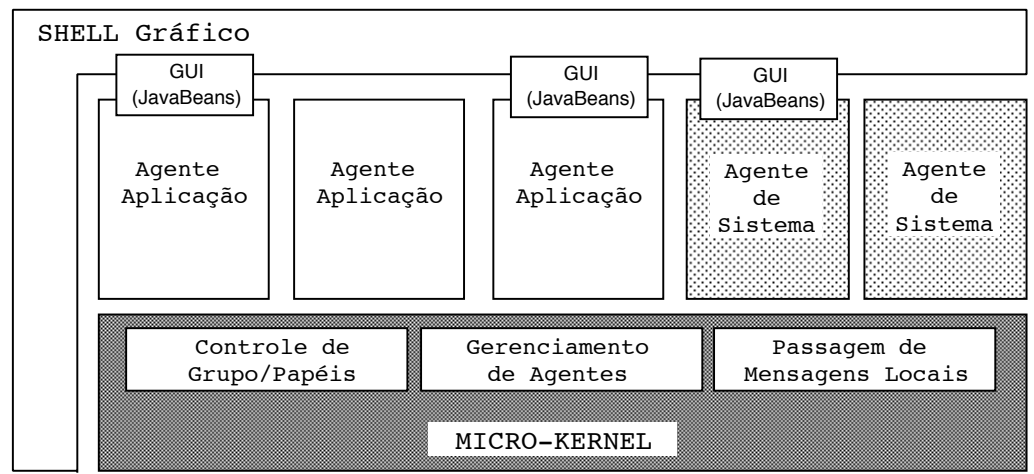

Figura 2.5: Arquitetura da plataforma MADKIT (GUTKNECHT; FERBER, 2000).

Controle de grupos e papéis - o micro-kernel é responsável por manter e alterar informações sobre o estado atual de grupos e estruturas de papéis; (2) Gerenciamento do ciclo de vida dos agentes; (3) Roteamento e distribuição de mensagens entre agentes locais.

- Agentificação de serviços - a filosofia básica da MADKIT é utilizar, onde for possível, a plataforma para o seu próprio gerenciamento. Assim, qualquer serviço além dos serviços básicos providos pelo micro-kernel são disponibilizados por meio de agentes.

- Modelo de componentes gráficos - cada agente é responsável pela sua própria GUI (Graphical User Interface). A GUI de cada agente é implementada a partir de componentes ${ }^{10}$ que se conectam a um shell gráfico global.

Na figura 2.5, ilustra-se a arquitetura da plataforma MADKIT. Observase que o micro-kernel, além de gerenciar o ciclo de vida e troca de mensagens entre os agentes, como ocorre nas plataformas tradicionais de agentes, também se encarrega de gerenciar organizações de agentes descritas em AGR, através do módulo de controle de grupos e papéis.

\subsubsection{TEAMCORE}

TEAMCORE (TAMBE; PYNADATH, 2001; PYNADATH et al., 2000) é uma arquitetura de integração de agentes heterogêneos que tem por base o modelo STEAM. Na figura 2.6, mostram-se os principais componentes da arquitetura TEAMCORE. Os componentes encontram-se dispostos em três camadas. $\mathrm{Na}$ camada inferior encontram-se a TOPI (Team Oriented Programming Interface) e o KARMA (Knowledgeable Agent Resources Manager Assistant). A TOPI é

\footnotetext{
${ }^{10} \mathrm{Na}$ versão padrão, os componentes seguem a especificação Java Beans (java.sun.com).
} 


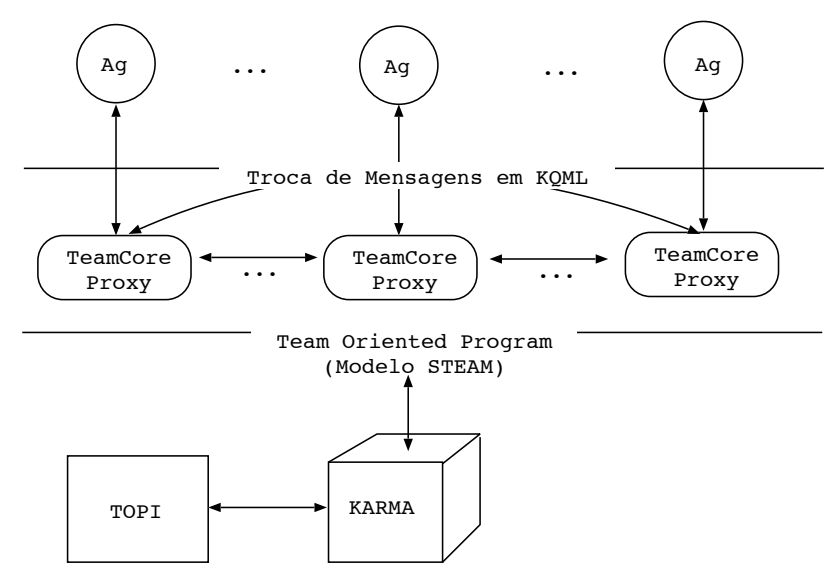

Figura 2.6: Arquitetura da infra-estrutura TEAMCORE (TAMBE; PYNADATH, 2001).

a interface entre o projetista de um time (organização de agentes) e a arquitetura TEAMCORE. Usando a TOPI o projetista pode especificar a hierarquia de sub-times e papéis, e a hierarquia de atividade conjunta que formam uma especificação STEAM. O KARMA é um agente assistente que tem como função verificar especificações STEAM e auxiliar no processo de formação e monitoração de times segundo a especificação.

Na camada intermediária se encontram TeamCore Proxies. Cada proxy encapsula planos de atividades relativos a um dado papel que foram especificados no modelo STEAM. Os proxies também encapsulam regras independente de domínio que são utilizadas para coordenar o trabalho conjunto.

Os agentes de domínio formam a camada superior da arquitetura. Todo agente de domínio que entra em uma organização implementada em TEAMCORE deve estar associado a um TeamCore Proxy. Os proxies irão tomar conta de grande parte do processo de coordenação de atividades. Os agentes de domínio irão realizar tarefas individuais.

Um último detalhe que merece menção é o fato de que todas as mensagens trocadas entre agentes de domínio, proxies e KARMA são escritas na linguagem de comunicação de agentes KQML (FININ; LABROU; MAYFIELD, 1997). Dessa forma há um serviço de transporte de mensagens implícito na arquitetura.

\subsubsection{S-MOISE+}

S-MOISE+ (HüBNER; SICHMAN; BOISSIER, 2005) é um middleware organizacional de código aberto que implementa o modelo MOISE+. Como mostra a figura 2.7, S-MOISE+ é estruturado em três camadas: a camada de comunicação que é 
utilizada para troca de mensagens, a camada organizacional que gerencia organizações de agentes e a camada de agentes, formada por agentes que participam da organização.

A camada organizacional é formado por dois elementos principais: OrgBox e um agente especial chamado OrgManager. OrgBox é uma API (Interface de Programa de Aplicação) que agentes externos devem utilizar para serem capazes de entrar em uma organização de agentes implementada no S-MOISE+. OrgManager é um agente interno que mantém o estado atual de uma organização de agentes. Este estado é formado, dentre outros elementos, pela especificação organizacional escrita em MOISE+, referências para os agentes que atualmente são membros da organização, grupos criados, sub-grupos, os papéis que cada agente está assumindo, missões dos agentes, etc., conforme definido na especificação organizacional.

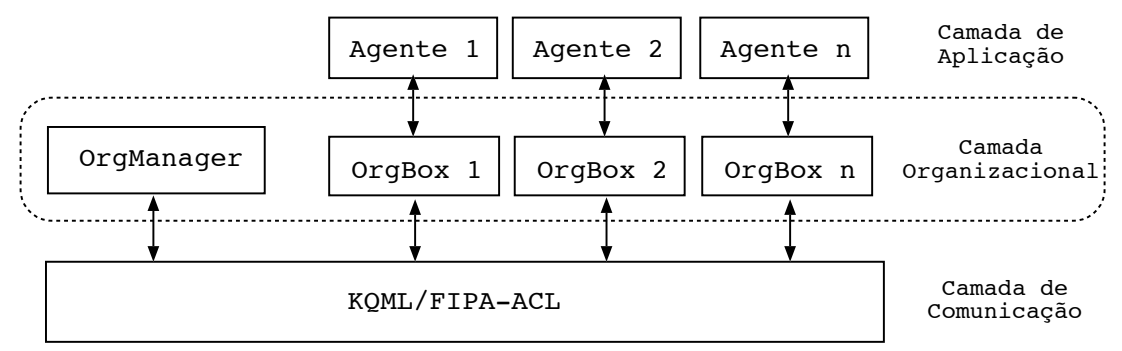

Figura 2.7: Componentes de S-MOISE+ (HüBNER; SICHMAN; BOISSIER, 2005).

Através de eventos disparados a partir das OrgBoxes, os agentes podem tanto consultar quanto modificar o estado corrente de uma organização de agentes mantido pelo OrgManager. Ao processar um evento provindo de uma OrgBox, o OrgManager busca constantemente manter o estado da organização consistente com a sua especificação. Dentre as informações que podem ser consultadas, permite-se aos agentes que entram na organização o acesso à especificação organizacional.

Por fim, os autores do S-MOISE+ ressaltam:

"Uma importante característica de nossa proposta é que ela não requer qualquer tipo de arquitetura interna específica para os agentes, uma vez que estamos interessados em sistemas abertos. O único requisito e que os agentes usem a API OrgBox para interagir com o sistema." (HüBNER; SICHMAN; BOISSIER, 2005, p. 117) 


\subsubsection{AMELI}

AMELI (ESTEVA et al., 2004) é uma infra-estrutura de software para implementar instituições eletrônicas (e-instituições) especificadas utilizando-se a linguagem ISLANDER. Uma e-instituição é o equivalente em AMELI à noção de organização de agentes. De maneira similar a S-MOISE+, AMELI define a arquitetura de uma e-instituição como sendo composta por três camadas (figura 2.8):

- camada de agentes externos - agentes externos que tomam parte na instituição;

- camada social (AMELI) - implementação da funcionalidade de controle da infra-estrutura da instituição;

- camada de comunicação - provê serviço de transporte de mensagens.

Agentes que participam de uma e-instituição não interagem diretamente. Toda interação é intermediada pela camada social (AMELI). A camada social é composta de:

- gerenciador da e-instituição (IM) - responsável por iniciar uma e-instituição, autorizar os agentes a entrar na e-instituição, e gerenciar a criação de novas cenas de execução; o IM mantém ainda informações sobre todos os participantes e todas as cenas de execução; há apenas um IM por e-instituição;

- gerenciador de transições $(\mathrm{TM})$ - sua função é gerenciar as transições que controlam os movimentos dos agentes entre as cenas; há um TM por transição;

- gerenciador de cena (SM) - responsável por controlar a execução de uma cena; há um SM por instância de cena;

- governor - funciona como mediador da participação de um agente externo na e-instituição; há um governor para cada agente participante.

AMELI provê os agentes externos com informações necessárias à sua participação na e-instituição. O AMELI cuida ainda para que normas e estruturas da einstituição sejam garantidas por meio dos elementos da camada social.

A comunicação do agente externo com o governor é feita diretamente através de um canal de comunicação. Nenhuma restrição é imposta a arquitetura interna dos agentes. Requer-se apenas que o agente siga um protocolo de interação préestabelecida para interagir com um governor. 


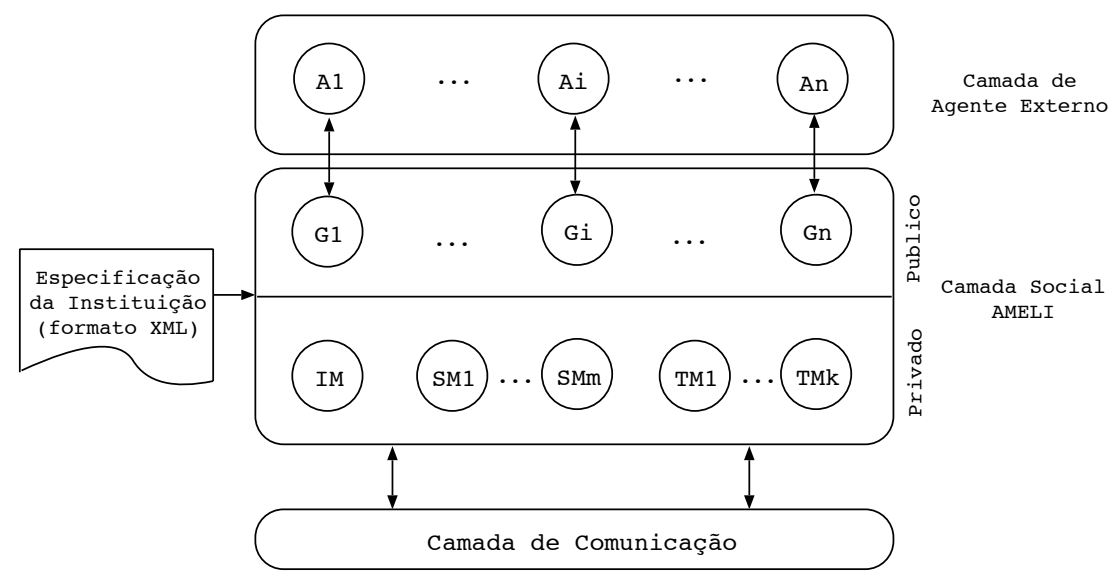

Figura 2.8: Arquitetura de uma e-instituição (ESTEVA et al., 2004).

\subsubsection{Arquitetura Genérica}

A partir das infraestruturas organizacionais apresentadas, observa-se o seguinte padrão arquitetural para SMA-COs: um sistema em camadas com pelo menos três camadas - em baixo, uma camada de transporte de mensagens (infraestrutura de comunicação); no meio, uma camada organizacional (infraestrutura organizacional); e, no topo, uma camada de agentes (organização de agentes). Essa arquitetura em três camadas é ilustrada de modo esquemático na figura 2.9. Na figura, o desenho dos agentes segue o modelo de agentes deliberativos apresentados na figura 2.2 .

A camada organizacional materializa o conceito de organização institucionalizada. Nesta camada, uma especificação organizacional, escrita em um dado modelo organizacional, é interpretada por uma infraestrutura organizacional. Como resultado, na camada de agentes, passa a existir uma organização de agentes na qual a atividade conjunta é explicitamente padronizada e controlada pela infraestrutura organizacional.

Para controlar a atividade conjunta dos agentes, a infraestrutura organizacional mantém internamente uma representação do estado da organização de agentes, além da especificação organizacional. No estado da organização, são mantidas informações sobre a população corrente da organização, os papéis que cada agente está assumindo, os grupos que foram criados, as atividades que estão sendo realizadas, etc. Com o passar do tempo, esse estado sofre mudanças causadas por eventos organizacionais disparados pelos agentes (e.g., criar um grupo, assumir um papel, entrar na organização, etc.). Deste modo, para ser membro de uma organização, todo agente tem de ser capaz de acessar, interpretar e agir conforme a especificação e o estado mantidos internamente pela infraestrutura organizaci- 


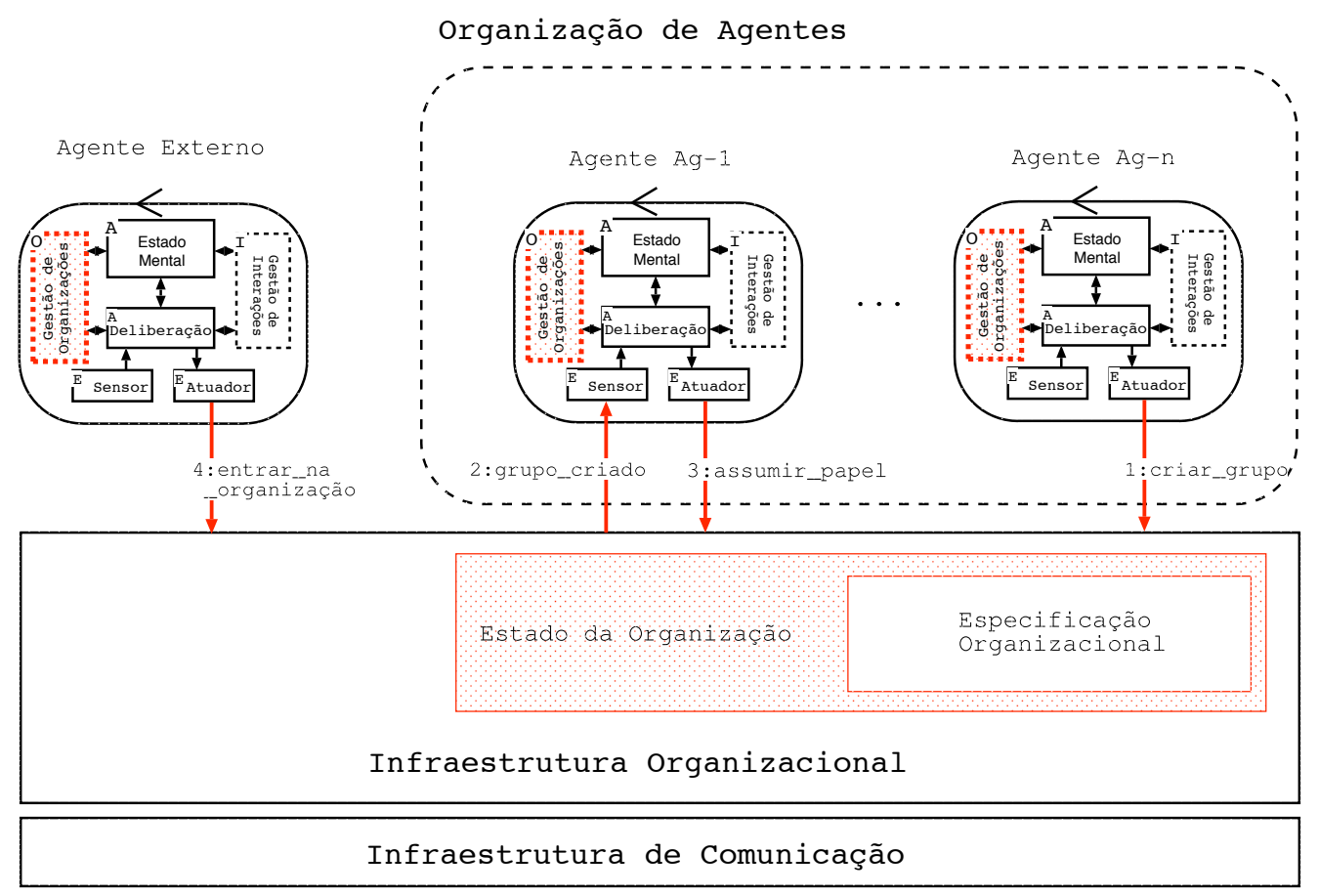

Figura 2.9: Arquitetura genérica de SMA-COs.

onal.

As arquiteturas de S-MOISE+ (figura 2.7) e AMELI (figura 2.8) refletem de forma direta essa estrutura de três camadas para SMA-COs. Na plataforma MADKIT (figura 2.5), a camada de comunicação e a camada organizacional podem ser respectivamente mapeadas nos módulos passagem de mensagens e controle de grupos e papéis, que compõem o micro-kernel. Por fim, a arquitetura TEAMCORE (figura 2.6) também se estrutura em três camadas. Mas nesse caso, há dois aspectos diferentes. O primeiro é que as duas camadas inferiores em TEAMCORE correspondem à camada organizacional. O segundo é que a camada de transporte de mensagens não aparece de forma explícita.

\subsection{Resumo}

Neste capítulo, os conceitos básicos de agente autônomo, sistema multiagentes (SMA), SMA centrado na organização (SMA-CO), organização, modelo organizacional e infraestrutura organizacional foram apresentados. Em suma, pode-se dizer que um SMA-CO é um SMA no qual, além dos agentes, organizações de agentes figuram como elementos centrais que compõem o SMA. Organizações de agentes caracterizam-se por apresentarem uma organização institucionalizada, i.e., padrões regulares e flexíveis que controlam ou restringem a atividade conjunta dos agentes, que são especificados formalmente e que podem ser implementados 
explicitamente. A especificação de uma organização de agentes, enfocando sua organização institucionalizada, é feita por meio de um modelo organizacional. A implementação de especificações organizacionais é facilitada utilizando-se uma infraestrutura organizacional. Como resultado, SMA-COs apresentam uma arquitetura que, em linhas gerais, segue o padrão apresentando na figura 2.9. 


\section{Engenharia Dirigida por Modelos}

O objetivo geral desta tese é mostrar como modelos organizacionais podem ser integrados de tal modo que o resultado possa ser utilizado em soluções de interoperabilidade organizacional. Dado este objetivo, antes de desenvolvê-lo, convém definir precisamente o que se entende por "modelo" e "integração de modelos", no caso particular dos modelos organizacionais. Este é o objetivo deste capítulo.

\subsection{Modelos e Metamodelos}

A exemplo dos conceitos de agente e organização, discutidos no capítulo anterior, a noção de modelo é um conceito amplo e, portanto, aberto a diversos usos e interpretações (FAVRE, 2006).

\subsubsection{Noção de Modelo}

No contexto desta tese, modelo significa essencialmente uma representação que simplifica e substitui uma dada realidade para certo propósito (GASEVIC; DJURIC; DEVEDZIC, 2006; BéZIVIN; GERBé, 2001). Seguindo (FAVRE, 2006), esta concepção de modelo será chamada de modelo como representação ${ }^{1}$.

De acordo com (STACHOWIAK, 1973) (apud (KüHNE, 2006, p. 371) e (LUDEWIG, 2003, p. 6)), a noção de modelo como representação pode ser formulada de modo mais enfático definindo-se três critérios explícitos:

- o critério do mapeamento $(\mu)$ - deve haver um sistema ou fenômeno original em relação ao qual o modelo foi criado como representação; ressalta-se que, no momento da criação de um modelo, não necessariamente, o sistema ou

\footnotetext{
${ }^{1}$ Através de um estudo etimológico detalhado, em (FAVRE, 2006), além da idéia de modelo como representação, são discutidos mais quatro outros possíveis sentidos para o termo "modelo", dentre os quais está a idéia de modelo como tipo (ou classe) que será mencionada na sequência.
} 
fenômeno original deve existir; caso o original exista, tem-se um modelo descritivo; caso contrário, produz-se um modelo prescritivo;

- o critério da redução $(\rho)$ - nem todas as propriedades, características ou estados do sistema ou fenômeno original devem se encontrar representados em um modelo; em outras palavras, todo modelo deve reter algumas características do original e descartar ou abstrair várias outras; e

- o critério pragmático $(\pi)$ - todo modelo deve ser capaz de substituir o sistema ou fenômeno original para algum propósito bem definido; ou, nas palavras de (BéZIVIN; GERBé, 2001, p. 274): “[todo] modelo dever ser capaz de responder a questões no lugar do original."

Em suma: partindo-se do conceito intuitivo de representação, tem-se um modelo quando, e somente quando, esses três critérios são satisfeitos.

\subsubsection{Especificações organizacionais como modelos}

Observa-se que uma especificação organizacional, criada por meio de um modelo organizacional (seção 2.3.2), atende aos critérios acima. De fato, no caso de uma especificação organizacional, há um sistema ou fenômeno original sendo representado que é uma particular organização de agentes sendo projetada. Em uma especificação organizacional, abstraem-se vários aspectos da real composição, estrutura e funcionamento de uma organização de agentes, dentre os quais, um dos mais importantes, é a constituição interna dos agentes que irão compô-la. Retêmse, preferencialmente, os padrões de atividade conjunta que irão caracterizar o comportamento ao longo do tempo da futura organização. Quanto ao propósito, destacam-se dois: por um lado, uma especificação organizacional é um artefato que um projetista, que pode ser tanto uma pessoa quanto um agente de software, cria como meio de analisar, projetar e implementar uma organização de agentes desejada; por outro lado, do ponto de vista dos agentes externos que pretendem fazer parte da organização, uma especificação organizacional funciona como documento que explicita e formaliza os padrões de estruturação e comportamento conjunto aceitáveis ou possíveis dentro da organização. Em conclusão, uma especificação organizacional é um modelo; um modelo de natureza prescritiva.

Além desta constatação, a natureza de especificações organizacionais não se restringe a um modelo prescritivo. Pode-se também pensar no caso de especificações organizacionais que representam os padrões de atividade conjunta de organizações de agentes pré-existentes. Neste caso, tem-se um modelo descri- 
tivo cujo propósito final pode ser variado. Por exemplo, no caso de SMA-CAs nos quais os agentes se auto-organizam, pode-se pensar em uma especificação organizacional que descreva a auto-organização e sirva como meio de predizer ou garantir propriedades no comportamento do SMA-CA como um todo.

\subsubsection{Modelos organizacionais como modelos}

Se as especificações organizacionais são modelos de organizações de agentes pelos critérios de (STACHOWIAK, 1973), o que se pode dizer com relação aos "modelos organizacionais", i.e., a linguagem na qual especificações organizacionais são criadas? Seriam eles também modelos como representação?

A resposta é não. Modelos organizacionais não se enquadram na definição de modelos como representação. Então o que justifica o termo "modelo" na construção "modelo organizacional"?

Uma justificativa é que, além do sentido modelo como representação, o termo "modelo" admite também um outro sentido que é o de modelo como tipo (ou modelo como classe), de acordo com (FAVRE, 2006). Neste caso, o termo "modelo" designa uma coleção de coisas que compartilham características ou qualidades comuns (e.g., um modelo de carro, um modelo de computador). Assim, ao invés de dizer que um modelo organizacional é um modelo porque representa algum sistema ou fenômeno, diz-se que ele é um modelo por que consiste em um tipo ou classe de especificações organizacionais que podem ser criadas.

No entanto, caso se considere que modelos organizacionais, como toda linguagem, são definidos por meio de um artefato de especificação, há uma outra justificativa para a construção "modelo organizacional". Uma justificativa que é indireta, mas em consonância com a noção de modelo como representação adotada no contexto desta tese. Pode-se dizer que a especificação de um modelo organizacional, em essência, é um modelo (i.e., uma representação) cujo propósito é caracterizar (de modo finito) um tipo ou classe (possivelmente infinita) de especificações organizacionais válidas e significativas. Assim, identificando-se modelos organizacionais com suas especificações obtém-se, indiretamente, a noção de modelo como representação. Essas observações são resumidas na figura 3.1.

Na figura 3.1, observa-se que na relação entre a especificação do modelo organizacional e o modelo organizacional utilizou-se entre parênteses o prefixo "meta". Com isso, quer-se dizer que as especificações de modelos organizacionais sendo modelos (representações) de modelos organizacionais (classes de especificações organizacionais), tecnicamente, podem ser imaginadas como metamodelos. 


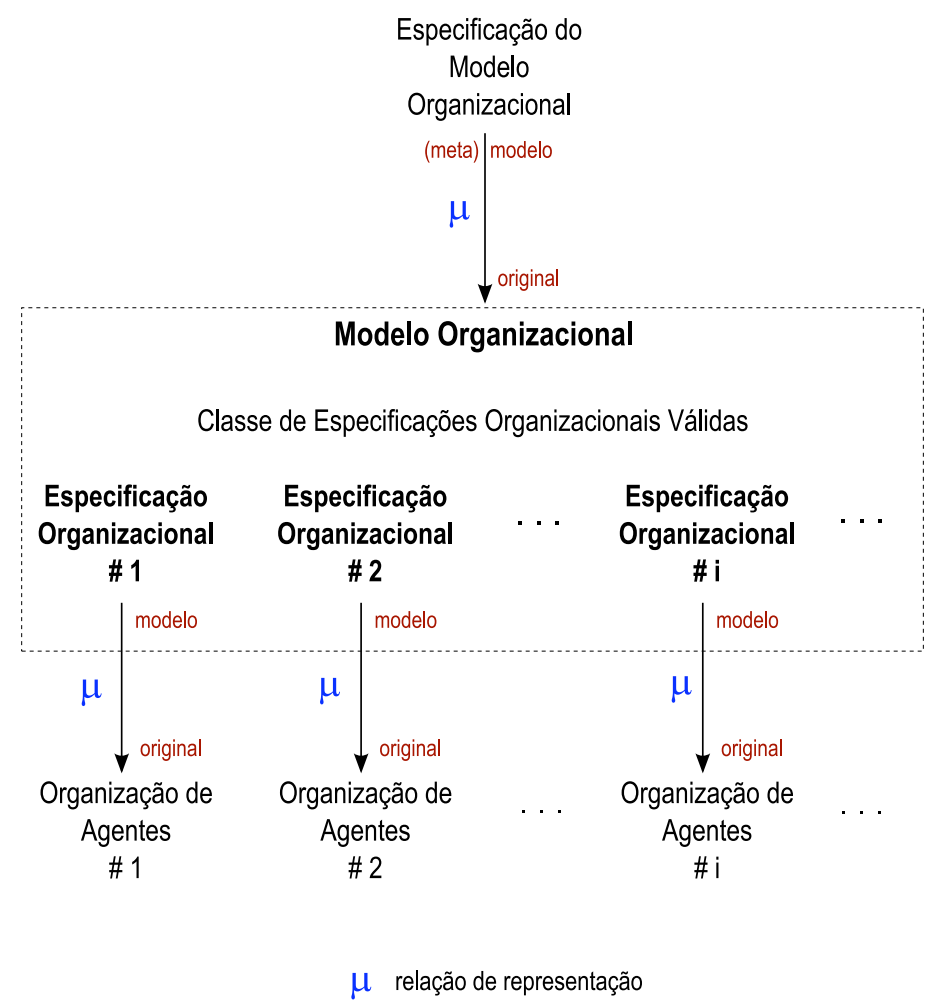

Figura 3.1: Modelos organizacionais e a noção de modelo.

\subsubsection{Noção de Metamodelo}

Não há um consenso na literatura sobre o que exatamente é um metamodelo. De modo geral, vários pesquisadores (KELLY; TOLVANEN, 2008; KLEPPE, 2008; GUIZZARDI, 2007; KüHNE, 2006; JOUAULT; BéZIVIN, 2006; FAVRE, 2005; SEIDEWITZ, 2003; CLARK; EVANS; KENT, 2002) concordam que metamodelo pode ser definido como um modelo que caracteriza uma classe de modelos - um modelo de modelos, por assim dizer -, normalmente criado para servir como (parte da) especificação de uma linguagem de modelagem.

Há, no entanto, dois pontos nesta definição que levam a opiniões diversas:

- Quanto ao critério do mapeamento $(\mu)$, metamodelos representam uma classe ou tipo de modelos. Quanto ao critério pragmático $(\pi)$, metamodelos servem como (parte da) especificações de linguagens de modelagem. E quanto ao critério da redução $(\rho)$, como se define um metamodelo?

- O que é uma linguagem de modelagem e em que consiste a sua especificação?

Começando pelo conceito de linguagem de modelagem, discutem-se esses questões. 


\subsubsection{Linguagens de modelagem}

Em acepção ampla, uma linguagem de modelagem pode ser entendida como uma coleção potencialmente infinita de modelos construídos a partir de um vocabulário de simbolos primitivos de modelagem, seguindo regras bem definidas de composição de símbolos e formação de modelos válidos. Neste caso, tem-se uma concepção de linguagem de modelagem que segue a linha das definições tradicionais das linguagens formais em Ciência da Computação (HOPCROFT; ULLMAN, 1979).

Dada a natureza das linguagens de modelagem que se tem em vista - i.e., os modelos organizacionais-, ao invés da acepção ampla acima, adota-se uma outra visão de linguagem de modelagem que é menos geral, porém mais de acordo com os objetivos deste trabalho. Seguindo a linha do Engenharia Dirigida por Modelos (SCHMIDT, 2006; MELLOR; CLARK; FUTAGAMI, 2003), define-se uma linguagem de modelagem como sendo um meio sistemático de se criar e interpretar modelos caracterizado pela especificação de:

- Uma estrutura conceitual, na qual definem-se o vocabulário de conceitos primitivos de modelagem subjacentes a uma dada linguagem, bem como os relacionamentos e restrições contextuais existentes entre os conceitos primitivos. Os conceitos primitivos de modelagem determinam a natureza dos elementos que irão compor um modelo. Os relacionamentos e restrições contextuais prescrevem como (instâncias de) conceitos primitivos podem ou devem ser arranjados para compor modelos válidos ou bem formados.

A especificação da estrutura conceitual comumente é designada por sintaxe abstrata da linguagem. Isto se deve ao fato de que ela prescreve uma forma para os modelos que é abstrata no sentido de que reflete uma particular conceitualização do domínio de aplicação da linguagem (BéZIVIN, 2005), ou "visão de mundo" (GUIZZARDI, 2007), em oposição a uma particular forma na qual os modelos podem ser concretamente criados ou visualizados pelos usuários da linguagem.

- Uma ou mais notações ou sintaxes concretas, que têm como propósito servir de veículo de expressão dos modelos criados conforme a estrutura conceitual subjacente à linguagem de modelagem.

Há duas categorias de notações tipicamente utilizadas: as notações textuais e as notações gráficas. Nas notações textuais, os modelos são escritos na forma de um texto estruturado, i.e., uma sequência de caracteres que seguem regras de boa formação que refletem a estrutura conceitual da linguagem. 
Nas notações gráficas, ao invés de escritos como texto, os modelos são desenhados como diagramas compostos por elementos gráficos tais como linhas, círculos, retângulos, etc. que veiculam de modo pictórico os conceitos de modelagem da linguagem. Observa-se que uma mesma estrutura conceitual de um linguagem de modelagem pode admitir variadas notações textuais, gráficas ou uma combinação de ambas.

- Um ou mais mapeamentos semânticos, nos quais busca-se caracterizar como modelos devem ser interpretados tendo em vista os critérios de redução e pragmático, i.e., ao simplificar e substituir um sistema ou fenômeno original dado um propósito bem definido. Desta forma, mapeamentos semânticos definem a natureza da relação de representação entre modelos e os originais que eles representam.

Em geral, especificações de mapeamentos semânticos são feitas a partir da estrutura conceitual das linguagens de modelagem. A razão é que as notações servem apenas como formas diferentes de se expressar concretamente modelos; formas que são capturadas em seus aspectos essenciais pela estrutura conceitual.

Esta concepção de linguagem de modelagem adotada é baseada em definições similares encontradas em (KELLY; TOLVANEN, 2008; KLEPPE, 2008; JOUAULT; BéZIVIN, 2006; CLARK; EVANS; KENT, 2002). Em conjunto, a especificação da estrutura conceitual, as possíveis notações e os relacionamentos entre elas, são comumente chamados de sintaxe da linguagem de modelagem. Por sua vez, a definição de mapeamentos semânticos constitui a semântica da linguagem de modelagem.

\subsubsection{Modelo de modelos}

Havendo diversos aspectos a serem especificados em uma linguagem de modelagem e sendo metamodelo um modelo criado para servir como (parte da) especificação de uma linguagem de modelagem, a questão é: quais aspectos podem ser especificados por meio de metamodelos?

A resposta para esta questão varia entre dois extremos.

Em um extremo, concebe-se metamodelos como modelos que retêm a estrutura conceitual dos modelos que podem ser escritos utilizando-se uma dada linguagem de modelagem. Em outras palavras, em um metamodelo representam-se apenas os conceitos de modelagem de uma linguagem de modelagem, bem como 
os seus relacionamentos e restrições de combinação, desconsiderando os outros aspectos. Esta é a visão mais tradicional e usual de metamodelo, implícita ou explicitamente adotada por boa parte dos pesquisadores (GUIZZARDI, 2007; KüHNE, 2006; BéZIVIN, 2005; SEIDEWITZ, 2003).

No outro extremo, propõe-se que a meta-modelagem, i.e., a criação de metamodelos, não seja uma técnica de especificação restrita apenas à estrutura conceitual de uma linguagem, mas que seja utilizada também para representar todos os aspectos de uma linguagem de modelagem. Em (CLARK; SAMMUT; WILLANS, 2008a; KLEPPE, 2008), por exemplo, mostra-se como metamodelos notacionais e metamodelos semânticos podem ser criados ao se especificar linguagens de modelagem.

Neste trabalho, adota-se a visão tradicional de metamodelos. Emprega-se o termo "metamodelo" para designar apenas modelos criados para capturar a estrutura conceitual de linguagens de modelagem. Com isto, espera-se evitar uma confusão terminológica entre metamodelos (na visão tradicional) e os modelos de mapeamento semântico entre metamodelos pois, pela visão de (CLARK; SAMMUT; WILLANS, 2008a; KLEPPE, 2008), estes últimos também poderiam ser chamados de metamodelos. Modelos de mapeamento semântico entre metamodelos são discutidos mais à frente (seção 3.2), ao se discutir a noção de integração de (meta)modelos.

Além disso, pressupõe-se que, para ser chamado de "metamodelo", o modelo tenha sido criado utilizando-se uma linguagem de meta-modelagem. Esta restrição é necessária porque na definição inicial da noção de modelo usou-se o conceito intuitivo (não definido) de representação. Desta maneira, restringe-se metamodelos a representações criadas a partir de primitivas e regras de modelagem bem definidas.

\subsubsection{Linguagens de meta-modelagem}

Há vários modos de se criar metamodelos. Por definição, metamodelos são similares aos modelos conceituais comumente usados na Engenharia de Software e Engenharia de Conhecimento (DIESTE et al., 2002), i.e., representações "dos conceitos e restrições essenciais de um domínio" (GUIZZARDI; HERRE; WAGNER, 2002). Assim, em princípio, qualquer linguagem de modelagem conceitual, tais como o modelo de Entidade Relacionamento (CHEN, 1976), Grafos Conceituais (GERBé; MINEAU; KELLER, 2001), diagramas de classe UML (GUIZZARDI et al., 2004), etc., podem ser utilizadas para escrever metamodelos. Na prática, no entanto, há 
várias linguagens especializadas em meta-modelagem, concebidas para a criação de metamodelos. Como exemplos, citam-se as linguagens MML (CLARK; EVANS; KENT, 2002), KM3 (JOUAUlT; BéZIVIN, 2006), MOF/OCL (OMG, 2006a; OMG, 2006b), XMF (CLARK; SAMMUT; WILLANS, 2008b), GOPPRR (KELLY; TOLVANEN, 2008) e Ecore (STEINBERG et al., 2008).

A vantagem óbvia de se utilizar uma linguagem de meta-modelagem é o fato dela ser projetada para a tarefa. Além disso, algumas delas fazem parte de plataformas de meta-modelagem que, a partir de metamodelos, automatizam a criação de processadores de linguagens tais como editores, interpretadores, comparadores e tradutores de modelos (KARAGIANNIS; KüHN, 2002; SELIC, 2003).

\subsubsection{Metamodelos Ecore}

No restante deste texto, e de modo especial na Parte II, serão criados vários metamodelos para representar e integrar modelos organizacionais. Para a criação destes metamodelos, adota-se a linguagem de meta-modelagem Ecore (STEINBERG et al., 2008), em conjunto com OCL (OMG, 2006b) para a escrita de restrições contextuais entre conceitos. Há duas razões principais para esta escolha. Em primeiro lugar, o par Ecore/OCL é expressivo o suficiente dados os objetivos e escopo deste trabalho. Adicionalmente, existe uma infraestrutura de metamodelagem de código aberto e livre que permite a manipulação destas linguagens (STEINBERG et al., 2008); assim, na prática, têm-se à disposição ferramentas que facilitam a implementação e testes dos metamodelos criados.

$\mathrm{Na}$ sequência, descrevem-se os conceitos primitivos e um exemplo de metamodelagem em Ecore. Na descrição do exemplo, comenta-se o uso complementar de OCL na escrita de restrições contextuais entre conceitos.

\subsubsection{Primitivas de meta-modelagem Ecore}

A exemplo de várias outras linguagens de meta-modelagem tais como MML (ClARK; EVANS; KENT, 2002), KM3 (JOUAult; BéZIVIN, 2006), MOF (OMG, 2006a) e XMF (CLARK; SAMMUT; WILLANS, 2008b), Ecore é uma linguagem fundamentada na modelagem orientada a objetos (BOOCH; RUMBAUGH; JACOBSON, 1999). Por este motivo, os conceitos primitivos de Ecore são as noções gerais de:

- classe, uma descrição de uma coleção de objetos (instâncias da classe) que compartilham atributos e relacionamentos; 
- atributo, um elemento da descrição de uma classe que relaciona instâncias da classe a um domínio de valores (tipo de dado ou tipo enumeração); atributos designam propriedades ou características básicas compartilhadas pelas instâncias da classe;

- referência, um relacionamento estrutural entre duas classes que descreve uma coleção de ligações (ou conexões) existentes entre instâncias das classes envolvidas;

- generalização, um relacionamento taxonômico entre duas classes, no qual há uma classe mais específica (subclasse) e uma classe mais geral (superclasse); por meio da generalização, toda instância da subclasse também é uma instância da superclasse; já o inverso é falso.

Em um metamodelo escrito em Ecore, as classes são utilizadas para representar explicitamente os conceitos primitivos de uma linguagem de modelagem. Os atributos capturam propriedades ou características definidoras dos conceitos. As referências explicitam relacionamentos estruturais entre conceitos. Por fim, os relacionamentos de generalização representam relações taxonômicas entre os conceitos de modelagem. Uma descrição mais completa da estrutura conceitual de Ecore é apresentada no apêndice A.

Em linhas gerais, criar um metamodelo em Ecore é semelhante a representar a estrutura conceitual de uma linguagem através de um diagrama de classes simplificado, muito parecido com um sub-conjunto mínimo dos diagramas de classe padrão UML (BOOCH; RUMBAUGH; JACOBSON, 1999), como exemplificado a seguir.

\subsubsection{Exemplo de meta-modelagem Ecore}

Na figura 3.2, apresenta-se um exemplo de metamodelo Ecore. O exemplo consiste na especificação da estrutura conceitual de uma (mini)linguagem para modelagem de empresas (mLE). A mLE é fictícia e bastante simples, mas permite ilustrar como os modelos organizacionais serão representados através de metamodelos na Parte II do texto.

\section{Modelagem específica de domínio}

Assim como os modelos organizacionais, a mLE constitui o que frequentemente se chama de linguagem de modelagem específica de domínio (CLARK; SAMMUT; 

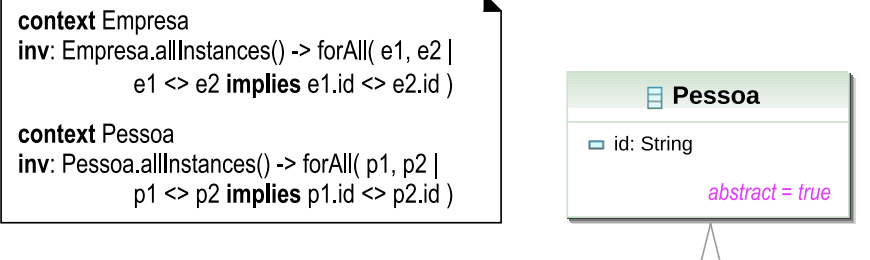

\begin{tabular}{|l|lr|r|}
\hline $\begin{array}{l}\text { 目 Empresa } \\
\begin{array}{l}\text { id: String } \\
\text { ramo: String }\end{array}\end{array}$ & empresa & funcionario & 目 Funcionario \\
\hline & & $1 . .^{*}$ & \\
\hline
\end{tabular}

«enumeration»

$\stackrel{\text { Sols }}{\underline{\underline{S}} \text { Situacao }}$

- ATIVO: 0

- APOSENTADO: 1
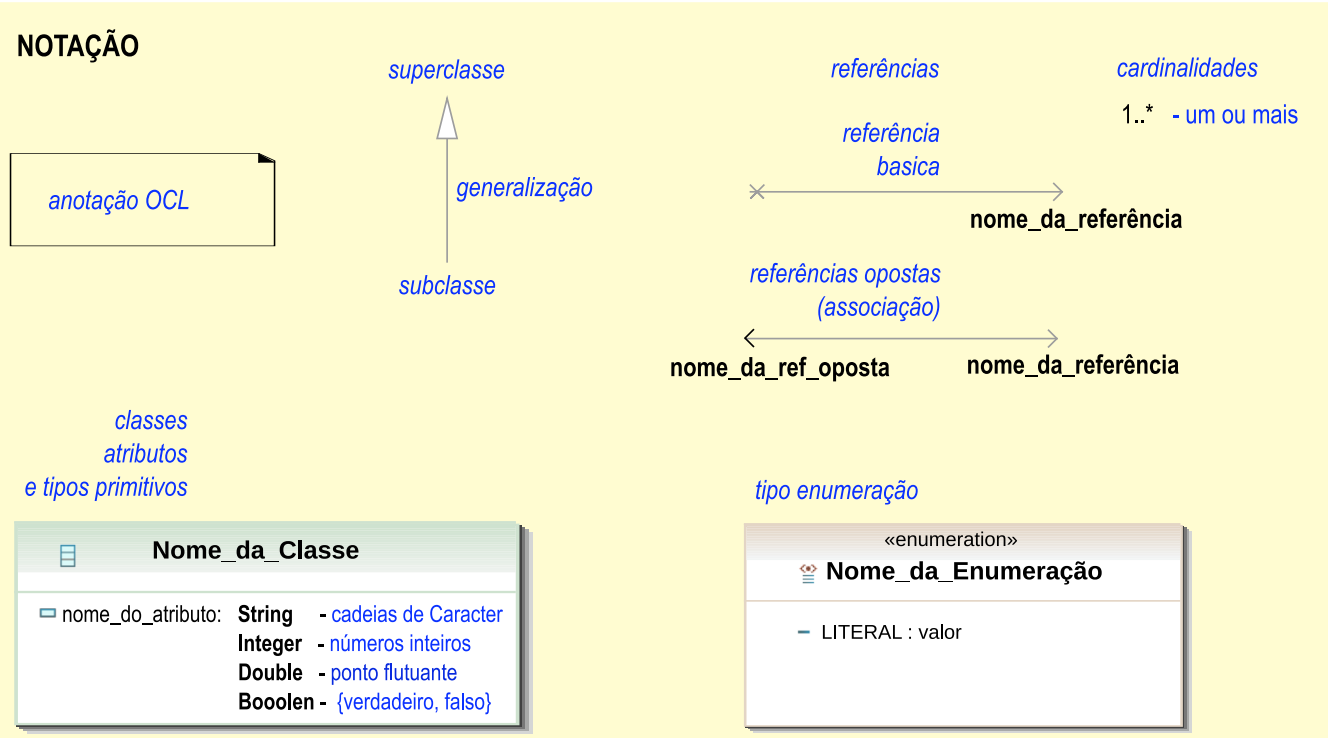

Figura 3.2: Metamodelo da mLE escrito em Ecore/OCL.

WILLANS, 2008a; KELLY; TOLVANEN, 2008; KLEPPE, 2008; JOUAULT; BéZIVIN, 2006). Uma linguagem de modelagem é dita específica de domínio, quando a sua área de aplicação consiste em um domínio bem definido e restrito. No caso dos modelos organizacionais, o domínio de aplicação é o projeto de organizações de agentes. Quanto à mLE, representada na figura 3.2, o seu domínio de aplicação é a modelagem de empresas enfocando algumas relações existentes entre empresas e pessoas.

Na visão de mundo da mLE, criam-se modelos a partir de três conceitos fundamentais:

- empresa - organização econômica constituída para explorar determinado ramo de negócio e oferecer ao mercado bens ou serviços;

- pessoa - ser humano, homem ou mulher;

- funcionário - pessoa que atualmente trabalha, ou já trabalhou, para uma empresa. 
Estes conceitos são explicitamente representados no metamodelo da figura 3.2 por meio das classes Empresa, Pessoa e Funcionario ${ }^{2}$, respectivamente.

Observando o metamodelo, nota-se que o conceito de empresa é caracterizado por dois atributos, id : String e ramo : String, e uma associação ${ }^{3}$ funcionario 1..*/ empresa 1..*, com o conceito de funcionário. Os atributos id e ramo representam o fato de que toda empresa tem um identificador e que atua em determinado ramo, respectivamente. A associação funcionario / empresa indica que toda empresa possui vários funcionários (no mínimo 1), e que todo funcionário trabalha, ou já trabalhou, em pelo menos um empresa.

Com relação ao conceito de funcionário, este é representado como uma especialização do conceito de pessoa. De modo essencial, o conceito de pessoa é representado por uma classe abstrata ${ }^{4}$, que possui como característica básica um atributo id : String. Como no caso de conceito de empresa, este atributo id representa o fato de que toda pessoa possui um identificador.

Além de caracterizados como pessoas, funcionários apresentam um atributo situacao : Situacao. Situacao é uma enumeração que admite apenas dois valores: ATIVO $=0$ e APOSENTADO $=1$. Por meio destes dois valores simbólicos, determina-se, de modo respectivo, se um funcionário atualmente trabalha ou se já trabalho em uma dada empresa; neste caso, a empresa em questão é a empresa referenciada pelo lado empresa $1 \ldots *$ da associação funcionario / empresa.

Por fim, a anotação presente no metamodelo explicita uma restrição adicional referente aos identificadores que caracterizam os conceitos de empresa e pessoa. A restrição, escrita em OCL, especifica que para todas as instâncias de empresa e pessoa, o identificador (atributo id) deve ser único - i.e., para quaisquer duas empresas (instâncias e1, e2 da classe Empresa) ou pessoas (instâncias p1, p2 da classe Pessoa), se estas são diferentes (e1 $<>$ e2 ou p1 $<>$ p2) o valor de seus identificadores devem ser diferentes (e1.id $<>$ e2.id ou p1.id $<>$ p2.id).

\section{Modelo criado conforme a mLE}

Observa-se que na figura 3.2, tem-se tão somente um metamodelo Ecore que especifica a estrutura conceitual (sintaxe abstrata) da mLE. Para criar concretamente

\footnotetext{
${ }^{2}$ Doravante, palavras grafadas na fonte typewriter são utilizadas para designar elementos de modelagem presentes em um metamodelo sob discussão (no caso presente, o metamodelo da mLE). Palavras grafadas em itálico (tais como empresa, pessoa e funcionário) designam os conceitos de modelagem representados pelos elementos do metamodelo.

${ }^{3}$ Associações consistem em duas referências, uma o oposto da outra.

${ }^{4}$ Uma classe abstrata é uma classe que não admite instâncias diretas.
} 


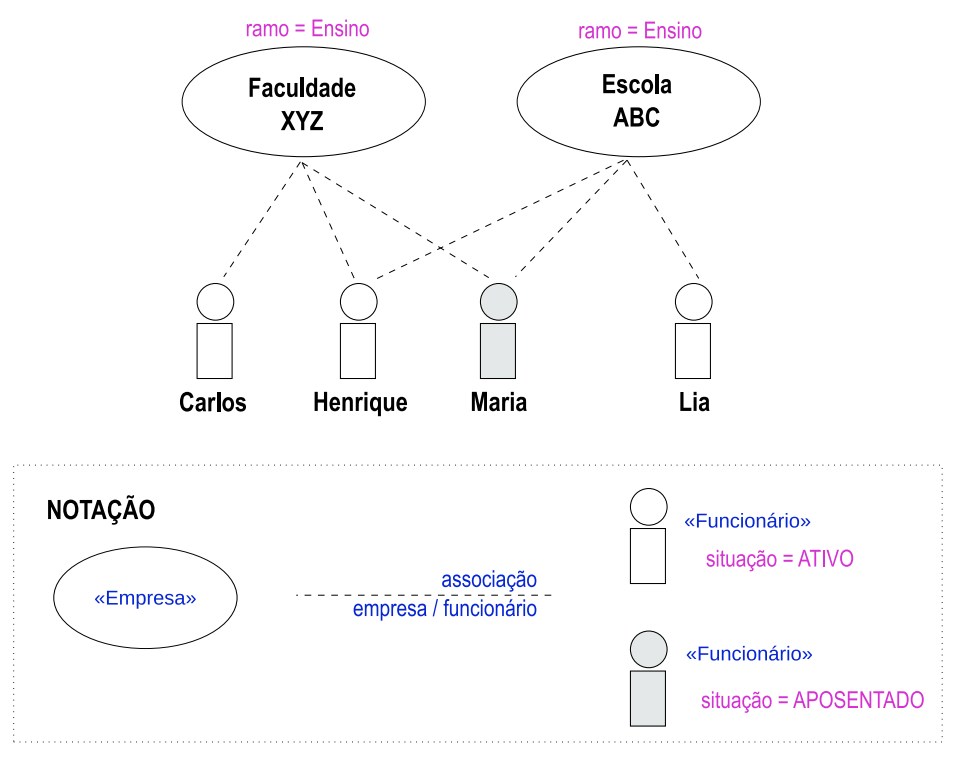

Figura 3.3: Modelo criado conforme o metamodelo Ecore da mLE.

modelos, como discutido anteriormente, necessita-se de uma notação textual ou gráfica. Na figura 3.3, apresenta-se uma possível notação gráfica e sua utilização para expressar um modelo criado conforme o metamodelo Ecore da mLE, representado na figura 3.2.

\subsection{Integração de (Meta)Modelos}

Como todo modelo, metamodelos são criados com um propósito em vista. No caso da presente tese, tem-se em vista substituir a especificação original de modelos organizacionais para fins de integração conceitual. Resta, então, discutir o que se entende por "integração conceitual" e como efetivamente ela pode ser realizada.

\subsubsection{Integração Conceitual}

Em linhas gerais, entende-se por integração conceitual o processo de correlacionar e juntar os metamodelos de duas (ou mais) linguagens de modelagem produzindo como resultado final um metamodelo integrado que subsome de modo consistente e sem redundâncias as estruturas conceituais representadas nos metamodelos iniciais.

Em outras palavras, sejam $L M_{1}$ e $L M_{2}$ duas linguagens de modelagem que compartilham a mesma área de aplicação. Supondo que $L M_{1}$ e $L M_{2}$ têm as suas estruturas conceituais expressas respectivamente por meio dos metamodelos $M M_{1}$ e $M M_{2}$, a integração conceitual de $L M_{1}$ e $L M_{2}$ consiste em: 
1. Comparar os metamodelos $M M_{1}$ e $M M_{2}$ e definir correspondências entre as estruturas conceituais expressas por ambos. Tais correspondências explicitam áreas de sobreposição semântica entre $M M_{1}$ e $M M_{2}$, i.e., conceitos e relacionamentos entre conceitos que, apesar de representações diversas em $M M_{1}$ e $M M_{2}$, têm interpretação semântica compatíveis, i.e., referem-se a objetos/fenômenos equivalentes ou similares no domínio de aplicação de $L M_{1}$ e $L M_{2}$.

2. A partir de $M M_{1}, M M_{2}$ e das correspondências entre $M M_{1}, M M_{2}$, produzir um metamodelo integrado $M M^{\text {int }}$ que:

(a) seja tão expressivo quanto $M M_{1}$ e $M M_{2}$ - i.e, $M M^{\text {int }}$ deve ser capaz de representar sem perda de informação e inconsistências todos os conceitos, relações e restrições representados por $M M_{1}$ e $M M_{2}$, e

(b) seja livre de replicações desnecessárias de elementos correspondentes - i.e, $M M^{\text {int }}$ deve representar de modo unificado conceitos e relacionamentos entre conceitos declarados explicitamente como correspondentes em $M M_{1}$ e $M M_{2}$.

Seguindo a linha das definições de linguagem de modelagem e metamodelo, esta concepção de integração conceitual é baseada principalmente em trabalhos da área de Engenharia Dirigida por Modelos (BRUNET et al., 2006; MELNIK, 2004; BERNSTEIN, 2003).

No entanto, observa-se que em essência a idéia de integração conceitual apresentada assemelha-se às noções de integração de visões (SABETZADEH; EASTERBROOK, 2006; CADISH; DISKIN, 1996) e esquemas (SCHMITT; SAAKE, 2005; BUNEMAN; DAVIDSON; KOSKY, 1992) nas área de Modelagem Conceitual e Bancos de Dados, e integração de ontologias (NOY, 2004; KALFOGLOU; SCHORLEMMER, 2003; KLEIN, 2001) na área de Engenharia de Conhecimento. Esta semelhança explica-se pelo fato de que tanto metamodelos quanto visões, esquemas e ontologias, todos consistem em representações alternativas de estruturas conceituais relativas a um dado domínio de aplicação (PARREIRAS; STAAB; WINTER, 2007; GUIZZARDI, 2007; GOGUEN, 2005). Tais representações diferem basicamente dado o uso a que se destinam: enquanto metamodelos são utilizados para se especificar a sintaxe abstrata de linguagens de modelagem, visões e esquemas servem como especificações da estrutura de bancos de dados, e ontologias funcionam como especificações de bases de conhecimento. 


\subsubsection{Identificação de Correspondências}

Como etapa inicial da integração conceitual, encontra-se a comparação de metamodelos. A questão central desta etapa é como determinar correspondências entre metamodelos. De modo geral, este é um processo inerentemente heurístico e de difícil automatização (MELNIK, 2004; BERNSTEIN, 2003). A razão para isto é que, em geral, a determinação da equivalência ou similaridade entre conceitos de modelagem requer interpretações semânticas e pragmáticas que vão além do que se encontra representado em metamodelos. Este problema também ocorre no caso de identificação de correspondências entre visões, esquemas (SHETH; LARSON, 1990) ou ontologias (KLEIN, 2001). Assim, não há à disposição um método algorítmico geral para o problema.

\subsubsection{Correspondências sintáticas}

Não obstante, há várias propostas de semi-automatização (SHVAIKO; EUZENAT, 2005; NOY, 2004; KALFOGLOU; SCHORLEMMER, 2003; RAHM; BERNSTEIN, 2001) baseadas principalmente na idéia de encontrar correspondências sintáticas entre metamodelos. Na realidade, a maioria das propostas são relativas a visões, esquemas ou ontologias, mas que podem ser adaptadas ao caso de metamodelos.

Para fins de ilustração, na figura 3.4 mostra-se o metamodelo Ecore de uma linguagem de modelagem que foi definida no mesmo domínio, mas de modo ligeiramente diferente da $\mathrm{mLE}$ apresentada na figura 3.2. Por brevidade, esta segunda linguagem será nomeada de mLE'.

Com base apenas nas informações sintáticas presentes nos dois metamodelos (figura 3.2 e figura 3.4), i.e., padrões de nomes, atributos, generalizações e associações entre classes, pode-se pensar inicialmente nas correspondências ilustradas na figura $3.5(\mathrm{a})$.

Neste caso, sugerem-se duas correspondências entre classes. Na primeira, temse a classe mLE : : Empresa como correspondente da classe mLE' : :Empresa. A justificativa é que as duas classes apresentam o mesmo nome e compartilham um atributo id : String. Na segunda, faz-se a classe mLE: :Funcionario corresponder a mLE' : : Empregado. Como justificativa, observa-se que tanto mLE : :Funcionario quanto mLE' : :Empregado compartilham um atributo id : String e estão associadas respectivamente às classes $\mathrm{mLE}:$ :Empresa e $\mathrm{mLE}$ ' : :Empresa que anteriormente foram identificadas como correspondentes.

Há no entanto, um problema com essa segunda correspondência sugerida. A 

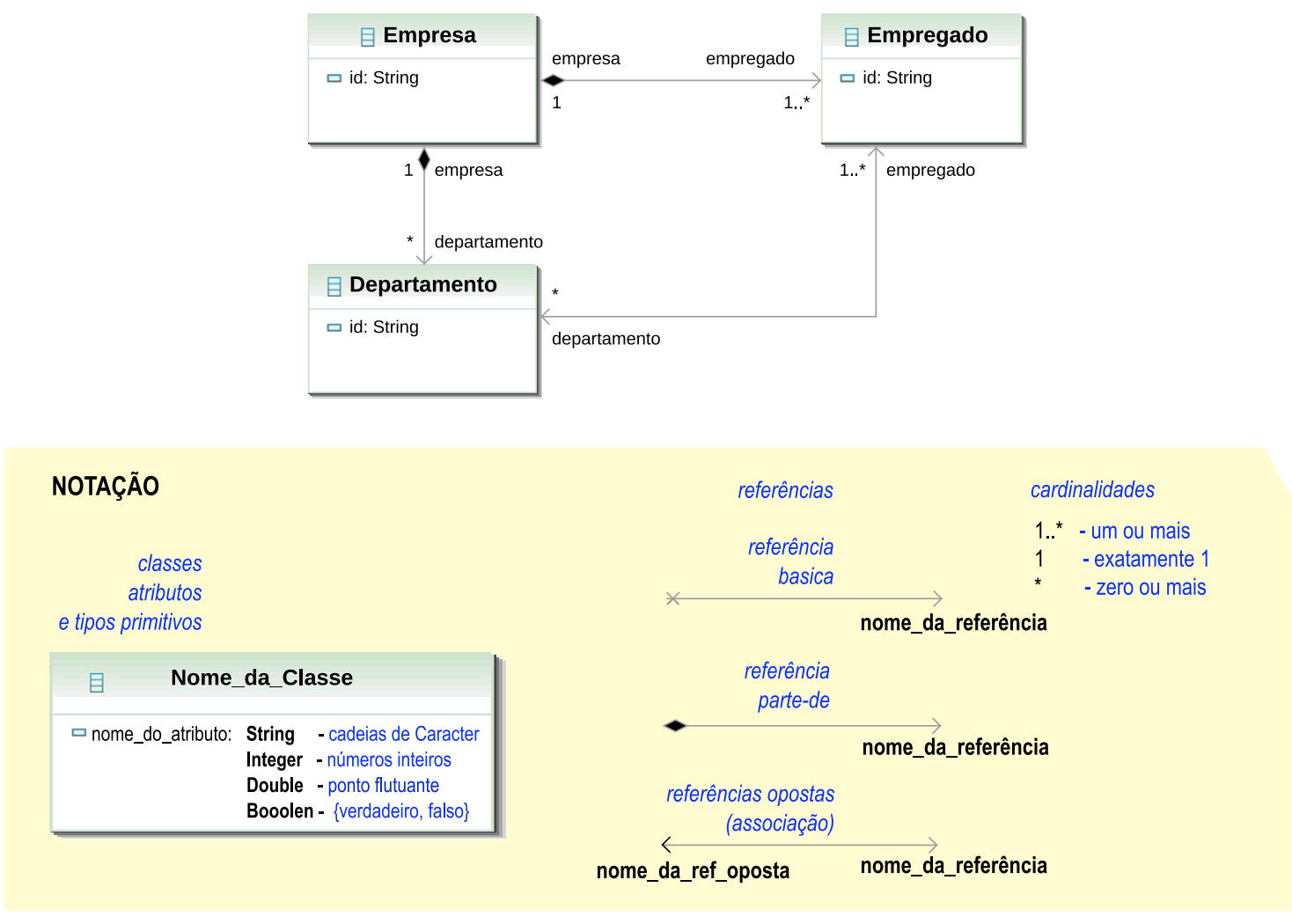

Figura 3.4: Metamodelo Ecore da mLE'.

associação empresa $1 \ldots *$ / funcionario $1 \ldots *$, presente em mLE, tem natureza distinta da associação empresa 1 / empregado 1..*, presente em mLE'. Através da referência empresa $1 \ldots *$, cada instância de mLE: :Funcionario pode estar associado a várias instâncias de mLE: :Empresa. Por sua vez, a referência empresa 1 implica que cada instância de mLE' : :Empregado só pode estar associado a uma única mLE' : :Empresa. Além disso, a referência empregado 1. .* é do tipo parte-de $e^{5}$ o que não acontece com funcionario $1 \ldots *$. De um ponto de vista estrutural, tal situação invalida a correspondência mLE: :Funcionario com mLE' : : Empregado sugerida inicialmente.

Desta maneira, sem interpretações semânticas e pragmáticas ou heurísticas adicionais, o máximo que se pode conseguir de modo consistente é a trivial correspondência entre as classes $\mathrm{mLE}:$ :Empresa e $\mathrm{mLE}$ ' : :Empresa.

Com alguns acréscimos, tais como dicionários de sinônimos, assim funcionam parte dos métodos atualmente existentes para descoberta (semi-)automática de correspondências entre metamodelos (FALLERI et al., 2008; FABRO; VALDURIEZ, 2007; LOPES; HAMMOUdI; ABDElOUAHAB, 2006; MELNIK, 2004). Nestas abordagens, além da identificação das correspondências em si, calculam-se também valores numéricos que indicam o grau de similaridade ou confiança das

\footnotetext{
${ }^{5}$ Um referência parte-de indica que as instâncias da classe referenciada são contidas por instâncias da classe que as referencia.
} 

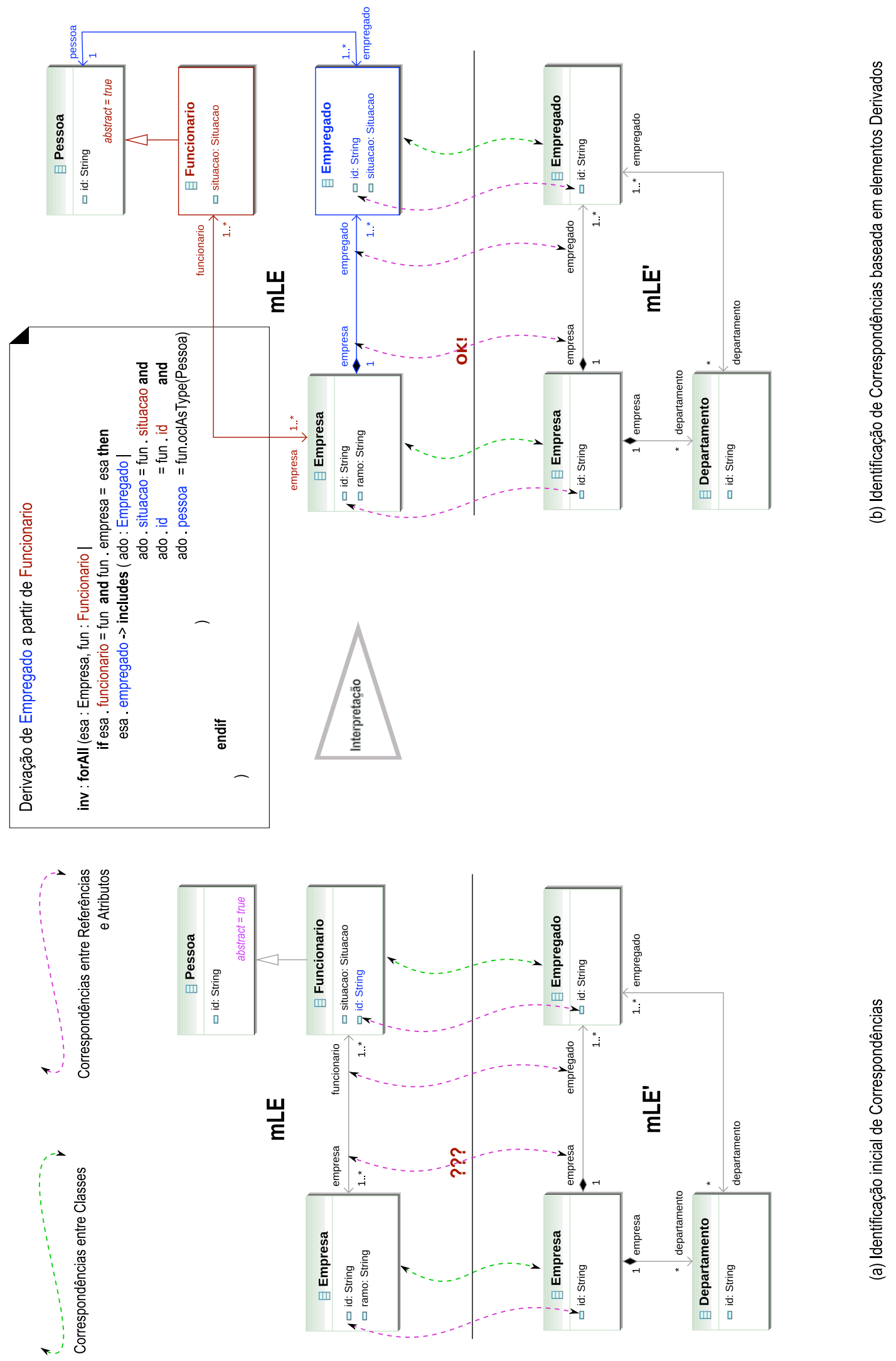

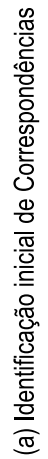

Figura 3.5: Identificação de correspondências entre metamodelos. 
correspondências encontradas. Por exemplo, no caso da correspondência entre mLE: :Empresa e mLE' : Empresa pode-se verificar que a correspondência não é total. Além do nome e do atributo id : String, há outras características não compartilhadas que fazem com que e mLE : Empresa e mLE' : :Empresa sejam correspondentes, mas até certo grau. Graus podem ser quantificados pelo quociente entre o número de características compartilhadas e o número de características totais dos elementos identificados como correspondentes.

\subsubsection{Correspondências semânticas}

Uma abordagem complementar à identificação de correspondências estruturais entre dois metamodelos é tentar estendê-los com elementos derivados a partir da interpretação de um metamodelo em relação ao outro (DISKIN; DINGEL, 2007).

Continuando com o exemplo dos metamodelos mLE e mLE', pode-se justificar uma correspondência indireta entre mLE : :Funcionario e mLE' : :Empregado interpretando o metamodelo mLE à luz do metamodelo mLE', ou vice-versa. Nota-se que em mLE' a noção de empregado é concebida como parte da definição de empresa que referencia implicitamente uma pessoa. Diferentemente, em mLE, o conceito de funcionário é visto como sendo um subtipo de pessoa que se caracteriza por se encontrar relacionada com uma ou mais empresas. Tem-se, então, pontos de vistas distintos sobre uma dada realidade, mas que podem ser reconciliados explicitando-se o fato de que empregados (em mLE') referenciam pessoas que são funcionários (em mLE).

Deste modo, uma possível interpretação de empregado seria como o correspondente da associação entre pessoas que são funcionários e empresas. Esta correspondência pode ser verificada reificando-se a associação entre mLE: :Empresa e mLE : Funcionario como uma classe derivada mLE: :Empregado, conforme se especifica na anotação OCL da figura 3.5(b). Cada instância da classe mLE' : : Empregado corresponde então a uma ligação entre mLE : :Empresa e mLE : Pessoa, esta última deixando de ser abstrata.

Ao contrário da identificação de correspondências sintáticas, a interpretação mútua de metamodelos e derivação de informações implícitas é um processo heurístico e sem regras bem definidas. Um processo que se vale essencialmente da especificação semântica das linguagens de modelagem envolvidas que, na maioria das vezes, encontra-se definida de modo informal, incompleto ou implícito (DISKIN; DINGEL, 2007). 


\subsubsection{Junção de Metamodelos}

Após a identificação de correspondências entre dois metamodelos, a etapa seguinte da integração conceitual é a junção dos metamodelos. Nesta etapa, a partir dos metamodelos e das correspondências entre eles, produz-se efetivamente um metamodelo integrado $M M^{\text {int }}$.

\subsubsection{Junção baseada em grafos e morfismos}

Ao contrário da identificação de correspondências, a junção de metamodelos (visões, esquemas ou ontologias) é um processo mais determinístico e passível de automatização. Algumas propostas de métodos algorítmicos de junção encontramse reportadas em (BUNEMAN; DAVIDSON; KOSKY, 1992; POTTINGER; BERNSTEIN, 2003; MELNIK, 2004; SCHMITT; SAAKE, 2005; SABETZADEH; EASTERBROOK, 2006; DISKIN; DINGEL; LIANG, 2006).

De modo comum, os algoritmos de junção citados, com exceção de (SCHMITT; SAAKE, 2005), podem ser descritos como junção baseada em grafos e morfismos. Neste caso, em linhas gerais, os metamodelos (visões, esquemas ou ontologias) são caracterizados abstratamente como grafos. No caso de metamodelos orientado a objetos, classes e tipos de dados constituem os vértices do grafo; atributos, associações e generalizações compõem as arestas. As correspondências entre metamodelos são formalizadas como morfismos ligando os elementos (vértices ou arestas) de um grafo aos elementos correspondentes em um outro grafo. Dados os grafos de dois (ou mais) metamodelos, e as correspondências (morfismos) existentes entre eles, a junção consiste em: (1) induzir classes de equivalência a partir de elementos ligadas por morfismos; (2) definir um grafo de integração composto pelas classes de equivalências induzidas.

Quanto às diferenças, os algoritmos de junção citados variam em três pontos principais: (1) quanto ao tipo de grafo utilizado para caracterizar metamodelos; (2) quanto à maneira pela qual correspondências são representadas como morfismos; e (3) quanto ao processo de gerar classes de equivalência e produzir o grafo de integração final.

Não é objetivo deste trabalho realizar uma comparação mais detida das diferentes abordagens para integração de metamodelos. Deseja-se apenas descrever um método geral pelo qual a integração conceitual de modelos organizacionais possa ser feita de modo sistemático. Com esta finalidade, apresenta-se a seguir como o algoritmo de junção descrito em (SABETZADEH; EASTERBROOK, 2006; 
DISKIN; DINGEL; LIANG, 2006), proposto originalmente para junção de visões em bases de dados, pode ser adaptado para metamodelos Ecore. A escolha deste algoritmo em particular se deve a três fatores principais. Em primeiro lugar, é um algoritmo simples, comparado às outras opções, e que serve de base para algoritmos mais sofisticados de junção. Em segundo lugar, é genérico e serve aos propósitos de integração conceitual de metamodelos que se tem em vista. Finalmente, tem uma exata fundamentação teórica no contexto da Teoria de Categorias, correspondendo à noção de soma amalgamada de grafos (pushout) (MENEZES; HAEUSLER, 2001).

\subsubsection{Metamodelos Ecore como grafos}

Em essência, todo metamodelo escrito em Ecore pode ser caracterizado matematicamente como um multi-grafo dirigido adornado por rotulações.

Definição 3.1. Um (multi-)grafo (dirigido) é uma quádrupla

$$
G=\langle N, \text { A, orig, dest }\rangle
$$

na qual $N$ é um conjunto não vazio de nodos (ou vértices), $A$ um conjunto de $\operatorname{arcos}$ (ou arestas) e orig, dest : $A \rightarrow N$ funções totais que associam cada arco a um nodo de origem e a um nodo de destino, respectivamente. Sendo orig $(a)=n_{o}$ e $\operatorname{dest}(a)=n_{d}, n_{o}$ e $n_{d}$ são chamados de nodos adjacentes.

Definição 3.2. Seja $G=\langle N, A$, orig, dest $\rangle$ um grafo. Uma rotulação de $G$ consiste em uma função $\operatorname{rot}^{N}: N \rightarrow R$ que associa nodos $n \in N$ a rótulos $r \in R$, ou uma função $\operatorname{rot}^{A}: A \rightarrow R$ que associa arcos $a \in A$ a rótulos $r \in R$.

Dadas essas definições, a caracterização de metamodelos Ecore como multigrafos dirigidos e rotulados pode ser feita da seguinte forma. Todo metamodelo $M M$ consiste em um grafo $G=\langle N, A$, orig, dest $\rangle$ e rotulações $\operatorname{rot}^{N}: N \rightarrow R$ e $\operatorname{rot}^{A}: A \rightarrow R$ nos quais:

- o conjunto de nodos $N$ é formado pelas classes, tipos de dados e enumerações presentes em $M M$;

- o conjunto de $\operatorname{arcos} A$ é formado pelos atributos, referências e generalizações presentes em $M M$;

- o valor $\operatorname{orig}(a)$ é sempre uma classe

- quando a é um atributo ou uma referência, orig(a) é a classe na qual o atributo ou a referência está definida; 
- quando a é uma generalização, orig(a) é a subclasse do relacionamento de generalização;

- o valor dest(a) pode ser uma classe, um tipo de dados ou uma enumeração

- quando a é um atributo, dest(a) é o tipo do atributo, podendo ser um tipo de dados ou uma enumeração;

- quando a é uma referência, dest(a) é a classe apontada pela referência;

- quando a é uma generalização, $\operatorname{dest}(a)$ é a superclasse do relacionamento de generalização;

- em geral, os valores $\operatorname{rot}^{N}(n)$ e $\operatorname{rot}^{A}(a)$ consistem em um nome, mas

- quando a é um atributo ou uma referência, $\operatorname{rot}^{A}(a)=\langle$ nome, min, max $\rangle$; neste caso, além do nome, as cardinalidades mínima e máxima do atributo ou da referência fazem parte do rótulo;

- quando a é uma generalizações, $\operatorname{rot}^{A}(a)=$ super .

Como ilustração desta caracterização de metamodelos Ecore como grafos, na figura 3.6, mostra-se como o exemplo do metamodelo da mLE (figura 3.2) pode ser redesenhado de modo explícito como multi-grafo dirigido e rotulado.

Embora metamodelos Ecore possam ser efetivamente desenhados como multigrafos dirigidos, explicitando-se todos os nodos e setas relativas a tipos de dados, enumerações e atributos, bem como separando referências opostas, como mostrado na figura 3.6, esta prática não é adotada neste texto. Com isto, evitam-se diagramas sobrecarregados com setas. No entanto, ressalta-se que por trás de cada metamodelo há um multi-grafo dirigido e rotulado, como ilustrado na figura 3.6.

\subsubsection{Correspondências como articulações}

Correspondências entre dois metamodelos, tais como as ilustradas na figura 3.5, podem ser representadas matematicamente como relações binárias entre os nodos e arestas dos grafos subjacentes aos metamodelos. No caso específico do algoritmo descrito em (SABETZADEH; EASTERBROOK, 2006; DISKIN; DINGEL; LIANG, 2006), tais relações binárias são representadas explicitamente por meio de articulações entre grafos. Consideram-se as definições: 


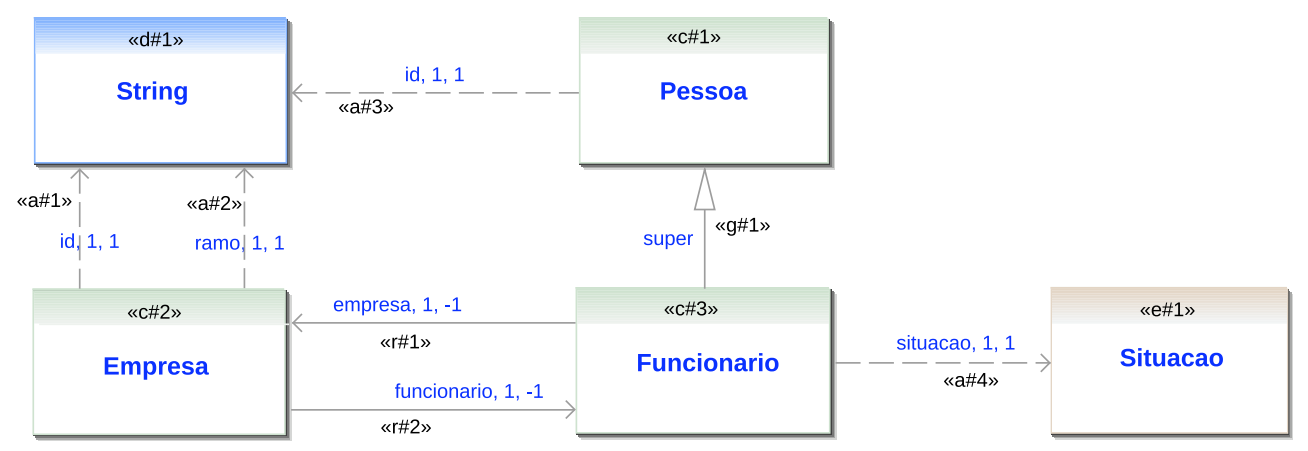

$$
\begin{aligned}
& N=\{d \# 1, c \# 1, c \# 2, c \# 3, e \# 1\} \\
& A=\{g \# 1, r \# 1, r \# 2, a \# 1, a \# 2, a \# 3, a \# 4\} \\
& \operatorname{orig}(g \# 1)=c \# 3, \operatorname{orig}(r \# 1)=c \# 3, \ldots \\
& \operatorname{dest}(g \# 1)=c \# 1, \operatorname{dest}(r \# 1)=c \# 2, \ldots \\
& \operatorname{rot}^{N}(d \# 1)=" \operatorname{String}, \operatorname{rot}^{N}(c \# 1)=" \text { Pessoa", } \ldots \\
& \operatorname{rot}^{A}(g \# 1)=\operatorname{super}_{\operatorname{rot}}(r \# 1)=\langle " \text { empresa" }, 1,-1\rangle, \ldots
\end{aligned}
$$

Figura 3.6: Metamodelo Ecore como grafo.

Definição 3.3. Sejam $G_{1}=\left\langle N_{1}, A_{1}\right.$, orig or $_{1}$ dest 1$\rangle$ e $G_{2}=\left\langle N_{2}, A_{2}\right.$, orig $_{2}$, dest $\left.{ }_{2}\right\rangle$ dois grafos. Um morfismo entre $G_{2}$ e $G_{2}$, denotado por $m_{1,2}: G_{1} \rightarrow G_{2}$, consiste em um par de funções parciais $m_{1,2}^{N}: N_{1} \rightarrow N_{2}$ e $m_{1,2}^{A}: A_{1} \rightarrow A_{2}$ tais que, para todo $a \in A_{1}$ no qual $m_{1,2}^{A}(a)$ é definido, tem-se:

$$
\begin{aligned}
& \operatorname{orig}_{2}\left(m_{1,2}^{A}(a)\right)=m_{1,2}^{N}\left(\operatorname{orig}_{1}(a)\right), \\
& \operatorname{dest}_{2}\left(m_{1,2}^{A}(a)\right)=m_{1,2}^{N}\left(\operatorname{dest}_{1}(a)\right) .
\end{aligned}
$$

Em outras palavras: um morfismo $m_{1,2}: G_{1} \rightarrow G_{2}$ é um mapeamento parcial entre dois grafos que preserva a estrutura dos grafos, levando nodos adjacentes de $G_{1}$ a nodos adjacentes em $G_{2}$.

Definição 3.4. Sejam $G_{1}=\left\langle N_{1}, A_{1}\right.$, orig ordest $\left._{1}\right\rangle$ e $G_{2}=\left\langle N_{2}, A_{2}\right.$, orig $_{2}$, dest $\left.{ }_{2}\right\rangle$ dois grafos. Uma articulação entre $G_{1}$ e $G_{2}$ consiste em

$$
\operatorname{art}\left(G_{1}, G_{2}\right)=\left\langle G^{a r t}, m_{\text {art }, 1}, m_{\text {art }, 2}\right\rangle
$$

onde $G^{\text {art }}=\left\langle N^{\text {art }}, A^{\text {art }}\right.$, orig ${ }^{\text {art }}$, dest $\left.{ }^{\text {art }}\right\rangle$ é um grafo, chamado de grafo de articulação, e $m_{a r t, 1}: G^{a r t} \rightarrow G_{1}$ e $m_{a r t, 2}: G^{a r t} \rightarrow G_{2}$ são morfismos.

Para explicar como articulações representam explicitamente correspondências, considera-se o exemplo das correspondências entre os metamodelos de mLE e mLE' identificadas na figura 3.5(b). Na figura 3.7, estas correspondências são representadas como uma articulação $\operatorname{art}(\mathrm{mLE}, \mathrm{mLE})$.

Os pontos a ressaltar são: 


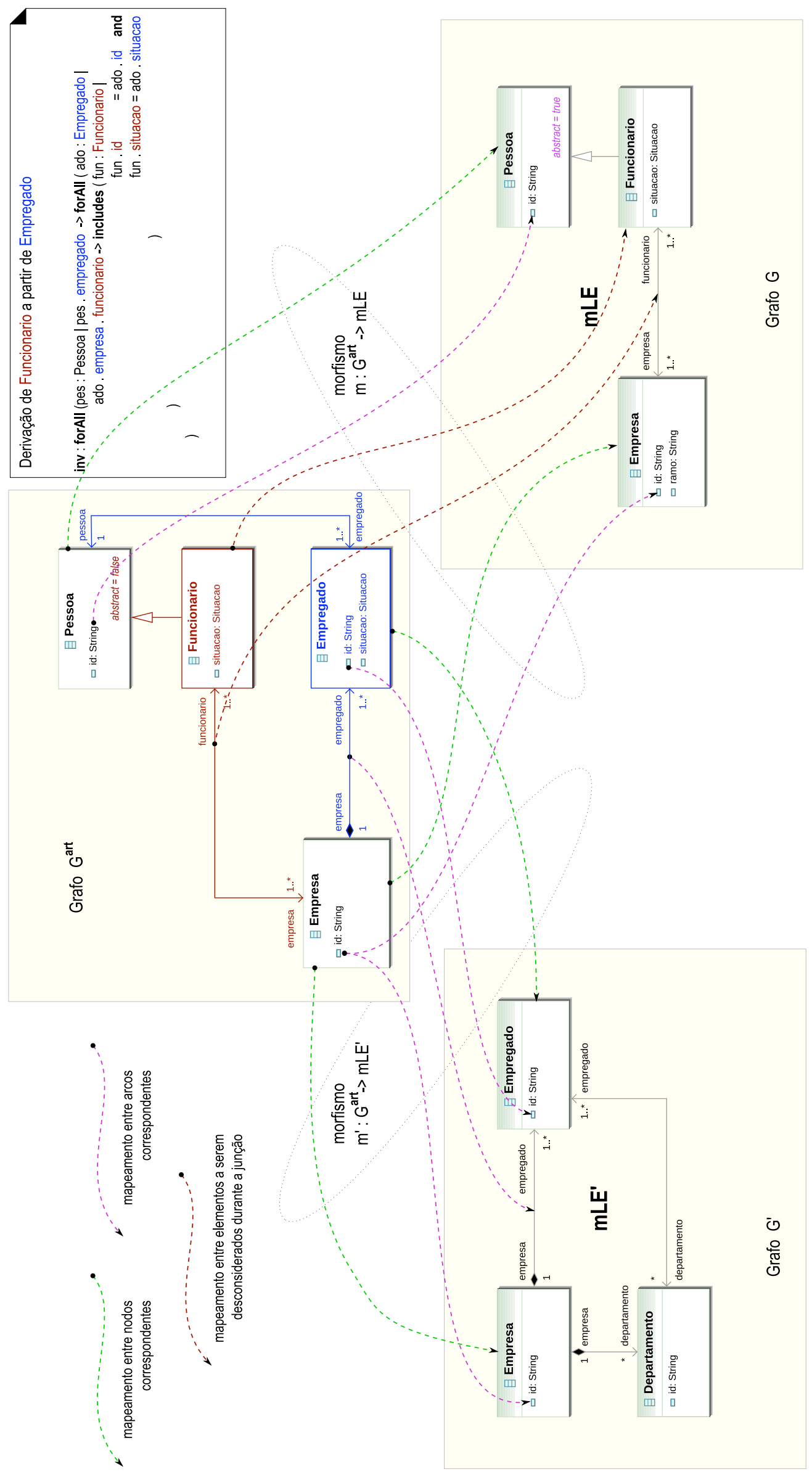

Figura 3.7: Correspondências como articulação entre grafos. 
- cada correspondência $\left(n, n^{\prime}\right)$ entre dois nodos (ou $\left(a, a^{\prime}\right)$ entre dois arcos) dá origem a um nodo $n^{\text {art }} \in N^{\text {art }}$ (ou arco $a^{\text {art }} \in A^{\text {art }}$ ), e mapeamentos $n^{\text {art }} \mapsto n$ e $n^{\text {art }} \mapsto n^{\prime}$ (ou, $n^{\text {art }} \mapsto a$ e $\left.n^{\text {art }} \mapsto a^{\prime}\right)$;

- caso os metamodelos originais não possam ser modificados, o grafo $G^{\text {art }}$ pode servir como um estrutura que explicita elementos derivados durante a identificação de correspondências;

- por fim, o grafo $G^{\text {art }}$ pode ser rotulado com "cores" para instruir o algoritmo de junção a eliminar alguns elementos redundantes durante a junção dos grafos de dois metamodelos; por exemplo, na figura 3.7, os elementos desenhados em vermelho e em azul são redundantes, uma vez que estes são capazes de representar a mesma informação ${ }^{6}$. Desta forma, a classe Funcionário, seus atributos e relacionamentos, rotulados com "vermelho" podem ser desconsiderados na junção de mLE e mLE'.

A representação explícita de correspondência como articulações é um tema comum nas propostas de integração de metamodelos (visões, esquemas ou ontologias). Em (POTTINGER; BERNSTEIN, 2003; LOPES; HAMMOUDI; ABDELOUAHAB, 2006), por exemplo, elas são chamadas de "modelos de correspondências". Já em (SABETZADEH; EASTERBROOK, 2006), o grafo de articulação $G^{\text {art }}$ é nomeado de "conector" e a representação $\left\langle G^{a r t}, m_{\text {art }, 1}, m_{\text {art }, 2}\right\rangle$ é chamada de "diagrama de interconexão". Em suma, independente do nome adotado, articulações funcionam como reificações de correspondências nas quais se pode adicionar ou excluir elementos como forma de guiar o processo de junção de grafos (metamodelos, visões, esquemas ou ontologias).

\subsubsection{Algoritmo de Junção}

Havendo caracterizado metamodelos Ecore como grafos e correspondências como articulações, passa-se à discussão do algoritmo de junção presente em (SABETZADEH; EASTERBROOK, 2006; DISKIN; DINGEL; LIANG, 2006).

A idéia básica do algoritmo de junção é realizar uma soma amalgamada de dois grafos $M M_{1}$ e $M M_{2}$ (metamodelos), módulo articulação $\operatorname{art}\left(M M_{1}, M M_{2}\right)$. Em símbolos:

$$
j u n c ̧ \tilde{a} o\left(M M_{1}, M M_{2}\right)=M M_{1} \oplus_{\operatorname{art}\left(M M_{1}, M M_{2}\right)} M M_{2}
$$

\footnotetext{
${ }^{6}$ Vide a anotação que mostra como Funcionario pode ser derivado de Empregado, e a anotação que mostra como derivar Empregado a partir de Funcionario, esta última na figura 3.5.
} 
A soma amalgamada $\oplus$ consiste na união de grafos, identificando elementos em comum. "Trata-se, portanto, de uma generalização da noção de união da Teoria de Conjuntos" (MENEZES; HAEUSLER, 2001, p. 199).

Assim, inicialmente, ao invés de grafos e articulações, consideram-se conjuntos $N_{1}, N_{2}$ e $N_{3}$, e funções parciais $m_{3,1}: N_{3} \rightarrow N_{1}$ e $m_{3,2}: N_{3} \rightarrow N_{2}$. Neste contexto de conjuntos, apresenta-se um algoritmo para realizar a soma amalgamada $N_{1} \oplus_{\left\langle N_{3}, m_{3,1}, m_{3,2}\right\rangle} N_{2}$. Em seguida, estende-se o algoritmo para fazer a soma amalgamada de dois grafos $M M_{1}=\left\langle N_{1}, A_{1}\right.$, orig o dest $\left._{1}\right\rangle$ e $M M_{2}=\left\langle N_{2}, A_{2}\right.$, orig $_{2}$, dest $\left._{2}\right\rangle$, módulo uma dada articulação $\operatorname{art}\left(M M_{1}, M M_{2}\right)$.

\section{Soma amalgamada de conjuntos}

Preliminarmente, necessita-se do conceito de união disjunta: Dada uma família de $n$ conjuntos $N_{1}, N_{2}, \ldots, N_{n}$, a união disjunta $N_{1} \uplus N_{2} \uplus \ldots \uplus N_{n}$ consiste na união $N_{1} \times\{1\} \cup N_{2} \times\{2\} \cup \ldots \cup N_{n} \times\{n\}$. Por exemplo, sejam $N_{1}=\{a, b, c\}$ e $N_{2}=\{b, c, d\}$; tem-se a união disjunta: $N_{1} \uplus N_{2}=\{(a, 1),(b, 1),(c, 1),(b, 2)$, $(c, 2),(d, 2)\}$. Por simplicidade, tal união pode ser escrita como $\left\{a_{1}, b_{1}, c_{1}, b_{2}\right.$, $\left.c_{2}, d_{2}\right\}$.

A idéia básica por trás da soma amalgamada de dois conjuntos $N_{1}$ e $N_{2}$ é primeiro representar elementos comuns através de dois mapeamentos: $m_{3,1}$ : $N_{3} \rightarrow N_{1}$ e $m_{3,2}: N_{3} \rightarrow N_{2}$. Por exemplo, dados $N_{1}=\{a, b, c\}$ e $N_{2}=\{b, c, d\}$, os elementos comuns são $b$ e $c$. Cria-se então, $N_{3}=\{\beta, \gamma\}$ e mapeamentos $m_{3,1}=\left\{\beta_{3} \mapsto\right.$ $\left.b_{1}, \gamma_{3} \mapsto c_{1}\right\}$ e $m_{3,2}=\left\{\beta_{3} \mapsto b_{2}, \gamma_{3} \mapsto c_{2}\right\}$.

Depois, iniciando com a união disjunta $\mathbf{U}=N_{1} \uplus N_{2} \uplus N_{3}$, particiona-se $\mathbf{U}$ em classes de equivalências induzidas pelos mapeamentos $m_{3,1}$ e $m_{3,2}$. Seguindo o mesmo exemplo, tem-se como união disjunta $\mathbf{U}=\left\{a_{1}, b_{1}, c_{1}, b_{2}, c_{2}, d_{2}, \beta_{3}, \gamma_{3}\right\}$. Como $m_{3,1}\left(\beta_{3}\right)=b_{1}$ e $m_{3,2}\left(\beta_{3}\right)=b_{2}$, os elementos $\left\{b_{1}, b_{2}, \beta_{3}\right\}$ formam uma classe de equivalência. Fazendo esta análise para todos os elementos de $m_{3,1}$ e $m_{3,2}$, tem-se o conjunto de classes de equivalência $\left.\mathbf{U}\right|_{m_{3,1}, m_{3,2}}=\left\{\left\{a_{1}\right\},\left\{b_{1}, b_{2}, \beta_{3}\right\},\left\{c_{1}\right.\right.$, $\left.\left.c_{2}, \gamma_{3}\right\},\left\{d_{2}\right\}\right\}$.

Por fim, define-se como soma amalgamada de $N_{1}$ e $N_{2}$, módulo $m_{3,1}: N_{3} \rightarrow$ $N_{1}$ e $m_{3,2}: N_{3} \rightarrow N_{2}$, um conjunto de representantes das classes de equivalência em $\left.\mathbf{U}\right|_{m_{3,1}, m_{3,2}}$ :

$$
N_{1} \oplus_{\left\langle N_{3}, m_{3,1}, m_{3,2}\right\rangle} N_{2}=\left\{a_{1}, \beta_{3}, \gamma_{3}, d_{2}\right\}
$$

$\mathrm{Na}$ escolha de representantes, havendo mais de uma possibilidade, como no caso 
das classes $\left\{b_{1}, b_{2}, \beta_{3}\right\}$ e $\left\{c_{1}, c_{2}, \gamma_{3}\right\}$, dá-se preferência para elementos de $N_{3}$. Dessa forma, ao se definir $N_{3}$ e os mapeamentos $m_{3,1}: N_{3} \rightarrow N_{1}$ e $m_{3,2}: N_{3} \rightarrow N_{2}$, tem-se a possibilidade de especificar como elementos equivalentes (ou elementos particulares de $N_{1}$ ou $N_{2}$ ) devem ser (re)nomeados ao final da soma amalgamada.

De modo mais sistemático, apresenta-se o algoritmo:

Algoritmo 3.1 $N_{1} \oplus_{\left\langle N_{3}, m_{3,1}, m_{3,2}\right\rangle} N_{2}$

- entrada : conjuntos $N_{1}, N_{2}$ e $N_{3}$, e mapeamentos $m_{3,1}: N_{3} \rightarrow N_{1}$ e $m_{3,2}: N_{3} \rightarrow N_{2}$

1. inicie:

(a) faça $\mathbf{U}:=N_{1} \uplus N_{2} \uplus N_{3}$;

(b) faça $\mathbf{S}:=\{\}$;

2. para cada $x \in N_{3}$ :

(a) faça $\mathbf{U}:=\mathbf{U}-\left\{(u, i) \in \mathbf{U} \mid(u, i)=(x, 3)\right.$ ou $\left.u=m_{3, i}(x)\right\}$;

(b) faça $\mathbf{S}:=\mathbf{S} \cup\{(x, 3)\}$;

3. para cada $(u, i) \in \mathbf{U}$ restante :

(a) faça $\mathbf{S}:=\mathbf{S} \cup\{(u, i)\}$;

\section{4. retorne $\mathbf{S}$.}

\section{Soma amalgamada de grafos}

No caso de grafos $M M_{1}=\left\langle N_{1}, A_{1}\right.$, orig , dest $\left._{1}\right\rangle$ e $M M_{2}=\left\langle N_{2}, A_{2}\right.$, orig , dest $\left._{2}\right\rangle$, e articulação $\operatorname{art}\left(M M_{1}, M M_{2}\right)=\left\langle G^{\text {art }}, m_{\text {art }, 1}, m_{\text {art }, 2}\right\rangle$, a soma amalgamada é feita em três etapas. Primeiro, faz-se a soma amalgamada dos conjuntos de nodos $N_{1}$ e $N_{2}$, módulo $m_{a r t, 1}^{N}: N^{\text {art }} \rightarrow N_{1}$ e $m_{a r t, 2}^{N}: N^{\text {art }} \rightarrow N_{2}$, obtendo-se:

$$
N_{S}=N_{1} \oplus_{\left\langle N^{a r t}, m_{a r t, 1}^{N}, m_{a r t, 2}^{N}\right\rangle} N_{2}
$$

Em seguida, faz-se a soma amalgamada dos conjuntos de arcos $A_{1}$ e $A_{2}$, módulo $m_{\text {art }, 1}^{A}: A^{\text {art }} \rightarrow A_{1}$ e $m_{\text {art }, 2}^{A}: A^{\text {art }} \rightarrow A_{2}$, obtendo-se:

$$
A_{S}=A_{1} \oplus_{\left\langle A^{a r t}, m_{a r t, 1}^{A}, m_{a r t, 2}^{A}\right\rangle} A_{2}
$$


Por último, definem-se as funções orig $: A_{S} \rightarrow N_{S}$ e dest de $_{S} A_{S} \rightarrow N_{S}$. O processo de definição de orig $_{S}$ e dest $t_{S}$ é simples. Observa-se que cada elemento $(n, i) \in N_{S}$ é um representante de uma classe de equivalência de nodos

$$
[(n, i)]=\left\{(x, i) \in N_{1} \uplus N_{2} \uplus N^{\text {art }} \mid(x, i)=(n, i) \text { ou } x=m_{a r t, i}^{N}(n)\right\}
$$

Desta forma, para cada $(a, j) \in A_{S}$, tem-se $\operatorname{orig}_{S}(a, j)=(n, i)$ se, e somente se, $\left(\operatorname{orig}_{j}(a), j\right) \in[(n, i)]$. Mutatis mutantis, define-se $\operatorname{dest}_{S}(a, j)=(n, i)$.

Como resultado final, obtém-se:

$$
M M_{1} \oplus_{\operatorname{art}\left(M M_{1}, M M_{2}\right)} M M_{2}=\left\langle N_{S}, A_{S}, \text { orig }_{S}, \text { dest }_{S}\right\rangle
$$

De modo sistemático, apresenta-se o algoritmo:

\section{Algoritmo 3.2 $M M_{1} \oplus_{\operatorname{art}\left(M M_{1}, M M_{2}\right)} M M_{2}$}

- entrada: grafos $M M_{1}=\left\langle N_{1}, A_{1}\right.$, orig , dest $\left._{1}\right\rangle$ e $M M_{2}=\left\langle N_{2}, A_{2}\right.$, orig , $_{2}$ dest $\left._{2}\right\rangle$, e articulação $\operatorname{art}\left(M M_{1}, M M_{2}\right)=\left\langle G^{\text {art }}, m_{\text {art }, 1}, m_{\text {art }, 2}\right\rangle$;

1. faça $N_{S}:=N_{1} \oplus_{\left\langle N^{a r t}, m_{a r t, 1}^{N}, m_{a r t, 2}^{N}\right\rangle} N_{2}$;

2. faça $A_{S}:=A_{1} \oplus_{\left\langle A^{a r t}, m_{a r t, 1}^{A}, m_{a r t, 2}^{A}\right\rangle} A_{2}$

3. inicialize :

(a) orig $_{S}:=\{\}$;

(b) dest $_{S}:=\{\}$;

4. para cada $(a, j) \in A_{S}$ :

(a) seja $[(n, i)]=\left\{(x, i) \in N_{1} \uplus N_{2} \uplus N^{\text {art }} \mid(x, i)=(n, i)\right.$ ou $x=$ $\left.m_{a r t, i}^{N}(n)\right\}$ tal que $\left(\operatorname{orig}_{j}(a), j\right) \in[(n, i)]$;

(b) faça orig $:=$ orig $_{S} \cup\{(a, j) \mapsto(n, i)\}$;

5. para cada $(a, j) \in A_{S}$ :

(a) seja $[(n, i)]=\left\{(x, i) \in N_{1} \uplus N_{2} \uplus N^{\text {art }} \mid(x, i)=(n, i)\right.$ ou $x=$ $\left.m_{a r t, i}^{N}(n)\right\}$ tal que $\left(\operatorname{dest}_{j}(a), j\right) \in[(n, i)]$;

(b) faça dest fedest $_{S} \cup\{(a, j) \mapsto(n, i)\}$;

6. retorne $\left\langle N_{S}, A_{S}\right.$, orig $_{S}$, dest $\left._{S}\right\rangle$; 


\section{Rotulações e cores}

O algoritmo $M M_{1} \oplus_{\operatorname{art}\left(M M_{1}, M M_{2}\right)} M M_{2}$ acima formaliza a descrição fornecida em (SABETZADEH; EASTERBROOK, 2006; DiSkin; DINGEL; LIANG, 2006). No entanto, dada a caracterização feita de modelos Ecore como grafos, deve-se estender o algoritmo para considerar as rotulações $\operatorname{rot}^{N}$ e $\operatorname{rot}^{A}$ ao se fazer a junção de grafos (metamodelos). Além destas rotulações, acrescenta-se uma rotulação $\operatorname{cor}^{N} \mathrm{e}$ $\operatorname{cor}^{A}$. A motivação é definir um algoritmo de junção que, baseada em uma "cor" do elemento, tome uma decisão de incluí-lo ou não no resultado final da junção, conforme mencionado na subseção 3.2.3.3.

Assim, neste trabalho, dado um grafo $G=\langle N, A$, orig, dest $\rangle$ e um conjunto de rótulos $C O R$, definem-se as rotulações de "cor" através de duas funções $\operatorname{cor}^{N}: N \rightarrow C O R$ e $\operatorname{cor}^{A}: A \rightarrow C O R$. De modo especial, neste texto, os metamodelos (grafos) são "coloridos" pelo conjunto conjunto $C O R=\{$ preto, azul, vermelho\}. A cor preto indica um elemento original do metamodelo; azul indica um elemento derivado durante o processo de identificação de correspondências; por fim, vermelho marca elementos a serem eliminados durante a junção de dois metamodelos.

Cabe aqui uma observação. Os rótulos $\operatorname{cor}^{N}$ dos nodos correspondentes a classes, enumerações e tipos de dados não devem ser confundidos com as cores internas dos retângulos utilizados para desenhá-los em um diagrama de classes. Por exemplo, na figura 3.7, todos os elementos dos grafos mLE e mLE' têm a cor preto, mesmo as classes sendo representadas por símbolos que internamente são verdes. Quando se quiser destacar a "cor" de uma classe, removem-se as cores internas. Por exemplo, na mesma figura, as classes do grafo $G^{\text {art }}$ têm as seguintes cores: $\operatorname{cor}^{N}($ Pessoa $)=\operatorname{cor}^{N}($ Empresa $)=\operatorname{preto} ; \operatorname{cor}^{N}($ Empregado $)=$ azul; e $\operatorname{cor}^{N}($ Funcionario $)=$ vermelho.

Finalmente, apresenta-se o algoritmo:

\section{Algoritmo 3.3 Junção de Metamodelos}

- entrada: dois metamodelos (grafos) $M M_{1}$ e $M M_{2}$; uma articulação $\operatorname{art}\left(M M_{1}\right.$, $\left.M M_{2}\right)$; rotulações $\operatorname{rot}_{i=1,2, a r t}^{N}$ e rot $_{i=1,2, a r t}^{A}$; e rotulações $\operatorname{cor}_{i=1,2, a r t}^{N}$ e $\operatorname{cor}_{i=1,2, a r t}^{A}$;

1. faça $M M_{S}:=M M_{1} \oplus_{\operatorname{art}\left(M M_{1}, M M_{2}\right)} M M_{2}$;

2. remova elementos em vermelho: 
(a) faça $N^{\text {int }}:=\bigcup_{(n, i) \in N_{S}}\left\{(n, i) \mid \operatorname{cor}_{i}^{N}(n) \neq\right.$ vermelho $\}$;

(b) faça $A^{\text {int }}:=\bigcup_{(a, i) \in A_{S}}\left\{(a, i) \mid \operatorname{cor}_{i}^{A}(a) \neq\right.$ vermelho $\wedge \operatorname{orig}_{S}(a, i) \in N^{\text {int }}$ $\left.\wedge \operatorname{dest}_{S}(a, i) \in N^{i n t}\right\}$

(c) faça orig int $:=\bigcup_{(a, i) \in A^{i n t}}\left\{(a, i) \mapsto \operatorname{orig}_{S}(a, i)\right\}$;

(d) faça dest int $^{=}=\bigcup_{(a, i) \in A^{i n t}}\left\{(a, i) \mapsto \operatorname{dest}_{S}(a, i)\right\}$;

3. defina rotulações $\operatorname{rot}_{i n t}^{N}$ e $\operatorname{rot}_{i n t}^{A}$ :

(a) faça $\operatorname{rot}_{\text {int }}^{N}:=\bigcup_{(n, i) \in N^{\text {int }}}\left\{(n, i) \mapsto \operatorname{rot}_{i}^{N}(n)\right\}$;

(b) faça $\operatorname{rot}_{\text {int }}^{A}:=\bigcup_{(a, i) \in A^{i n t}}\left\{(a, i) \mapsto \operatorname{rot}_{i}^{A}(a)\right\}$;

4. retorne $M M^{i n t}=\left\langle N^{i n t}, A^{i n t}\right.$, orig $\left.g^{i n t}, d e s t^{i n t}\right\rangle, \operatorname{rot}_{i n t}^{N}$ e $\operatorname{rot}_{i n t}^{A}$.

Resumidamente, faz-se inicialmente uma soma amalgamada de $M M_{1}$ e $M M_{2}$, módulo articulação $\operatorname{art}\left(M M_{1}, M M_{2}\right)$. Em seguida, eliminam-se nodos e arcos considerados redundantes, i.e., marcados em vermelho. Por fim, refazem-se as rotulações de nodos e arcos. Neste caso, nota-se que os rótulos escolhidos são os rótulos dos representantes de classes de equivalência, módulo articulação $\operatorname{art}\left(M M_{1}, M M_{2}\right)$. Assim, ao se definir $\operatorname{art}\left(M M_{1}, M M_{2}\right)$, tem-se a possibilidade de especificar como nodos ou arcos correspondentes (ou nodos ou arcos particulares de $M M_{1}$ ou $M M_{2}$ ) devem ser (re)rotulados ao final do processo de junção.

\section{Exemplo de junção de metamodelos}

Finalizando o exemplo das linguagens mLE e mLE', na figura 3.8 mostram-se as entradas, a soma amalgamada e o resultado final da junção de mLE e mLE', seguindo os algoritmos apresentados.

Na figura 3.8, tem-se também uma visão geral do processo de integração conceitual de metamodelos, conforme definido de início. Na parte superior, vê-se a etapa de identificação de correspondências. Na parte inferior, a etapa de junção dos metamodelos, culminando na criação de um metamodelo integrado $M M^{\text {int }}$.

\subsection{Resumo}

Neste capítulo, apresentaram-se as noções de modelo, metamodelo, linguagem de modelagem e a integração conceitual de linguagens de modelagem via corres- 

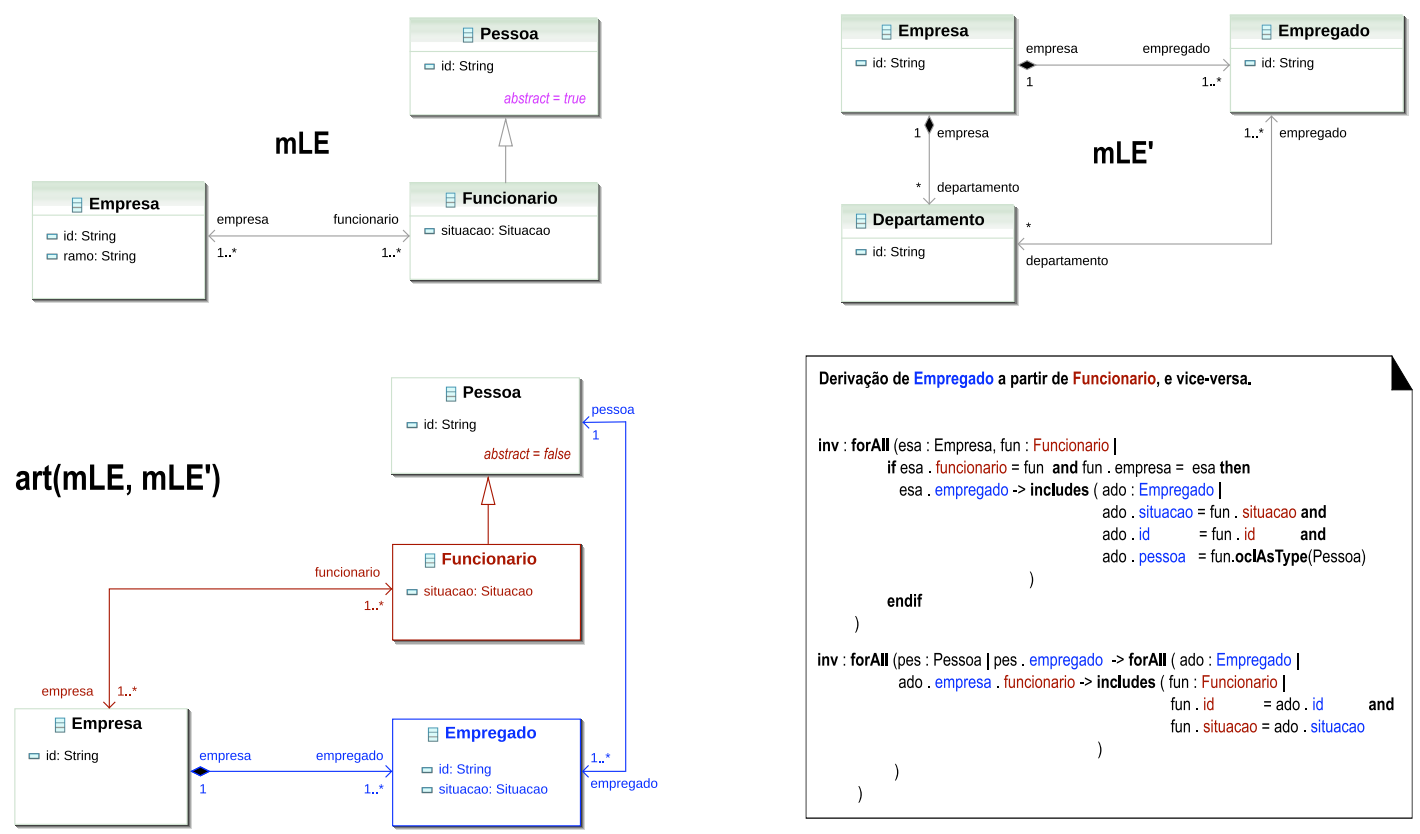

( a ) Entrada : metamodelos $\mathrm{mLE}$ e $\mathrm{mLE}$; articulação(mLE, $\mathrm{mLE}$ ') e rotulações.
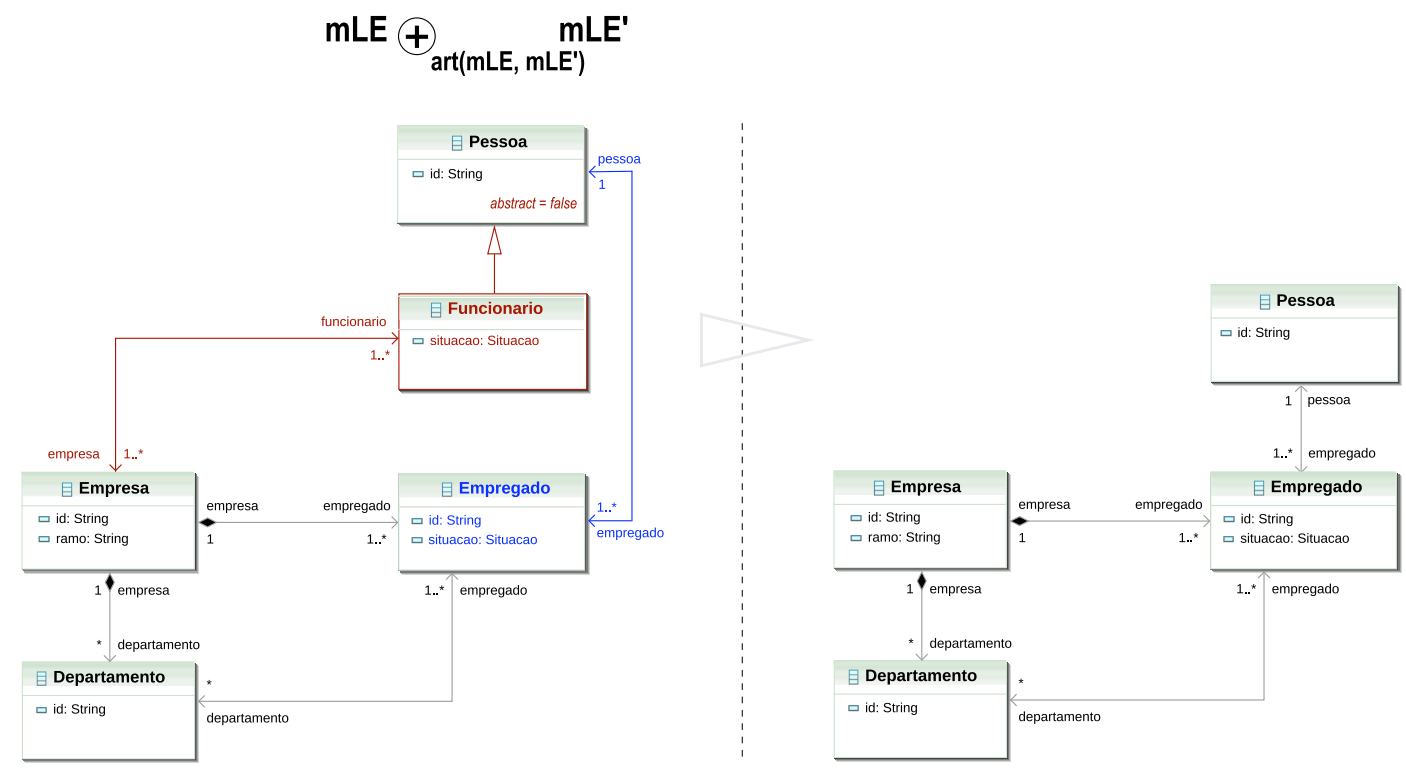

(b) Soma Amalgamada de $m L E$ e $m L E^{\prime}$, módulo art(mLE, mLE').

(c ) Resultado final da junção.

Figura 3.8: Junção dos metamodelos mLE e mLE'. 
pondência e junção de metamodelos. Modelos foram caracterizados como representações que simplificam e substituem sistemas ou fenômenos sob alguns aspectos e para alguns propósitos. Metamodelos são modelos que reduzem linguagens de modelagem às suas estruturas conceituais, servindo como substituto da especificação da sintaxe abstrata das linguagens. Quanto aos propósitos específicos, metamodelos podem ser utilizados para automatizar a criação de processadores de linguagens de modelagem (editores, geradores de código, tradutores, etc.).

No escopo desta tese, metamodelos são a base sobre a qual se assenta a integração conceitual de modelos organizacionais. Modelos organizacionais foram caracterizados como linguagens de modelagem; logo, passíveis de serem representados via metamodelos. Reduzidos a metamodelos, a integração conceitual de modelos organizacionais consiste em duas etapas principais: a identificação de correspondências (áreas de sobreposição semântica entre os metamodelos) e a junção de metamodelos (união dos metamodelos, eliminando elementos redundantes semanticamente).

De modo particular, para a criação de metamodelos, utilizou-se a linguagem Ecore (STEINBERG et al., 2008), em conjunto com anotações OCL (OMG, 2006b). Quanto à identificação de correspondências, discutiu-se que atualmente tal processo é inerentemente heurístico e que, no máximo, pode ser semi-automatizado por algoritmos que descubram semelhanças estruturais entre dois metamodelos. Por fim, com relação à junção de metamodelos, apresentou-se um algoritmo completo de junção baseado na soma amalgamada de grafos (SABETZADEH; EASTERBROOK, 2006; DISKIN; DINGEL; LIANG, 2006). 


\section{Parte II}

\section{Integração de Modelos Organizacionais}




\section{Modelagem de Organizações de Agentes}

O objetivo deste capítulo é apresentar um estudo comparativo da estrutura conceitual de vários modelos organizacionais de agentes existentes. Os resultados obtidos com este estudo embasarão a integração conceitual destes modelos, a ser conduzida nos próximos capítulos que compõem esta parte do texto.

O capítulo inicia buscando responder de maneira geral à seguinte questão: o que se pode esperar de um modelo organizacional, em termos de conceitos de modelagem, dado que seu objetivo básico é expressar formalmente a organização de um SMA-CO? A este respeito, identificam-se cinco dimensões de modelagem organizacional, discutidas na seção 4.1.

Em seguida, utilizando como base de comparação as dimensões de modelagem e representando os modelos por meio de metamodelos Ecore, na seção 4.2, apresentam-se de modo detalhado a estrutura conceitual de seis modelos organizacionais propostos na literatura.

Ao final, na seção 4.3, apresenta-se um quadro comparativo dos modelos organizacionais analisados. O conteúdo de parte significativa deste capítulo foi originalmente publicado em (COUTINHO; SICHMAN; BOISSIER, 2009; COUTINHO; SICHMAN; BOISSIER, 2007; COUTINHO; SICHMAN; BOISSIER, 2005).

\subsection{Dimensões de Modelagem}

$\mathrm{Na}$ maioria dos modelos organizacionais encontrados na literatura, podem ser identificados cinco grandes temas recorrentes ${ }^{1}$ de modelagem no que diz respeito à criação de especificações organizacionais:

- a modelagem funcional que se caracteriza pela especificação de metas (objetivos, tarefas) e decomposição de metas (planos conjuntos, interrelacio-

\footnotetext{
${ }^{1}$ Não por que aparecem em todos os modelos, mas porque ocorrem em mais de um.
} 
namentos entre metas) ligados à satisfação do propósito da organização de agentes;

- a modelagem estrutural ligada à especificação de papéis, grupos e relacionamentos entre estes, que podem ou não ser definidos a partir de objetivos organizacionais;

- a modelagem dialógica caracterizada pela especificação de estruturas de interação direta entre papéis por troca de mensagens tendo em vista a realização de objetivos organizacionais;

- a modelagem normativa na qual definem-se normas (permissões, obrigações, etc.) que interrelacionam e regulamentam elementos funcionais, estruturais e dialógicos;

- e, por fim, a modelagem ontológica na qual estruturas conceituais (ontologias de domínio) compartilhadas são definidas.

A estes temas recorrentes, dá-se a denominação de dimensões de modelagem organizacional.

Observa-se ainda que a identificação dessas dimensões de modelagem tem por base a noção de organização como padrão de atividade conjunta. No entanto, como discutido na seção 2.3.1, a noção de organização pode também ser interpretada como um coletivo de agentes cuja atividade conjunta deve acontecer conforme padrões organizacionais. Assim, em alguns modelos organizacionais, além de elementos para especificação de padrões organizacionais, identifica-se também a presença de elementos explícitos destinados à modelagem de estados de uma organização de agentes. Na modelagem de um estado organizacional pode-se ter:

- a representação dos agentes que em um dado momento compõem uma organização;

- a representação de:

- papéis assumidos por agentes e grupos de agentes formados (instanciação de elementos da modelagem estrutural);

- metas e planos conjuntos sendo executados por agentes ou grupos de agentes que assumiram papéis (instanciação de elementos da modelagem funcional); 


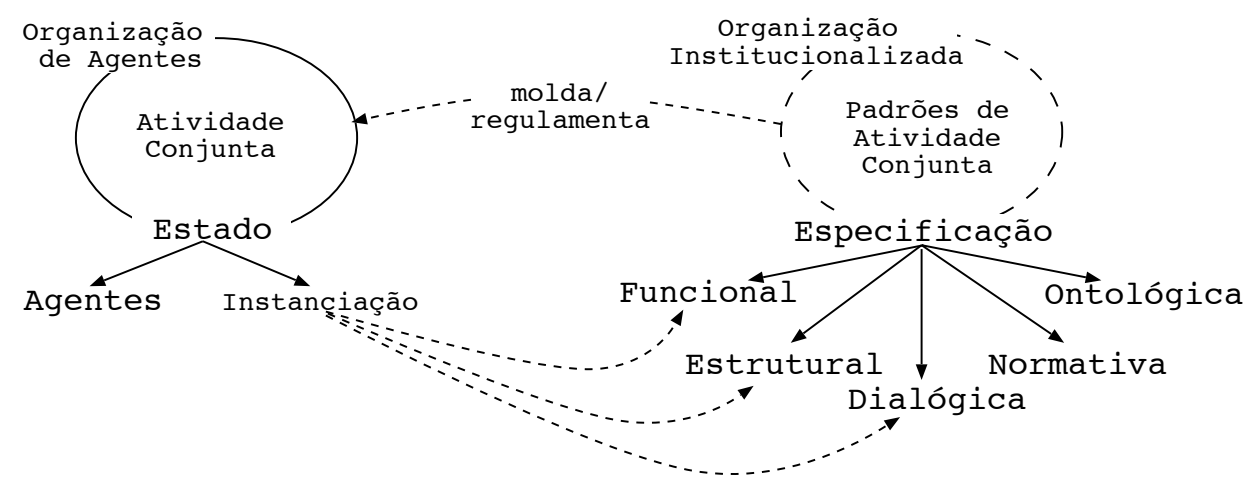

Figura 4.1: Dimensões de modelagem organizacional.

- interações dialógicas em andamento envolvendo agentes que assumiram papéis (instanciação de elementos da modelagem dialógica).

Na figura 4.1, resumem-se essas observações.

A identificação destes temas de modelagem organizacional constituem o ponto de partida para análise, comparação e integração de modelos organizacionais, tendo em vista o problema de interoperabilidade organizacional tratado nesta tese. Desta maneira, antes de analisar casos particulares de modelos organizacionais com relação às dimensões de modelagem identificadas, na sequência, busca-se justificar porque estas dimensões aparecem como temas recorrentes de modelagem organizacional.

\subsubsection{Dimensões Primárias}

Uma primeira justificativa, de caráter geral, é que todo sistema ${ }^{2}$ projetado exibe alguns aspectos fundamentais (BUNGE, 1979; ACKOFF, 1999) que, de um ponto de vista de Engenharia, são candidatas naturais a serem modeladas:

- o comportamento funcional do sistema - i.e., as relações entre entrada (estímulo, insumo) e saída (resposta, resultado) que acoplam o sistema a elementos externos que constituem o ambiente no qual o sistema se situa;

- a estrutura interna do sistema - i.e., os elementos e subsistemas que compõem o interior do sistema e os relacionamentos que interconectam estes elementos e subsistemas;

- o comportamento estrutural do sistema - i.e., as ações e interações entre componentes internos que ao logo do tempo moldam ou são moldadas pela

\footnotetext{
${ }^{2}$ Excetuando-se sistemas conceituais (tais como teorias), que não apresentam comportamento, mas apenas estrutura.
} 
estrutura interna do sistema.

A partir desta observação, percebe-se de imediato que as três primeiras dimensões de modelagem identificadas nos modelos organizacionais (a funcional, a estrutural e a dialógica) correspondem respectivamente, aos três aspectos fundamentais de todo sistema listados acima.

\subsubsection{Comportamento funcional}

Na modelagem do comportamento funcional, tradicionalmente, o sistema é visto como uma caixa preta na qual a composição interna do sistema, em um primeiro momento, não importa. O ambiente impõe requisitos funcionais, como funções e tarefas, que o sistema deve realizar. Sem descortinar a estrutura interna do sistema, os requisitos funcionais podem ainda ser subdivididos recursivamente até se chegar a funções ou tarefas atômicas que são dispostas sob uma dada ordenação (grafo de dependências). Posteriormente, quando a estrutura interna for determinada, as funções podem ser associadas aos componentes do sistema que, ao operarem em conjunto e respeitando a ordenação definida entre as funções, irão realizar os requisitos funcionais do sistema. Esta maneira de modelar comportamento é comum tanto no desenvolvimento de sistemas computacionais quanto na representação de processos em organizações humanas. Técnicas de modelagem tais como DFD (Data Flow Diagram) (YOURDON, 1992), HIPO (Hierarchical Input Process Output) (KATZAN, 1976), IDEF0 (Integrated Definition for Functional Modeling) (RICO, 2004) e os diagramas de atividades da UML (Unified Modeling Language) (BOOCH; RUMBAUGH; JACOBSON, 1999) são exemplos típicos.

\subsubsection{Estrutura interna}

Na modelagem da estrutura interna, por outro lado, o sistema é visto como uma caixa transparente. Representam-se que elementos, ou subsistemas formados por estes elementos, são partes do sistema e como estas partes encontram-se interrelacionadas. A exemplo da modelagem do comportamento funcional, a modelagem da estrutura interna de sistemas também aparece como tema recorrente tanto no desenvolvimento de sistemas computacionais quanto na representação de organizações humanas. Por exemplo, na UML (Unified Modeling Language) (BOOCH; RUMBAUGH; JACOBSON, 1999) um sistema computacional é decomposto em objetos especificados através de classes; classes interrelacionam-se e podem ser agrupadas em pacotes; e, como um todo estes elementos compõem a estrutura interna do sistema. No caso de organizações humanas, um exemplo tradicional 
de modelagem estrutural são os organogramas, diagramas que representam as relações hierárquicas dentro de uma empresa, ou seja, a distribuição dos setores, as unidades funcionais, os cargos e o interrelacionamento entre eles.

\subsubsection{Comportamento estrutural}

Na modelagem do comportamento estrutural, que se baseia na estrutura interna, o sistema também é visto como uma caixa transparente. No entanto, o que se busca descrever é um ordenamento de interações diretas entre componentes que ocorrem ao longo do tempo e que fazem o sistema funcionar, i.e., se "movimentar" ao longo do tempo para realizar determinadas funções ou tarefas. Por um lado, a ocorrências de interações diretas é limitada pela estrutura interna do sistema. Por exemplo, componentes não conectados diretamente na estrutura interna não podem agir um sobre o outro diretamente. Por outro lado, o fato de haver interação direta entre componentes é o que explica ou dá origem aos interrelacionamentos presentes na estrutura interna do sistema, quando a modelagem do comportamento estrutural precede a modelagem da estrutura interna.

Um outro fato a observar é que o comportamento funcional e o comportamento estrutural, assim como a estrutura interna e o comportamento estrutural, também são aspectos complementares na modelagem de sistemas. O primeiro é uma visão do comportamento de fora para dentro: requisitos funcionais do ambiente decompostos em funções atômicas atribuídas e realizadas pela estrutura interna. O segundo, de modo inverso, é uma visão do comportamento de dentro para fora: a estrutura interna que interage ao longo do tempo resultando na realização de requisitos funcionais. Assim as duas visões podem coexistir em um mesmo modelo como descrições que, sendo coerentes entre si, se complementam e representam um aspecto fundamental de todo sistema que é o seu comportamento.

Como exemplos de modelagem do comportamento estrutural no desenvolvimento de sistemas computacionais, podem-se citar os diagramas de seqüência e os diagramas de colaboração da UML (Unified Modeling Language) (BOOCH; RUMBAUGH; JACOBSON, 1999). Nestes diagramas, representam-se objetos e trocas de mensagens entre objetos que estão conectados por ligações estruturais e que realizam dada funcionalidade de um sistema. No caso de organizações humanas, a descrição de processos de negociação tais como leilões, onde pessoas desempenhando papéis ou representando grupos seguem uma coreografia de troca direta de mensagens com uma dada finalidade, são exemplos de descrição de comporta- 
mento estrutural.

\subsubsection{Dimensões Secundárias}

Enquanto as dimensões de modelagem funcional, estrutural e dialógica podem ser justificadas a partir de uma análise da modelagem de sistemas em geral, o mesmo não ocorre com as dimensões de modelagem normativa e ontológica. Conquanto apareçam nos modelos organizacionais, as dimensões normativa e ontológica não constituem temas básicos de modelagem no projeto de sistemas em geral. Ao contrário, elas estão relacionadas a aspectos específicos de sistemas que são descritos em nivel social (JENNINGS; CAMPOS, 1997) e em nivel de conhecimento (NEWELL, 1982), respectivamente.

\subsubsection{Modelagem normativa}

De acordo com (ACKOFF, 1999, p. 27), há três tipos básicos de sistemas e modelos correspondentes:

- determinísticos: sistemas e modelos nos quais nem as partes e nem o todo têm interesses próprios ${ }^{3}$;

- animados: sistemas e modelos nos quais o todo tem interesses próprios mas as partes não;

- sociais: sistemas e modelos nos quais tanto as partes quanto o todo têm interesses próprios.

Dada esta classificação, percebe-se que sistemas computacionais tradicionais são determinísticos; agentes autônomos são animados; e organizações de agentes são sistemas sociais.

Sendo determinísticos, sistemas computacionais tradicionais irão ter uma arquitetura na qual o comportamento funcional, a estrutura interna e o comportamento estrutural são previstos em detalhes. Como os componentes do sistema não irão ter autonomia de objetivos, supõe-se que eles não irão apresentar comportamentos inesperados, estando desse modo acoplados de maneira rígida ao que determina a arquitetura do sistema.

Por outro lado, nas organização de agentes, dada a sua natureza de sistema social, a suposição de acoplamento rígido a uma arquitetura (organização) não

\footnotetext{
${ }^{3}$ Utiliza-se o termo "interesse próprio" como tradução do termo em Inglês "purposeful", utilizado pelo autor para descrever os três tipos básicos de sistemas e modelos.
} 
é realista. Agentes são componentes autônomos que terão interesses diversos, especialmente em organizações abertas. Assim, nem a organização (especificações funcional, estrutural e dialógica) poderá ser muito detalhada chegando ao extremo de determinar precisamente a atividade conjunta dos agentes, eliminando por completo a autonomia destes; e nem se pode supor benevolência por parte dos agentes em relação aos objetivos organizacionais.

Neste contexto, a análise que se faz é que a especificação de normas, i.e., permissões, obrigações, etc., a exemplo do que ocorre nas organizações humanas, ocorre em alguns modelos organizacionais como um mecanismo complementar às especificações funcional, estrutural e dialógica que ajuda a acoplar os agentes à organização de modo mais flexível. Por um lado, normas prestam-se a capturar de modo explícito interrelacionamentos entre os aspectos funcional, estrutural e dialógicos, e.g., agentes em dado papel obrigam-se a se comportar funcional ou dialogicamente de determinada maneira. Por outro lado, normas podem ser utilizadas para regulamentar explicitamente sanções ou penalidades a comportamentos desviantes.

\subsubsection{Modelagem ontológica}

Com relação à modelagem ontológica, este é um tema recorrente não apenas na modelagem de organização de agentes, mas de modo amplo no desenvolvimento de SMA de modo geral. Isto porque agentes em interação direta irão trocar conteúdo (informação, conhecimentos) relativos a um dado domínio de aplicação cujos conceitos básicos, necessariamente, devem ser compartilhados para que a comunicação seja possível (vide seção 2.2.1). Assim, alguns modelos organizacionais provêem elementos para representar conceitos, e relacionamentos entre conceitos, que os agentes em uma organização devem ser capazes de interpretar de modo comum para que as eventuais trocas de mensagens durante a atividade conjunta sejam significativas.

Por fim, cita-se que as dimensões de modelagem identificadas nos modelos organizacionais encontram um paralelo nas Ciências Sociais. Em um estudo comparativo pioneiro (TIMASHEFF, 1952), no qual o autor analisa os conceitos básicos presentes em vários trabalhos na área de Sociologia, tais como interação social, grupo social, norma, papel, função, cultura, etc., encontra-se a seguinte afirmação: 
tendências principais são discerníveis. Relacionismo ... enfatiza relações sociais e interações sociais; normativismo ... enfatiza normas, padrões ideais, ou instituições; e funcionalismo ... pondo ênfase em funções"

[Traduzido de (TIMASHEFF, 1952, p. 177)]

Em uma passagem posterior, o autor faz ainda a seguinte conexão entre relacionamento social e interação social, distinguindo-os de funções:

"Se se concorda com os autores ... relacionamentos sociais e interação social são duas visões do mesmo elemento da realidade social; um estático, ou seja, estrutural, e o outro cinético. O último termo é preferível ao frequentemente utilizado 'funcional,' dado que o termo 'função' e seus derivados devem ser reservados para conotar um outro elemento da realidade social."

[Traduzido de (TIMASHEFF, 1952, p. 177)]

Concluindo, pode-se dizer que as tendências - funcionalismo, relacionismo (estrutural e cinético) e normativismo -, que aparecem em trabalhos sobre grupos sociais humanos, quando transpostas à modelagem de organizações de agentes, por analogia, corroboram as (quatro primeiras) dimensões de modelagem identificadas nos modelos organizacionais.

\subsection{Modelos Organizacionais}

Passa-se agora a uma revisão analítica da estrutura conceitual de vários modelos organizacionais presentes na literatura, alguns dos quais já foram brevemente discutidos na subseção 2.3.2. Os modelos serão analisados destacando-se seus conceitos principais e como estes cobrem o espaço de modelagem organizacional descrito na seção anterior.

Em detalhes, serão discutidos os modelos organizacionais TAEMS (DECKER; LESSER, 1994), AGR (FERBER; GUTKNECHT; MICHEL, 2004; GUTKNECHT, 2001), STEAM (TAMBE et al., 1999; TAMBE, 1997), MOISE+ (HüBNER, 2003; HüBNER; SICHMAN; BOISSIER, 2002), ISLANDER (ESTEVA; PADGET; SIERRA, 2002; ESTEVA, 2003) e OPERA (DIGNUM, 2004; DIGNUM et al., 2002).

Tendo em vista o problema de interoperabilidade organizacional, o critério principal utilizado na escolha destes modelos foi o fato de estarem associados a infraestruturas organizacionais que permitem a implementação de organizações de agentes conforme o modelo. Como apresentado na seção 2.3.3, os modelos AGR, STEAM, MOISE+ e ISLANDER satisfazem a este critério. Observa-se ainda que 
o modelo TAEMS também satisfaz parcialmente a este critério. TAEMS possui algumas ferramentas associadas, dentre as quais a arquitetura GPGP/JAF (LESSER et al., 2004; VINCENT; HORLING; LESSER, 2000), que apesar de não restringirem explicitamente o comportamento dos agentes segundo uma especificação organizacional TAEMS, apresentam as outras características de uma infraestrutura organizacional que foram arroladas na seção 2.3.3.

Como critério auxiliar de escolha, buscou-se apresentar modelos que fossem paradigmáticos com relação às dimensões de modelagem identificadas. Neste sentido, TAEMS é um modelo organizacional essencialmente funcional; AGR essencialmente estrutural; STEAM e MOISE+ combinam as dimensões funcional e estrutural; ISLANDER enfatiza as dimensões dialógica, estrutural, normativa e ontológica; e por fim, OPERA que, apesar de não ter correntemente uma infraestrutura organizacional associada, é o único modelo organizacional que apresenta conceitos cobrindo todas as dimensões de modelagem identificadas.

Ao final da seção, outros modelos organizacionais e linguagens genéricas para modelagem de SMAs encontrados na literatura, que não se enquadram diretamente nos critérios estabelecidos, serão ainda descritos de modo sucinto.

A análise da estrutura conceitual de cada modelo organizacional será feita em duas etapas. Primeiro, descrevem-se de modo geral os seus principais conceitos e ilustra-se, através de um exemplo, como estes são aplicados para criar uma especificação organizacional. Em seguida, apresenta-se um metamodelo Ecore que formaliza os conceitos e relacionamentos entre conceitos que foram discutidos. Ao final, comenta-se como os modelos cobrem as dimensões de modelagem identificadas.

A utilização de metamodelos Ecore para descrever modelos organizacionais tem dois motivos principais. Primeiro, permite que a estrutura conceitual dos vários modelos sejam descritas formalmente de modo homogêneo. Na definição original dos diversos modelos organizacionais um misto de descrição textual, teoria de conjuntos, lógica, BNF (KNUTH, 1964) e esquemas XML (DTD, XSD, etc. (MURATA et al., 2005)), é utilizado. Do ponto de vista de análise e comparação, tal diversidade dificulta o trabalho aqui proposto. Em segundo lugar, a utilização de metamodelos habilita a aplicação de técnicas da Engenharia Dirigida por Modelos (Capítulo 3) para definir e operacionalizar mapeamentos entre os diversos modelos organizacionais, uma das contribuições principais desta tese, e que é apresentada nos próximos capítulos. 


\subsubsection{TAEMS}

TAEMS (Task Analysis, Environment Modeling, and Simulation) é um modelo organizacional cuja primitiva básica de modelagem é o conceito de tarefa (LESSER et al., 2004; DECKER, 1996; DECKER; LESSER, 1994). Consiste em uma linguagem para a representação hierárquica de ambientes de tarefas com a capacidade de expressar maneiras alternativas de se realizarem tarefas, a caracterização de métodos (tarefas atômicas) de acordo com qualidade, custos e duração esperados, e a representação de interações entre tarefas.

Em TAEMS, a estrutura de tarefas em um dado ambiente é descrita segundo três níveis: objetivo, subjetivo e generativo. O nível objetivo descreve a estrutura de tarefas 'real' no contexto de uma situação de resolução de problema ao longo do tempo. O nível subjetivo descreve como os agentes percebem e participam desta resolução de problema. Assim, enquanto o nível objetivo descreva a estrutura de tarefas de um ponto de vista externo e global, o nível subjetivo descreve a estrutura de tarefas do ponto de vista de cada agente, de maneira local. De forma geral, cada agente terá uma visão limitada da estrutura de tarefas 'real' que acontece em um dado ambiente. Normalmente, cada agente irá conhecer as tarefas que ele deve executar, além das tarefas que porventura tenham relações de dependência com as que deve executar. Por fim, o nível generativo descreve processos de como gerar visões objetivas e subjetivas em um dado domínio de resolução de problemas.

A especificação de uma estrutura de tarefas é feita definindo-se tarefas, relacionamentos e agrupamentos entre tarefas. Grupos de tarefas definem conjuntos de tarefas independentes, a menos de uso de recursos comuns. Tarefas dentro de um grupo são interdependentes. Há dois tipos de relacionamentos entre tarefas: relação de subtarefa (tle - task local effect) e efeitos não locais (nle - non local effects). A relação de subtarefa é utilizada para definir uma árvore de decomposição de tarefas. Tarefas individuais que não possuem subtarefas, i.e., as folhas da árvore, são chamadas de método. Os métodos são as unidades de tarefas que irão ficar a cargo dos agentes. Métodos podem ter associados estatísticas de duração $\mathrm{D}(\mathrm{T})$, qualidade $\mathrm{Q}(\mathrm{T})$ e custos $\mathrm{C}(\mathrm{T})$. Estes valores podem ser utilizados para avaliar o desempenho da organização. A qualidade total de um grupo de tarefas, por exemplo, pode ser calculado combinando-se as qualidades dos métodos de maneira recursiva por meio de funções de qualidade. Efeitos não locais (nle) são relacionamentos entre tarefas, definidos pelo projetista do sistema, que afetam positiva ou negativamente a qualidade, custo e duração das tarefas relacionadas. 


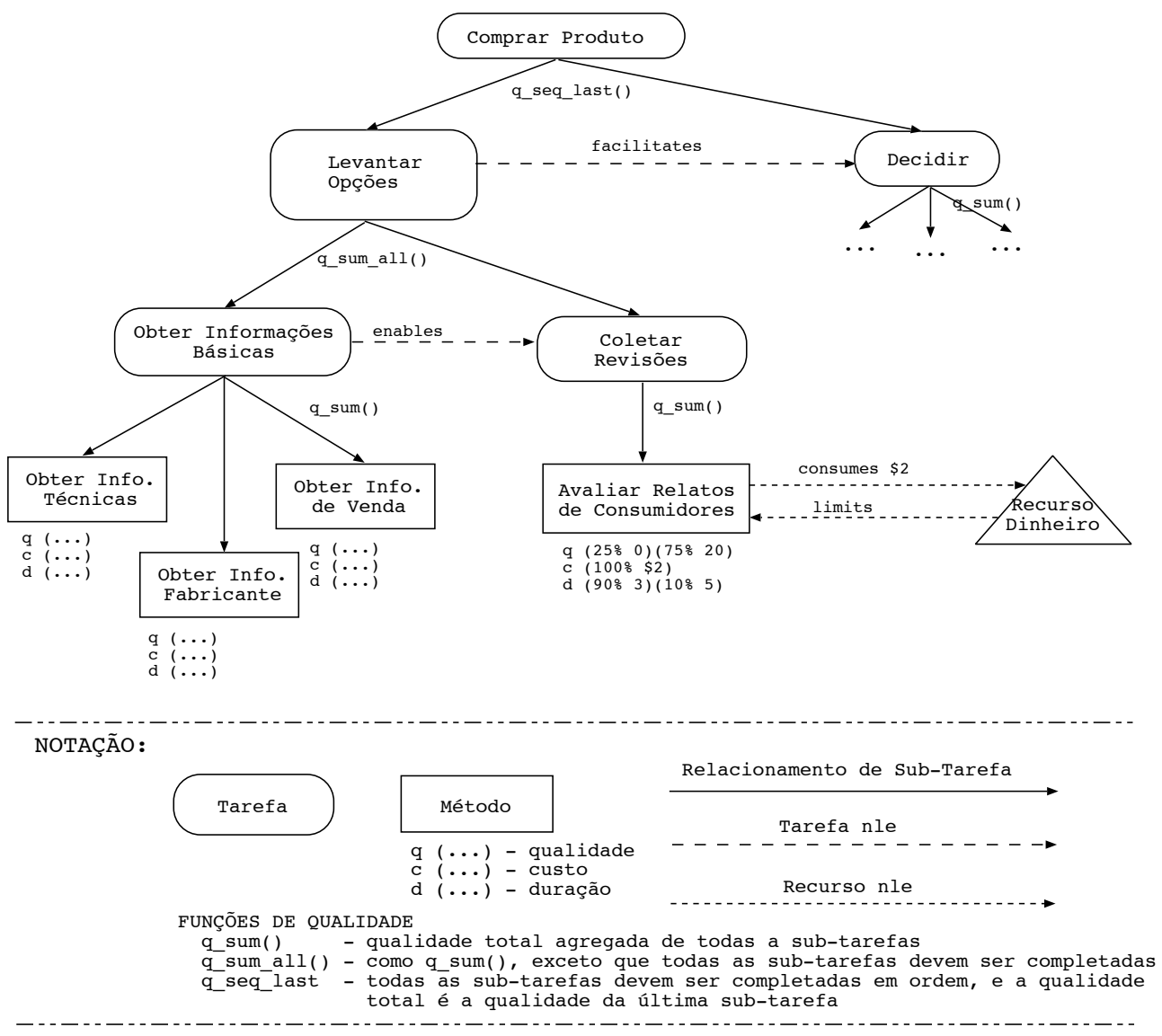

Especificação TAEMS parcial (estrutura de tarefas, nível objetivo) para a atividade de um agente em um SMA para comércio eletrônico. O modelo descreve como um agente deve proceder, dentro de uma organização, para recomendar a compra de um dado produto a um usuário. Ele tem de seguir uma estrutura de tarefas decompostas em duas grandes tarefas "Levantar Opções" e "Decidir" sobre a compra. Por sua vez, estas duas tarefas são também decompostas. No caso de "Levantar Opções", esta é dividida em três métodos. Relacionamentos não locais (nle) determinam coordenações extras entre a execução das tarefas. A especificação mostrada na figura é adaptada de (LESSER et al., 2004, p. 110).

Figura 4.2: Exemplo de modelagem TAEMS. 


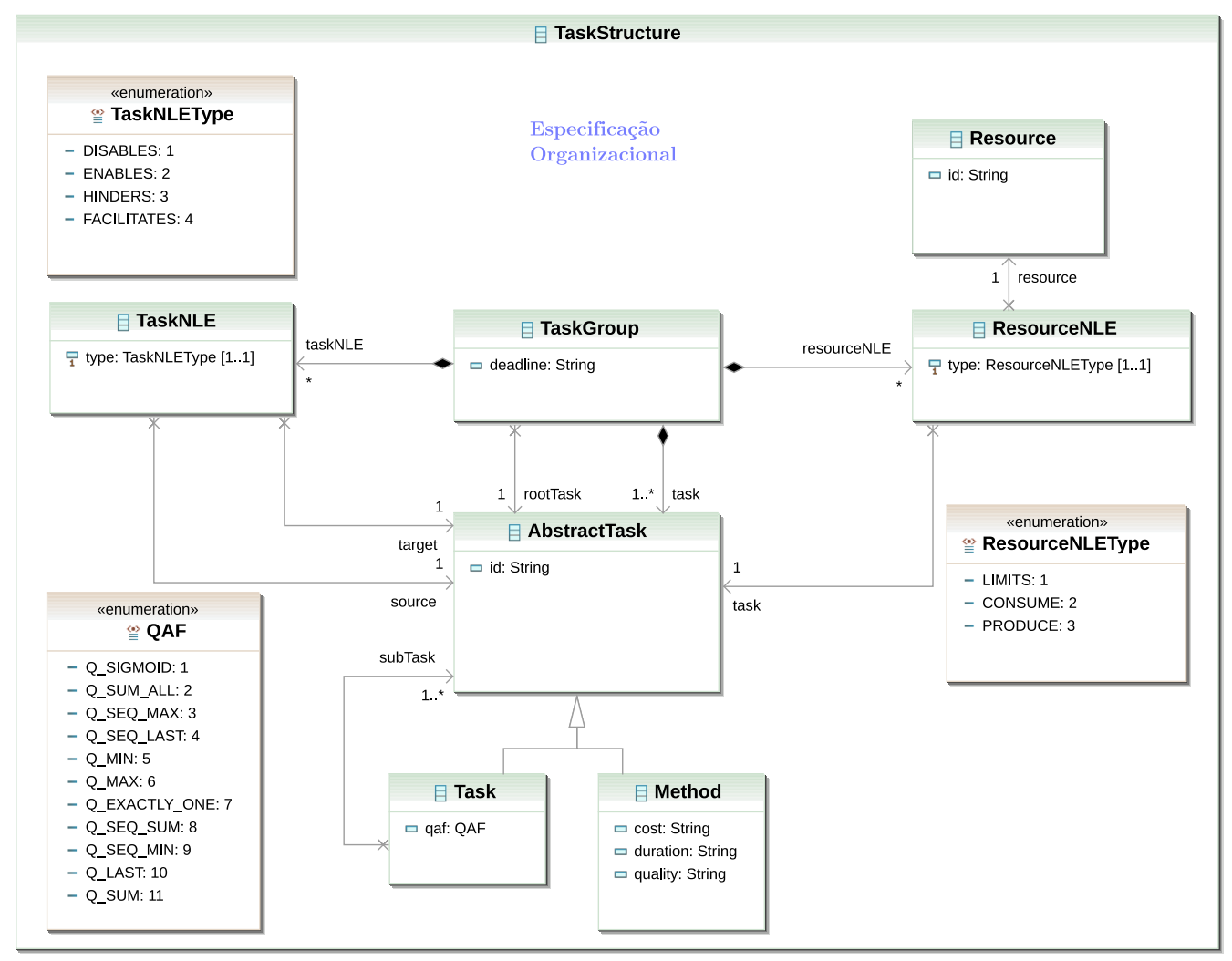

Metamodelo Ecore elaborado a partir de (LESSER et al., 2004; DECKER, 1996).

Figura 4.3: Metamodelo TAEMS.

Exemplos possíveis são: facilita, habilita, dificulta, desabilita, etc. A definição deste efeitos permite modelar os aspectos característicos de cada domínio de tarefa. Quando relacionamentos locais (task-le) e não-locais (nle) existem entre tarefas que estão a cargo de mais de um agente, a situação é chamada de relacionamentos de coordenação, ou seja, são situações onde os agentes deverão coordenar suas atividades conjuntas.

Na figura 4.2, apresenta-se um exemplo de estrutura de tarefas no domínio de comércio eletrônico. Na figura 4.3, apresenta-se um metamodelo Ecore que formaliza os principais conceitos e relacionamentos entre conceitos encontrados no modelo TAEMS.

\section{Comentários}

TAEMS é um modelo organizacional especializado exclusivamente na especificação do comportamento funcional de uma organização de agentes, correspondente à dimensão funcional. No modelo TAEMS, não há conceitos de papel, relacionamentos entre papéis, interações dialógicas, normas, etc. que caracterizam as outras dimensões de modelagem. A unidade de análise em TAEMS são 
as tarefas, que são decompostas hierarquicamente em estruturas de tarefas, seja de um ponto de vista global (ponto de vista da organização) ou local (ponto de vista do agente).

\subsubsection{AGR}

O modelo AGR (Agent, Group, Role) (FERBER; GUTKNECHT; MICHEL, 2004; GUTKNECHT, 2001) é uma evolução do modelo AALAADIN (FERBER; GUTKNECHT, 1998). Como sugere o acrônimo, seus conceitos primitivos são agente, grupo e papel. Um agente é uma entidade ativa, capaz de se comunicar com outros agentes, e que pode desempenhar um ou mais papéis, dentro de um ou mais grupos. Nenhuma restrição é imposta à arquitetura interna de um agente ou sobre suas capacidades mentais. Segundo os autores, "um agente pode ser tão reativo quanto uma formiga, ou tão esperto quanto um humano" (FERBER; GUTKNECHT; MICHEL, 2004, p. 220). Um grupo é um conjunto de agentes que compartilham algumas características comuns. Um grupo serve tanto como um contexto para padrões de atividades, como também é utilizado como meio de particionar organizações. Um mesmo agente pode participar simultaneamente de mais de um grupo. Agentes podem se comunicar se, e somente se, pertencerem ao mesmo grupo. Um papel é a representação abstrata de posições funcionais (funcionamento esperado) de agentes dentro de um grupo. Todo agente deve desempenhar ao menos um papel nos grupos dos quais participa e alguns papéis podem vir a ser desempenhado por vários agentes.

Dados os três conceitos primitivos que descrevem uma organização enquanto coletivo de agentes, no modelo AGR a especificação de uma organização enquanto padrões de atividade conjunta é feita criando-se estruturas de grupo compostas pela definição de papéis e restrições entre papéis. Papéis são definidos por meio de um identificador e cardinalidades (números máximo e mínimo de agentes permitidos). Dois tipos principais de restrições estruturais entre papéis são propostos: correspondência (estabelece que agentes desempenhando um papel devem automaticamente desempenhar um outro papel) e dependência (um agente pode desempenhar um papel se, e somente se, estiver desempenhando também um outro).

Na figura 4.4, representam-se os conceitos e os relacionamentos entre os conceitos do modelo AGR de modo mais preciso através de um metamodelo Ecore. Um exemplo de modelagem utilizando o AGR encontra-se na figura 4.5. 


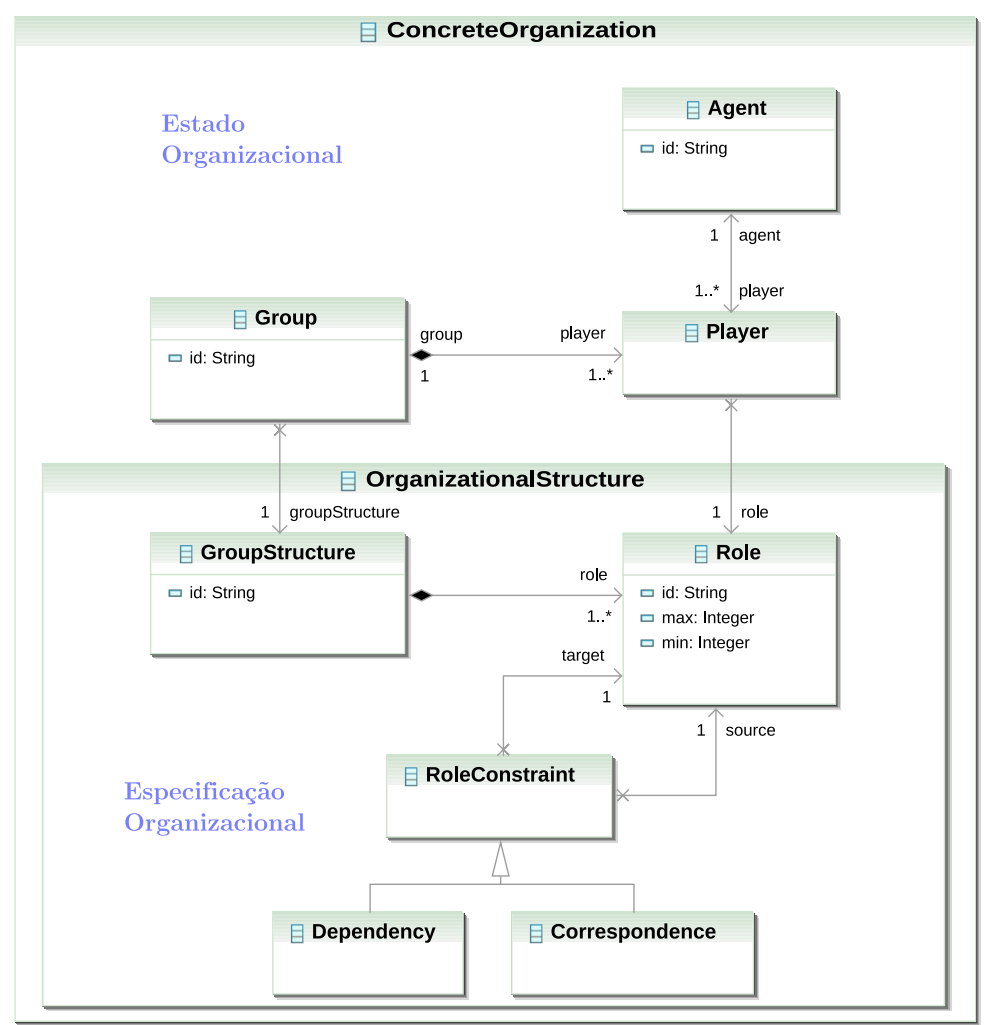

Metamodelo Ecore elaborado a partir dos trabalhos (FERBER; GUTKNECHT; MICHEL, 2004; GUTKNECHT, 2001).

Figura 4.4: Metamodelo AGR.

\section{Comentários}

A principal característica do modelo AGR é sua visão minimalista de organização como estruturas de grupos compostas por papéis e relacionamentos entre papéis. Desta maneira, AGR cobre apenas a dimensão de modelagem da estrutura interna de uma organização de agentes (modelagem estrutural). Na definição do AGR (FERBER; GUTKNECHT; MICHEL, 2004; GUTKNECHT, 2001), menciona-se ainda que o comportamento conjunto dos agentes podem ser orquestrado por protocolos de interação (modelagem dialógica), mas não se fixam a natureza e os detalhes destes protocolos.

\subsubsection{STEAM}

STEAM (a Shell for TEAMwork) é um modelo organizacional cujo enfoque é o trabalho em times (teamwork) (TAMBE, 1997; PYNADATH et al., 2000; TAMBE; PYNADATH, 2001). Desta maneira, em STEAM, uma organização de agentes é concebida como um grande time de agentes. Duas hierarquias separadas são utilizadas para se especificar a estrutura interna e o funcionamento de um time: uma hierarquia de subtimes e papéis, e uma hierarquia de atividade conjunta, 

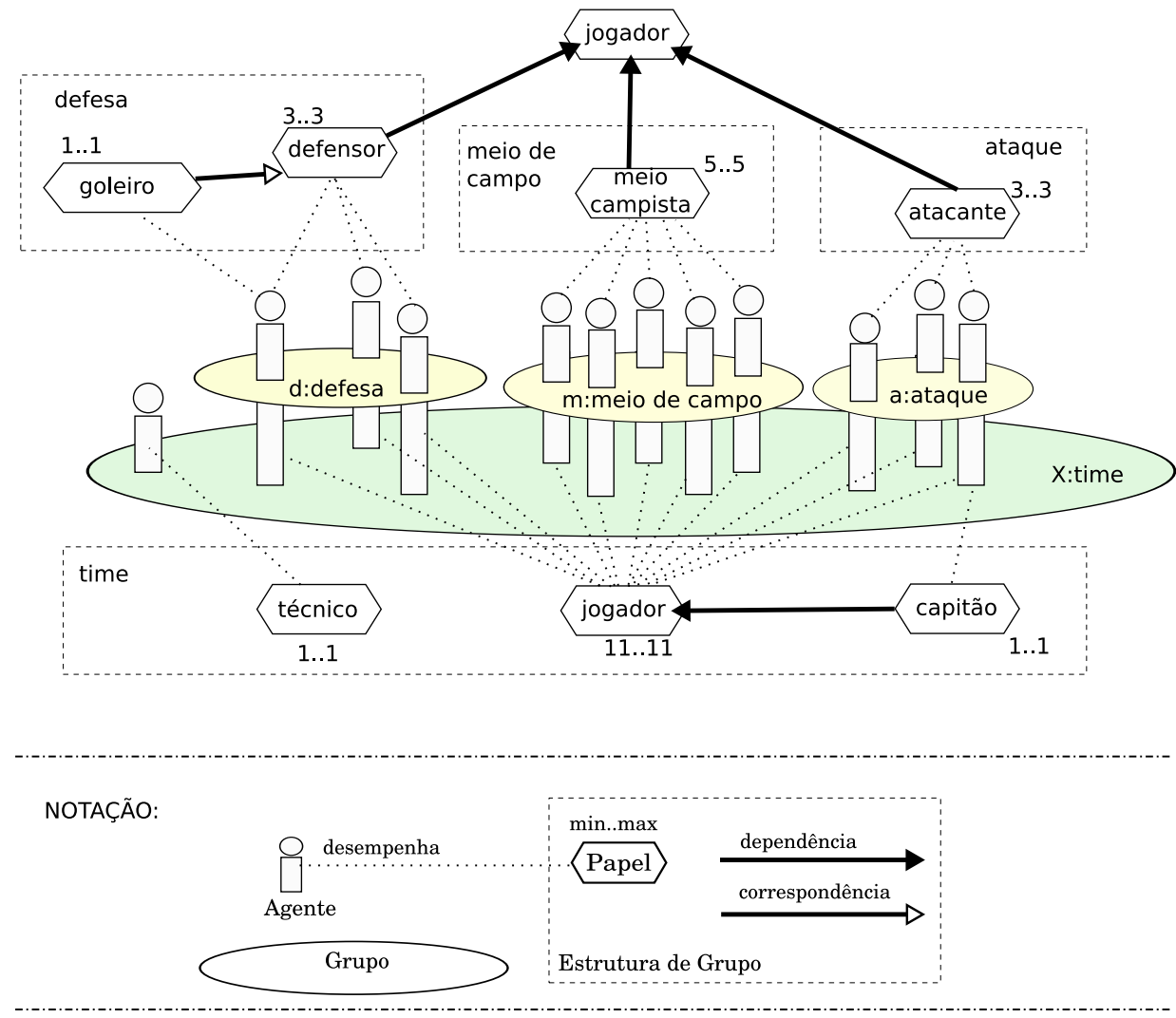

Modelagem da organização de um dos times em um jogo de futebol simulado (exemplo inspirado no campeonato de futebol de robôs simulados promovido pela RoboCup - http://www.robocup.org/). O time é composto por onze agentes no papel de jogador e um no papel de técnico. Ao iniciar uma partida, o time se subdivide em três grupos: defesa, meio de campo e ataque. Apenas agentes que previamente assumiram o papel de jogador do time estão habilitados a fazer parte destes grupos, como também assumir o papel de capitão do time.

Figura 4.5: Exemplo de modelagem AGR. 
respectivamente.

A hierarquia de subtimes e papéis (organization hierarchy) é uma árvore na qual a raiz representa um time, os nós internos representam possíveis subtimes e as folhas representam agentes individuais. Um exemplo é apresentado na figura $4.6(\mathrm{a})$.

A hierarquia de atividade conjunta (operator hierarchy) também é uma árvore. Cada nó da árvore é chamado de operador. Um operador representa uma atividade ou objetivo a ser realizado. Na especificação de operadores podem ser declaradas pré- e pós-condições. Operadores sem filhos representam atividades atômicas. Um operador ligado a um ou mais operadores filho (nó interno) representa um plano reativo (LYONS; HENDRIKS, 1992) que consiste na decomposição de uma atividade (operador) em subatividades interrelacionadas (operadores filhos). Na especificação de um plano reativo, podem ser declarados o tipo de combinação de operadores filho. Há dois tipos de combinações de operadores: combinação-E (todos os operadores filho devem ser realizados para concluir o operador pai) e combinação-OU (pelo menos um dos operadores filho deve ser realizado para concluir o operador pai). Além dos tipos de combinação, relações de dependência entre operadores podem também ser declaradas. Essas relações de dependência são utilizadas para determinar restrições extras relacionadas à ordem relativa na qual se espera que operadores sejam executados. Um exemplo de hierarquia de atividade conjunta encontra-se na figura 4.6(b).

A ligação entre a hierarquia de subtimes e papéis, e a hierarquia de atividade conjunta se dá através dos papéis. Tanto agentes individuais quanto subtimes são atribuídos a papéis. E, a cada papel, associam-se um ou mais operadores da hierarquia de atividade conjunta. Assim, ao assumir um papel, tanto agentes individuais e quanto subtimes ficam mapeados a operadores na hierarquia de atividade conjunta, determinando, deste modo, tanto as capacidades que agentes individuais devem possuir para participar de um subtime quanto a atividade conjunta esperada de cada subtime.

De modo complementar às hierarquias de papéis e atividade conjunta, STEAM provê ainda um conjunto de regras independentes de domínio que devem ser utilizadas pelos agentes individuas que compõem a hierarquia de times (organização de agentes $)^{4}$. Tais regras estabelecem de forma explícita as responsabilidades e comprometimentos dos agentes participantes. "Em essência, elas tentam prover os agentes com conhecimento de senso comum em teamwork, de tal maneira a

\footnotetext{
${ }^{4}$ No caso da infraestrutura organizacional TEAMCORE (seção 2.3.3.2, página 35), essas regras são encapsuladas nos proxies que representam os agentes dentro da organização.
} 


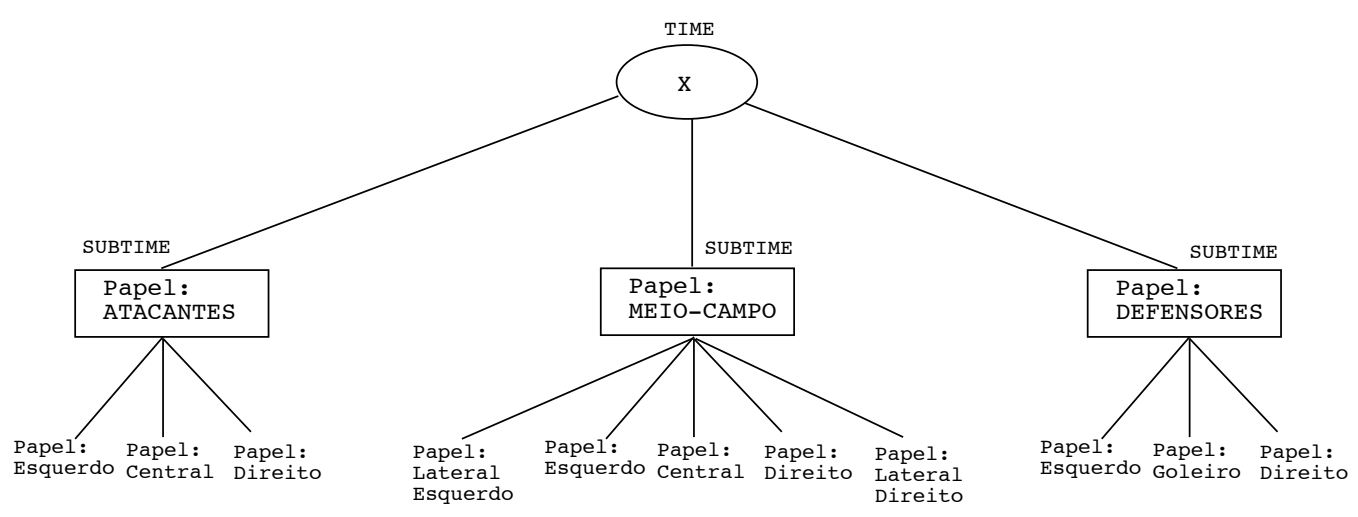

(a) Hierarquia de subtimes e papéis.

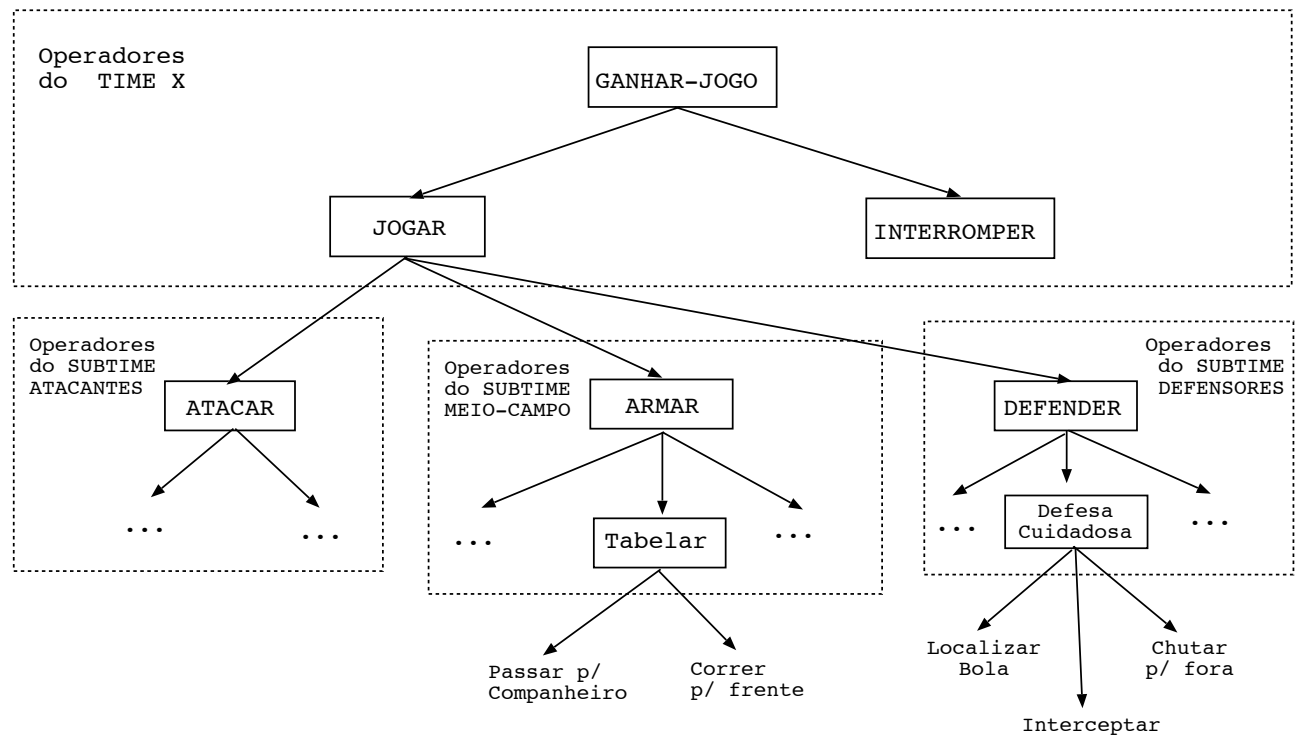

(b) Hierarquia de atividade conjunta.

Parte de uma especificação STEAM para um time de futebol de robôs simulado (similar ao time do exemplo da figura 4.5). Na hierarquia de subtimes e papéis (figura (a)), o time é decomposto em três subtimes: um subtime no papel de ATACANTES, outro no papel de MEIO-CAMPO e um último no papel de DEFENSORES. Por sua vez, cada um dos três subtimes são formados por papéis individuais. Na hierarquia de atividade conjunta (figura (b)), encontrase o plano geral de ações para os subtimes e agentes individuais durante uma partida. Os retângulos pontilhados determinam a associação de operadores à hierarquia de subtimes e papéis. Este exemplo é uma adaptação de um exemplo presente em (TAMBE et al., 1999, Figs. 3 e 4; p. 226-226).

Figura 4.6: Exemplo de modelagem STEAM. 


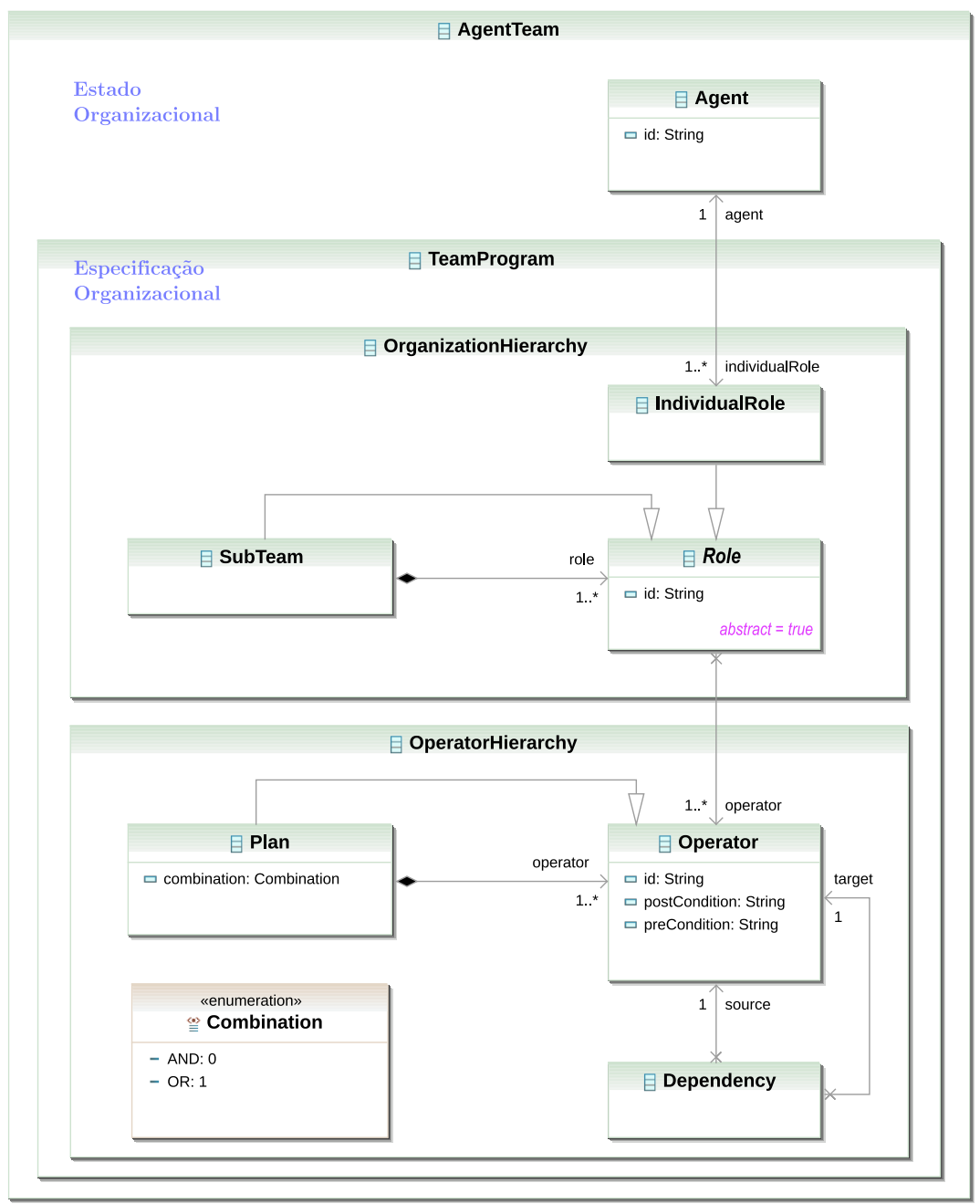

Metamodelo Ecore elaborado a partir dos trabalhos (TAMBE; PYNADATH, 2001; PYNADATH et al., 2000; TAMBE, 1997).

Figura 4.7: Metamodelo STEAM.

habilitá-los a autonomamente raciocinar sobre coordenação e comunicação em teamwork" (TAMBE et al., 1999, p. 224).

Na figura 4.7, apresenta-se um metamodelo Ecore no qual os conceitos e os relacionamentos entre os conceitos do modelo organizacional STEAM são formalizados.

\section{Comentários}

No modelo STEAM, pode-se perceber um primeiro modelo organizacional no qual tanto aspectos funcionais (hierarquia de atividade conjunta) quanto aspectos estruturais (hierarquia de subtimes e papéis) são levados em consideração na especificação de uma organização de agentes. Neste sentido, observa-se que STEAM apresenta algumas similaridades tanto com o modelo TAEMS quanto com o modelo AGR. Por exemplo, as idéias de operadores, planos e dependências 
entre operadores se assemelham, respectivamente, aos conceitos de tarefas, subtarefas e efeitos não locais em TAEMS. Por sua vez, as noções de subtimes e papéis assemelham-se, respectivamente, os conceitos de estrutura de grupo e papel em AGR.

\subsubsection{MOISE+}

MOISE+ (Model of Organization for multI-agent SystEms) (HüBNER, 2003; HüBNER; SICHMAN; BOISSIER, 2002) é um modelo organizacional no qual a especificação de uma entidade organizacional (denominação dada a uma organização de agentes) é subdividida em três partes: uma especificação estrutural, uma especificação funcional e uma especificação deôntica.

A especificação estrutural define a estrutura interna de uma organização de agentes em termos de papéis, relações entre papéis e especificações de grupos. O conceito de papel tem a função básica de ser o elo entre o agente e a organização. O papel define um conjunto de restrições que o agente deve aceitar para fazer parte de um grupo da organização. As restrições estruturais são definidas em termos de ligações e compatibilidades que um papel possui com outros papéis. Há três tipos básicos de ligações: conhecimento, comunicação e autoridade. Havendo uma ligação de conhecimento entre um papel A e um papel B, um agente que assumir A tem permissão para representar (conhecer) o(s) agente(s) que assume(m) o papel B. No caso da ligação de comunicação, A pode trocar mensagens com B. No caso da ligação de autoridade, A têm autoridade sobre $\mathrm{B}^{5}$. As ligações restringem o comportamento do agente depois que ele assume um papel. Por sua vez, a relação de compatibilidade restringe os papéis que um agente pode desempenhar em função dos papéis que já desempenha. Havendo relação de compatibilidade entre um papel A e um papel B, um agente que assumiu A pode também assumir B. Além das ligações (conhecimento, comunicação e autoridade) e compatibilidades, há ainda um terceiro tipo de relacionamento entre papéis: a relação de herança. No entanto, esta relação não tem efeito direto no comportamento dos agentes como as outras. Ele serve para simplificar o processo de especificação dos papéis. Na herança, o papel origem da relação é dito subpapel (ou especialização) e o destino superpapel (ou generalização). Por meio da herança, que pode ser múltipla, um subpapel, além de características particulares, passa a ter também propriedades de um ou mais superpapeis, tais como ligações e compatibilidades definidas no superpapel.

\footnotetext{
${ }^{5} \mathrm{O}$ modelo não detalha o que pode ser representado (conhecido) sobre um agente e nem o que significa ter autoridade sobre um agente.
} 

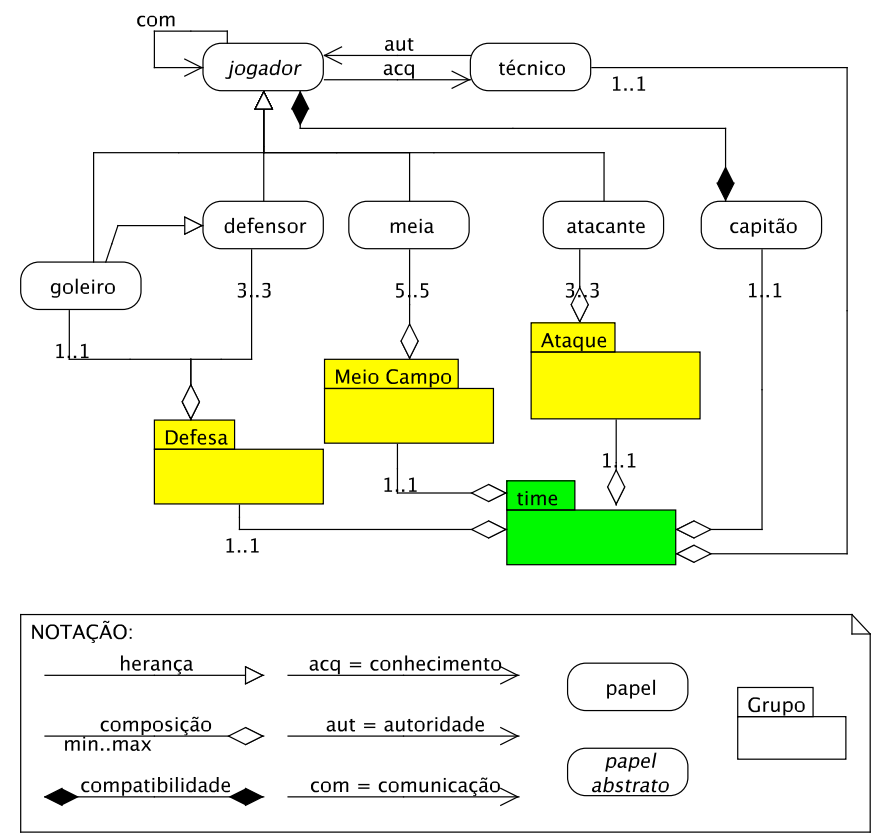

(a) Especificação Estrutural.

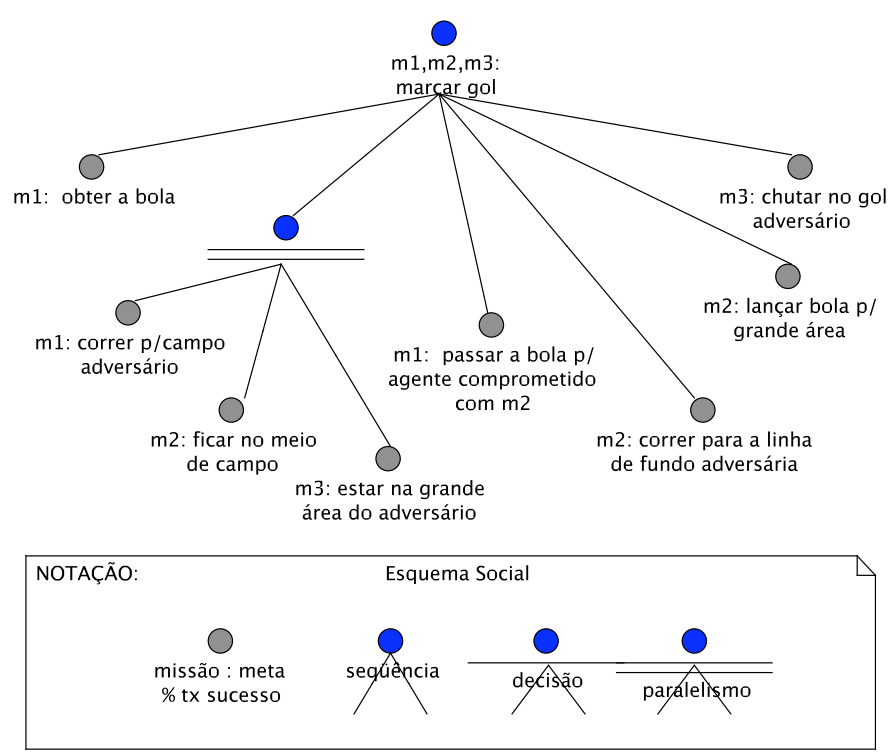

(b) Especificação Funcional.

Parte da especificação MOISE+ para a organização de um time de futebol de robôs simulado (similar ao time do exemplo da figura 4.5). Em (a), vêse a especificação estrutural; em (b), vê-se um esquema social que compõe a especificação funcional. Na tabela abaixo, tem-se a especificação deôntica ligando papéis a missões.

\begin{tabular}{ccc}
\hline papel & relação deôntica & missão \\
\hline \hline zagueiro & permissão & $\mathrm{m} 1$ \\
meio de campo & obrigação & $\mathrm{m} 2$ \\
atacante & obrigação & $\mathrm{m} 3$ \\
\hline
\end{tabular}

(c) Especificação Deôntica

Figura 4.8: Exemplo de modelagem MOISE+. 
Papéis somente podem ser assumidos por agentes dentro de um grupo. Uma especificação de grupo consiste em $(i)$ uma coleção de papéis que podem ser assumidos no grupo, (ii) sub-grupos que podem ser criados dentro do grupo, (iii) ligações que são válidas para os papéis do grupo, (iv) compatibilidades que são válidas para papéis no grupo, $(v)$ e cardinalidades que determinam a boa formação do grupo, tais como números mínimo e máximo de agentes por papel, números mínimo e máximo de sub-grupos por grupo. Na figura 4.8(a), apresenta-se um exemplo de uma especificação estrutural escrita segundo o modelo MOISE+.

A especificação funcional descreve como objetivos relacionados à finalidade da organização de agentes como um todo podem ser atingidos. Tais objetivos são chamados de metas globais. A descrição se baseia na definição de esquemas sociais, missões e uma relação de preferência entre missões. Um esquema social é definido como uma árvore de decomposição de objetivos, onde a raiz é uma meta global e as folhas são metas que podem ser atingidas por um agente individualmente (vide exemplo na figura 4.8(b)). Um nó interno e seus filhos na árvore representam um plano para atingir uma sub-meta global associada ao nó interno. O plano consiste em realizar as metas representadas pelos filhos de acordo com um dado operador associado ao nó interno. Há três operadores possíveis: seqüência (realizar uma meta filho, em seguida a outra, etc.), escolha (realizar apenas uma das metas filho), e paralelismo (realizar todas as metas filho em paralelo). Um plano pode ter ainda uma taxa de sucesso. Esta taxa indica o quão efetivo é o plano para atingir uma (sub)meta global. Missões são conjuntos coerentes de (sub)metas globais que podem ser atribuídos a um mesmo agente através de um de seus papéis. Um agente que se compromete com uma missão é responsável pela satisfação de todas as metas dessa missão. No contexto de um esquema social, missões possuem cardinalidade: um número máximo e mínimo de agentes que podem assumí-las. Por fim, a especificação funcional se completa por meio da definição de uma relação de preferência entre as missões. Esta relação indica que missões são preferíveis de um ponto de vista global.

A especificação deôntica relaciona a especificação estrutural à especificação funcional. Isto é feito definindo-se com quais missões um papel tem permissão ou obrigação de se comprometer (vide exemplo na figura 4.8(c)). Permissões e obrigações podem ainda ter restrições temporais associadas, isto é, estabelecem-se períodos de tempo nos quais tais permissões ou obrigações são válidas.

Os conceitos e os relacionamentos entre os conceitos do modelo MOISE+ são apresentados de modo mais preciso através do metamodelo Ecore que consta na figura 4.9 . 


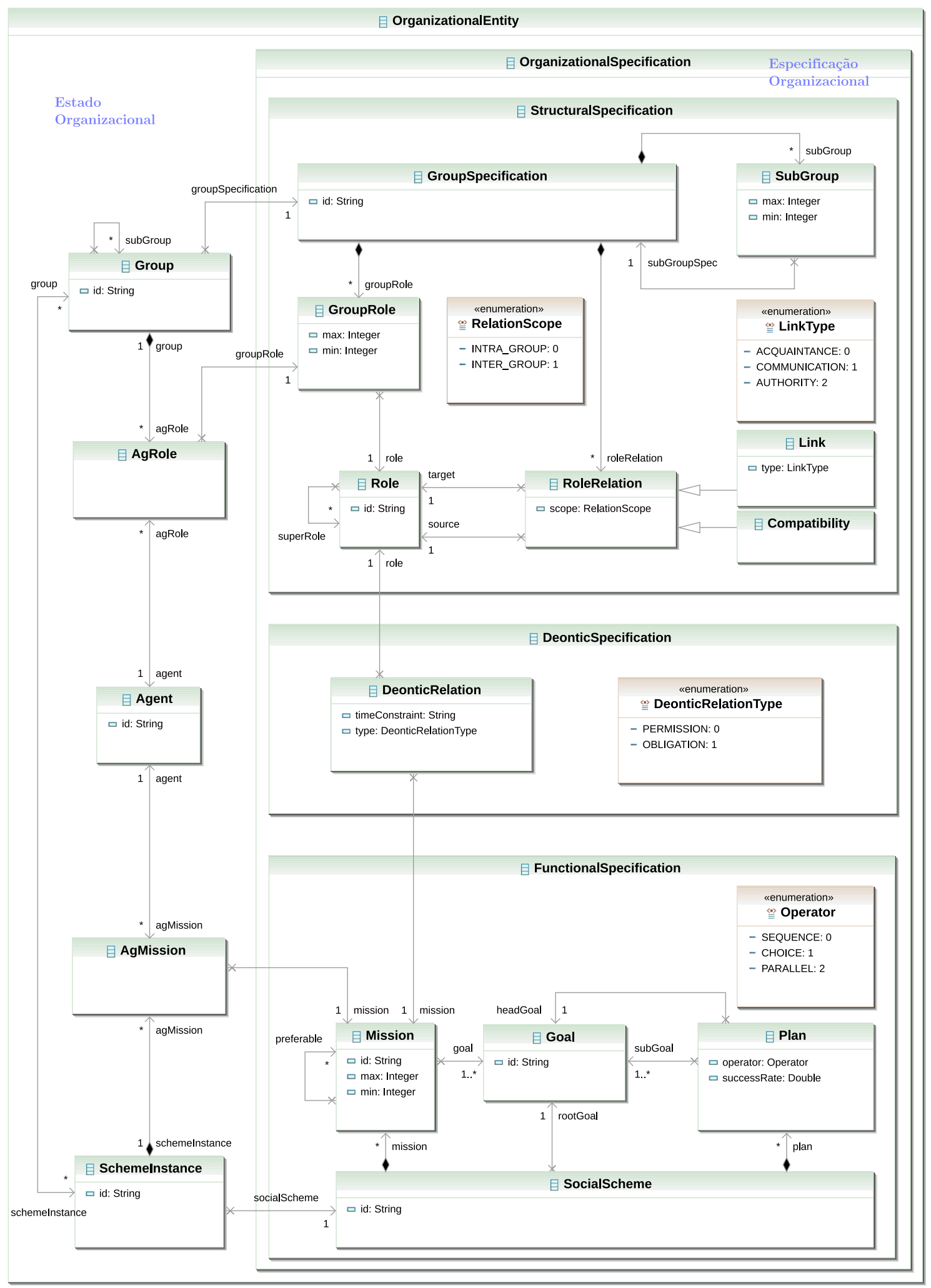

Metamodelo Ecore elaborado a partir da definição formal do modelo MOISE+ feita em (HüBNER, 2003) e do modelo de dados (esquema XML) da infraestura S-MOISE+ disponível em http://moise.sourceforge.net/ (último acesso 31/03/2009).

Figura 4.9: Metamodelo MOISE+. 


\section{Comentários}

A exemplo de STEAM, MOISE+ é um modelo organizacional que enfatiza tanto aspectos estruturais quanto aspectos funcionais na especificação de uma organização de agentes.

Comparando MOISE+ com AGR e STEAM, tendo em vista apenas a dimensão estrutural, pode-se perceber similaridades, tais como estruturas de grupos, papéis e relacionamentos entre papéis, e alguns conceitos novos, tais como a herança entre papéis e cardinalidades em subgrupos. Por outro lado, comparando MOISE+ com STEAM e TAEMS, tendo em vista apenas a dimensão funcional, pode-se também perceber uma mesma idéia básica, a decomposição hierárquica (árvore) de metas em planos conjuntos, mas sem o conceito de relações binárias entre metas (tais como os efeitos não locais de TAEMS e dependências de STEAM), e um novo conceito, a idéia de missão que agrupa metas.

MOISE + acrescenta ainda os conceitos de permissão e obrigação, elementos de modelagem normativa, cuja idéia é relacionar as especificações estrutural e funcional. Diferentemente de STEAM, onde as hierarquias de atividade conjunta e de subtimes e papéis são rigidamente ligadas, a relação entre as especificações estrutural e funcional em MOISE+ são mais flexíveis, e portanto melhor adaptáveis à reorganização (HüBNER, 2003).

\subsubsection{ISLANDER}

ISLANDER é uma linguagem declarativa para a especificação de instituições eletrônicas (ESTEVA; PADGET; SIERRA, 2002; ESTEVA, 2003). Instituições eletrônicas, na concepção dos autores, são a contra-parte computacional de instituições humanas:

\footnotetext{
"Instituições estabelecem como interações de um certo tipo devem e serão estruturadas dentro de uma organização. Instituições humanas não apenas estruturam interações humanas mas também impõem comportamentos individuais e sociais obrigando cada indivíduo a agir de acordo com as normas." [Traduzido de (ESTEVA; PADGET; SIERRA, 2002, p. 348)]
}

Em ISLANDER, uma instituição eletrônica é especificada a partir de quatro elementos básicos: uma infra-estrutura de diálogo (dialogic framework), cenas, estruturas de atuação (performative structure), e normas.

$\mathrm{Na}$ infra-estrutura de diálogo, são definidas as ilocuções válidas, os papéis participantes e os relacionamentos entre papéis. As ilocuções válidas são aquelas 
(a) Estrutura de Atuação

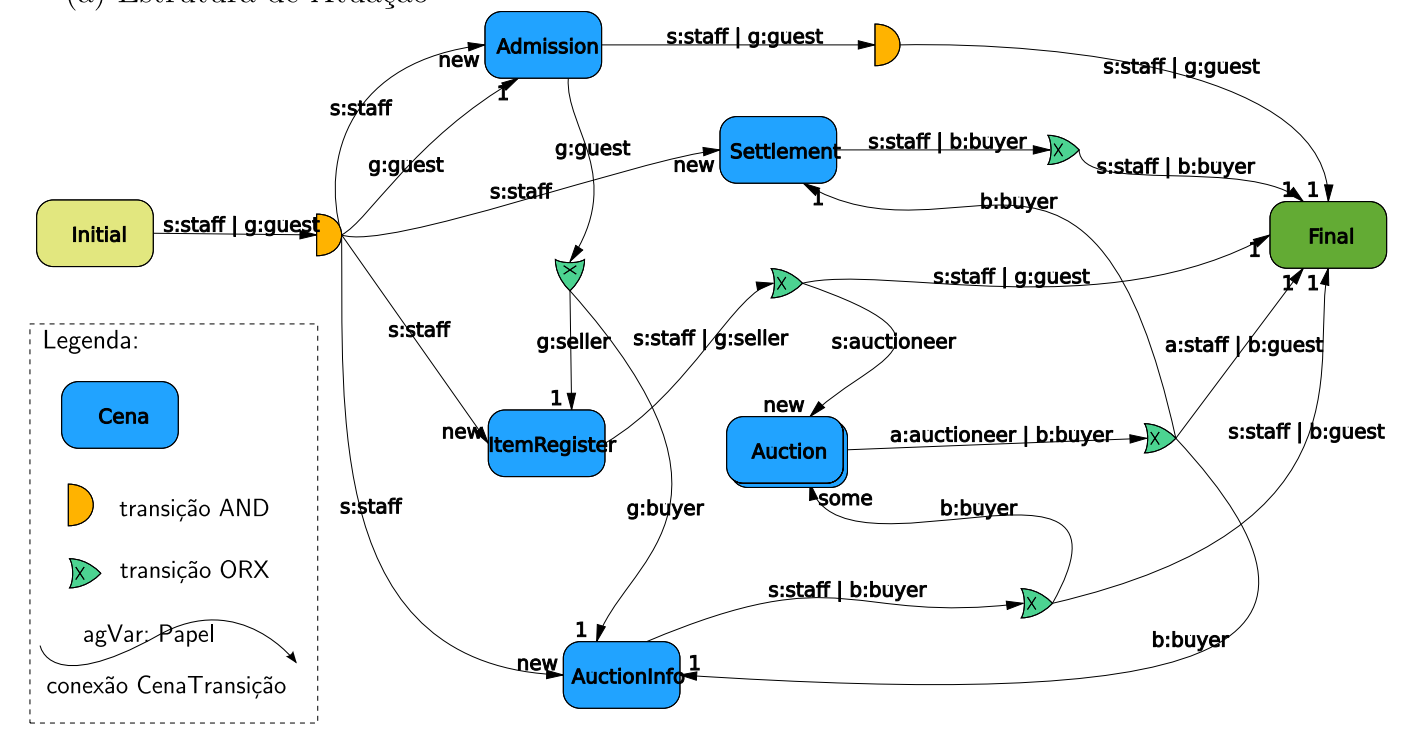

(b) Infraestrutura de Diálogo
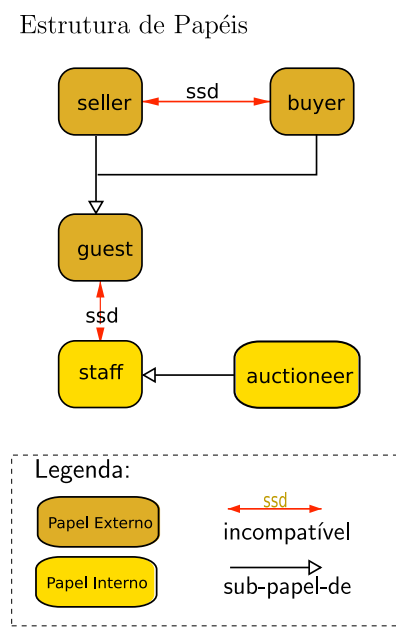

(c) Protocolo da Cena 'Admission'

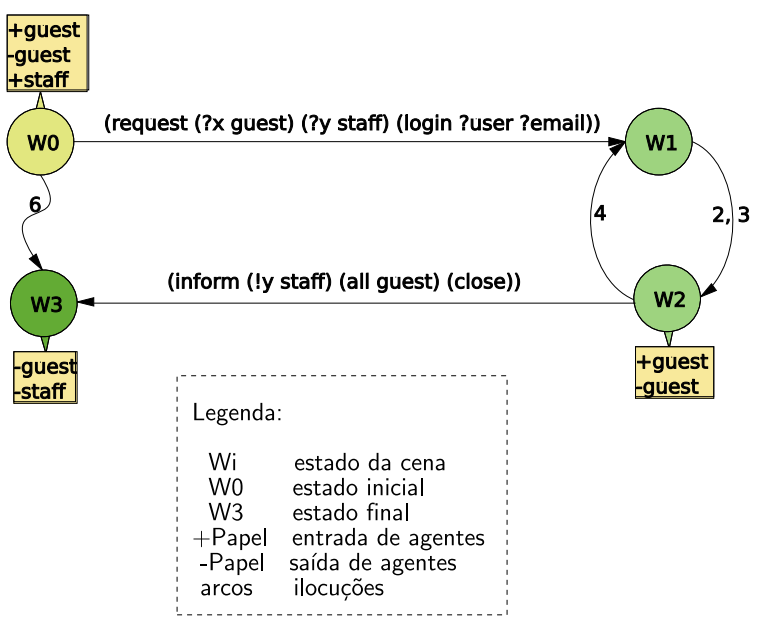

(d) Norma

(define-norm obligation2pay as

antecedent $=($ (Auction (inform (?y auctioneer) $($ ?x buyer) (sold (?good-id ?price ?x))))

defeasible-antecedent $=(($ Settlement (inform (!x buyer) (?y staff) (payment (!price)))) consequent $=(($ obligation $! \mathrm{x}$ (inform $(! \mathrm{x}$ buyer $)($ ? staff) (payment $($ !price $)))$ Settlement))

)

Figura 4.10: Exemplo de modelagem ISLANDER. 
que seguem uma ontologia comum pré-definida, uma dada linguagem de comunicação de agentes (illocutionary particles), e uma linguagem de representação de conhecimento específica. Cada papel define um padrão de comportamento dentro da instituição. Todo agente para fazer parte da instituição necessita adotar um papel. Há dois tipos de papéis: papel interno e papel externo. Os papéis internos só podem ser assumidos por "agentes de staff". Agentes de staff são agentes que fazem parte da implementação da instituição. Os papéis externos são desempenhados por agentes externos que querem se juntar à instituição. Quanto aos relacionamentos entre papéis há dois tipos básicos: incompatibilidades e subpapéis. Uma relação de incompatibilidade (ssd - static separation of duties) entre papéis significa que um agente com um dos papéis não pode assumir o outro. A relação de subpapéis define uma hierarquia de herança na qual papéis filhos (origem da relação) herdam características (tais como incompatibilidades, ou a possibilidade de participar de determinadas cenas) de, possivelmente, vários papéis pai (destino da relação).

Uma cena é uma coleção de agentes desempenhando diferentes papéis e em interação uns com os outros para realizar uma dada atividade. Cada cena segue um protocolo de comunicação bem definido. O protocolo de comunicação de uma cena é estabelecido em termos de possíveis interações diretas (esquemas de ilocuções) entre papéis. Para cada papel dentro de uma cena, o protocolo de comunicação dita o que pode ser dito, por quem, para quem, e quando.

A estrutura de atuação estabelece relacionamentos entre cenas. A idéia é especificar uma rede de cenas que caracterizam atividades mais complexas. As conexões entre cenas definem que agentes, em dados papéis, podem se mover de uma cena para outra, dadas algumas restrições.

As normas definem os comprometimentos que os agentes passam a ter à medida em que participam (movem-se pelas cenas) da instituição. Uma norma caracteriza-se por antecedentes (ilocuções proferidas por um agente em uma dada cena) que acarretam em obrigações (ilocuções que devem ser proferidas pelo mesmo agente na mesma ou em outra cena).

Na figura 4.10, pode-se ver um exemplo de especificação de uma instituição eletrônica para um exemplo de sistema de mercado eletrônico. A figura é uma adaptação de um exemplo discutido em (ESTEVA; PADGET; SIERRA, 2002). O exemplo consiste em um mercado eletrônico onde produtos são vendidos através de leilões. Agentes externos representando compradores (papel buyer) e vendedores (papel seller) chegam ao mercado, são admitidos (cenas Admission e 


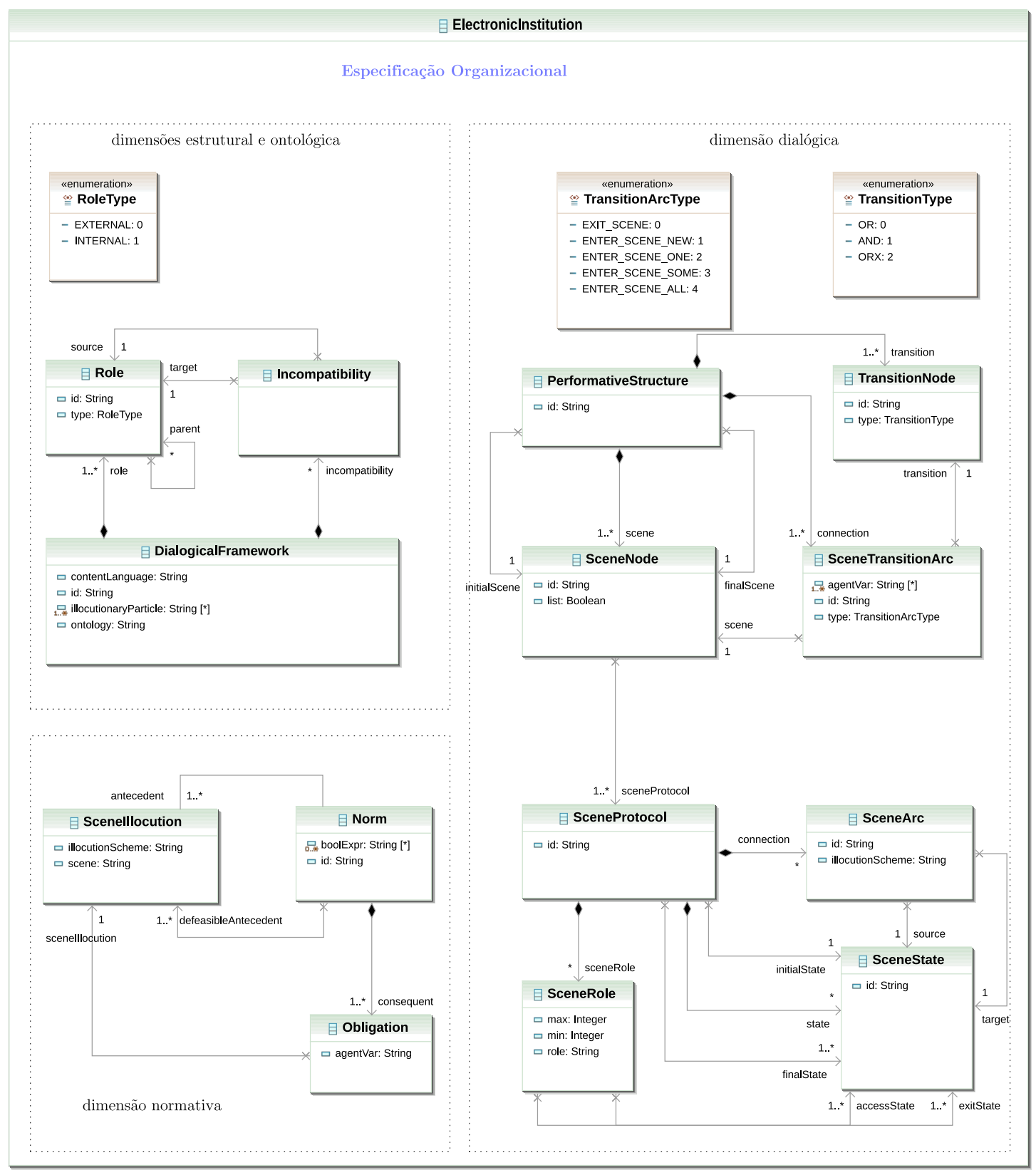

Metamodelo Ecore elaborado a partir da definição da linguagem ISLANDER constante nos trabalhos (ESTEVA, 2003; ESTEVA; PADGET; SIERRA, 2002) e do modelo de dados (esquema XML) do editor ISLANDER disponível em http://e-institutions.iiia.csic.es/eide/pub/ (último acesso 19/03/2009).

Figura 4.11: Metamodelo ISLANDER. 
ItemRegister), participam de leilões (cenas AuctionInfo e Auction), passam por um protocolo de saída (cena Settlement) e finalmente saem do mercado. Todo este processo é orquestrado pela estrutura de atuação e cenas ilustradas na subfigura 4.10(a). Nas subfiguras 4.10(b) e (c), são ilustrados a estrutura de papéis que compõe a infra-estrutura de diálogo do mercado eletrônico e o protocolo de interação da cena Admission, respectivamente. Na subfigura (d), apresenta-se um exemplo de especificações de norma. A norma define uma obrigação do comprador: pagar pelos produtos que arrematou antes de sair.

Na figura 4.11, tem-se um metamodelo Ecore no qual se representam os principais conceitos e relacionamentos entre conceitos encontrados no modelo ISLANDER.

\section{Comentários}

O primeiro aspecto relevante a ser mencionado é que, em ISLANDER, o que se chama de instituição eletrônica corresponde à noção de organização como padrões de atividade conjunta. Além dessa mudança de terminologia, pode-se ver neste modelo uma mudança de enfoque em relação aos modelos discutidos anteriormente: mudança de um enfoque estrutural/funcional para um enfoque estrutural/dialógico, que incorpora ainda aspectos normativos ontológicos. Assim, mais do que propostas concorrentes, ISLANDER e os modelos anteriores podem ser encarados como abordagens complementares. Por exemplo, no exemplo do futebol de robôs, a modelagem do esquema de jogo feita em STEAM e MOISE+ (figura 4.6 e figura 4.8) torna-se complicada em ISLANDER, uma vez que neste modelo toda interação entre agentes é direta por troca de mensagens, não havendo possibilidade de especificar interação indireta por meio do ambiente ou por planos compartilhados que não dependem de troca de mensagens. De modo inverso, ao se tenta modelar com o MOISE+ ou STEAM uma organização de agentes no qual existem estruturas complexas de diálogo, a tarefa se mostra também complicada e pouco natural.

\subsubsection{OPERA}

OperA (Organizations per Agents) (DIGNum, 2004; DIGNuM et al., 2002) é um modelo organizacional no qual uma organização de agentes é representada através da especificação de quatro estruturas conceituais: a estrutura social, a estrutura de interações, a estrutura de normas e a estrutura de comunicação. 
Na estrutura social, definem-se papéis, objetivos, grupos e dependências funcionais entre papéis. Na definição de papéis, abstraem-se agentes individuais, identificando-se objetivos ou atividades que devem ser realizadas para atingir os propósitos globais da organização de agentes. Há dois tipos de papéis: papel institucional e papel externo. Os papéis institucionais só podem ser assumidos por agentes internos ligados à infraestrutura organizacional que implementa a organização, similares aos agentes de "staff" presentes em ISLANDER. Os papéis externos podem ser desempenhados por agentes desenvolvidos de modo independente da organização. Na definição de papéis, objetivos podem ainda ser subdivididos em subobjetivos. Grupos provêem meios de agregar papéis tendo em vista a definição de normas ou interações que envolvam todos os papéis do grupo. Dependências entre papéis descrevem como os papéis se relacionam em termos da realização conjunta de (sub)objetivos. Um papel que depende de outro significa que a realização de um dos (sub)objetivos do primeiro é delegada ou requisitada pelo segundo.

A estrutura de interação define como a atividade conjunta da organização deve ocorrer. Esta definição é feita em termos de cenas, padrões de interação e transições entre cenas. Cenas são representações de interações específicas envolvendo papéis que trocam mensagens tendo como resultado a execução de certos objetivos relacionados aos papéis. Na definição de uma cena, não se estabelecem protocolos específicos de interação mas padrões abstratos de interação que, em essência, consistem em uma ordenação de estados intermediários rumo a execução dos objetivos ligados a cena. Tais estados intermediários são também chamados de landmarks. Quaisquer protocolos de interação que os agentes venham a instanciar, em tempo de execução, para interagir no contexto de uma cena devem respeitar estes padrões de interação definidos. As transições entre cenas são utilizadas para coordenar e sincronizar uma rede de cenas que em conjunto caracterizam o comportamento global da organização. Por meio das transições, define-se como agentes podem trafegar entre as cenas por meio de relações de evolução de papéis.

Na estrutura normativa, definem-se normas relativas a papéis e grupos (normas de papéis), cenas (normas de cenas) e transição (normas de transições). Normas são especificadas utilizando-se expressões lógicas que seguem o formalismo LCR (Logic for Contract Representation) introduzido em (DIGNUM, 2004, cap. 4). Há três tipos de normas: permissões, obrigações e proibições. Na definição de normas de papéis, especificam-se as regras de comportamento de papéis ou grupos de papéis, independemente das cenas de interação nas quais participam. 
Na definição de normas relativas a cenas, descreve-se o comportamento esperado de papéis ou grupos de papéis no contexto da cena. Na definição de normas de transição, impõem-se limitações extras a papéis trafegando entre cenas.

Por fim, na estrutura de comunicação indicam-se a linguagem de comunicação, a linguagem de representação de conhecimento e a ontologia de domínio utilizadas na organização de agentes.

Na figura 4.12, os principais conceitos do modelo OPERA, e seus interrelacionamentos, são representados em um metamodelo Ecore. Na figura 4.13, ilustra-se um trecho de uma especificação organizacional feita em OPERA.

\section{Comentários}

OPERA é um modelo organizacional que cobre todas as dimensões de modelagem identificadas no início do capítulo. No entanto, deve-se observar que a modelagem funcional em OPERA ocorre de maneira implícita, i.e., como parte da definição de papéis, e é muito básica com relação ao que se encontra em TAEMS, STEAM e MOISE+. Nesta dimensão, relacionam-se apenas subobjetivos de um objetivo, sem a idéia explícita de plano que os interrelacione. Quanto à modelagem estrutural, esta segue a linha geral dos outros modelos: há a idéia de papéis, grupos, relacionamentos entre papéis. Com relação às dimensões dialógica e ontológica, o modelo OPERA é muito parecido com o que se vê em ISLANDER, no qual a estrutura de interação é dividida em dois níveis: um nível macro onde uma ordenação entre as cenas é definida; e um nível micro, no qual especifica-se a atividade conjunta de cada cena. A principal diferença é que, na especificação da atividade conjunta das cenas, em ISLANDER os protocolos de interação são mais detalhados do que os padrões de interação em OPERA, em termos de mensagens específicas que agentes devem tocar. Por fim, com relação à dimensão normativa, OPERA é mais elaborado do que ISLANDER e MOISE+. Há um formalismo explícito, o LCR (Logic for Contract Representation), no qual expressões envolvendo objetivos, papéis, grupos, cenas, transições e elementos temporais podem ser escritas de tal modo a especificar interrelacionamentos extras, ligando as várias dimensões de modelagem.

No entanto, o principal ponto negativo de OPERA, com relação aos outros modelos analisados, é que ele não se encontra correntemente associado a uma infraestrutura computacional que implemente especificações OPERA, nos moldes das infraestruturas apresentadas no capítulo 2. 


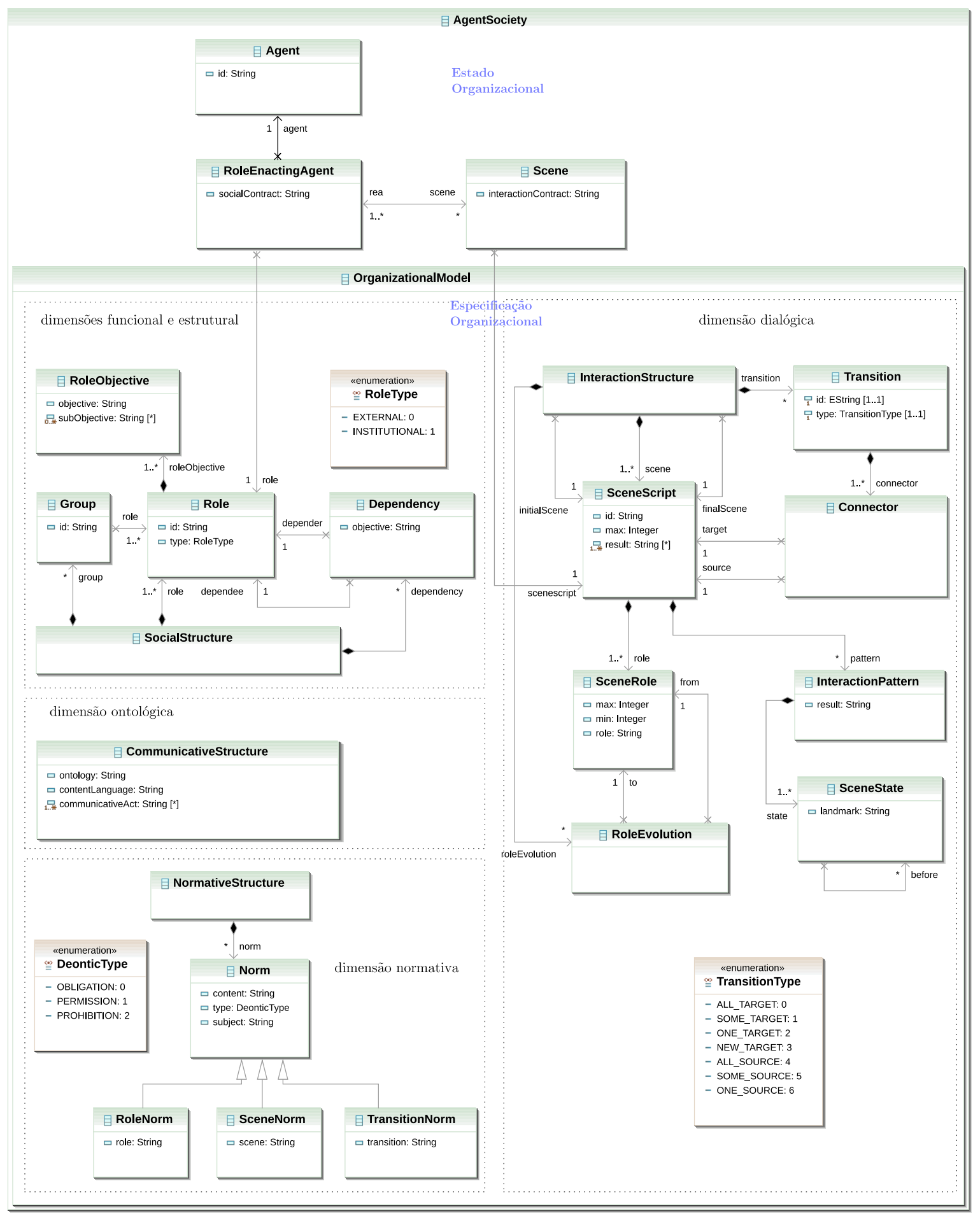

Metamodelo Ecore elaborado a partir da definição formal do modelo OPERA constante no trabalho (DIGNUM, 2004).

Figura 4.12: Metamodelo OPERA. 


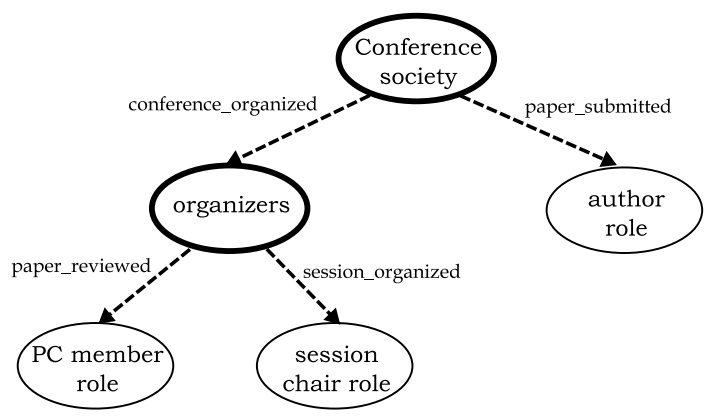

(a) Estrutura Social: papéis, grupos e dependências.

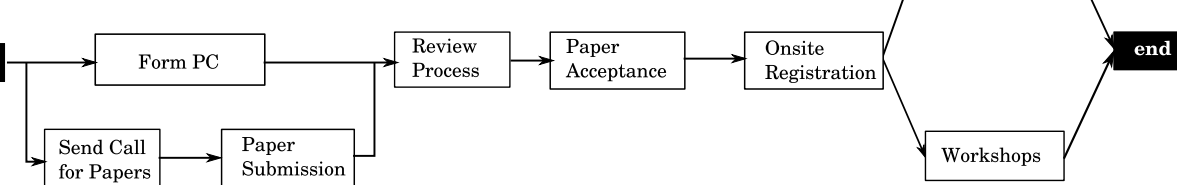

(b) Estrutura de Interação: cenas e transições.
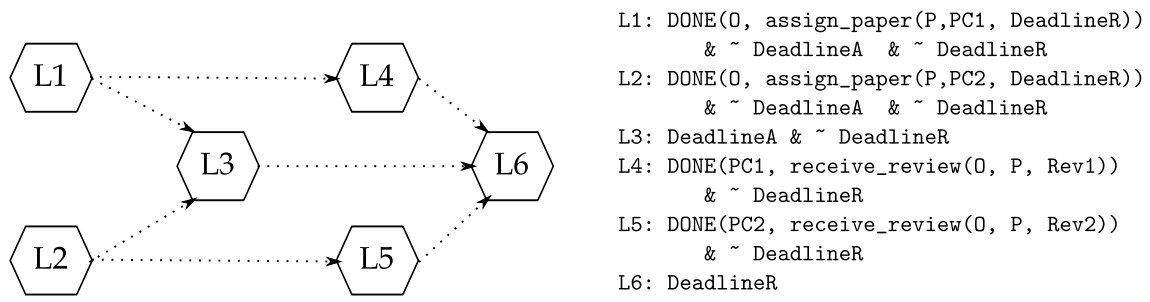

(c) Padrão de interação da cena "Review Process".

Parte de uma especificação OPERA para uma organização de agentes cuja finalidade é auxiliar a realização de conferências. Na subfigura (a), tem-se parte da estrutura social da organização, na qual pode-se observar alguns grupos, papéis e seus relacionamento de dependência funcional. Na subfigura (b), tem-se a estrutura de interação global da organização, na qual se percebem as principais cenas e transições entre cenas. Na subfigura (c), mostra-se o padrão de interação de uma das cenas da estrutura de interação. A descrição dos estados é feita utilizando-se expressões do formalismo LCR. Exemplo extraído de (DIGNUM, 2004, Capítulo 3).

Figura 4.13: Exemplo de modelagem OPERA. 


\subsubsection{Outros Modelos}

A literatura sobre modelagem organizacional em SMAs é vasta. Por limitações de escopo e tempo, não se pode analisar em detalhes outros modelos organizacionais existentes, ou alguns trabalhos que, apesar de não se enquadrarem na concepção de modelo organizacional adotada nesta pesquisa, lidam com a noção de organização de agentes. Nesta seção, listam-se algumas das principais omissões:

- ODML - Organizational Design Modelling Language (HORLING; LESSER, 2004), um modelo organizacional minimalista voltado exclusivamente para modelagem e avaliação da estrutura interna de organizações de agentes;

- AGRE - Agent, Group, Role, Environment (FERBER; MICHEL; BAEZ, 2005) - uma extensão do modelo AGR que inclui aspectos do ambiente físico e social na modelagem da organização de um SMA. A idéia geral é que toda a atividade conjunta organizada deve se dar em domínios chamados de espaços. Os espaços podem ser físicos (áreas) ou sociais (grupos).

- MOISE ${ }^{\text {Inst }}$ (GâTEAU et al., 2005) - uma extensão do modelo MOISE+ que acrescenta novas especificações: uma especificação contextual (contextos de atividade e transições entre contextos), e uma especificação normativa (conjunto de normas que amplia a especificação deôntica).

- AUML - Agent UML (PARUNAK; ODELL, 2002) - uma extensão do metamodelo da UML para lidar com o desenvolvimento de SMA. No que diz respeito à modelagem organizacional, o metamodelo toma por base elementos do AGR.

- MAS-ML - MAS Modeling Language (SILVA; CHOREN; LUCENA, 2004) - uma linguagem de modelagem baseada na estrutura conceitual TAO (Taming Agents and Objects in Software Engineering) (SILVA et al., 2003). Com relação à modelagem organizacional, organizações de agentes (entidades coletivas) são considerados como uma extensão da noção de agente; ou seja, além dos mecanismos de padronização e controle da atividade conjunta, organizações podem ter um estado mental, autonomia, etc.

- GAIA (ZAMBONELLi; JENNINGS; WOOLDRIDGE, 2003) - Gaia não é uma linguagem de modelagem organizacional, mas sim uma metodologia de desenvolvimento de software orientado a agentes. No entanto, como organização é um conceito central em SMAs, metodologias forçosamente devem prover meios de modelar o conceito de organização. De maneira particular, Gaia 
prescreve a criação de três modelos: modelo de papéis, modelo de interação e modelo de estrutura organizacional.

- TROPOS (KOLP; GIORGINI, 2002)- Uma outra metodologia de desenvolvimento de software orientado a agentes. Tropos é baseada em modelo de captura de requisitos chamado i* que oferece conceitos tais como ator, objetivos, dependência social, e estruturas sociais.

\subsection{Considerações Finais}

Mais do que de grandes diferenças ou incompatibilidades, podem-se perceber várias similaridades e complementaridade entre as estruturas conceituais dos modelos organizacionais analisados. Os pontos comuns e complementares acontecem em dois níveis. Num primeiro nível, eles ocorrem na forma das dimensões de modelagem que foram identificadas. Por exemplo, quase todos os modelos, com exceção de TAEMS, apresentam conceitos para representar a estrutura interna de organizações (dimensão estrutural). Quase todos os modelos, com exceção de AGR e ISLANDER, promovem a modelagem do comportamento funcional de organizações (dimensão funcional). ISLANDER e OPERA apresentam estruturas conceituais bastante similares para representar o comportamento estrutural (dimensão dialógica) de organizações. Conceitos normativos aparecem em MOISE+, ISLANDER e OPERA (dimensão normativa). Por fim, elementos para modelar explicitamente a linguagem de comunicação utilizada e ontologias do domínio de aplicação da organização são previstos tanto em ISLANDER como em OPERA ${ }^{6}$. Essas observações são resumidas na tabela 4.1, na qual pode-se observar a distribuição dos principais conceitos de cada modelos organizacional analisado ao longo das dimensões de modelagem identificadas.

Em um nível mais detalhado de análise, podem-se ainda identificar vários pontos comuns ou complementares entre os modelos organizacionais dentro de cada dimensão analisada. Uma observação rápida pela tabela 4.1 corrobora esta afirmação. Um estudo mais aprofundado dessas similaridades e diferenças intradimensões é conduzido no próximo capítulo.

\footnotetext{
${ }^{6}$ Apesar de identificada como uma dimensão de modelagem organizacional, a modelagem de primitivas de comunicação entre agentes e ontologias de domínio é um tema mais amplo, encontrado não apenas na modelagem de organizacões de agentes, mas também na modelagem de SMAs como um todo. Por isto, deliberadamente, a dimensão ontológica não é analisada em mais detalhes no escopo deste trabalho.
} 
Dimensões De Modelagem Organizacional

\begin{tabular}{|c|c|c|c|c|c|}
\hline MODELO & FUnCIONAL & ESTRUTURAL & DiALÓGICA & Normativa & ONTOLÓGICA \\
\hline TAEMS & $\begin{array}{l}\text { tarefas, efeitos } \\
\text { locais, efeitos não } \\
\text { locais ( facilita, } \\
\text { impede, ...) }\end{array}$ & não & não & não & não \\
\hline AGR & não & $\begin{array}{l}\text { papéis, grupos, } \\
\text { relações entre } \\
\text { papéis }\end{array}$ & $\begin{array}{l}\text { menciona que } \\
\text { pode ser } \\
\text { modelado, mas } \\
\text { não fixa como }\end{array}$ & não & não \\
\hline STEAM & $\begin{array}{l}\text { operadores, } \\
\text { planos, } \\
\text { dependências }\end{array}$ & $\begin{array}{l}\text { papéis: de time } \\
\text { e individuais }\end{array}$ & não & não & não \\
\hline MOISE+ & $\begin{array}{l}\text { metas, planos e } \\
\text { missões }\end{array}$ & $\begin{array}{l}\text { papéis, grupos, } \\
\text { relações entre } \\
\text { papéis } \\
\text { (herança, } \\
\text { ligações, ...) }\end{array}$ & não & $\begin{array}{l}\text { relações } \\
\text { deônticas entre } \\
\text { papéis e } \\
\text { missões } \\
\text { (permissão, } \\
\text { obrigação) }\end{array}$ & não \\
\hline ISLANDER & não & $\begin{array}{l}\text { papéis, relações } \\
\text { entre papéis } \\
\text { (composição, } \\
\text { ssd, dsd) }\end{array}$ & $\begin{array}{l}\text { cenas, } \\
\text { transições, } \\
\text { protocolos de } \\
\text { interação }\end{array}$ & $\begin{array}{l}\text { obrigações em } \\
\text { cenas }\end{array}$ & $\begin{array}{l}\text { sim; mas não } \\
\text { detalhado na } \\
\text { análise feita }\end{array}$ \\
\hline OPERA & $\begin{array}{l}\text { objetivos, } \\
\text { subobjetivos }\end{array}$ & $\begin{array}{l}\text { papéis, grupos, } \\
\text { dependências }\end{array}$ & $\begin{array}{l}\text { cenas, } \\
\text { transições, } \\
\text { padrões de } \\
\text { interação }\end{array}$ & $\begin{array}{l}\text { permissões, } \\
\text { obrigações, } \\
\text { proibições de } \\
\text { papéis, cenas e } \\
\text { transições }\end{array}$ & $\begin{array}{l}\text { sim; mas não } \\
\text { detalhado na } \\
\text { análise feita }\end{array}$ \\
\hline
\end{tabular}

Tabela 4.1: Quadro comparativo dos modelos organizacionais analisados. 


\section{Modelo Organizacional Abstrato}

Neste capítulo, de modo complementar à análise feita no capítulo anterior, sintetiza-se um modelo organizacional abstrato. Através desse modelo abstrato, busca-se mostrar de modo explícito duas constatações principais:

- dentro de cada dimensão de modelagem, abstraindo-se a terminologia e algumas particularidades de cada modelo, podem-se identificar padrões nas estruturas conceituais dos modelos organizacionais;

- os padrões identificados podem ser combinados de modo consistente em uma única estrutura conceitual (metamodelo) que representa de modo essencial e integrado as estruturas conceituais (metamodelos) dos modelos organizacionais previamente analisados.

O capítulo consiste em cinco seções principais. Da seção 5.1 à seção 5.4, detalhamse os padrões conceituais básicos que emergem de uma comparação mais detalhada da estrutura conceitual dos modelos organizacionais. Cada seção concentrase em uma das dimensões de modelagem definidas no capítulo anterior, excetuandose a dimensão ontológica. Na seção 5.5, conclui-se a combinação dos padrões conceituais obtendo-se o modelo organizacional abstrato.

\subsection{Dimensão Funcional}

Conforme caracterizado na seção 4.1, na dimensão funcional concentram-se conceitos de modelagem utilizados para especificar o comportamento funcional de uma organização de agentes, i.e., o comportamento conjunto de agentes quando a estrutura interna da organização não é levada em consideração. 


\subsubsection{Padrão Conceitual}

Comparando-se detidamente os exemplos de modelagem e os metamodelos de TAEMS, STEAM, MOISE+ e OPERA apresentados respectivamente nas seções 4.2.1, 4.2.3, 4.2.4 e 4.2.6, chega-se à conclusão de que as especificações funcionais seguem um padrão, ilustrado na figura 5.1.

\subsubsection{Grafos de planos hierárquicos e relações entre metas}

Em essência, o padrão comum na dimensão funcional desses modelos pode ser representado por grafos dirigidos onde:

- os nodos correspondem à definição de metas (em MOISE+), operadores (em STEAM), objetivos (em OPERA) ou tarefas (em TAEMS) a serem realizadas pelos agentes de uma organização;

- os arcos representam

- ou a decomposição de uma meta (operador, objetivo ou tarefa) em submetas (suboperadores, subobjetivos ou subtarefas) de modo acíclico, dando origem à noção de planos hierárquicos,

- ou relações binárias entre metas (operadores, objetivos ou atividades) distintas, tais como as dependências em STEAM ou os efeitos não locais (nles) em TAEMS.

Além disso, em cada grafo destaca-se um nodo raiz que corresponde à uma meta primária cujo planejamento e futura realização por meio da decomposição em submetas interrelacionadas é prescrita pelo grafo.

Tais grafos de planos hierárquicos e relações entre metas recebem o nome de "grupos de tarefas" em TAEMS, "hierarquias de atividade conjunta" em STEAM, "esquemas sociais" em MOISE+ e "definições de objetivos de papéis" em OPERA.

\subsubsection{Metamodelo Ecore}

No centro da figura 5.1, por meio de um metamodelo Ecore, representa-se o padrão conceitual identificado na dimensão funcional. Nas tabelas 5.1 e 5.2, detalha-se como o metamodelo efetivamente captura o padrão identificado em seus aspectos essenciais. Na tabela 5.1, descrevem-se as classes e referências entre classes que 


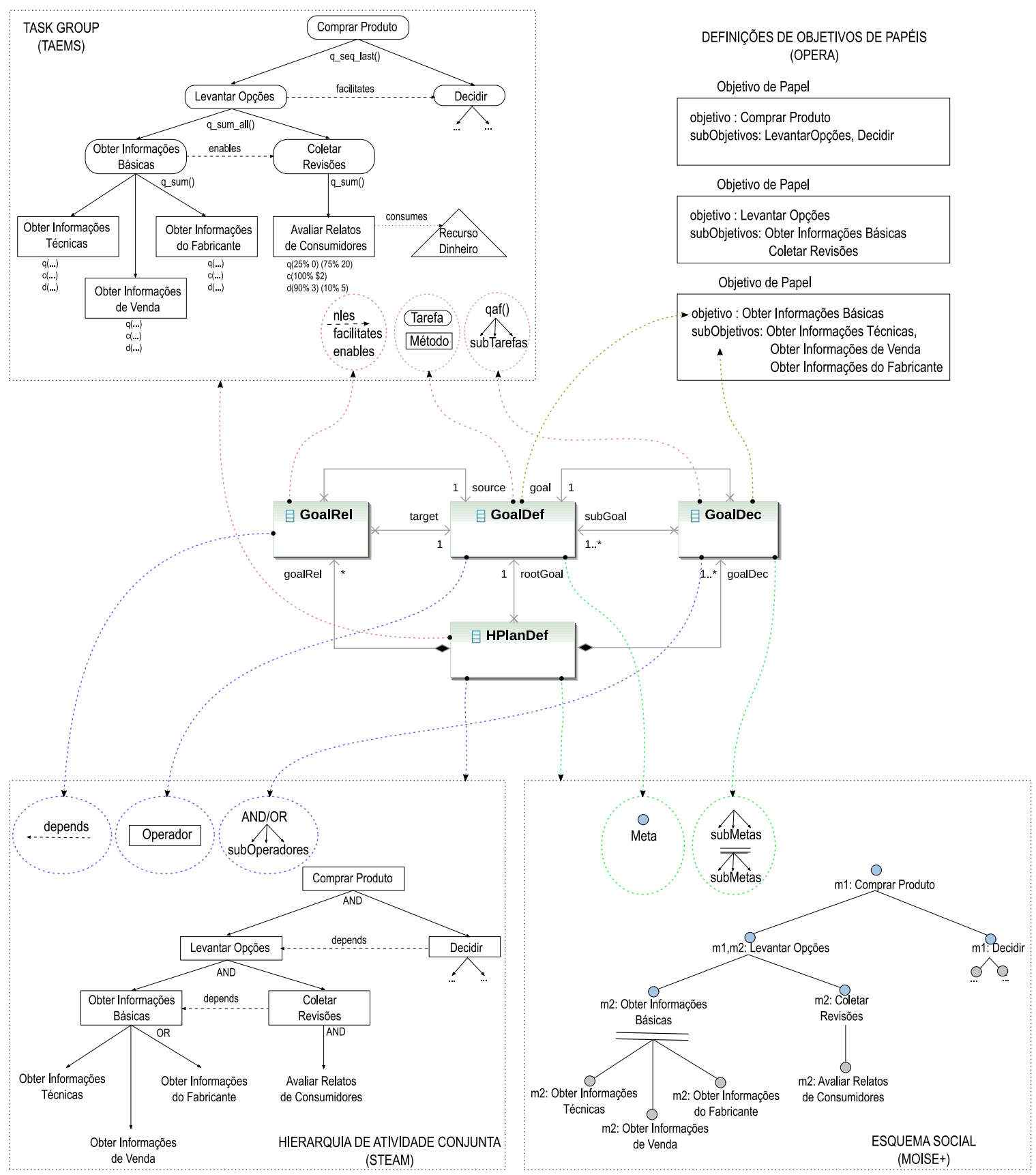

Exemplo de uma mesma especificação funcional no domínio de comércio eletrônico, mostrada inicialmente na figura 4.2, escrita em TAEMS, STEAM, MOISE+ e OPERA (sentido anti-horário). No centro, abstraindo alguns conceitos particulares e homogeneizando a terminologia empregada, apresenta-se um metamodelo Ecore que captura e integra os padrões conceituais que se identificam nas várias abordagens de especificação funcional. As setas pontilhadas de classes do metamodelo para elementos das especificações indicam como o metamodelo representa os conceitos básicos por trás das especificações particulares.

Figura 5.1: Exemplo de uma especificação funcional em TAEMS, STEAM, MOISE+ e OPERA. 
compõem o metamodelo. Já na tabela 5.2, especificam-se em OCL restrições contextuais que formalizam a semântica estática do metamodelo.

\subsubsection{Particularidades}

Além dos aspectos comuns capturados pelo padrão funcional descrito nas tabelas 5.1 e 5.2, há alguns aspectos particulares que devem ser destacados.

Em TAEMS, o mais detalhado de todos os modelos no que diz respeito à modelagem funcional, há ainda as noções de recursos e efeitos não locais entre tarefas e recursos (vide seção 4.2.1) que não se encontram representadas no padrão de modelagem funcional apresentado. A razão desta escolha é que tais conceitos só aparecem em TAEMS.

Já em MOISE+, não há a noção de relações binárias entre metas. Há, no entanto, as noções particulares de missão e preferências entre missões (vide seção 4.2.4). Estas, por não ocorrem explicitamente nos outros modelos organizacionais, também não se encontram representadas no padrão de modelagem funcional apresentado.

Em OPERA, a modelagem funcional ocorre de maneira implícita, sendo parte da definição de papéis (modelagem estrutural). Conforme já comentado ao final da seção 4.2.6, tem-se então uma modelagem funcional com poucos recursos em relação ao que se encontra em TAEMS, STEAM e MOISE+. A citação a seguir ilustra este fato:

Um objetivo $\gamma$ de papel pode ser descrito especificando-se um conjunto de subobjetivos que devem ser perseguidos para atingir o objetivo $\gamma$. Subobjetivos dão uma indicação de como um objetivo deve ser atingido, ou seja, descrevem os estados que devem ser parte de qualquer plano que um agente atuando o papel irá especificar para atingir aquele objetivo. Entretanto, subobjetivos abstraem quaisquer questões temporais que devem estar presente em um plano, e desta forma não devem ser igualado com planos.

[traduzido de (DIGNUM, 2004, p. 60-61)

Não obstante o fato de não haver a noção explícita de planos hierárquicos, pode-se ainda identificar o padrão básico de decomposição hierárquica de metas em OPERA, fazendo uma correspondência entre as noções gerais de meta e submeta com os conceito de objetivos e subobjetivos de papel.

Por fim, nota-se que os conceitos abstratos de decomposição de metas em submetas e relações binárias entre metas, admitem subtipos concretos com naturezas 


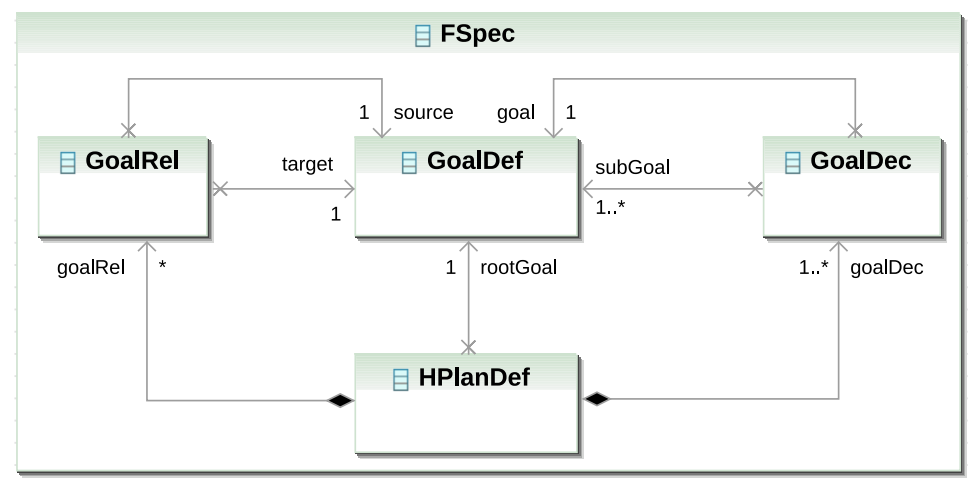

Classe Descrição

FSpec Representa o conceito de especificação funcional - i.e., especificações organizacionais restritas à dimensão funcional.

GoalDef Parte de uma especificação funcional que representa a definição de uma meta. Abstrai os conceitos de tarefa em TAEMS, operador em STEAM, meta em MOISE + , ou objetivo em OPERA.

HPlanDef Parte de uma especificação funcional que representa a definição de um grafo de planos hierárquicos e relações entre metas. Cada grafo HPlanDef é caracterizada por uma única meta raiz, a meta referenciada por rootGoal, uma ou mais decomposições de metas, referenciadas por goalDec, e zero ou mais relações entre metas, referenciadas por goalRel. Abstrai os conceitos de grupo de tarefas em TAEMS, hierarquia de atividade conjunta em STEAM, esquema social em MOISE+ e definição de objetivos de papéis em OPERA.

GoalDec Parte de um grafo HPlanDef que representa a decomposição de uma meta, a meta referenciada por goal, em uma ou mais submetas diretas, as metas referenciadas por subGoal. Abstrai os relacionamentos de subtarefas em TAEMS, o conceitos de plano em STEAM e MOISE + , e as definições de subobjetivos em OPERA.

GoalRel Parte de um um grafo HPlanDef que representa uma relação dirigida entre uma meta origem, a meta referenciada por source, e uma meta destino, a meta referenciada por target. Abstrai o conceito de efeitos não locais (habilita, desabilita, facilita, dificulta) em TAEMS e as dependências em STEAM.

Tabela 5.1: Padrão de especificação funcional: descrição das classes. 
HPlanDef : :getAllSubGoal(goal : GoalDef) : Set(GoalDef), uma consulta que retorna o conjunto de todas as submetas nas quais uma dada meta goal é direta ou indiretamente decomposta no contexto de um grafo HPlanDef, via decomposições referenciadas por HPlanDef : :goalDec.

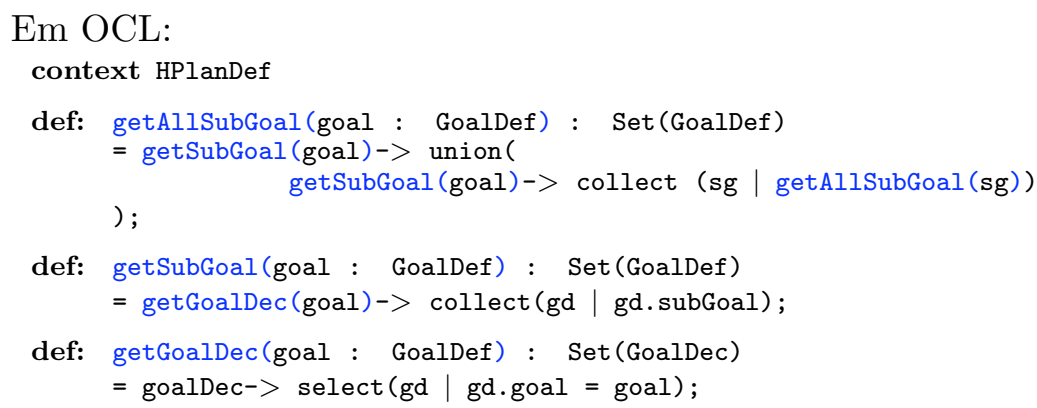

\section{Restrições Contextuais (Semântica Estática)}

(1) No contexto de um grafo HPlanDef, toda decomposição de meta em submetas deve ser atingível a partir da meta raiz. Em outras palavras, toda meta decomposta em submetas em um grafo HPlanDef ou é a própria meta raiz ou é, direta ou indiretamente, uma submeta da meta raiz.

Em OCL:

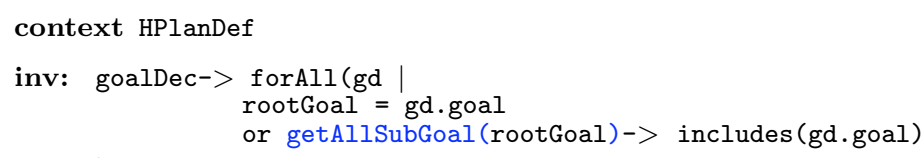

(2) No contexto de um grafo HPlanDef, toda relação entre metas deve ter a meta origem e a meta destino pertencentes à coleção de todas as submetas da meta raiz do grafo. Em outras palavras, toda relação entre metas deve envolver apenas submetas da meta raiz de um grafo HPlanDef.

Em OCL:

context HPlanDef

inv: getAllSubGoal (rootGoal) $->$ includesAll ( )

goalRel-> collect(gr | Set $\{$ gr.source, gr.target $\}$ )

(3) Levando em conta apenas a relação de decomposição de metas em submetas, todo grafo HPlanDef deve ser acíclico. Em outras palavras, no contexto de um grafo HPlanDef, nenhuma meta pode ser, direta ou indiretamente, uma submeta dela mesma.

Em OCL:

context HPlanDef

inv: not getAllSubGoal (rootGoal)-> includes (rootGoal) and getAllSubGoal (rootGoal) $>$ forAll (sg

not getAllSubGoal (sg)-> includes (sg)

Tabela 5.2: Padrão de especificação funcional: restrições contextuais. 
diversas nos modelos organizacionais analisados. Em TAEMS, por exemplo, há onze subtipos de decomposição de uma tarefa em subtarefas (vide enumeração QAF, figura 4.3) e quatro subtipos de efeitos não locais (habilita, desabilita, facilita, dificulta). Em STEAM, por outro lado, há apenas dois subtipos básicos de decomposição ( $A N D$ e $O R$ ) complementados pela relação de dependência. Em MOISE+, por sua vez, há três subtipos de decomposição de uma meta em submetas (sequência, escolha e paralelismo).

\subsection{Dimensão Estrutural}

Conforme definido na seção 4.1, na dimensão estrutural encontram-se conceitos de modelagem utilizados para especificar a estrutura interna de uma organização de agentes: a estrutura de papéis e grupos na qual os agentes devem se encaixar para fazer parte da organização.

\subsubsection{Padrão Conceitual}

Cinco modelos organizacionais analisados apresentam conceitos para criar especificações estruturais, i.e., especificações organizacionais restritas à dimensão estrutural. São eles: AGR, STEAM, MOISE+, ISLANDER e OPERA, apresentados respectivamente nas seções 4.2.2, 4.2.3, 4.2.4, 4.2.5 e 4.2.6. A partir de uma análise detida dos exemplos e metamodelos apresentados, conclui-se que as especificações estruturais desses modelos organizacionais também podem ser caracterizadas por um padrão abstrato, ilustrado na figura 5.2.

\subsubsection{Grafos de papéis e grupos}

Na dimensão estrutural, os modelos organizacionais apresentam três conceitos fundamentais: papéis, grupos e relações entre papéis. A combinação destes três conceitos forma a especificação da estrutura interna de organizações de agentes.

Em essência, pode-se representar tais conceitos através de grafos dirigidos onde:

- os nodos correspondem

- ou à definição de grupos (em AGR, MOISE+, OPERA) ou (sub)times (em STEAM),

- ou à definição de papéis (em todos os modelos); 
- os arcos representam

- ou a decomposição de um grupo em subgrupos (ou times em subtimes), formando uma hierarquia de grupos,

- ou relações binárias entre papéis,

- ou a ligação entre um papel e o grupo (ou subtime) no qual o papel pode ser desempenhado por agentes.

Com relação à hierarquia de grupos, há duas situações presentes nos modelos. Em uma, há um único grupo raiz que representa toda a organização (em STEAM, MOISE+ e OPERA). Na outra, não há explicitamente um grupo raiz (no caso de AGR). Quanto às relações binárias, em geral elas são dirigidas e, nos modelo AGR, MOISE+ e ISLANDER se subdividem em vários tipos com significados diversos.

Tais grafos de papéis e grupos recebem o nome de "hierarquia de subtimes e papéis" em STEAM, "estrutura organizacional" em AGR, "especificação estrutural" em MOISE+. Em ISLANDER, são parte da definição da "infraestrutura de diálogo". Já em OPERA, formam a "estrutura social".

\subsubsection{Metamodelo Ecore}

No centro da figura 5.2, à esquerda, representa-se o padrão conceitual identificado na dimensão estrutural por meio de um metamodelo Ecore. Na tabela 5.3, detalha-se como o metamodelo efetivamente captura o padrão identificado em seus aspectos essenciais, descrevendo-se as classes e referências entre classes, e especificando-se restrições contextuais que formalizam a semântica estática do metamodelo.

\subsubsection{Particularidades}

Além das similaridades apontadas no padrão de modelagem estrutural da tabela 5.3, os modelos organizacionais diferem em alguns pontos particulares. Há quatro pontos principais a se destacar.

O primeiro diz respeito à estrutura de grupos e subgrupos. Em STEAM e MOISE+, a definição de grupos forma efetivamente uma hierarquia, ou seja, um grafo acíclico. Por outro lado, em AGR e OPERA, não há relacionamentos explícitos entre as definições de grupos. No padrão de modelagem estrutural, este fato é traduzido da seguinte maneira: em AGR e OPERA, para toda definição 


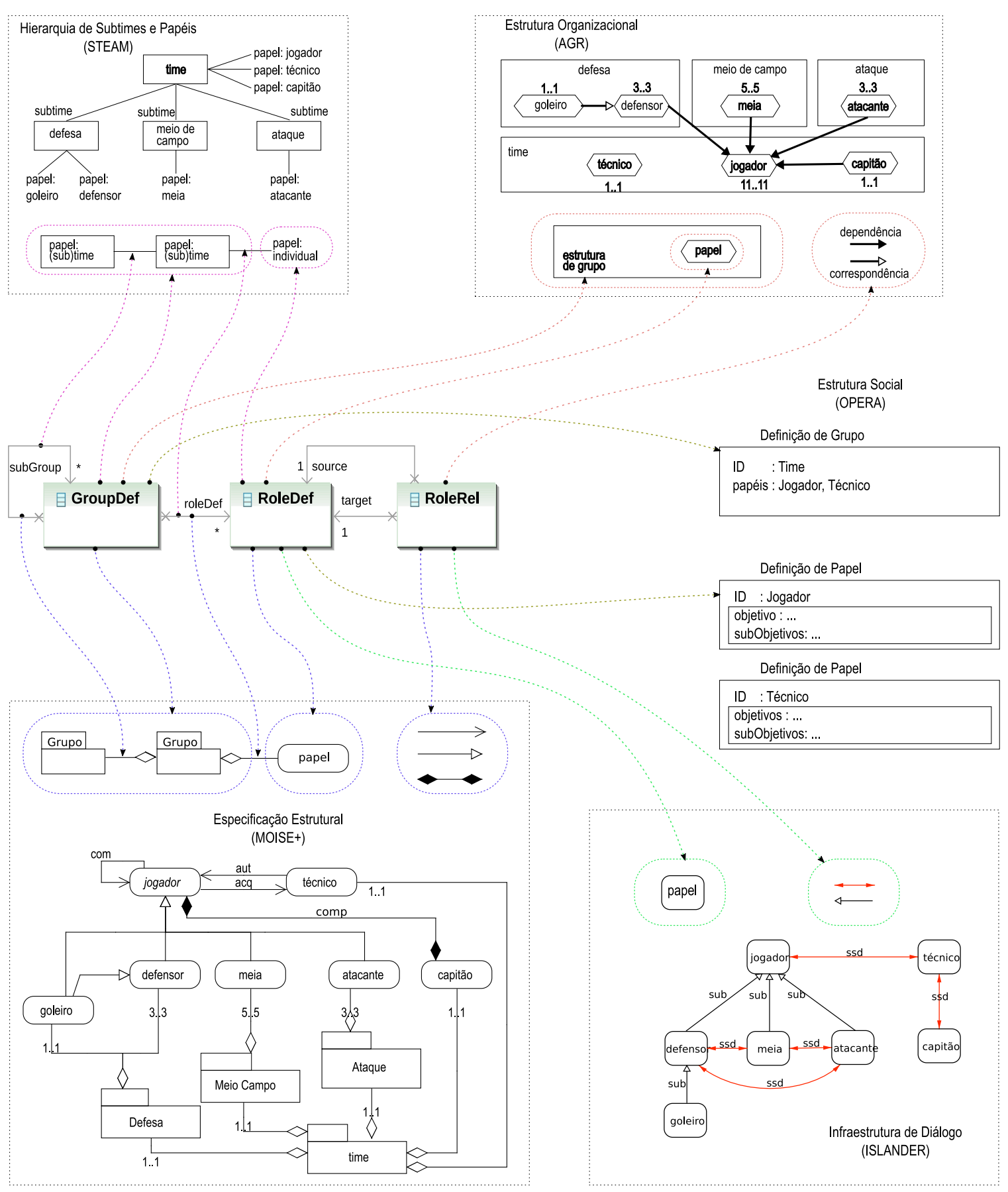

Exemplo de uma mesma especificação estrutural no domínio de futebol de robôs, mostrada inicialmente na figura 4.5, escrita em STEAM, AGR, MOISE+, ISLANDER e OPERA (sentido anti-horário). No centro, à esquerda, abstraindo alguns conceitos particulares e homogeneizando a terminologia empregada, apresenta-se um metamodelo Ecore que captura e integra os padrões conceituais que se identificam nas várias abordagens de especificação estrutural. As setas pontilhadas de classes do metamodelo para elementos das especificações indicam como o metamodelo representa os conceitos básicos por trás das especificações particulares.

Figura 5.2: Exemplo de uma especificação estrutural em STEAM, AGR, MOISE+, ISLANDER e OPERA. 


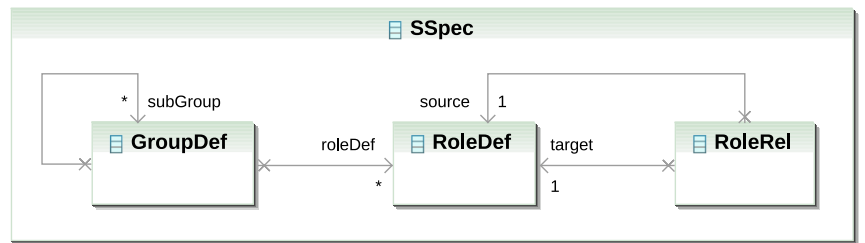

Classe Descrição

SSpec Representa o conceito de especificação estutural - i.e., especificações organizacionais restritas à dimensão estrutural.

GroupDef Parte de uma especificação estrutural que representa a definição de um grupo. Cada definição de grupo é caracterizada ou por declarações de papéis que agentes podem desempenhar em grupos criados a partir da definição, os papéis referenciados por roleDef, ou por possíveis definições de subgrupos, as definições referenciadas por subGroup, ou ambas. Abstrai os conceitos de estrutura de grupo em AGR, subtime em STEAM, especificação de grupo em MOISE+, e grupo em OPERA.

RoleDef Parte de uma especificação estrutural que representa a definição de um papel. Abstrai os conceitos de papel em AGR, MOISE+, ISLANDER e OPERA, e papel individual em STAEMS.

RoleRel Parte de uma especificação estrutural que representa uma relação dirigida entre dois papéis - um papel origem, referenciado por source, e um papel destino, referenciada por target. Abstrai o conceito de restrições entre papéis em AGR, relação entre papéis e herança em MOISE +, incompatibilidades e subpapéis em ISLANDER.

\section{Definições Auxiliares}

GroupDef $:$ :getAllSubGroup() : Set(GroupDef), uma consulta que retorna o conjunto de todas as definições de grupo que, direta ou indiretamente são subgrupos de uma instância de GroupDef via referência subGroup.

Em OCL:

context GroupDef

def: getAllSubGroup() : Set(GroupDef)

$=$ subGroup $->$ union (

);

subGroup-> collect (sg | sg.getAllSubGroup())

Restrições Contextuais (Semântica Estática)

(1) Toda definição de grupo deve ou referenciar definições de papéis ou definições de subgrupos, ou ambos.

Em OCL:

context GroupDef

inv: roleDef-> notEmpty() or subGroup-> notEmpty()

(2) Nenhuma definição de grupo pode ser, direta ou indiretamente, um subgrupo dela mesma - i.e., a definição de grupos e subgrupos deve formar um grafo dirigido acíclico.

Em OCL:

context GroupDef

inv: not self.getAllSubGroup()-> includes(self)

Tabela 5.3: Padrão de modelagem estrutural. 
de grupo g, instância de GroupDef, a coleção de subconjuntos é vazia; i.e., tem-se sempre g. subGroup $=\{\}$. Em STEAM e MOISE+, tem-se g.subGroup $\neq\{\}$.

O segundo ponto é a noção de cardinalidade, presente em AGR e MOISE+, mas não nos outros modelos. Cardinalidades podem ser definidas para papéis ou subgrupos. No caso de papéis, cardinalidades indicam um número máximo e mínimo de agentes que podem desempenhar o papel no contexto de uma definição de grupo. No caso de cardinalidades de subgrupos, presente apenas em MOISE+, elas determinam quantos subgrupos de um dado tipo podem ser criados no contexto de uma definição de grupo. Por serem essencialmente atributos das classes RoleDef e GroupDef, ou atributos das associações entre estas classes, e por não ocorrem na maioria dos modelos analisados, cardinalidades não se encontram representadas no padrão de modelagem estrutural apresentado.

Como terceiro ponto, de modo análogo às relações funcionais entre metas, observa-se que a noção abstrata de relação estrutural entre papéis admite subtipos concretos com naturezas diversas nos modelos organizacionais analisados. Em AGR, há dois subtipos: dependências e correspondências. Em MOISE+, três subtipos: ligações, compatibilidade e herança. Em ISLANDER, dois subtipos: subpapéis, similares à herança em MOISE+, e incompatibilidade, com sentido oposto da compatibilidade em MOISE+.

Em OPERA, há um único tipo de relação dirigida entre papéis: dependência. No entanto, diferentemente das relações entre papéis encontradas nos outros modelos, a relação de dependência entre papéis em OPERA não é propriamente estrutural, mas sim funcional. Em outras palavras, em OPERA, a relação de dependência reflete diretamente a decomposição de objetivos em subobjetivos, elementos da dimensão funcional. Quando um dos subobjetivos definidos no escopo de um papel é um objetivo de um outro papel, tem-se uma relação de dependência entre os dois papéis em OPERA. Tal idéia é diferente da dependência estrutural presente em AGR. Em AGR, dependência indica que desempenhar um dado papel é pré-requisito para desempenhar um outro papel.

O último ponto a ser destacado diz respeito à natureza das definições de grupo. Em todos os modelos analisados, com exceção de MOISE+, agentes desempenhando papéis em um mesmo grupo podem, a princípio, trocar mensagens entre si. Além disso, na falta de restrições explícitas, tais como incompatibilidades ou dependências entre os papéis, agentes são livres para desempenhar os papéis que quiserem em um mesmo grupo. Em MOISE+, dá-se o inverso. Se não há ligações de comunicação ou compatibilidades explícitas entre dois papéis, agentes 
pertencentes a um mesmo grupo são impedidos de se comunicar ou desempenhar mais de um papel.

\subsection{Dimensão Dialógica}

De acordo com a seção 4.1, a dimensão de modelagem dialógica é caracterizada pela especificação de estruturas de interação direta entre papéis por troca de mensagens, tendo em vista a realização das metas organizacionais.

\subsubsection{Padrão Conceitual}

Dentre os modelos analisados no capítulo anterior, apenas dois, ISLANDER e OPERA, descritos respectivamente nas seções 4.2 .5 e 4.2.6, apresentam conceitos explícitos para modelagem dialógica. Nestes modelos, as especificações dialógicas, i.e., especificações organizacionais restritas à dimensão dialógica, seguem estruturas conceituais muito parecidas, ilustradas na figura 5.3.

\subsubsection{Hipergrafos de cenas}

Em um nivel macro, tanto em ISLANDER quanto em OPERA, as interações diretas por troca de mensagem são particionadas em cenas. Cenas são coordenadas por meio de um ou mais hipergrafos dirigidos ${ }^{1}$ nos quais:

- os nodos correspondem às definições de cenas;

- os hiperarcos representam relações de ordenamento parcial e/ou sincronização entre várias cenas de origem e várias cenas de destino, dando origem ao conceito de transição entre cenas.

Em cada hipergrafo de cenas, destacam-se ainda:

- uma cena inicial, nodo a partir do qual agentes desempenhando papéis têm acesso ao hipergrafo. Partindo da cena inicial e seguindo os relacionamentos constantes entre as cenas, todas as definições de cenas que compõem um hipergrafo devem ser atingíveis;

\footnotetext{
${ }^{1}$ Um hipergrafo dirigido é uma generalização de um grafo dirigido na qual os arcos, ao invés de ligar apenas dois nodos, ligam vários nodos origem a vários nodos destinos. Formalmente, estendendo-se a definição 3.1 de (multi-)grafo dirigido, tem-se: um hipergrafo dirigido $G=\langle N, A$, orig, dest $\rangle$ caracteriza-se por funções totais orig, dest : $A \rightarrow \wp(N)$ que associam hiperarcos a subconjuntos de nodos origem e subconjuntos de nodos destino, respectivamente.
} 
- uma cena final, nodo no qual termina, com êxito, a participação dialógica de agentes no âmbito de uma organização. De modo complementar à cena inicial, deve-se poder atingir a cena final a partir de qualquer definição de cena constante em um hipergrafo. Caso contrário, o hipergrafo de cenas não se encontra bem formado.

Em ISLANDER, os hipergrafos de cenas recebem o nome de "estrutura de atuação", e em OPERA, chamam-se "estrutura de interação".

Em um nivel micro, as interações dentro de cada cena são regidas por um ou mais scripts de diálogo predefinidos. Estes correspondem aos conceitos de protocolo de cena, em ISLANDER, e padrão de interação, em OPERA. Definições de (scripts de) diálogo intra-cenas não se encontram detalhados na figura 5.3. Exemplos podem ser vistos nas figuras 4.10 e 4.13. A razão para a omissão é que as representações de interação intra-cena (nível micro) têm naturezas distintas em ISLANDER e OPERA, não apresentando uma estrutura conceitual comum, como descrito a seguir.

\subsubsection{Metamodelo Ecore}

No centro da figura 5.3, observa-se que o padrão conceitual identificado na dimensão dialógica de ISLANDER e OPERA é representado por meio de um metamodelo Ecore. Nas tabelas 5.4 e 5.5, detalha-se como o metamodelo captura, em essência, o padrão identificado.

\subsubsection{Particularidades}

No que toca à especificação dialógica, tanto em ISLANDER como em OPERA tem-se a descrição de uma rede ou fluxo de cenas na qual são previstas e orquestradas todas os possíveis ou desejáveis episódios de interação diretas entre os componentes de uma organização. Como mencionado anteriormente, esta estrutura comum dá-se em nível macro. Isto quer dizer que uma organização de agentes (padrões de atividade conjunta) sob um ponto de vista amplo, assume a forma geral dos hipergrafos de cenas apresentados.

A principal diferença entre ISLANDER e OPERA ocorre no nível micro. Em outras palavras, restringindo o ponto de vista a cada cena em particular, os modelos analisados apresentam diferentes maneiras de se especificar como agentes devem ou podem interagir. 


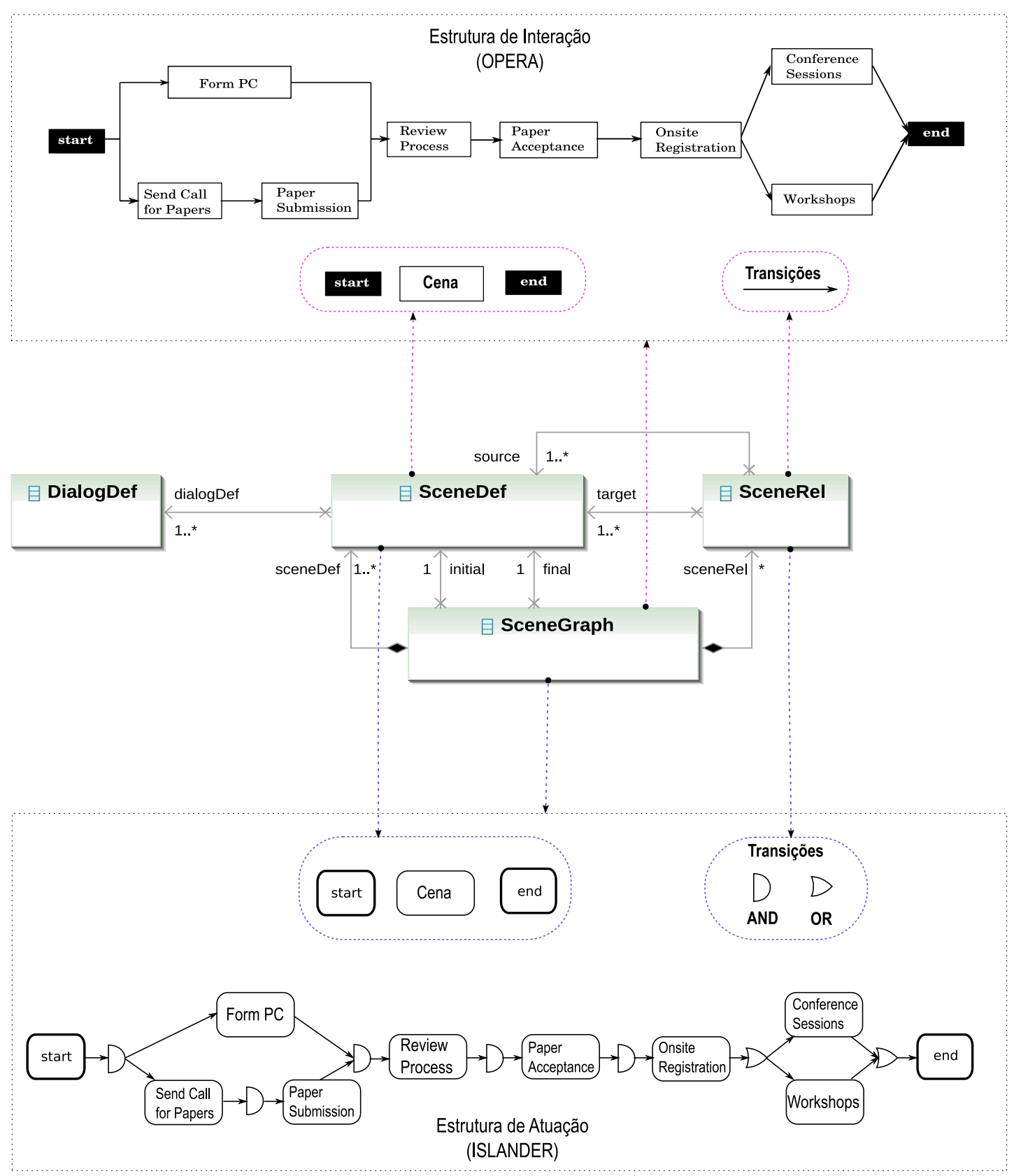

Exemplo de uma mesma especificação dialógica no domínio de gerenciamento de conferência, incialmente mostrada na figura 4.13, escrita em ISLANDER e OPERA. No centro, apresenta-se um metamodelo Ecore que representa o padrão conceitual que se identifica nas duas abordagens de especificação dialógica. As setas pontilhadas de classes do metamodelo para elementos das especificações indicam como o metamodelo representa os conceitos básicos por trás das especificações particulares.

Figura 5.3: Exemplo de uma especificação dialógica em ISLANDER e OPERA. 


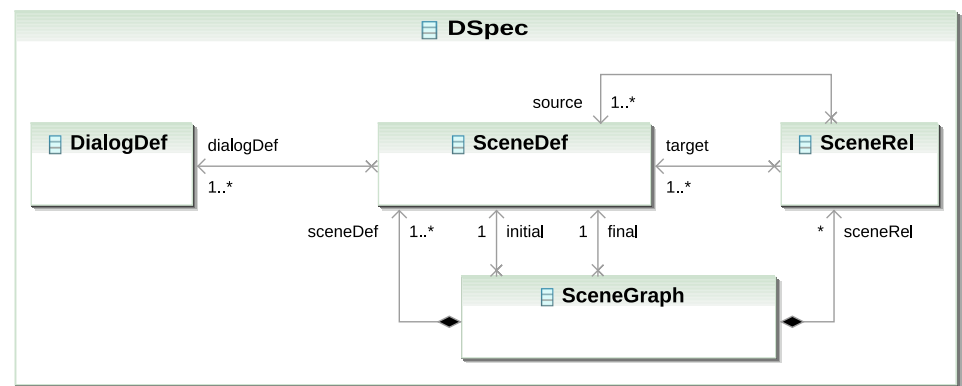

Classe Descrição

DSpec Representa o conceito de especificação dialógica - i.e., especificações organizacionais restritas à dimensão dialógica.

SceneGraph Parte de uma especificação dialógica que representa a definição de um hipergrafo de cenas. Cada hipergrafo de cenas caracteriza-se por uma ou mais definições de cenas, as definições referenciadas por sceneDef, e vários relacionamentos entre cenas, os relacionamentos referenciados por sceneRel. Além dessas referências, destacam-se uma cena inicial, cena referenciada por initial, e uma cena final, cena referenciada por final.

Abstrai os conceitos de estrutura de atuação em ISLANDER e estrutura de interação em OPERA.

SceneDef Parte de um hipergrafo de cenas que representa a definição de uma cena. Cada definição de cena é caracterizada pela declaração de um script de diálogo, via referência dialogDef.

Abstrai os conceitos de definição de cena em ISLANDER e OPERA.

SceneRel Parte de um hipergrafo de cenas que representa um relacionamento dirigido entre uma ou mais cenas de origem, as cenas referenciadas por source, e uma ou mais cenas de destino, as cenas referenciadas por target.

Abstrai os conceitos de transição entre cenas em ISLANDER e OPERA. Observa-se que, em OPERA, há sete subtipos concretos para SceneRel (DIGNUM, 2004, p. 69-70): all-targets, some-target, one-target, new-target, all-source, some-source e onesource (representados na figura 4.12, página 101, pela enumeração TransitionType). Respectivamente, os quatro primeiros subtipos em OPERA correspondem de modo exato aos subtipos em ISLANDER (ESTEVA, 2003, p. 33-37): enter-scene-all, enter-scene-some, enter-scene-one e enter-scene-new (representados figura 4.11, página 97, pela enumeração TransitionArcType). E, os três últimos, correspondem ao subtipo exit-scene combinado com os tipos de transição $A N D, O R$ e ORX (enumeração TransitionType, figura 4.11, página 97). Para detalhes, consultar as referências.

DialogDef Parte de uma especificação dialógica que representa a definição de um script de diálogo.

Abstrai os conceitos de protocolo de cena, em ISLANDER, e padrão de interação, em OPERA.

Tabela 5.4: Padrão de modelagem dialógica: descrição das classes. 
Classe Definições Auxiliares

SceneGraph Consultas OCL que, a partir de uma definição de cena, retornam as antecessoras e as sucessoras imediatas no contexto de um hipergrafo de cenas.

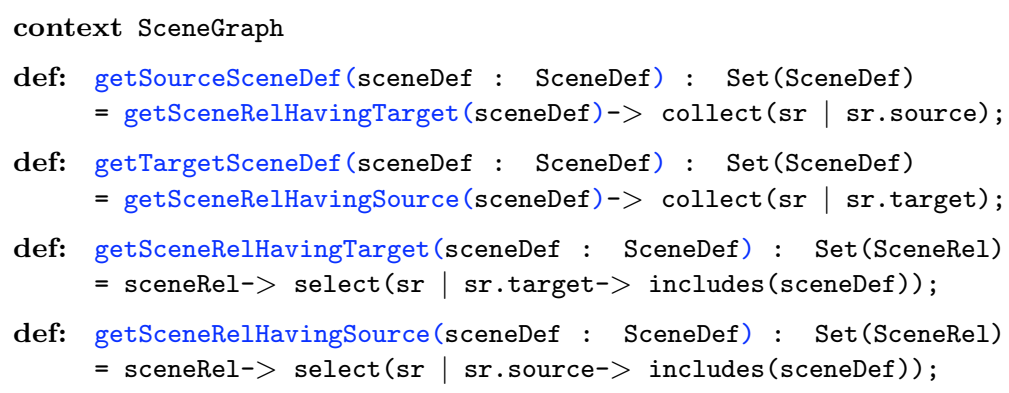

(1) As cenas inicial e final são cenas definidas no contexto de um mesmo SceneGraph. Em OCL:

context SceneGraph

inv: sceneDef-> includes(initial) and sceneDef-> includes(final )

(2) Em um SceneGraph, não deve haver relacionamentos chegando à cena inicial ou partindo da cena final. Em OCL:

context SceneGraph

inv: getSceneRelHavingTarget(initial)-> isEmpty() and getSceneRelHavingSource (final ) -> isEmpty()

(3) Em um SceneGraph, toda definição de cena deve, direta ou indiretamente, ser atingível a partir da cena inicial bem como levar à cena final, via os relacionamentos dirigidos entre as cenas. Em OCL:

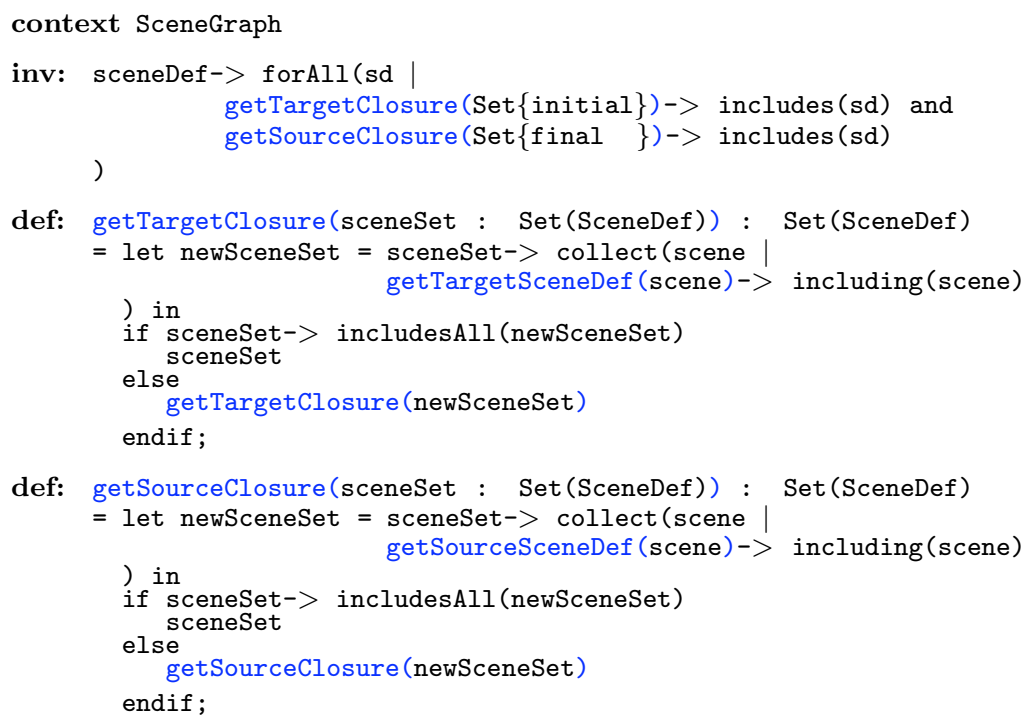

(4) Todo relacionamento dirigido entre cenas deve envolver apenas cenas definidas no contexto de um mesmo SceneGraph. Em OCL:

context SceneGraph

inv: sceneRel-> forAll (sr |

sceneDef-> includesAll (sr.source) and

sceneDef-> includesAll (sr.target)

)

Tabela 5.5: Padrão de especificação dialógica: restrições contextuais. 
Por um lado, em ISLANDER, há a noção de protocolo de cena, como exemplificado na figura 4.10. Em um protocolo de cena, descreve-se em detalhes um protocolo de comunicação. No protocolo de comunicação especificam-se todos os papéis envolvidos, e a forma e sequenciamento de todas as possíveis trocas de mensagens (por meio de esquemas de ilocução), tendo em vista a realização dos objetivos da organização. Citando (ESTEVA, 2003):

"Uma cena define um protocolo de interação para um grupo de agentes. Para definir uma cena é necessário especificar quais são os papéis participantes ..., e o protocolo de conversação. $\mathrm{O}$ protocolo de conversação é especificado por um grafo dirigido. O grafo é especificado por seus nodos, que representam estados de conversação e as conexões entre eles rotuladas com esquemas de ilocução e restrições, ou timeouts."

[Traduzido de (ESTEVA, 2003, p. 66-67)]

Por outro lado, em OPERA, há a noção de padrão de interação, como mostra o exemplo da figura 4.13. Diferentemente dos protocolos de cena, um padrão de interação não determina em detalhes quais são e como devem ocorrer as trocas de mensagens em uma dada cena. Ao invés disso, delimita-se uma ordem parcial entre estados de cena (ou landmarks) intermediários rumo à consecução dos objetivos ligados à cena. Quaisquer protocolos de comunicação detalhados, tais como os protocolos de cena de ISLANDER, devem respeitar o padrão de interação estabelecido. Citando (DIGNum, 2004):

"Em geral, scripts podem ser estrita ou fracamente [loosely] especificados. Em uma especificação estrita, a atividade dos agentes é completamente fixada como um protocolo, e a atuação do agente tem pouco espaço de variação. Muitos dos atuais SMAs são projetados desta forma, e.g. (Esteva et al., 2002b [referência ao modelo ISLANDER, (ESTEVA; PADGET; SIERRA, 2002)]). Em uma especificação fraca, a interação é descrita em termos e objetivos gerais, e os agentes são livres para interagir como quiserem. No meio destes extremos há uma faixa de possibilidades. Estados de cena [landmarks] são utilizados em OperA para descrever [padrões de interação] ..."

[Traduzido de (DIGNUM, 2004, p. 66-67)]

"Um padrão de interação descreve o modo de atingir o resultado de uma cena, como desejado pela organização. Padrões de interação dão uma indicação de como o resultado pode ser atingido, isto é, descreve os estados que devem ser parte de qualquer protocolo que enventualmente será utilizado por atores para atingir o resultado."

[Traduzido de (DIGNUM, 2004, p. 68)] 


\subsection{Dimensão Normativa}

A dimensão de modelagem normativa, como apresentada na seção 4.1, caracterizase pelo conceito geral de norma (permissões, obrigações, etc.). Normas ocorrem em especificações organizacionais como um mecanismo que interrelaciona e complementa às especificações funcional, estrutural e dialógica.

\subsubsection{Padrão Conceitual}

Três modelos organizacionais analisados apresentam conceitos para criar especificações normativas, i.e., especificações organizacionais restritas à dimensão normativa. São eles: MOISE+, ISLANDER e OPERA, apresentados respectivamente nas seções 4.2.4, 4.2.5 e 4.2.6.

\subsubsection{O conceito de Norma}

Ao contrário do que ocorre nas outras dimensões, além do conceito geral de norma, não é possível identificar um padrão claro nas especificações normativas dos modelos organizacionais analisados.

\subsubsection{Metamodelo Ecore}

Na tabela 5.6, por meio de classes Ecore, representam-se os conceitos de especificação normativa e norma.

\subsubsection{Particularidades}

Na linguagem ISLANDER, normas são escritas como expressões lógicas de acordo com o formato:

$$
\begin{gathered}
\left(s_{1}, \gamma_{1}\right) \wedge \ldots \wedge\left(s_{m}, \gamma_{m}\right) \wedge e_{1} \wedge \ldots \wedge e_{n} \wedge \\
\wedge \neg\left(\left(s_{m+1}, \gamma_{m+1}\right) \wedge \ldots \wedge\left(s_{m+n}, \gamma_{m+n}\right)\right) \rightarrow o b l_{1} \wedge \ldots \wedge o b l_{p}
\end{gathered}
$$

Em (ESTEVA, 2003), esta expressão lógica é descrita da seguinte maneira:

" $\left(s_{1}, \gamma_{1}\right), \ldots,\left(s_{m+n}, \gamma_{m+n}\right)$ são pares de cenas e esquemas de ilocução, $e_{1}, \ldots, e_{n}$ são expressões booleanas envolvendo variáveis dos esquemas de ilocução, ᄀ é a negação por falha [defeasible negation], e $o b l_{1}, \ldots, o b l_{p}$ são obrigações. O significado destas regras é que se as ilocuções $\left(s_{1}, \gamma_{1}\right), \ldots,\left(s_{m+n}, \gamma_{m+n}\right)$ foram proferidas, as expressões $e_{1}, \ldots, e_{n}$ forem satisfeitas e as ilocuções $\left(s_{m+1}, \gamma_{m+1}\right), \ldots,\left(s_{m+n}, \gamma_{m+n}\right)$ não foram proferidas, [então] as obrigações $o b l_{1}, \ldots, o b l_{p}$ valem. 


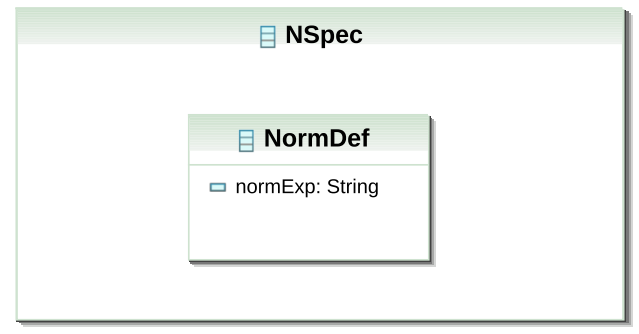

\section{Classe Descrição}

NSpec Representa o conceito de especificação normativa - i.e., especificações organizacionais restritas à dimensão normativa.

NormDef Parte central de uma especificação normativa. Representa a definição de uma norma. De modo geral, normas são caracterizadas por uma expressão normativa (atributo normExp) que se refere a elementos encontrados nas dimensões estrutural, funcional e dialógica. A forma e significado da expressão normativa varia consideravelmente nos modelos organizacionais analisados. Abstrai os conceitos de relação deôntica encontrada em MOISE+, e os conceitos particulares de norma encontrados em ISLANDER e OPERA.

Tabela 5.6: Padrão de modelagem normativa.

Para representar a noção de obrigação, define-se o predicado obl como segue:

$$
o b l(x, \psi, s)=\text { agente } x \text { é obrigado a proferir } \psi \text { na cena } s
$$

onde $\psi$ é um esquema de ilocução. Denotam-se, o conjunto de obrigações por $\mathrm{Obl}$ e qualquer obrigação concreta por $o b l_{i} \in$ Obl."

[traduzido de (ESTEVA, 2003, p. 38), ênfase nossa].

No modelo OPERA, normas são especificadas utilizando-se expressões lógicas escritas no formalismo LCR (Logic for Contract Representation). Há três modalidades de normas: obrigações, permissões e proibições. O seguinte trecho resume a sintaxe para a escrita desses modalidades (DIGNUM, 2004, p. 149):

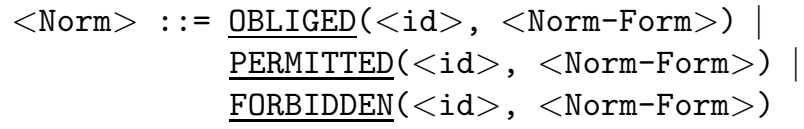

Informalmente, OBLIGED $(<\mathrm{id}>,<$ Norm-Form $>$ ) representa uma obrigação do(s) agente(s) no papel referenciado por $<$ id $>$ em atingir o estado $<$ Norm-Form $>$ descrito como uma fórmula $\mathrm{LCR}^{2}$. A partir da noção de obrigação, definem-se os conceitos de permissão e proibição. Uma permissão PERMITTED $(<\mathrm{id}>,<$ Norm-Form $>$ ) é definida como uma abreviação de $\neg$ OBLIGED ( $<$ id $>, \neg<$ Norm-Form $>$ ). Por sua vez, uma

\footnotetext{
${ }^{2}$ Para uma descrição precisa e completa de fórmulas LCR, consultar (DIGNUM, 2004).
} 
proibição $\underline{\text { FORBIDDEN }}(<\mathrm{id}>,<$ Norm-Form $>$ ) significa o mesmo que $\underline{\text { OBLIGED }}(<\mathrm{id}>, \neg$ $<$ Norm-Form $>$ ).

Por último, em MOISE+, o conceito geral de norma traduz-se em relações deônticas que ligam papéis a missões. Há dois tipos de relações deônticas: permissões e obrigações.

"Uma permissão $\operatorname{per}(\rho, m, t c)$ determina que um agente com o papel $\rho$ pode se comprometer com a missão $m$. Restrições temporais $(t c)$ são estabelecidas para a permissão, isto é, se estabelece um conjunto de períodos de tempo onde a permissão é válida ... Uma obrigação $\operatorname{obl}(\rho, m, t c)$ estabelece que um agente com o papel $\rho$ é obrigado a se comprometer com a missão $m$ nos períodos de tempos determinados em tc." (HüBNER, 2003, p. 46-47)

Neste caso, tem-se expressões normativas - $\operatorname{per}(\rho, m, t c)$ e obl $(\rho, m, t c)-$ de natureza menos abrangente do que o que se encontra em OPERA e ISLANDER.

\subsection{Considerações Finais}

Combinando-se os padrões conceituais identificados em cada uma das dimensões de modelagem organizacional, mostrados nas tabelas 5.1, 5.2, 5.3, 5.4, 5.5 e 5.6, obtém-se o metamodelo ilustrado na figura 5.4.

Na base do metamodelo, formando a dimensão estrutural, encontram-se conceitos que descrevem a estrutura interna de organizações de agentes. Acima, de modo complementar, tanto sob um enfoque dialógico quanto funcional, têm-se conceitos que representam o comportamento organizacional. Ao lado, compondo a dimensão normativa, o conceito de norma que funciona como mecanismo de regulamentação e interrelacionamento dos elementos presentes nas outras três dimensões.

Assim, de modo essencial e integrado, caracteriza-se a existência de uma estrutura conceitual comum nos modelos organizacionais analisados. Deste modo, torna-se possível construir um metamodelo organizacional integrado, que possa ser utilizado em soluções para o problema de interoperabilidade organizacional. Tal metamodelo integrado é mostrado a seguir. 


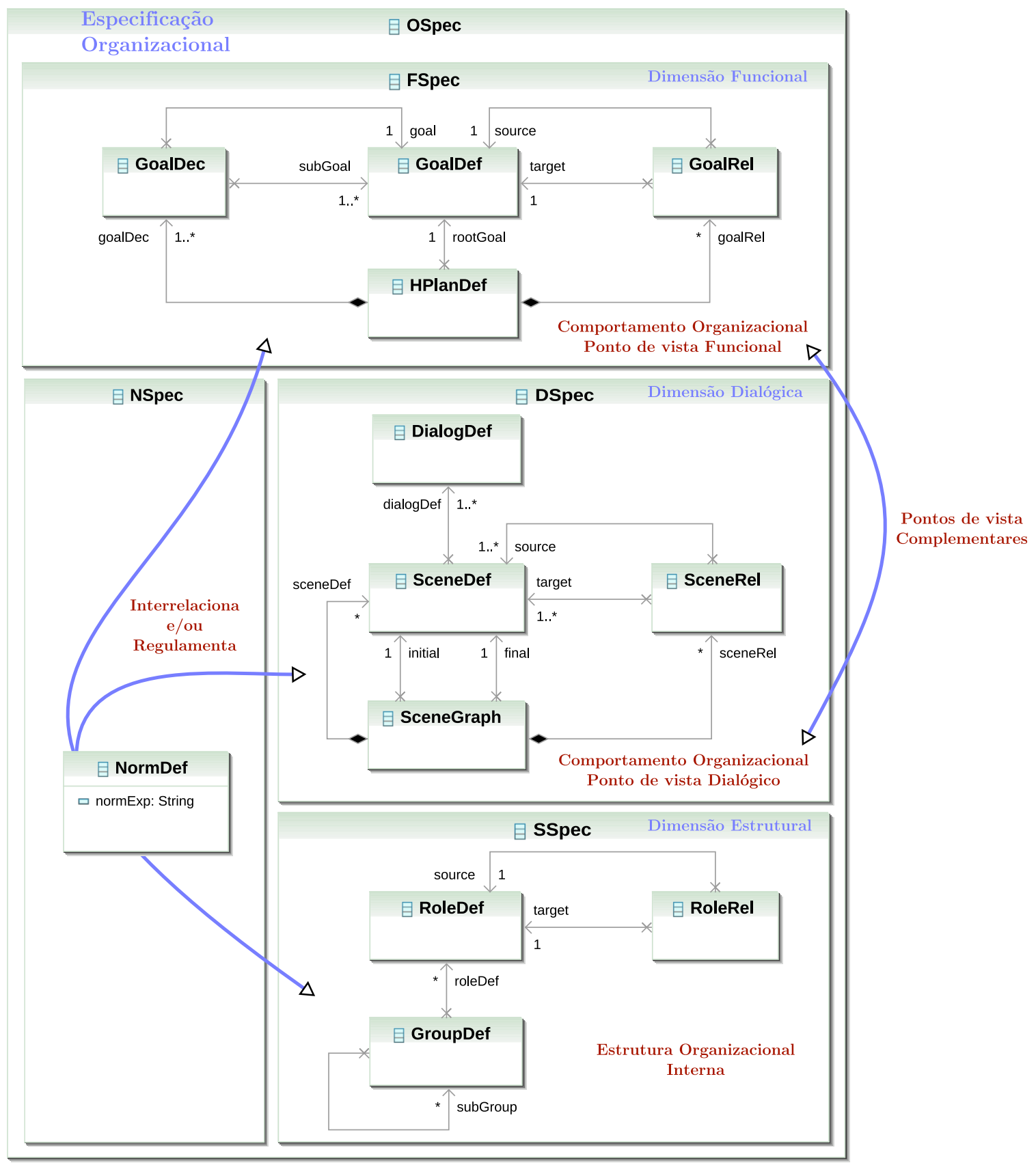

Figura 5.4: Modelo Organizacional Abstrato. 


\section{Modelo Organizacional Integrado}

Nesta tese, defende-se a idéia de que as dimensões de modelagem organizacional propostas no capítulo 4, além de úteis como balizas para a análise e comparação sistemática de modelos organizacionais, também servem como ponto de partida para a integração conceitual de modelos organizacionais. No capítulo anterior, conquanto se mostrou que, abstraindo detalhes de representação e particularidades, pode-se criar uma união consistente dos modelos organizacionais existentes, ainda não se mostrou de modo concreto como fazê-lo. Neste capítulo, apresentase (seção 6.1) e aplica-se (seção 6.2) um método de integração para realizar esta tarefa. Como resultado (seção 6.3), obtém-se um metamodelo que representa a integração conceitual de alguns dos modelos discutidos nos capítulos anteriores.

Parte dos resultados apresentados neste capítulo foi originalmente publicada em (COUTINHO et al., 2008).

\subsection{Método de Integração}

Sejam $O M_{1}, O M_{2}, \ldots, O M_{n}$, modelos organizacionais que se deseja integrar. Tendo por base as noções de (meta)modelos e integração de (meta)modelos discutidas no capítulo 3, delineia-se o seguinte método de integração iterativo.

Para $n$ modelos, são feitas $n-1$ iterações. Na primeira iteração, tomam-se $O M_{1}$ e $O M_{2}$, e realizam-se sequencialmente três etapas:

1. Criam-se metamodelos $M M_{1}$ e $M M_{2}$ que representem a estrutura conceitual de $O M_{1}$ e $O M_{2}$, respectivamente. De modo geral, os metamodelos $M M_{1}$ e $M M_{2}$ são concebidos como multi-grafos dirigidos e rotulados nos quais os nodos representam conceitos de modelagem e os arcos, relacionamentos entre conceitos (vide subseção 3.2.3.2).

2. Comparam-se os metamodelos $M M_{1}$ e $M M_{2}$ e definem-se correspondências 


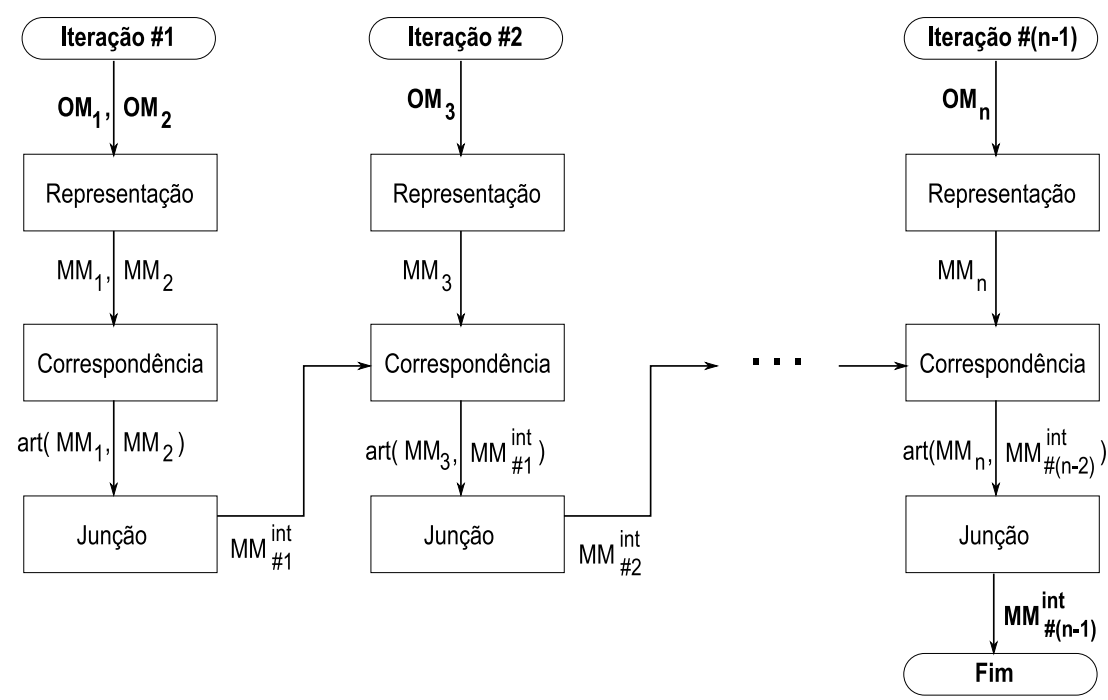

Figura 6.1: Método geral de integração.

entre as estruturas conceituais expressas por ambos. Durante a identificação de correspondências, levam-se em conta não apenas as similaridades sintáticas explícitas, mas também as similaridades semânticas implícitas entre os metamodelos. Estas últimas, conforme discutido na subseção 3.2.2, podem ser explicitadas estendendo um dos metamodelos, ou ambos, com elementos derivados. De modo geral, as correspondências identificadas são representadas como articulações $\operatorname{art}\left(M M_{1}, M M_{2}\right)$ entre os grafos subjacentes aos metamodelos $M M_{1}$ e $M M_{2}$ (vide subseção 3.2.3.3).

3. A partir de $M M_{1}, M M_{2}$ e $\operatorname{art}\left(M M_{1}, M M_{2}\right)$, produz-se um metamodelo integrado $M M_{\# 1}^{i n t}$ que subsome $M M_{1}$ e $M M_{2}$, evitando a replicação desnecessária de elementos equivalentes. De modo geral, a criação de $M M_{\# 1}^{\text {int }}$ segue o algoritmo 3.3 de junção de metamodelos descrito na subseção 3.2.3.4.

Da segunda iteração em diante, para cada modelo organizacional $O M_{2<i \leq n}$, realizam-se as mesmas três etapas da primeira iteração com as seguintes diferenças:

1. No lugar de $M M_{1}$ e $M M_{2}$ têm-se $M M_{i}$ e $M M_{\#(i-2)}^{i n t}$, respectivamente; $M M_{i}$ consiste em um metamodelo criado para representar a estrutura conceitual do modelo organizacional $O M_{i}$, e $M M_{\#(i-2)}^{i n t}$ é o metamodelo integrado gerado na iteração anterior;

2. No lugar de $\operatorname{art}\left(M M_{1}, M M_{2}\right)$ define-se $\operatorname{art}\left(M M_{i}, M M_{\#(i-2)}^{\text {int }}\right)$, i.e., a articulação dos grafos subjacentes a $M M_{i}$ e $M M_{\#(i-2)}^{\text {int }}$;

3. No lugar de $M M_{\# 1}^{i n t}$ produz-se $M M_{\#(i-1)}^{i n t}$, i.e., o metamodelo integrado resultante da junção de $M M_{i}$ ao metamodelo integrado $M M_{\#(i-2)}^{i n t}$ da iteração 
anterior, dada a $\operatorname{art}\left(M M_{i}, M M_{\#(i-2)}^{\text {int }}\right)$.

Na figura 6.1, ilustra-se o método de integração delineado.

Na primeira etapa, os modelos organizacionais são representados concretamente por metamodelos escritos em Ecore/OCL, conforme já mencionado e amplamente realizado nos capítulos anteriores.

Na segunda etapa, inerentemente heurística (MELNIK, 2004; BERNSTEIN, 2003), propõe-se a utilização da noção de dimensões de modelagem organizacional como base para a definição de correspondências entre modelos organizacionais. A idéia é dividir o trabalho a partir das dimensões de modelagem. Primeiro, determinam-se a natureza e extensão de cada modelo organizacional, situando seus conceitos de modelagem em uma ou mais dimensões. Em seguida, para cada dimensão coberta pelos modelos, determinam-se as correspondências. Assim, comparam-se os conceitos de modelagem funcional de um modelo com os conceitos funcionais do outro, os conceitos estruturais com conceitos estruturais, etc. Como guia de comparação, utilizam-se como base os padrões conceituais especificados no capítulo 5 .

Ressalta-se que tanto a primeira quanto a segunda são etapas realizadas manualmente. A justificativa é que estas são etapas criativas, no caso da primeira, ou heurísticas, no caso da segunda. Já a terceira etapa, sendo mecânica, pode ser completamente automatizada pelo algoritmo de junção utilizado.

Abaixo, especifica-se o método de integração de modelos organizacionais na forma de um algoritmo.

\section{Algoritmo 6.1 Integração de Modelos Organizacionais}

- entrada: $n$ modelos organizacionais $O M_{1}, O M_{2}, \ldots, O M_{n}$;

1. crie $M M_{A}:=$ metamodelo de $O M_{1}$;

2. para $i:=1$ até $n-1$ faça

(a) crie $M M_{B}:=$ metamodelo de $O M_{i+1}$;

(b) defina $\operatorname{art}\left(M M_{A}, M M_{B}\right):=\left\langle G^{\text {art }}, m_{\text {art }, A}, m_{\text {art }, B}\right\rangle$;

(c) gere $M M_{\# i}^{\text {int }}:=M M_{A} \oplus_{\operatorname{art}\left(M M_{A}, M M_{B}\right)} M M_{B}$;

(d) faça $M M_{A}:=M M_{\# i}^{\text {int }}$;

3. retorne $M M_{\#(n-1)}^{i n t}$. 


\subsection{Aplicação do Método}

Nesta seção, o método de integração proposto é aplicado para integrar conceitualmente os modelos AGR, STEAM, MOISE+ e ISLANDER. Dado que a motivação básica por trás da integração de modelos organizacionais é o problema de interoperabilidade organizacional, o critério básico por trás dessa escolha de modelos é a possível implementação de organizações de agentes a partir de especificações organizacionais escritas nos modelos. Como apenas AGR, STEAM, MOISE+ e ISLANDER se encontram associados a infraestruturas organizacionais, conforme descrito na seção 2.3.3, neste capítulo investe-se na integração desses modelos.

Na sequência, realizam-se três iterações do método de integração. Na primeira iteração (subseção 6.2.1), integram-se os modelos organizacionais AGR e STEAM. Na segunda iteração (subseção 6.2.2), acrescenta-se o modelo MOISE+ à integração anterior. Na terceira e última iteração (subseção 6.2.3), adiciona-se o modelo ISLANDER. Ao final (seção 6.3), obtém-se como resultado um metamodelo que integra as estruturas conceituais dos modelos organizacionais AGR, STEAM, MOISE+ e ISLANDER.

\subsubsection{Primeira Iteração}

Na primeira iteração, comparam-se e juntam-se as estruturas conceituais AGR e STEAM, produzindo o metamodelo integrado $M M_{\# 1}^{\text {int }}$.

\subsubsection{Etapa 1: Representação}

A representação de AGR e STEAM por meio de metamodelos Ecore foi previamente realizada no capítulo 4 , como mostram respectivamente as figuras 4.4 e 4.7 .

\subsubsection{Etapa 2: Correspondências}

Com o auxílio da tabela 4.1, observa-se que os conceitos de modelagem de AGR situam-se apenas na dimensão estrutural. Por outro lado, STEAM estende-se pelas dimensões estrutural e funcional. Logo, as possíveis correspondências entre os dois modelos limitam-se ao contexto da dimensão estrutural. 


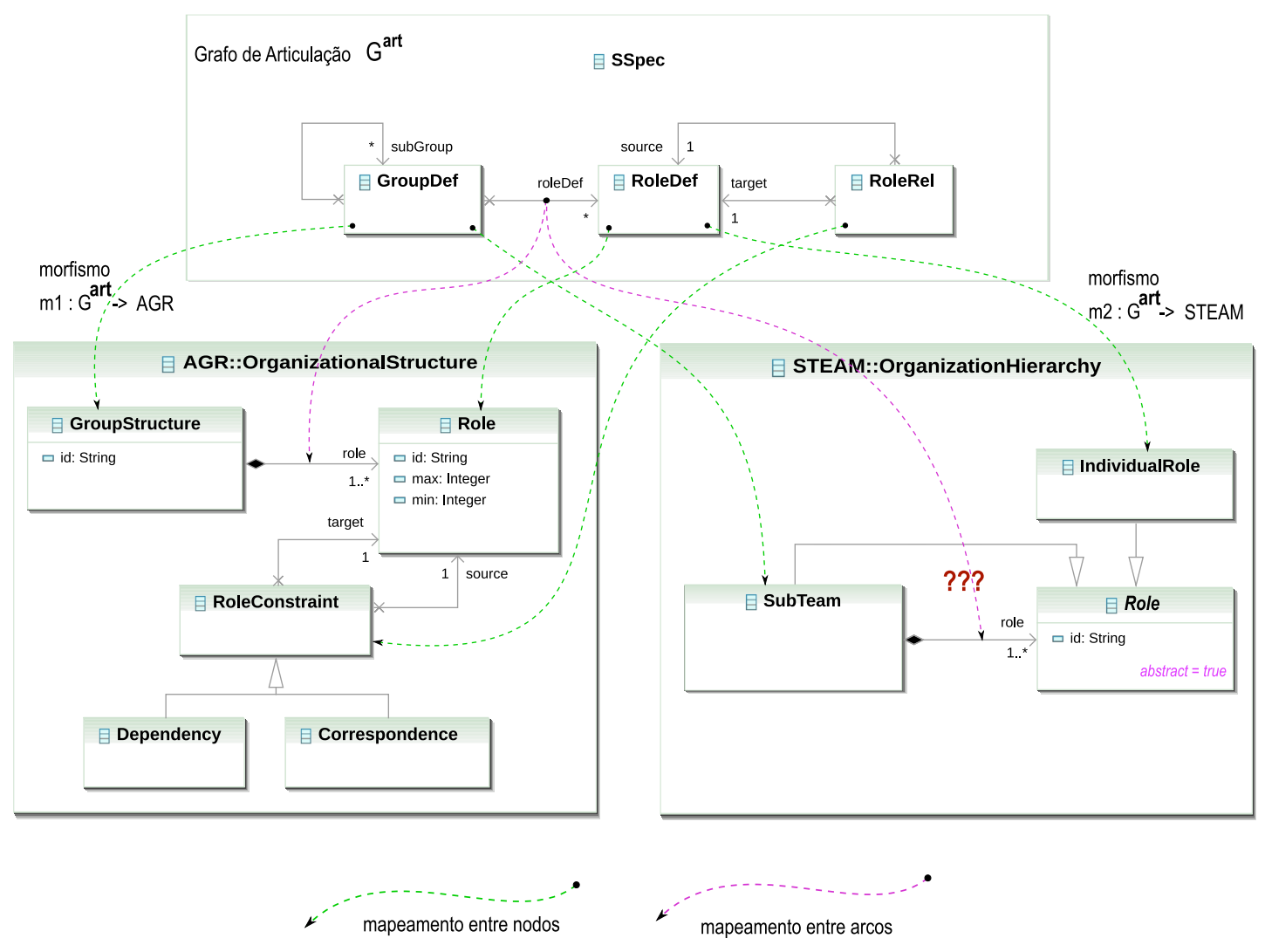

Figura 6.2: Comparação entre as especificações estruturais de AGR e STEAM.

\section{Comparação inicial entre as especificações estruturais}

Nesse contexto, a estrutura organizacional em AGR e a hierarquia de subtimes e papéis em STEAM são identificadas como especificações similares. Conforme discutido na seção 5.2, observa-se que ambas são variações da noção de especificação estrutural. Assim, tendo por base o padrão de modelagem estrutural descrito na tabela 5.3, apresenta-se na figura 6.2 uma comparação inicial entre as especificações estruturais de AGR e STEAM.

Na comparação, destacam-se os seguintes pontos:

- as classes AGR::GroupStructure e STEAM: :SubTeam são definidas como correspondentes, ambas identificadas com o conceito de definição de grupo, classe GoupDef;

- as classes AGR::Role e STEAM: :IndividualRole são definidas como correspondentes, ambas identificadas com o conceito de definição de papel, classe RoleDef; e

- a classe AGR: :RoleConstraint é identificada com o conceito de relação binária dirigida entre papéis, classe RoleRel, não havendo uma correspondente em STEAM. 
De modo geral, essas correspondências são previstas na descrição do padrão de modelagem estrutural.

De modo específico, i.e., levando em conta os detalhes de representação dos metamodelos de AGR e STEAM utilizados, nota-se um ponto problemático nesta identificação inicial de correspondências entre classes. O problema surge quando se tenta identificar, em STEAM, a correspondente da referência roleDef * entre GroupDef e RoleDef. A uma primeira vista, pode-se pensar em mapear roleDef * para a referência role $1 \ldots *$ entre STEAM: SubTeam e STEAM: :Role. No entanto este mapeamento não é consistente. O motivo é que a classe RoleDef, alvo da referência roleDef *, não se encontra mapeada diretamente para a classe STEAM: : Role, alvo da referência role $1 \ldots *$, mas sim para a subclasse STEAM: : IndividualRole (na figura 6.2, essa correspondência problemática é indicada pelos três pontos de interrogação).

Para sanar esse problema, a solução é identificar STEAM: :Role como sendo a correspondente do conceito de definição de papel, e não STEAM: : IndividualRole. Por um lado, esta mudança de interpretação resolve o problema da referência roleDef *. Por outro lado, ela leva a um acoplamento forte entre os conceitos de definição de grupo e definição de papel, conforme se pode observar no modelo STEAM.

Em STEAM, a noção de papel é definida da seguinte maneira:

"Um papel é uma especificação abstrata de um conjunto de atividades que um indivíduo ou um subtime assume a serviço da atividade geral do time. Assim, um papel restringe um membro de um time $v i$ (ou um subtime $\Omega$ ) a alguns suboperadore(s) $o p_{v i}$ do operador do time $[\mathrm{OP}]_{\Theta} . "$

[Traduzido de (TAMBE, 1997, p. 99)].

Em outras palavras, em STEAM, a noção de papel é abstrata, materializandose tanto na especificação de atividades para grupos de agentes como um todo (papéis de subtimes), quanto na especificação de atividades a cargo de agentes individuais (papéis individuais). Devido a isto, no metamodelo de STEAM proposto, o conceito de papel é representado por uma classe abstrata, a classe STEAM: :Role, com dois subtipos concretos, as classes STEAM::IndividualRole e STEAM : : SubTeam.

Em suma, do fato de STEAM: :SubTeam ser uma especialização de STEAM: :Role, decorre que cada instância de STEAM: :SubTeam, além de corresponder a uma definição de grupo, também consiste em uma definição de papel. Assim, ao se mapear diretamente GroupDef para STEAM: :SubTeam e RoleDef para STEAM::Role, 
indiretamente adota-se a visão acoplada de STEAM a respeito dos conceitos de definição de grupo e definição de papel.

\section{Substituição de herança por delegação}

Tendo em vista a separação dos conceitos de definição de grupo e definição de papel, uma possibilidade é substituir o relacionamento de generalização (herança) entre STEAM: :SubTeam e STEAM: :Role por uma referência parte-de (composição) ao se definir a articulação entre AGR e STEAM.

Na figura 6.3, mostra-se uma segunda comparação entre as especificações estruturais de AGR e STEAM na qual adota-se esta estratégia. Observa-se que entre as classes GroupDef e RoleDef, além de roleDef *, define-se uma nova referência supRoleDef 0..1. A idéia básica é utilizar supRoleDef como uma similar da generalização entre STEAM: : SubTeam e STEAM : :Role, fazendo cada instância de STEAM: : SubTeam corresponder a uma instância de GroupDef que contem (ao invés de ser) uma instância de RoleDef. Como AGR: :GroupStructure não compartilha esta característica com STEAM : SubTeam, tem-se a cardinalidade 0..1 para supRoleDef.

No projeto de software orientado a objetos, esta idéia consiste no refatoramento de classes conhecido como "substituição de herança por delegação" (FOWLER, 1999, p. 352). Este refatoramento tem por base o princípio de favorecer a composição de objetos, no lugar da herança entre classes, como meio de promover uma maior reutilização de classes (GAMMA et al., 1994, p. 20).

\section{Referências e atributos derivados}

Na figura 6.3, nota-se que a nova referência supRoleDef 0 . .1 é mapeada para uma referência derivada ${ }^{1}$ de mesmo nome, mas com cardinalidade 1 , no metamodelo de STEAM. A derivação de supRoleDef 1 é especificada pela invariante ST1, contexto STEAM: :SubTeam. Na invariante ST1, para cada instância de STEAM: :SubTeam, determina-se que supRoleDef deve apontar para a própria instância convertida a uma instância de STEAM: :Role. A este respeito, nota-se que o prefixo sup é uma alusão à referência super encontrada em algumas linguagens de programação orientadas a objeto, tais como Java. De modo similar a super, supRoleDef é uma referência que reflete a generalização entre classes STEAM: :SubTeam e STEAM : :Role.

Além de supRoleDef 1, há duas outras referências derivadas na figura 6.3: roleDef $*$ e subGroup *. A estas, mapeiam-se as referências homônimas envol-

\footnotetext{
${ }^{1}$ Seguindo a convenção introduzida no capítulo 3, para dar destaque, elementos derivados são desenhados na cor azul.
} 


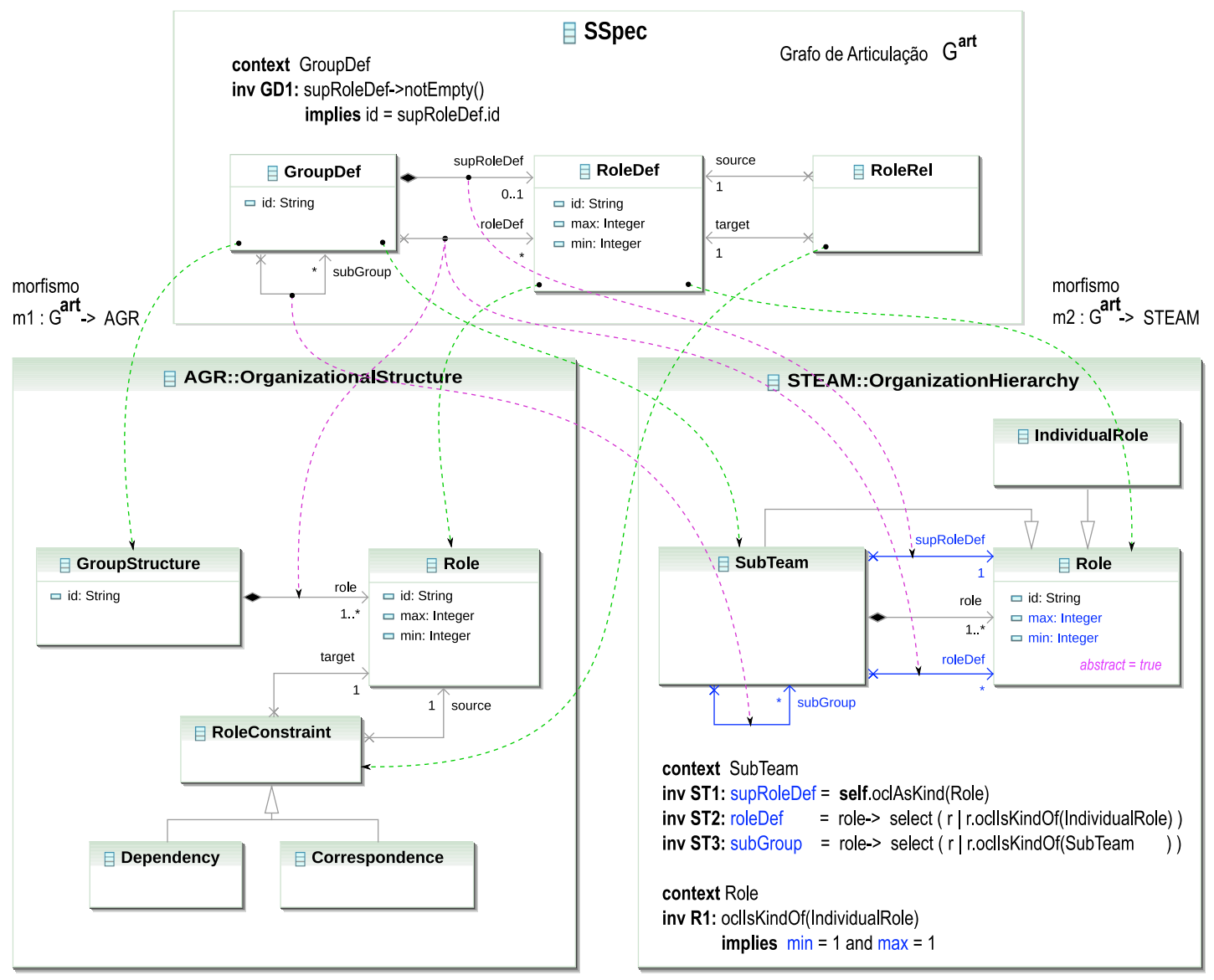

Figura 6.3: Elementos derivados na especificação estrutural de STEAM. 
vendo as classes GroupDef e RoleDef do grafo de articulação. Tanto roleDef * quanto subGroup * são derivadas a partir da referência role $1 \ldots *$ existente entre STEAM: : SubTeam e STEAM : :Role.

De início, identificou-se que roleDef deveria corresponder a role. No entanto, como a classe STEAM : :Role subdivide-se nas subclasses STEAM: :IndividualRole e STEAM : : SubTeam, observa-se que não apenas roleDef mas também subGroup são referências materializadas em STEAM por meio de role. Para tornar explícita esta constatação, estende-se o metamodelo de STEAM com a derivação de roleDef e subGroup a partir de role.

A derivação de roleDef * é caracterizada pela invariante ST2, definida no contexto de STEAM: :SubTeam. Determina-se que, para obter roleDef, selecionamse somente as instâncias do tipo STEAM: : IndividualRole dentre todas as que são referenciadas por role. O motivo da exclusão de STEAM: SubTeam é que apenas STEAM: IndividualRole consiste em definições de papéis no sentido de especificação de atividades a cargo de agentes individuais. Este é o sentido de papel adotado em AGR, motivo da correspondência feita inicialmente entre AGR: Role e STEAM: : IndividualRole.

A derivação de subGroup * é caracterizada pela invariante ST3, contexto STEAM: :SubTeam. De modo complementar à ST2, especifica-se que subGroup é obtida selecionando-se apenas as instâncias do tipo STEAM: : SubTeam dentre todas as instâncias referenciadas por role.

Finalizando a comparação entre AGR e STEAM quanto à especificação estrutural, observa-se um importante detalhe: há cardinalidades implícitas em STEAM: : IndividualRole que não devem ser perdidas quando RoleDef é mapeada diretamente para STEAM: Role. De fato, o conceito de papel individual em STEAM admite apenas um único agente por papel (vide referência agente 1, da classe STEAM: : IndividualRole para STEAM: :Agent, figura 6.4). Comparando com AGR, cada instância de STEAM: : IndividualRole equivale a uma instância de AGR: :Role com cardinalidades $\min =1 \mathrm{e} \max =1 . \mathrm{E}$, de modo inverso, cada instância de AGR: :Role como cardinalidade $\max =n$ equivale a $n$ instâncias de STEAM: : IndividualRole. Esta comparação leva à derivação dos atributos max : Integer e min : Integer para a classe STEAM: Role, conforme especificado pela invariante $\mathrm{R} 1$.

Desta forma, acrescentam-se os atributos atributos max : Integer e min : Integer à classe RoleDef do grafo de articulação. Estes são mapeados para os 


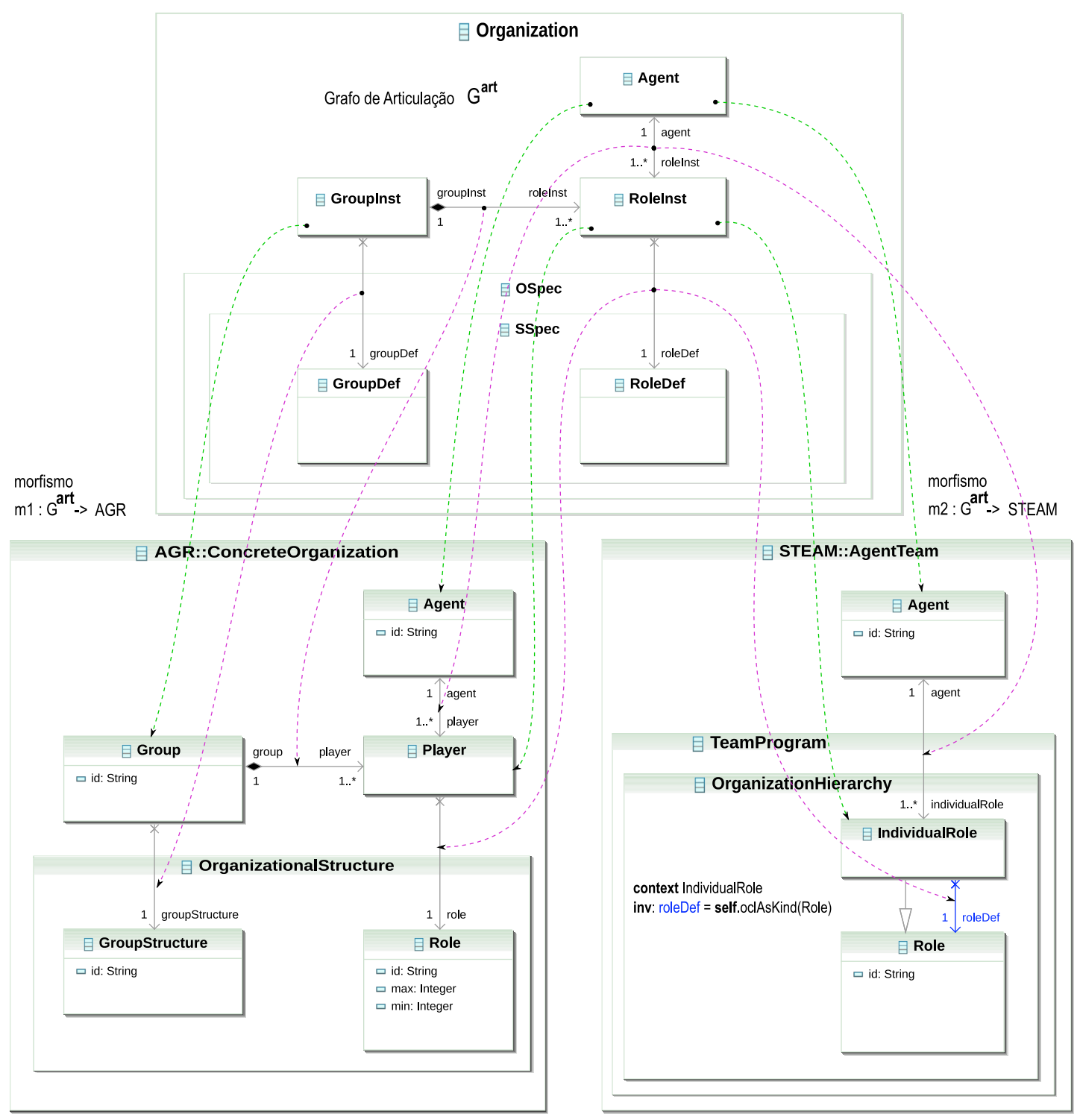

Figura 6.4: Comparação entre as estados organizacionais de AGR e STEAM.

atributos de mesmo nome nas classes correspondentes AGR: :Role e STEAM: : Role ${ }^{2}$.

\section{Comparação entre os estados organizacionais}

Ainda na dimensão estrutural, os metamodelos de AGR e STEAM podem também ser comparados quanto à modelagem de estados de uma organização de agentes. Esta comparação é ilustrada na figura 6.4.

Explicitamente, o metamodelo de AGR apresenta três classes: AGR: : Agent, AGR: :Group e AGR: :Player. Por sua vez, o metamodelo de STEAM conta apenas com a classe STEAM: :Agent. Assim, o mapeamento óbvio é definir as clas-

\footnotetext{
${ }^{2}$ Neste capítulo, na representação gráfica de articulações, omitem-se os mapeamentos entre atributos (e de algumas referências) correspondentes. Isto minimiza o problema de diagramas de articulação sobrecarregados com setas. Adota-se então a seguinte convenção: possuindo o mesmo nome, atributos e referências contidos por classes correspondentes, também são correspondentes.
} 
ses AGR: : Agent e STEAM: : Agent como correspondentes. Ambas representam um agente que, em um dado momento, participa de uma organização. As outras clasSes AGR: :Group e AGR: :Player não têm correspondentes explícitas em STEAM. AGR: :Player representa a ligação entre um agente e um papel, no contexto de um grupo. AGR: :Group representa o estado corrente de um grupo criado conforme uma dada definição de grupo. Visando uniformizar os nomes de classes, na articulação, AGR: :Group é renomeada para GroupInst (instância de grupo) e AGR: : Player para RoleInst (instância de papel).

Para evitar redundância na junção final dos dois metamodelos, nota-se um pequeno ajuste a ser feito. Em AGR, a relação entre um agente e os vários papéis que este assume em uma organização, é intermediada por AGR: :Player. Por outro lado, em STEAM, há uma associação direta entre agentes e papéis. Assim, caso RoleInst não seja mapeada para uma corresponde em STEAM, a junção irá conter a mesma informação via uma classe e uma associação.

Há duas maneiras de se evitar a redundância levando ao mesmo resultado final. A primeira é reificar a associação entre STEAM: :Agent e STEAM: :Role por meio de uma classe derivada a qual se mapeia RoleInst. A segunda é desacoplar STEAM: : IndividualRole de STEAM : :Role, fazendo a substituição de herança por delegação, e mapear RoleInst a STEAM: IndividualRole. Observando que STEAM: : IndividualRole, em realidade, tanto especifica um papel quanto determina um único agente que o realiza, adota-se a segunda alternativa na figura 6.4.

\subsubsection{Etapa 3: Junção}

A figura 6.5 resume em um único diagrama de articulação as comparações efetuadas entre os metamodelos de AGR e STEAM. No diagrama de articulação, com exceção dos atributos, explicitam-se todos os mapeamentos entre os elementos do grafo de articulação $G^{\text {art }}$ e elementos dos metamodelos de AGR e STEAM. Os mapeamentos entre $G^{\text {art }}$ e o metamodelo de AGR, e $G^{\text {art }}$ e o metamodelo de STEAM, formam os morfismo $m_{1}: G^{\text {art }} \rightarrow$ AGR e $m_{2}: G^{\text {art }} \rightarrow$ STEAM, respectivamente. A tripla $\left\langle G^{\text {art }}, m_{1}, m_{2}\right\rangle$ constitui a articulação $\operatorname{art}($ AGR, STEAM) a ser utilizada na etapa de junção dos metamodelos.

\section{Rotulações de cor}

Além dos metamodelos (grafos rotulados) e da articulação, a entrada do algoritmo de junção (subseção 3.2.3.4) admite rotulações de cores. Assim, antes de realizar a junção, convém destacar a definição das rotulações de cor para os metamodelos 


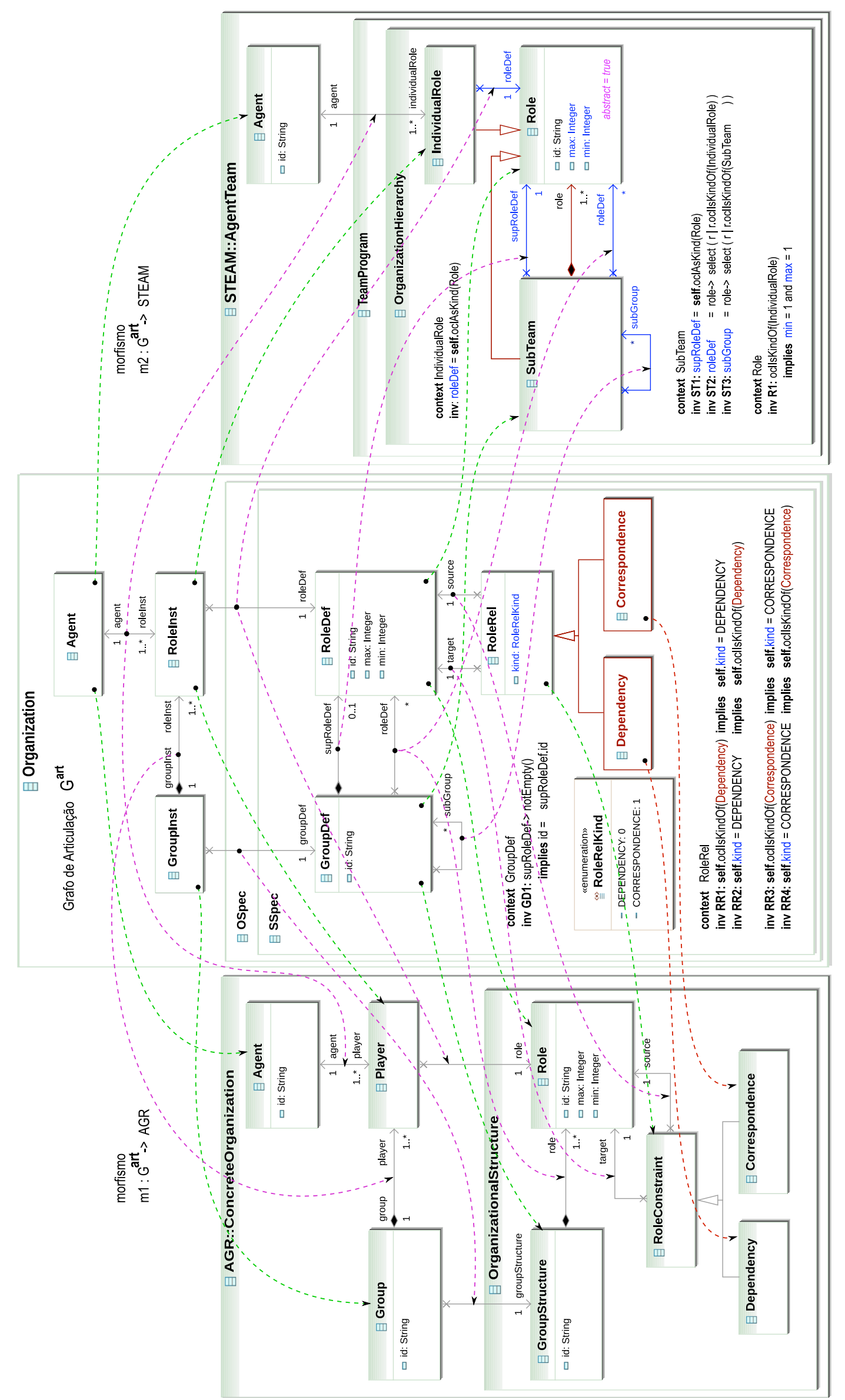

Figura 6.5: Articulação entre metamodelos de AGR e STEAM. 
de AGR e STEAM, e o grafo de articulação G ${ }^{\text {art }}$ da figura 6.5.

No metamodelo de STEAM, os seguintes elementos são rotulados com vermelho ${ }^{3}$ :

- a generalização entre STEAM: :SubTeam e STEAM: :Role - conforme já discutido, esta generalização é substituída pela referência supRoleDef 1;

- a generalização entre STEAM : IndividualRole e STEAM : :Role - conforme já discutido, substituída pela referência roleDef 1;

- a referência role $1 \ldots *$ entre STEAM: :SubTeam e STEAM: :Role - conforme já discutido, dividida nas referências roleDef $*$ e subGroup $*$.

No grafo de articulação, têm-se duas classes rotuladas com vermelho: as classes Dependency e Correspondence (ambas discutidas a seguir). Por fim, no metamodelo de AGR, nenhum elemento é rotulado diretamente com vermelho.

\section{Substituição de subclasses por enumeração}

Como se pode observar na figura 6.5, no grafo de articulação final, além dos elementos já discutidos, definem-se ainda as classes Dependency e Correspondence, a enumeração RoleRelKind e o atributo kind : RoleRelKind. Dependency e Correspondence são definidas como subclasses de RoleRel que mapeiam as homônimas encontradas em AGR. A enumeração RoleRelKind é formada pelos literais DEPENDENCY e CORRESPONDENCE. O atributo kind é definido no contexto da classe RoleRel conforme especificado pelas invariantes RR1, RR2, RR3 e RR4. As invariantes RR1 e RR2 determinam que self.kind = DEPENDENCY se, e somente se, self é uma instância da subclasse Dependency. Da mesma forma, RR3 e RR4 especificam que self.kind $=$ CORRESPONDENCE se, e somente se, self é instância de Correspondence.

Dado que Dependency e Correspondence são rotuladas com vermelho, notase que o objetivo é excluí-las da integração conceitual de AGR e STEAM. No lugar, a idéia é utilizar o atributo kind : RoleRelKind, como indicam as invariantes RR1, RR2, RR3 e RR4. A razão para esta substituição de subclasses por uma enumeração é que AGR: :Dependency e AGR: Correspondence não acrescentam atributos ou referências à superclasse AGR: : RoleConstraint (correspondente de RoleRel). Logo, podem ser representadas de modo mais compacto por um atributo kind acrescentado à superclasse.

\footnotetext{
${ }^{3}$ Relembrando: no algoritmo utilizado, a cor vermelha indica elementos a serem desconsiderados durante a junção.
} 


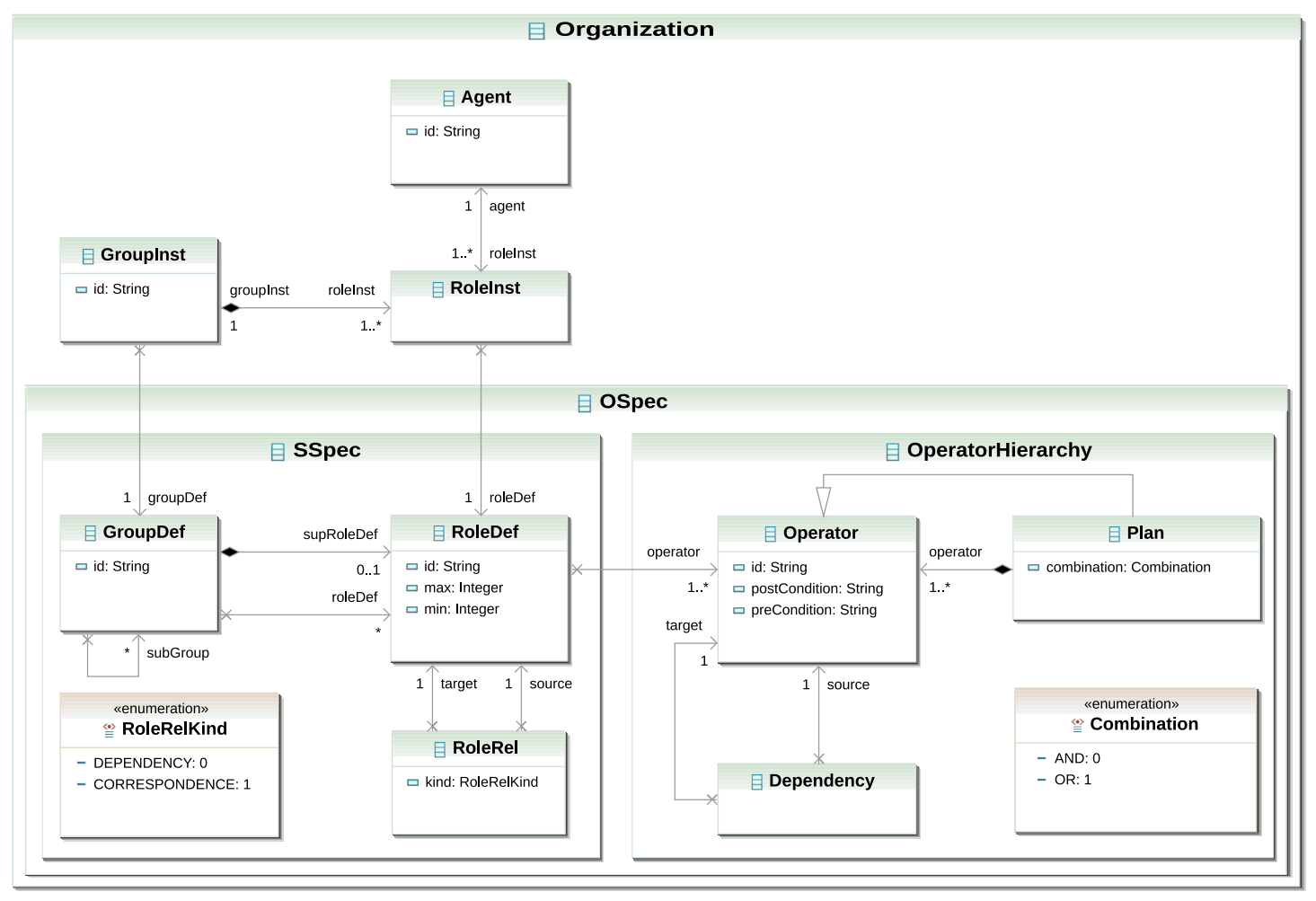

Figura 6.6: $M M_{\# 1}^{i n t}$ - metamodelo integrado da primeira iteração.

\section{Resultado da junção}

Aplicando o algoritmo de junção aos metamodelos de AGR (figura 4.4) e STEAM (figura 4.7), à articulação e às rotulações de cor estabelecidas (figura 6.5), obtémse como resultado o metamodelo integrado $M M_{\# 1}^{\text {int }}$ apresentado na figura 6.6.

Uma vez que os conceitos de STEAM situados na dimensão funcional não têm correspondentes em AGR, eles são simplesmente mantidos na integração $M M_{\# 1}^{\text {int }}$ sem modificações. A referência operator $1 \ldots *$ observada entre RoleDef e Operator se deve à referência de mesmo nome existente originalmente no metamodelo de STEAM entre STEAM: :Role e STEAM: : Operator (figura 4.7).

\subsubsection{Segunda Iteração}

Na segunda iteração, acrescenta-se o modelo MOISE+ à integração de AGR e STEAM obtida na primeira iteração $\left(M M_{\# 1}^{\text {int }}\right)$, produzindo o novo metamodelo integrado $M M_{\# 2}^{\text {int }}$.

\subsubsection{Etapa 1: Representação}

A representação de MOISE+ por meio de um metamodelo Ecore, já realizada, encontra-se ilustrada na figura 4.9. O metamodelo $M M_{\# 1}^{\text {int }}$ que integra AGR e 
STEAM é exibido na figura 6.6.

\subsubsection{Etapa 2: Correspondências}

Com o auxílio da tabela 4.1, nota-se que MOISE+ situa-se nas dimensões funcional, estrutural e normativa. Por sua vez, a integração entre AGR e STEAM cobre as dimensões estrutural e funcional. Logo, MOISE+ pode ser comparado à integração de AGR e STEAM tanto com relação à dimensão estrutural quanto com relação à funcional. Com relação à dimensão normativa, observa-se que os conceitos de relações deônticas presentes em MOISE + reificam e estendem a ligação simples (referência operator 1..*) que há entre as dimensões estrutural e funcional do metamodelo $M M_{\# 1}^{i n t}$, figura 6.6.

\subsection{Comparação quanto à dimensão estrutural}

Quanto à dimensão estrutural, os metamodelos de MOISE+ e $M M_{\# 1}^{\text {int }}$ podem ser comparados conforme ilustrado na figura 6.7. Intermediando a comparação, propõe-se um grafo de articulação que preserva os nomes de classes, referências e atributos adotados em $M M_{\# 1}^{\text {int }}$. Por isso, na figura 6.7, omitem-se os mapeamentos entre o grafo de articulação e o metamodelo $M M_{\# 1}^{\text {int }}$, o que simplifica a figura.

\section{Especificações estruturais}

No metamodelo da primeira integração, há as três classe MM $M_{\# 1}^{\text {int }}:$ GroupDef, $\operatorname{MM}_{\# 1}^{\text {int }}:$ : RoleDef e MM $M_{\# 1}^{\text {int }}:$ :RoleRel que caracterizam o padrão de especificação estrutural, proposto na figura 5.3. Em MOISE+, as correspondentes são MOISE+: :GroupSpecification, MOISE+: : Role e MOISE+: :RoleRelation, respectivamente:

- assim como MM int $_{1}^{\text {int }}:$ GroupDef, a classe MOISE+: :GroupSpecification representa uma definição de grupo no qual especificam-se possíveis papéis e subgrupos;

- assim como $M_{\# 1}^{\text {int }}:$ :RoleDef, a classe MOISE+: :Role consiste na definição de papéis associados a definições de grupo;

- assim como $M_{\# 1}^{\text {int }}::$ RoleRel, a classe MOISE+: : RoleRelation caracteriza relacionamentos entre um papel de origem e um papel de destino.

Além dessas correspondências, há algumas particularidades em como estes conceitos ocorrem no metamodelo de MOISE+ que levam a uma extensão do atual metamodelo integrado. 

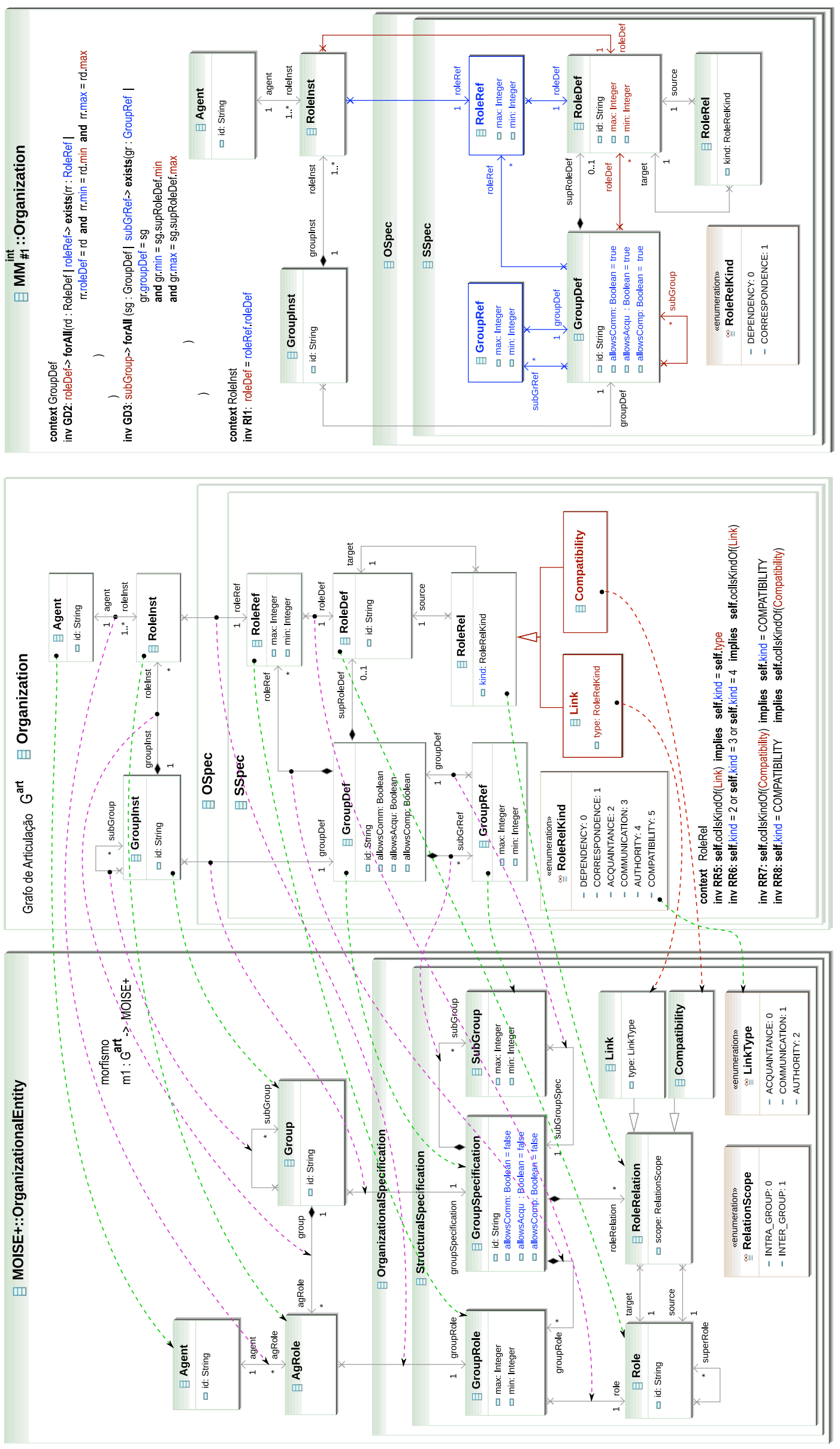

Figura 6.7: Comparação entre o metamodelo de MOISE+ e $M M_{\# 1}^{\text {int }}$ quanto à dimensão estrutural. 


\section{Referências a papéis e a subgrupos}

Uma primeira particularidade que merece destaque é a forma na qual definições de grupo ligam-se a definições de papel e a definições de subgrupos. Na integração de AGR e STEAM, definições de grupo ligam-se a papéis e subgrupos por meio das referências roleDef * e subGroup *. No metamodelo de MOISE+, estas ligações são representadas não por referências, mas pelas classes MOISE+: :GroupRole e MOISE+ : : SubGroup.

Por meio de MOISE+::GroupRole e MOISE+: :SubGroup, uma mesma definição de papel ou de subgrupo pode assumir diferentes cardinalidades, uma para cada grupo onde as definições são referenciadas. As cardinalidades são representadas pelos atributos max : Integer e min : Integer. O atributo max indica a quantidade máxima de agentes por papel, ou de subgrupos por grupo, permitida em um grupo bem formado. O atributo min indica a quantidade mínima.

Na integração de AGR e STEAM, esta flexibilidade não é possível pois as cardinalidades são declaradas diretamente como atributos da definição de papel, e não como atributos da relação entre uma definição de grupo e uma definição de papel ou de subgrupo. Desta forma, nota-se que as informação sobre cardinalidades de papéis e subgrupos de MOISE+ nem sempre podem ser expressas na integração de AGR e STEAM. Mas o contrário é sempre possível, conforme se mostra derivando-se classes $\mathrm{MM}_{\# 1}^{\text {int }}::$ RoleRef e $\mathrm{MM}_{\# 1}^{\text {int }}::$ GroupRef a partir das referências roleDef * e subGroup *.

A classe MM $\# 1$ int $:$ : RoleRef é definida como correspondente de MOISE+ : :GroupRole. De modo similar a MOISE+: :GroupRole, a classe MM\#1 : :RoleRef conta com os atributos max : Integer e min : Integer, e referencia uma única definição de papel. No contexto de $M_{\# 1}^{\text {int }}:$ :GroupDef, a derivação de $M_{\# 1}^{\text {int }}::$ RoleRef é especificada pela invariante GD2 (canto superior direito da figura 6.7). A invariante estabelece que para cada instância rd de $M_{\# 1}^{\text {int }}::$ RoleDef referenciada por roleDef, sempre se pode criar uma instância $\operatorname{rr}$ de $M_{\# 1}^{\text {int }}::$ RoleRef que aponta para $r d$ e tem os atributos $r r \cdot \min =r d \cdot \min$ e rr $\cdot \max =r d \cdot \max$.

A classe MMM1 De modo similar a MOISE+: :SubGroup, a classe MM $M_{1}^{\text {int }}:$ :GroupRef possui os atributos max : Integer e min : Integer, e referencia uma única definição de grupo. No contexto de $M_{\# 1}^{\text {int }}::$ GroupDef, a derivação de $M_{\# 1}^{\text {int }}:$ GroupRef é especificada pela invariante GD3. A invariante determina que para cada instância sg de $M_{\# 1}^{\text {int }}:$ GroupDef referenciada por subGroup, sempre se pode criar uma 
instância gr de MM\#1 ${ }_{\# 1}^{\text {int }}:$ GroupRef que aponta para sg e tem os atributos gr $\cdot \min =$ sg. supRoleDef $\cdot$ min e gr.max $=$ sg. supRoleDef $\cdot \max$.

Por serem mais expressivas, as classes RoleRef e GroupRef substituem as referências roleDef * e subGroup * no grafo de articulação. Logo as referências substituídas são marcadas com vermelho para serem desconsideradas ao se aplicar o algoritmo de junção na etapa seguinte. Também, marcam-se com vermelho os atributos max e min na classe $\mathrm{MM}_{\# 1}^{\mathrm{int}}:$ :RoleDef. A razão é que a mesma informação encontra-se agora representada como atributos das classes RoleRef e GroupRef no grafo de articulação.

\section{Ligações e compatibilidades entre papéis}

Uma outra particularidade em MOISE+ diz respeito à possibilidade de se definir ligações e compatibilidades entre papéis como parte da especificação de um grupo. A este respeito, há duas observações a serem feitas.

Primeiro, ligações são representadas pela classe MOISE+: :Link e compatibilidades por MOISE+::Compatibility, ambas subclasses de MOISE+: :RoleRelation. Como MOISE+ : : RoleRelation é identificada como correspondente da classe MM\#1 int $_{\text {: }}$ RoleRel, tem-se novos subtipos para $M_{\# 1}^{\text {int }}:$ :RoleRel. De fato, a partir das descrições apresentadas no capítulo 4, observa-se que os conceitos de ligação e compatibilidade presentes em MOISE+, em essência, são diferentes dos conceitos de dependência e correspondência encontrados em AGR. Em MOISE+, as ligações habilitam a comunicação, conhecimento ou autoridade entre papéis. A compatibilidade determina que um agente desempenhando um papel pode desempenhar um outro. Em AGR, a dependência determina que um agente só pode desempenhar um papel se previamente já desempenha um outro. Neste caso, a correspondência estabelece que assumir um papel implica em automaticamente assumir um outro.

De modo similar ao procedimento adotado com respeito aos relacionamentos de dependência e correspondência de AGR, as classes MOISE+: :Link e MOISE+: : Compatibility são marcadas em vermelho no grafo de articulação por intermédio das classes Link e Compatibility. A informação contida por elas será representada como novos valores na enumeração RoleRelKind, conforme definido pelas invariantes RR5, RR6, RR7 e RR8, no contexto de RoleRel. Parte desses valores são os literais ACQUAINTANCE, COMMUNICATION e AUTHORITY que representam os tipos de ligação. Um outro valor é COMPATIBILITY substituindo a classe MOISE+: : Compatibility.

A segunda observação a respeito de ligações e compatibilidades é sobre a natureza do conceito de grupo que elas implicam. Caso não sejam explicitamente 
especificadas, um grupo especificado em MOISE+ não permite a compatibilidade ou quaisquer ligações entre papéis. Em outras palavras, de antemão, agentes que desempenham um dado papel não têm permissão de desempenhar outros papéis, e nem de conhecer ou trocar mensagens com os agentes que desempenham outros papéis, tanto no mesmo quanto em outros grupos. Caso se queira a compatibilidade ou ligações entre papéis, isto deve ser explicitado estabelecendo-se as relações desejadas entre os papéis ao se especificar um grupo.

Diferentemente, em AGR e STEAM tem-se o oposto. Nestes modelos, a definição de um grupo não implica a priori em restrições de compatibilidade e de interligação entre os papéis. Salvo relacionamentos explícitos de dependência e restrições de cardinalidade máxima, em AGR e STEAM os agentes são livres para desempenhar os papéis que desejarem, no grupo que desejarem, e não encontram impedimento quanto ao conhecimento e comunicação com agentes em outros papéis.

Na articulação da figura 6.7, estas observações são explicitadas por meio dos atributos derivados allowsComm : Boolean, allowsAcqu : Boolean e allowsComp : Boolean nas definições de grupo MOISE+: :GroupSpecification e MM $\# 1$ : : GroupDef. Do lado de MOISE+, estes três atributos têm o valor false. Isto indica, respectivamente, as restrições de comunicação, conhecimento e compatibilidade existentes em MOISE+. Por outro lado, na integração de AGR e STEAM, os três atributos assumem o valor true, o que indica a ausência das respectivas restrições. Como consequência, concluí-se que a noção de definição de grupo admite uma faixa de variação que vai desde a noção de grupo em MOISE+, na qual allowsComm $=$ allowsAcqu $=$ allowsComp $=$ false, até as noções de grupo em AGR e STEAM, nas quais allowsComm = allowsAcqu = allowsComp = true.

Conquanto opostas nestes aspectos, nota-se que as definições de grupo em AGR e STEAM podem ser expressas em MOISE+. Para tanto, basta que ligações de comunicação e compatibilidades sejam definidos explicitamente entre todos os papéis da especificação estrutural. Já o inverso, de modo geral, não é possível sem perda de informação.

\section{Escopo de relações}

Na classe MOISE+: :RoleRelation, há o atributo scope : RelationScope. Este atributo admite dois valores: INTRA_GROUP e INTER_GROUP. O valor INTRA_GROUP significa que a relação vale apenas para papéis definidos em uma mesma especificação de grupo. O valor INTER_GROUP significa que a relação envolve papéis 
definidos em diferentes especificações de grupo.

Esta distinção de escopo para relações entre papéis não ocorre na integração de AGR e STEAM. Logo, o atributo scope : RelationScope será acrescentado à classe $M_{\# 1}^{\text {int }}:$ : RoleRel ao final da junção do metamodelo de MOISE+ com $M M_{\# 1}^{\text {int }}$.

\section{Herança entre papéis}

Além de ligações e compatibilidades, encontra-se uma terceira forma de relacionamento entre papéis em MOISE+: a herança. No metamodelo de MOISE+, a herança é representada por meio da referência superRole * envolvendo instâncias da classe MOISE+: : Role.

Da mesma forma que o escopo de relações, o conceitos de herança entre papéis não ocorre na integração de AGR e STEAM. Logo, a referência superRole * será acrescentado à classe $M_{\# 1}^{\text {int }}:$ : RoleDef ao final da junção do metamodelo de MOISE+ com $M M_{\# 1}^{\text {int }}$.

Por se tratar de um relacionamento entre papéis, uma forma alternativa de representar a herança seria como um subtipo de MM $_{\# 1}^{\text {int }}:$ : RoleRel. Como a herança não tem efeito direto no comportamento dos agentes como as outras relações, sendo antes um modo de simplificar a definição de papéis em MOISE+, optase por preservar a representação da relação de herança por meio da referência superRole $*$.

\section{Estados Organizacionais}

Finalizando a comparação quanto à dimensão estrutural, comentam-se as correspondências entre as representações de estados organizacionais presentes no metamodelo de MOISE+ e na integração de AGR e STEAM. A este respeito, na figura 6.7, identificam-se as seguintes correspondências diretas.

Assim como MM\#1 : :GroupInst, a classe MOISE+: :Group representa o estado corrente de uma instância de grupo criado conforme uma dada definição de grupo. De modo particular, na representação de uma instância de grupo em MOISE+, há a referência subGroup * que relaciona os subgrupos de um dado grupo, respeitando a definição de grupos na especificação estrutural.

Assim como MM \#1 $_{\text {int }}:$ : Agent, a classe MOISE+: : Agent representa um agente que, em um dado momento, participa de uma organização.

Assim como MM int $_{\text {int }}:$ RoleInst, a classe MOISE+ : : AgRole associa agentes a papéis, 
porém com uma diferença. Enquanto $\mathrm{MM}_{\# 1}^{\text {int }}:$ :RoleInst originalmente associa agentes a instâncias de MM int $_{1}^{\text {int }}:$ RoleDef via referência roleDef 1 , a classe MOISE+ : : AgRole associa agentes a instâncias de MOISE+ : :GroupRole via referência groupRole 1. Como MOISE+ : : GroupRole é correspondente de $M_{\# 1}^{\text {int }}:$ : RoleRef, e não de MM\#1 RoleDef, há uma inconsistência quando se tenta fazer a correspondências entre as referências roleDef 1 e groupRole 1. Para restaurar a consistência, a solução é substituir roleDef 1 por uma referência derivada roleRef 1 que aponta para RoleRef, e não para RoleDef. A derivação de roleRef 1 a partir de roleDef 1 encontra-se especificada pela invariante RI1, no contexto de MM $_{\# 1}^{\text {int }}:$ : RoleInst. Substituída por roleRef 1, roleDef 1 é marcada com vermelho.

\subsection{Comparação quanto à dimensão funcional}

Quanto à dimensão funcional, o metamodelo de MOISE+ e o primeiro metamodelo integrado podem ser comparados por meio do diagrama de articulação ilustrado na figura 6.8. Como a dimensão funcional de $M M_{\# 1}^{i n t}$ é formada apenas por classes do metamodelo de STEAM, pode-se dizer que a comparação realizada na figura 6.8 é, em essência, entre MOISE+ e STEAM. Para ressaltar este fato, o metamodelo de STEAM será diretamente mencionado na sequência, ao invés do metamodelo $M M_{\# 1}^{\text {int }}$.

\section{Especificações funcionais}

Formando o grafo de articulação entre as especificações funcionais de MOISE+ e STEAM, encontram-se as classes HPlanDef, GoalDef, GoalDec e GoalRel que compõem o padrão funcional descrito na seção 5.1, tabelas 5.1 e 5.2. A partir do padrão funcional, as seguintes classes são identificadas como correspondentes:

- MOISE+: : Goal e STEAM : : Operator - relacionadas por intermédio de GoalDef, ambas são vistas como representações particulares do conceito de definição de meta;

- MOISE+: : Plan e STEAM : :Plan - relacionadas por intermédio GoalDec, ambas são vistas como representações particulares do conceito de decomposição de meta em submetas;

- STEAM : :Dependency, sem correspondente no metamodelo de MOISE+ - mapeada por GoalRel, ela é vista como um tipo específico de relação dirigida entre metas; 

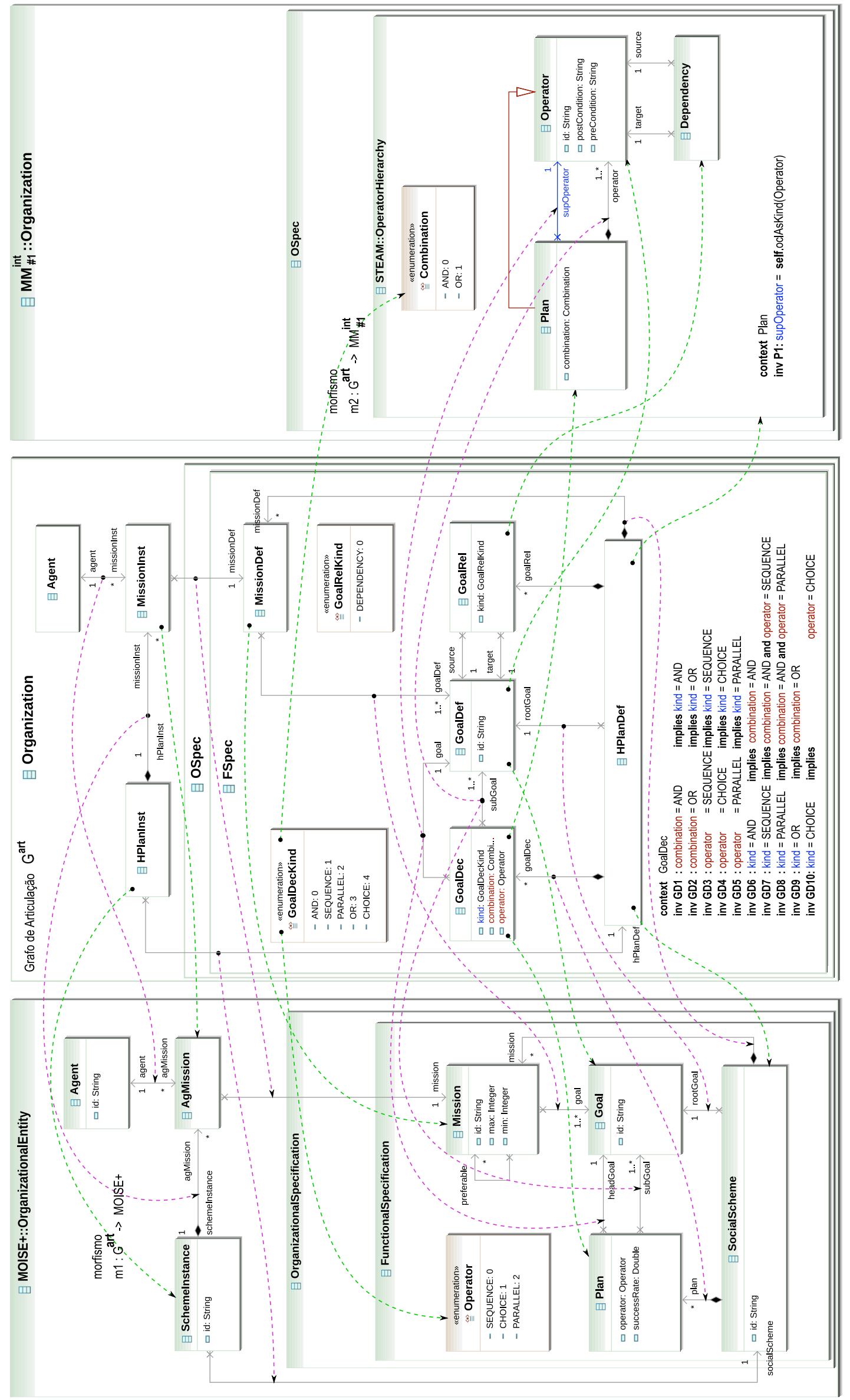

Figura 6.8: Comparação entre o metamodelo de MOISE+ e $M M_{\# 1}^{\text {int }}$ quanto à dimensão funcional. 
- MOISE+: : SocialScheme e STEAM : : OperatorHierarchy - relacionadas por intermédio de HPlanDef, ambas são caracterizadas como representações particulares do conceito de grafo de planos hierárquicos e relações entre metas.

\section{Definição e decomposição de metas}

Para que as duas primeiras correspondências acima ocorram conforme o padrão funcional da seção 5.1, nos metamodelos de MOISE+ e STEAM, deve haver similares para as referências goal 1 e subGoal $1 \ldots *$ entre as classes GoalDec e GoalDef. No metamodelo de MOISE+, as similares são respectivamente as referências headGoal 1 e subGoal 1..*, entre MOISE+::Plan e MOISE+::Goal. No metamodelo de STEAM, identifica-se apenas a referência operator $1 \ldots *$ entre STEAM: :Plan e STEAM:: Operator como similar de subGoal $1 \ldots *$. Com relação a goal 1, não se encontra de modo explícito uma referência similar no metamodelo de STEAM.

No entanto, como há uma generalização entre as classes STEAM : Plan e STEAM: : Operator, nota-se que todo plano também é um operador em STEAM. Assim, a exemplo do caso das classes STEAM: :SubTeam e STEAM: :Role, pode-se derivar uma referência correspondente à goal 1 aplicando a "substituição de herança por delegação". Deste modo, define-se uma referência derivada supOperator 1 entre STEAM : Plan e STEAM : : Operator a partir do relacionamento de generalização entre as classes. A derivação de supOperator 1 é especificada pela invariante P1, no contexto de STEAM: :Plan (canto inferior direito da figura 6.8). Na invariante P1, para cada instância de STEAM: :Plan, determina-se que supOperator 1 deve apontar para a própria instância convertida a uma instância de STEAM : : Operator. Com isso, a referência goal 1 entre GoalDec e GoalDef pode ser mapeada para supOperator 1 sem mais problemas.

Como supOperator 1 substitui a generalização entre as classes STEAM: :Plan e STEAM: :Operator, a generalização é marcada com vermelho para posterior eliminação durante a etapa de junção.

\section{Tipos de decomposição de metas}

Na correspondência entre as classes MOISE+: :Plan e STEAM: :Plan, um outro ponto que merece destaque são os tipos de decomposição de uma meta em submetas.

A este respeito, na classe MOISE+: :Plan, há o atributo operator : Operator. Por meio de operator, representam-se os três tipos de decomposição de metas de 
MOISE+: a sequência (operator $=$ SEQUENCE), a escolha (operator $=$ CHOICE) e o paralelismo (operator $=$ PARALLEL). O significado destes tipos de decomposição de metas é definido da seguinte forma:

"A decomposição de metas é feita por meio de planos (denotados pelo operador $=$ ) ...

- sequência ",": o plano " $g_{1}=g_{4}, g_{7}$ " significa que a meta $g_{1}$ será satisfeita se a meta $g_{4}$ for satisfeita e depois a meta $g_{7}$ também o for. ...

$$
\text { isSatisfied }\left(g_{1}\right) \Leftarrow i \text { sSatisfied }\left(g_{4}\right) \wedge \text { isSatisfied }\left(g_{7}\right)
$$

- escolha "|": o plano " $g_{7}=g_{8} \mid g_{9}$ " significa que a meta $g_{7}$ será satisfeita se uma, e somente uma, das metas $g_{8}$ ou $g_{9}$ for satisfeita.

$$
\begin{aligned}
\text { isSatisfied }\left(g_{7}\right) \Leftarrow \quad & \left(\text { isSatisfied }\left(g_{8}\right) \wedge \neg \text { isSatisfied }\left(g_{9}\right)\right) \vee \\
& \left(\text { isSatisfied }\left(g_{9}\right) \wedge \neg \text { isSatisfied }\left(g_{8}\right)\right) \vee
\end{aligned}
$$

- paralelismo "||": o plano " $g_{4}=g_{5} \| g_{6}$ " significa que a meta $g_{4}$ será satisfeita quando ambas as metas $g_{5}$ e $g_{6}$ o forem. Contudo, ao contrário da sequência, as duas sub-metas podem ser buscadas em paralelo.

$$
\begin{aligned}
& \quad \text { isSatisfied }\left(g_{1}\right) \Leftarrow i \text { sSatisfied }\left(g_{5}\right) \wedge \text { isSatisfied }\left(g_{6}\right) \\
& \text {..” }(\text { HüBNER, 2003, p. 41) }
\end{aligned}
$$

De modo similar, na classe STEAM: :Plan, encontra-se o atributo combination : Combination. Por meio de combination, representam-se os dois tipos de decomposição de meta de STEAM: a combinação $E$ (combination = AND) e a combinação $O U$ (combination $=\mathrm{OR}$ ). Sendo $[\mathrm{OP}]_{\Theta}$ um plano e $\mathrm{op}_{\nu i}$ os suboperadores do plano, o significado das combinações E e OU é definido da seguinte maneira:

$$
\begin{aligned}
& \text { "1. AND-Combination: }[\mathrm{OP}]_{\Theta} \Longleftrightarrow \bigwedge_{i=1}^{n} o p_{\nu i} \\
& \text { 2. OR-Combination: }[\mathrm{OP}]_{\Theta} \Longleftrightarrow \bigvee_{i=1}^{n} o p_{\nu i} \\
& \text {.." (TAMBE, 1997, p. 99) }
\end{aligned}
$$

Comparando essas definições, chega-se a três conclusões: (1) os operadores de sequência e paralelismo de MOISE+ são similares, mas não equivalentes, à combinação E de STEAM; (2) a combinação OU de STEAM não tem similar em MOISE+; e (3) o operador escolha de MOISE+ não tem similar em STEAM. Quanto a primeira conclusão, observa-se que tanto a sequência quanto o paralelismo implicam em uma combinação E. No entanto, o inverso não pode ser afirmado: nem sempre uma combinação E implica em uma sequência ou paralelismo. Esta constatação é formalizada pelas invariantes GD6, GD7 e GD8 encontradas na parte de baixo do grafo de articulação da figura 6.8. Quanto a segunda e terceira conclusões, elas são respectivamente formalizadas pelas invariantes GD9 e GD10. 
Nas invariantes citadas, utiliza-se o atributo kind : GoalDecKind definido na classe GoalDec do grafo de articulação. O objetivo de kind é representar complemente a informação constante nos atributos operator : Operator e combination : Combination. Neste sentido, a faixa de valores de kind consiste na união dos literais das enumerações MOISE+: :Operator e STEAM: :Combination. A representação dos atributos operator e combination por intermédio de kind é especificada nas invariantes GD1, ..., GD5.

Como kind é capaz de representar a mesma informação que atributos operator e combination contêm, estes dois tornam-se redundantes e são marcados com vermelho para posterior eliminação durante a etapa de junção.

\section{Relações entre metas}

No contexto de GoalDec, as invariantes GD7 e GD8 determinam que os operadores de sequência e paralelismo de MOISE+ podem ser mapeados para a combinação $E$ de STEAM. Esta correspondência é possível sem perda de informação devido a possibilidade de se definir relações de dependências entre metas em STEAM. No metamodelo de STEAM, relações de dependências são representadas pela classe STEAM: : Dependency.

Uma relação de dependência entre duas metas particulares significa que a realização de uma das metas deve preceder a realização da outra. Deste modo, pode-se por exemplo representar o operador de sequência de MOISE+ definindo-o em STEAM como uma combinação $E$ em conjunto com dependências que levam a formação de uma ordem linear entre metas. Já o operador de paralelismo de MOISE+ pode ser representado em STEAM por uma combinação E sem nenhum relacionamento de dependências entre as metas.

Por outro lado, dada uma combinação E e uma ordem parcial qualquer induzida por dependências entre metas, não há uma especificação correspondente em MOISE + sem perda de informação. Isto justifica a afirmação feita anteriormente de que nem sempre uma combinação $E$ de STEAM implica em um operador de sequência ou de paralelismo de MOISE+.

No grafo de articulação da figura 6.8, nota-se que a classe STEAM: : Dependency é mapeada pela classe RoleRel. Provinda do padrão funcional, a classe RoleRel representa de modo geral o conceito de relação binária entre metas. Como STEAM: :Dependency é um tipo particular de relação entre metas, e não o conceito geral de relação entre metas, acrescenta-se à RoleRel um atributo kind : RoleRelKind. O objetivo deste atributo é representar por meio do valor kind $=$ 
DEPENDENCY a particular relação de dependência de STEAM.

\section{Missões}

Em MOISE+ não há a possibilidade de se especificar relações de dependência entre metas. No entanto, há a possibilidade de agrupar metas formando missões, característica ausente em STEAM. No metamodelo de MOISE+, missões são representadas pela classe MOISE+ : : Mission. No grafo de articulação da figura 6.8, MOISE+: : Mission é mapeada pela classe MissionDef.

\section{Estados organizacionais}

Finalizando a comparação quanto à dimensão funcional, comenta-se sobre a representação de estados organizacionais relativos à execução de metas.

A este respeito, no metamodelo de MOISE+, tem-se as classes MOISE+: : SchemeInstance e MOISE+: :AgMission. A classe MOISE+: :SchemeInstance representa execuções particulares de um dado esquema social. Na execução de um esquema social, agentes assumem missões. A classe MOISE+: : AgMission representa a relação entre um agente que se compromete com uma dada missão no contexto de uma execução de esquema social.

No metamodelo que integra AGR e STEAM, não há elementos explícitos para representação de estados organizacionais relativos a execução de metas. Logo, nenhuma comparação pode ser feita a este respeito entre os metamodelos de MOISE+ e o metamodelo que integra AGR e STEAM.

No grafo de articulação da figura 6.8, as classes MOISE+: :SchemeInstance e MOISE+: : AgMission são mapeadas pelas classes HPlanInst e MissionInst.

\subsection{Comparação quanto à dimensão normativa}

Apesar de não apresentar conceitos explícitos na dimensão normativa, o metamodelo que integra AGR e STEAM pode ainda ser comparado com o metamodelo de MOISE+ quanto a esta dimensão. A comparação se dá conforme mostrado na figura 6.9 .

A idéia básica é que as classes MOISE+: :DeonticRelation e MOISE+: :Mission têm a mesma função da referência operator $1 \ldots *$ entre classes MM $\# 1$ int $:$ RoleDef e $M_{\# 1}^{\text {int }}::$ Operator. Isto é, tanto as classes de MOISE+ quanto a referência operator 1..* ligam definições de papéis a definições de metas. No entanto, 


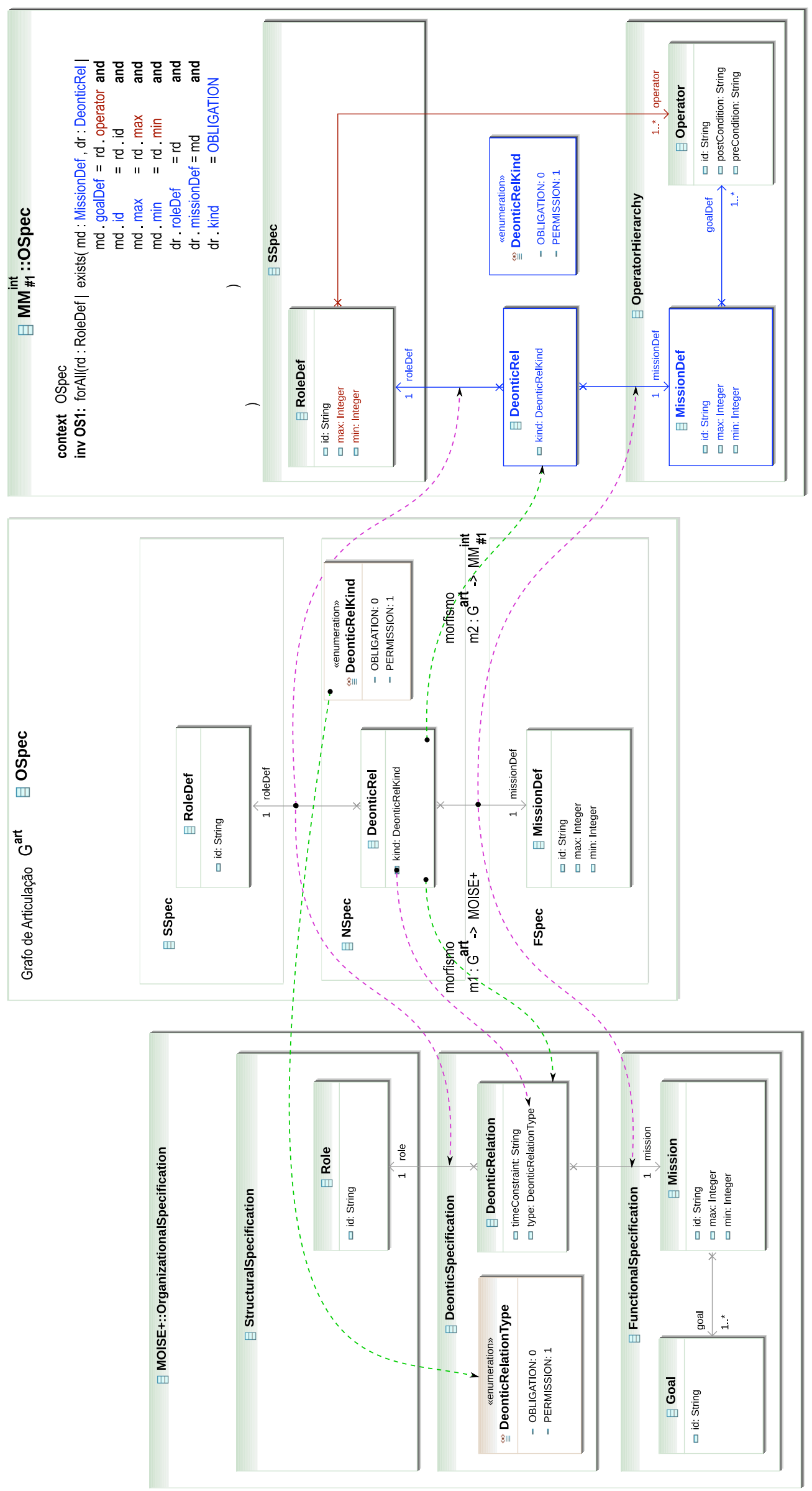

Figura 6.9: Comparação entre o metamodelo de MOISE+ e $M M_{\# 1}^{\text {int }}$ quanto à dimensão normativa. 
enquanto operator 1..* liga diretamente definições de papéis a definições de metas, as classes de MOISE+ o fazem com um grau maior de liberdade. A classe MOISE+: :Mission, por exemplo, permite particionar as metas de um papel em missões, i.e., subconjuntos coesos de metas no contexto de esquemas sociais. A classe MOISE+: : DeonticRelation, por sua vez, possibilita a definição de relações deônticas entre papéis e missões, i.e., relações nas quais se distinguem metas obrigatórias e metas permitidas associadas a um papel.

Nota-se então que as classes de MOISE+, por serem mais expressivas, podem substituir a referência operator 1..* na junção final de MOISE+, AGR e STEAM. Para tanto, no grafo de articulação da figura 6.9, no lugar da referência operator $1 \ldots *$, definem-se as classes DeonticRel e MissionDef que mapeiam respectivamente as classes MOISE+: :DeonticRelation e MOISE+::Mission. Em seguida, mostra-se como classes similares $\mathrm{MM}_{\# 1}^{\text {int }}:$ :DeonticRel e $\mathrm{MM}_{\# 1}^{\text {int }}::$ MissionDef podem ser derivadas na integração de AGR e STEAM partir da referência operator $1 . . *$.

A derivação de $M_{\# 1}^{\text {int }}::$ DeonticRel e $M_{\# 1}^{\text {int }}:$ :MissionDef ocorre obedecendo à condição invariante OS1, definida no contexto de MM\#1 : OSpec (canto superior direito da figura 6.9). Na invariante OS1, determina-se que a referência operator $1 . . *$ de cada definição de papel rd pode ser interpretada como uma definição de missão md e uma relação deôntica dr de obrigação entre rd e md. A metas da missão md consistem no conjunto de operadores referenciado por operator 1. *. Já o identificador, a cardinalidade máxima e a cardinalidade mínima de md são os mesmos que os da definição de papel rd. Sobre a relação deôntica dr, tem-se que dr aponta para rd e md.

Uma vez sendo possível derivar $M_{\# 1}^{\text {int }}:$ :DeonticRel e MM $_{\# 1}^{\text {int }}:$ :MissionDef na integração de AGR e STEAM, a referência operator 1..* torna-se redundante. Assim, ela é marcada com vermelho para ser desconsiderada ao se aplicar o algoritmo de junção na etapa seguinte.

Por fim, observa-se que embora se possa interpretar completamente a referência operator $1 \ldots *$ a partir das classes MOISE+: :DeonticRelation e MOISE+: : Mission, via derivação de $M_{\# 1}^{\text {int }}:$ : DeonticRel e $M_{\# 1}^{\text {int }}:$ :MissionDef, o inverso não é possível sem perda de informação.

\subsubsection{Etapa 3: Junção}

Consideradas em conjunto, as figuras 6.7, 6.8 e 6.9 veiculam uma articulação $\operatorname{art}\left(M O I S E+, M M_{\# 1}^{i n t}\right)$, bem como rotulações de cores, que representam as cor- 


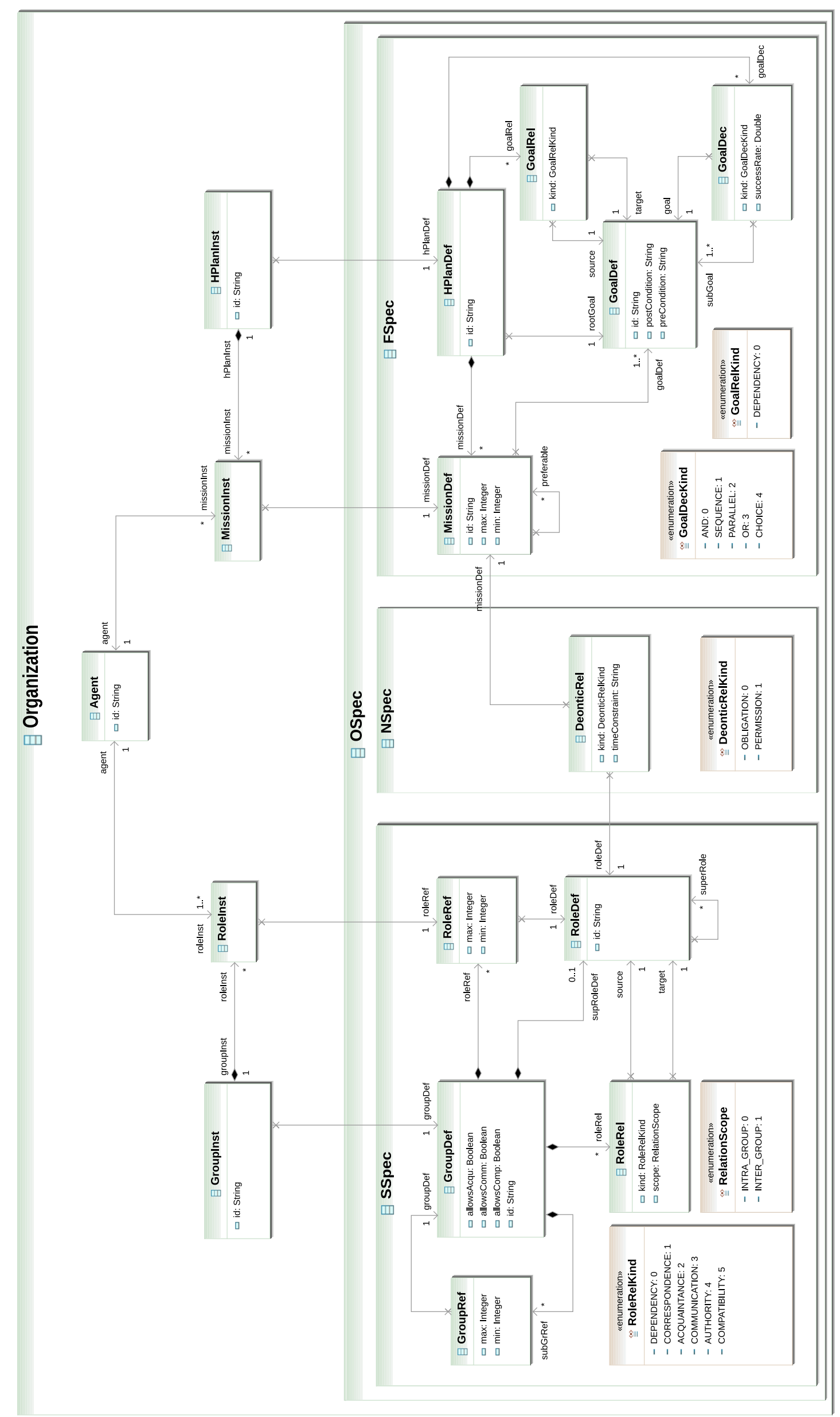

Figura 6.10: $M M_{\# 2}^{\text {int }}$ - metamodelo integrado da segunda iteração. 
respondências identificadas entre o metamodelo de MOISE+ e o metamodelo $M M_{\# 1}^{i n t}$ da iteração anterior. Tendo por base essa articulação e rotulações de cores definidas nas figuras 6.7, 6.8 e 6.9, e aplicando-se o algoritmo de junção aos metamodelos de MOISE+ (figura 4.9) e $M M_{\# 1}^{\text {int }}$ (figura 6.6), obtém-se como resultado o metamodelo integrado $M M_{\# 2}^{\text {int }}$ apresentado na figura 6.10.

Nota-se que o metamodelo obtido reflete a estrutura geral do metamodelo de MOISE + acrescido de elementos particulares, tais como dependências e correspondências entre papéis, dependências entre metas, etc., presentes nos metamodelos de AGR e STEAM. Isso se deve ao fato de que a estrutura conceitual de MOISE + é mais abrangente, subsumindo, com exceções, as estruturas conceituais de AGR e STEAM.

\subsubsection{Terceira Iteração}

Na terceira iteração, acrescenta-se o modelo ISLANDER ao metamodelo $M M_{\# 2}^{\text {int }}$ obtido na segunda iteração, produzindo o metamodelo integrado final $M M_{\# 3}^{i n t}$.

\subsubsection{Etapa 1: Representação}

Realizada no capítulo 4, a representação de ISLANDER por meio de um metamodelo Ecore encontra-se ilustrada na figura 4.11. O metamodelo obtido na segunda iteração é exibido na figura 6.10.

\subsubsection{Etapa 2: Correspondências}

Novamente com o auxílio da tabela 4.1, observa-se que os conceitos de modelagem de ISLANDER ocorrem nas dimensões estrutural, dialógica, normativa e ontológica. Por sua vez, o metamodelo $M M_{\# 2}^{\text {int }}$ cobre as dimensões estrutural, funcional e normativa. Utilizando como critério de comparação as dimensões de modelagem em comum, conclui-se que ISLANDER pode ser comparado à integração de AGR, STEAM e MOISE+ no que diz respeito às dimensões estrutural e normativa.

\subsection{Comparação quanto à dimensão estrutural}

Restritos à dimensão estrutural, os metamodelos de ISLANDER e $M M_{\# 2}^{\text {int }}$ podem ser comparados conforme ilustrado na figura 6.11. Intermediando a comparação, define-se um grafo de articulação que preserva os nomes de classes, referências 
e atributos adotados em $M M_{\# 2}^{i n t}$. Deste modo, visando simplificar a figura 6.11, omitem-se os mapeamentos entre o grafo de articulação e o metamodelo $M M_{\# 2}^{i n t}$.

Na dimensão estrutural, duas classes do metamodelo de ISLANDER encontram correspondentes diretos em $M M_{\# 2}^{\text {int }}$ :

- a classe ISLANDER: :Role, que representa uma definição de papel, logo correspondente de $\mathrm{MM}_{\# 2}^{\text {int }}:$ :RoleDef; e

- a classe ISLANDER::Incompatibility, que representa um tipo de relação entre papéis, logo correspondente de $\mathrm{MM}_{\# 2}^{\mathrm{int}}:$ : RoleRel.

Além destas correspondências diretas, podem-se ainda derivar correspondentes das classes $\mathrm{MM}_{\# 2}^{\text {int }}::$ RoleDef e $\mathrm{MM}_{\# 2}^{\text {int }}::$ RoleRef a partir das referências role $*$ e incompatibility $*$ que se originam na classe ISLANDER: :DialogicalFramework. Estas correspondências são detalhadas a seguir.

\section{Definições de papel}

Com relação à correspondência entre ISLANDER : : Role e MM Mn $_{\text {int }}:$ :RoleDef, dois pontos merecem destaque.

O primeiro é a existência de uma relação de herança entre papéis similar à relação de herança incorporada a $M M_{\# 2}^{\text {int }}$ a partir do metamodelo de MOISE+. A exemplo do que ocorre no metamodelo de MOISE+, no metamodelo de ISLANDER, a relação de herança é representada por uma referência que liga uma definição de papel a zero ou mais definições de papéis pai, ou super papéis.

O segundo ponto é que há uma distinção entre papéis externos e papéis internos em ISLANDER que não ocorre em AGR, STEAM e MOISE+. Essa distinção foi discutida na subseção 4.2.5. Na classe ISLANDER: : Role, a representação de papéis externos e internos se dá através do atributo type : RoleType. Não ocorrendo em $M M_{\# 2}^{\text {int }}$, este atributo será incorporada à classe $\mathrm{MM}_{\# 2}^{\text {int }}:$ : RoleDef na junção dos metamodelos ao final da iteração.

\section{Relacionamento de incompatibilidade}

Além de herança, em ISLANDER também é possível especificar relacionamentos de incompatibilidade entre papéis, representados por instâncias da classe ISLANDER: : Incompatibility. De modo similar à classe $M_{\# 2}^{\text {int }}::$ RoleRel, os relacionamentos de incompatibilidade representados por ISLANDER: :Incompatibility são dirigidos de um papel origem a um papel destino. 

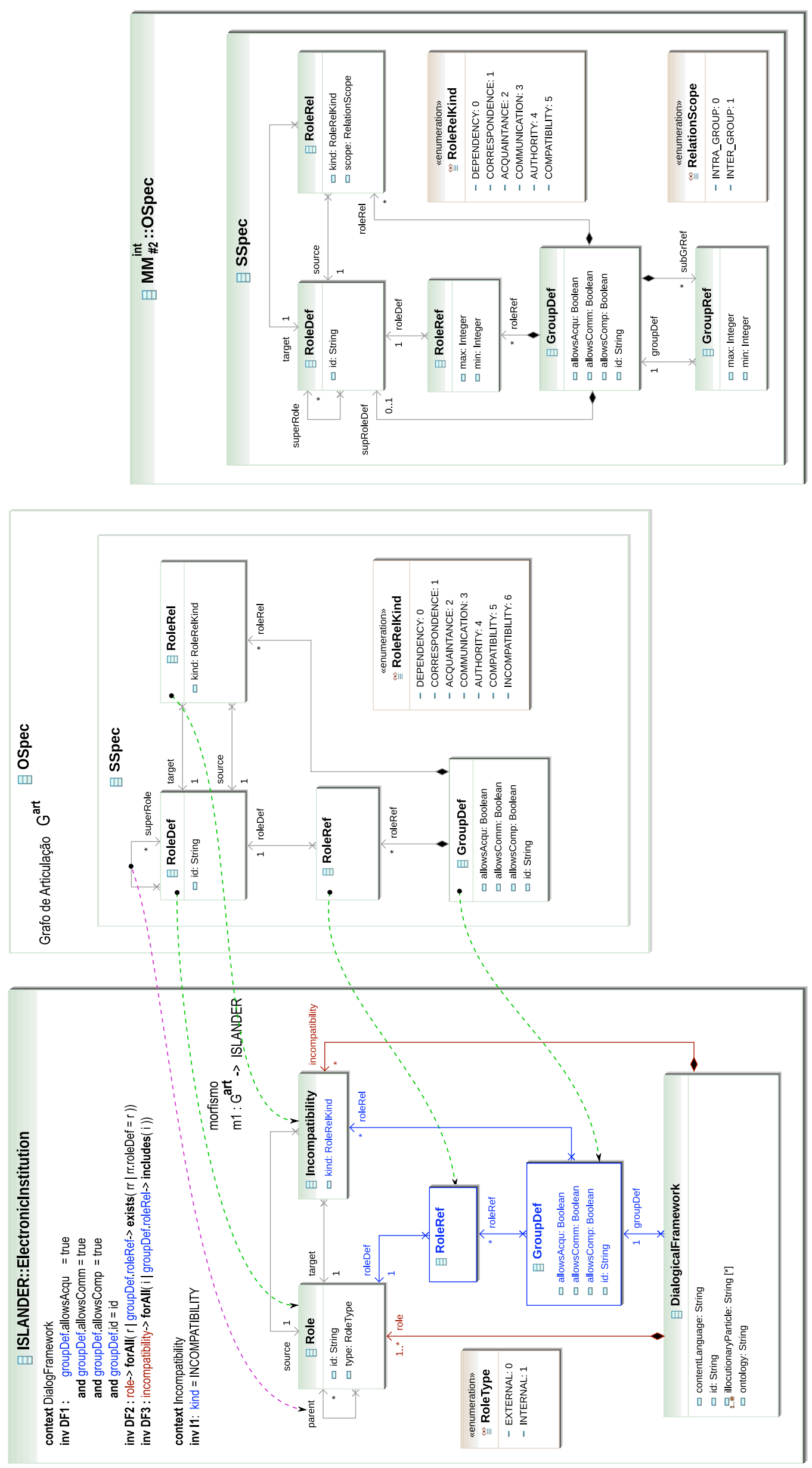

Figura 6.11: Comparação entre o metamodelo de ISLANDER e $M M_{\# 2}^{\text {int }}$ quanto à dimensão estrutural. 
Assim como a distinção entre papéis internos e externos, relacionamentos de incompatibilidade não estão presentes em $M M_{\# 2}^{i n t}$. Há vários tipos de relacionamentos entre papéis representados pela classe $\mathrm{MM}_{\# 2}^{\text {int }}:: \operatorname{RoleRel}$, mas todos são diferentes da noção de incompatibilidade em ISLANDER, conforme discutida na subseção 4.2.5. Para distinguí-los dos outros relacionamentos entre papéis já representados pela classe MM $_{\# 2}^{\text {int }}::$ RoleRel, acrescenta-se o literal INCOMPATIBILITY à enumeração RoleRelKind do grafo de articulação da figura 6.11.

\section{Definições de grupos}

Nota-se que não há explicitamente o conceito de definição de grupo no metamodelo de ISLANDER. Tanto papéis quanto incompatibilidades são definidos no contexto de estruturas de diálogo representadas pela classe ISLANDER: :DialogicalFramework. Mesmo referenciando papéis e relacionamentos entre papéis, o conceito de estrutura de diálogo é em essência diferente do conceito de definição de grupo.

Porém, visando um mapeamento entre as estruturas conceituais de ISLANDER e $M M_{\# 2}^{\text {int }}$ coerente com o padrão de modelagem estrutural da seção 5.2, pode-se interpretar os papéis e incompatibilidades presentes em uma estrutura de diálogo como uma definição implícita de grupo. Nesta interpretação, o metamodelo de ISLANDER é estendido com classes ISLANDER: : RoleDef e ISLANDER: : RoleRef derivadas a partir das referências role * e incompatibility * presentes em ISLANDER: :DialogicalFramework. As condições de derivação de ISLANDER: : RoleDef e ISLANDER: : RoleRef são formalizadas nas invariantes DF1, DF2 e DF3, definidas no contexto de ISLANDER: :DialogicalFramework (canto superior esquerdo da figura 6.11).

Na invariante DF1, especificam-se os valores dos atributos allowsAcqu, allowsComm, allowsComp e id para a definição de grupo implícita em uma estrutura de diálogo. Como a definição de grupo é referente a uma estrutura de diálogo específica, o atributo id da definição de grupo assume o mesmo valor que o atributo id da estrutura de diálogo. Com relação aos outros atributos, nota-se que ISLANDER é compatível com AGR e STEAM mas não com MOISE+. Isto é, em ISLANDER, os agentes que assumem um papel não estão impedidos de antemão de conhecer, se comunicar com ou assumir outros papéis.

Esta última observação explica porque há a relação de incompatibilidade entre papéis em ISLANDER e uma relação inversa de compatibilidade em MOISE+. Em ISLANDER, a priori todos os papéis são compatíveis. Já em MOISE+, os 
papéis são incompatíveis na ausência de um relacionamento de compatibilidade explícito, como já discutido na iteração anterior.

Nas invariantes DF2 e DF3, determina-se que os papéis e relacionamentos entre papéis que irão compor a definição de grupo derivada devem ser aqueles que se encontram referenciados por role $1 \ldots *$ e por incompatibility $*$. Com isso, ao invés de referenciar diretamente papéis e incompatibilidades, uma estrutura de diálogo referencia uma definição de grupo que contém referências a definições de papéis e definições de incompatibilidades. Por isso, role $1 \ldots *$ e incompatibility

* encontram-se marcadas com vermelho. O vermelho indica que as referências tornam-se redundantes nesta situação.

\subsection{Comparação quanto à dimensão normativa}

Quanto à dimensão normativa, o metamodelo de ISLANDER e a integração $M M_{\# 2}^{i n t}$ são consideravelmente diferentes.

Por um lado, no metamodelo $M M_{\# 2}^{\text {int }}$, há o conceito de relação dê̂ntica, provindo de MOISE+. Como já comentado nas subseções 4.2.4 e 5.4.2, em MOISE+, uma relação deôntica é uma associação de obrigação ou permissão entre missões (conjunto de metas) e papéis. Por outro lado, em ISLANDER, há o conceito de norma. Neste caso, como discutido nas subseções 4.2 .5 e 5.4.2, uma norma é uma expressão condicional que é ativada por mensagens trocadas entre agentes no contexto de uma cena e que leva a obrigações na forma de novas mensagens que os agentes devem trocar no contexto de determinadas cenas. Deste modo, constata-se que os conceitos de relação deôntica em $M M_{\# 2}^{\text {int }}$ e norma em ISLANDER têm forma, referentes e significados diferentes.

Logo, não se identificam correspondências entre o metamodelo $M M_{\# 2}^{\text {int }}$ e o metamodelo de ISLANDER quanto à dimensão normativa.

\subsubsection{Etapa 3: Junção}

As correspondências entre o metamodelo de ISLANDER e o metamodelo $M M_{\# 2}^{\text {int }}$ da iteração anterior resumem-se então ao diagrama de articulação e rotulações de cores representadas na figura 6.11. Aplicando o algoritmo de junção aos metamodelos de ISLANDER (figura 4.11) e $M M_{\# 2}^{\text {int }}$ (figura 6.10), tendo por base a articulação e rotulações de cores da figura 6.11, obtém-se como resultado o metamodelo integrado $M M_{\# 3}^{i n t}$ apresentado nas figuras 6.12 e 6.13 .

A figura 6.12 consiste no metamodelo $M M_{\# 2}^{\text {int }}$ da segunda iteração acrescido 


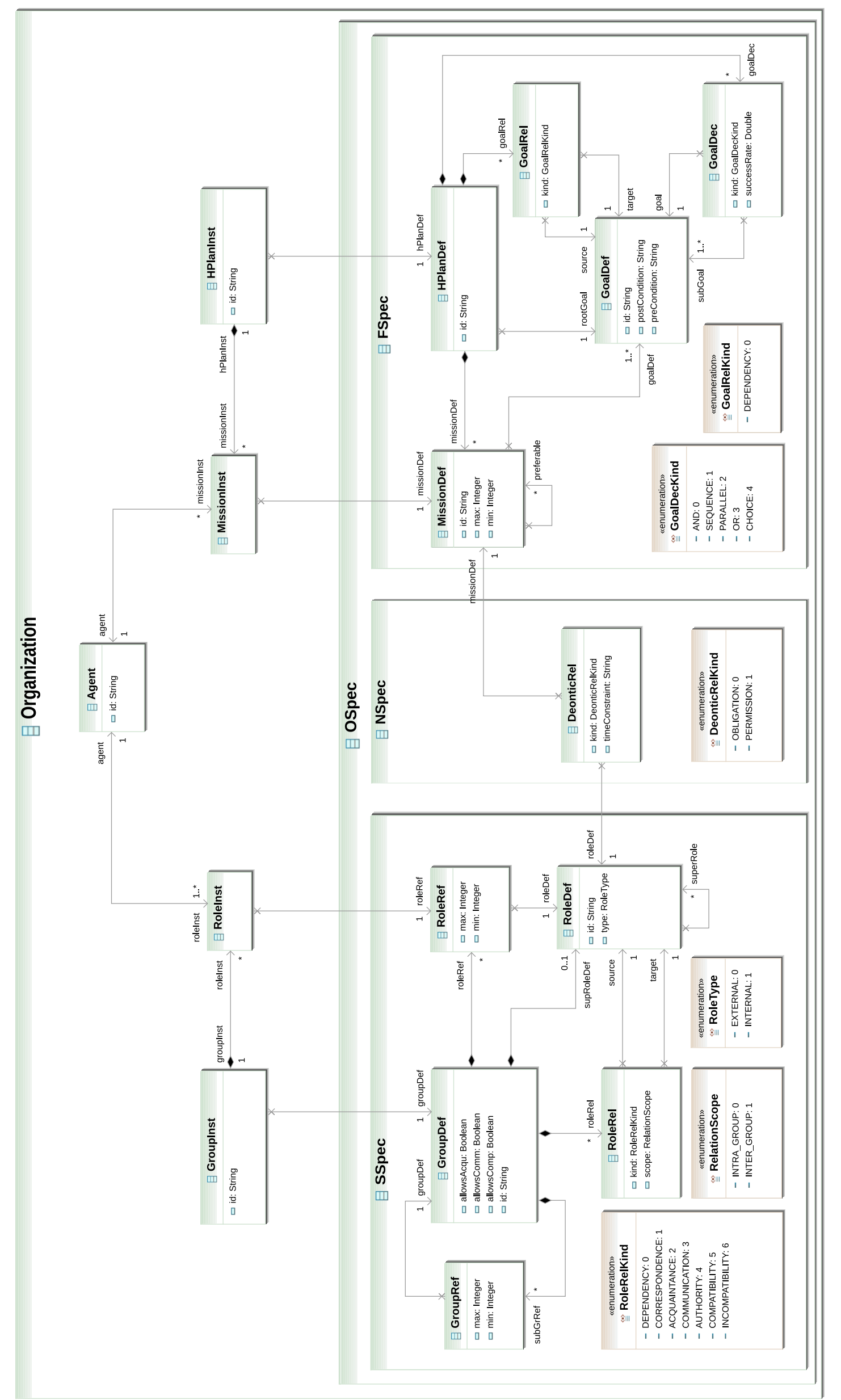

Figura 6.12: $M M_{\# 3}^{\text {int }}$ - metamodelo integrado da terceira iteração (parte 1). 


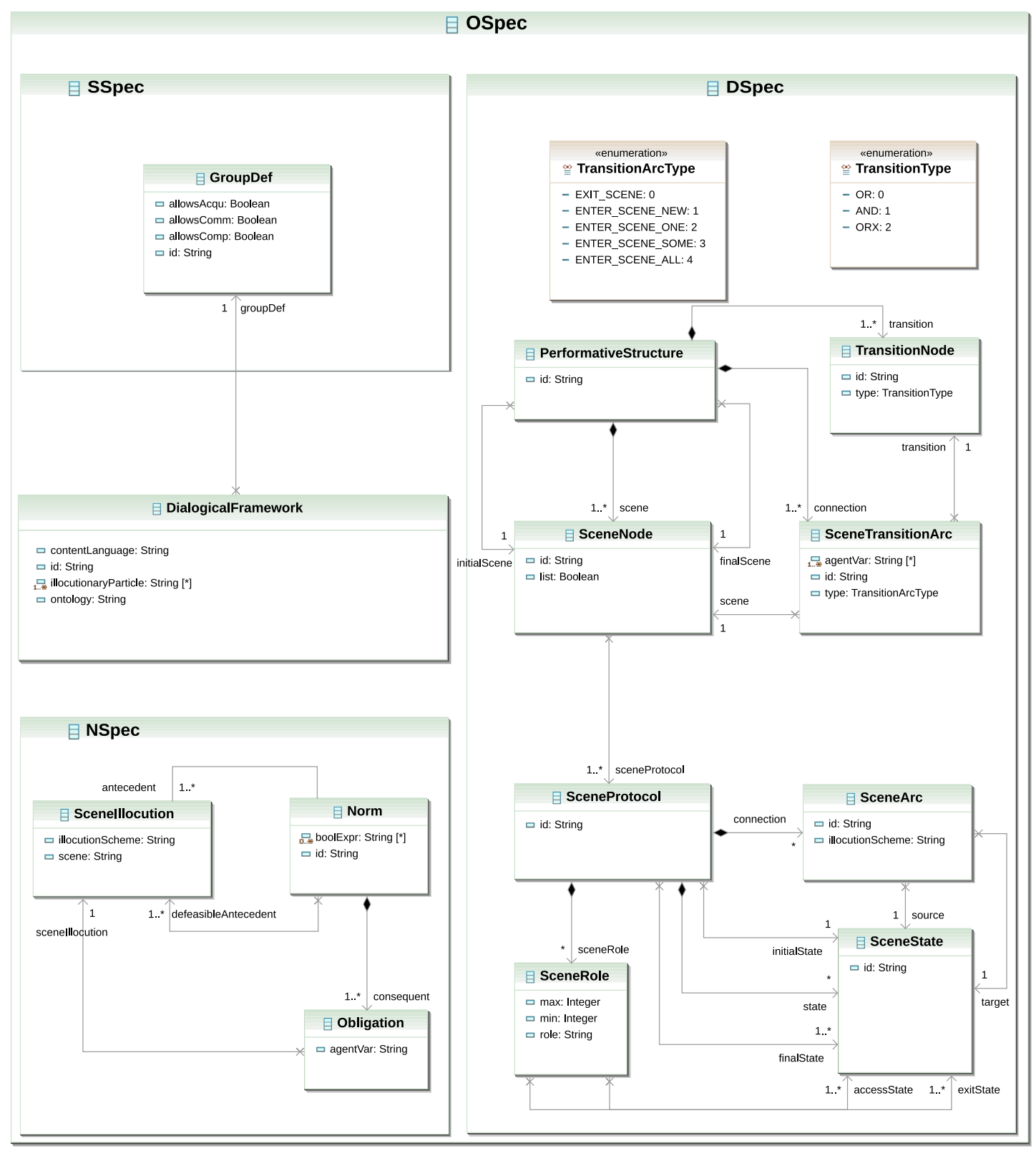

Figura 6.13: $M M_{\# 3}^{\text {int }}$ - metamodelo integrado da terceira iteração (parte 2).

das características particulares de ISLANDER quanto a dimensão estrutural, i.e., a distinção entre papéis internos e externos e a relação de incompatibilidade. A figura 6.13 consiste nas classes do metamodelo de ISLANDER relativas às dimensões dialógica, normativa e ontológica. Diferentemente do metamodelo original (figura 4.11), observa-se que a classe $\mathrm{MM}_{\# 3}^{\text {int }}:$ : DialogicalFramework referencia a classe $\mathrm{MM}_{\# 3}^{\text {int }}:$ : GroupDef da dimensão estrutural, conforme discutido anteriormente.

\subsection{Resultado Final}

O resultado final, o metamodelo $M M_{\# 3}^{\text {int }}$ representado nas figuras 6.12 e 6.13 , integra concretamente as estruturas conceituais dos modelos organizacionais AGR, 


\section{STEAM, MOISE+ e ISLANDER.}

Nas dimensões estrutural e funcional, o metamodelo $M M_{\# 3}^{\text {int }}$ apresenta a estrutura geral do metamodelo de MOISE+. Como mencionado anteriormente, isso se deve ao fato de que nestas dimensões a estrutura conceitual de MOISE+ é mais abrangente, subsumindo, com algumas exceções, as estruturas conceituais de AGR, STEAM e ISLANDER.

Nas dimensão dialógica e ontológica, o metamodelo $M M_{\# 3}^{i n t}$ é formado apenas pelas classes do metamodelo de ISLANDER. A razão disso é que, dentre os modelos organizacionais selecionados para integração, apenas ISLANDER apresenta conceitos de modelagem nessas dimensões.

Na dimensão normativa, o metamodelo $M M_{\# 3}^{\text {int }}$ é um misto no qual tanto o conceito de relação deôntica de MOISE+ quanto o conceito de norma de ISLANDER podem ser expressos.

Sendo uma integração conceitual de AGR, STEAM, MOISE+ e ISLANDER, qualquer especificação organizacional escrita em um desses modelos pode ser expressa sem perda de informação em $M M_{\# 3}^{\text {int }}$. Já o contrário, i.e., traduzir uma especificação organizacional conforme $M M_{\# 3}^{\text {int }}$ para algum dos modelos originais pode ocasionalmente levar a perda de informação. Por exemplo, caso se tenha uma especificação organizacional válida de acordo com MOISE+, esta especificação pode ser expressa completamente em $M M_{\# 3}^{\text {int }}$. Uma vez expressa em $M M_{\# 3}^{\text {int }}$, a mesma especificação pode ser convertida de volta para MOISE+ sem perda de informação. Entretanto, caso se deseje converter a especificação para AGR, provavelmente haverá perda de informação porque AGR não apresenta a dimensão funcional. Além disso, mesmo restringindo a especificação à dimensão estrutural, há conceitos tais como subgrupos, ligações de comunicação, compatibilidade, etc. que não podem ser expressos em AGR.

No que tange ao problema de interoperabilidade organizacional, a importância do processo de integração discutido neste capítulo é que ele pode ser utilizado como ponto de partida para o desenvolvimento de soluções de interoperabilidade. Este assunto é tratado nos capítulos que compõem a terceira e última parte desta tese. 


\section{Parte III}

\section{Interoperabilidade Organizacional}




\section{$7 \quad$ Infraestrutura MAORI}

A integração de modelos organizacionais realizada na Parte II tem como motivação inicial o problema de interoperabilidade organizacional. Na subseção 1.1.2, este problema foi enunciado da seguinte maneira:

Caso não possuam uma arquitetura flexível o suficiente, ou não sejam providos mecanismos explícitos de interoperabilidade, os agentes feitos para operar em organizações de agentes especificadas a partir de determinado modelo organizacional provavelmente não serão capazes de funcionar em organizações de agentes que utilizam um modelo organizacional diferente.

Observando os resultados da análise e comparação dos modelos organizacionais apresentados nos capítulos precedentes, o problema fica ainda mais evidente.

Ainda na subseção 1.1.3, foram discutidos quatro abordagens gerais para este problema: (1) a padronização, i.e., a definição de um padrão de modelagem organizacional; (2) a delegação, i.e., a criação de representantes ou delegados que assumem o raciocínio organizacional dos agentes; (3) a universalidade, i.e., a criação de arquiteturas de agentes ou infraestruturas organizacionais universais; e (4) a adaptação, i.e., a criação de adaptadores encarregados de converter especificações entre diferentes modelos organizacionais. Ao final da discussão, constatou-se que as abordagens (1), (3) e (4) naturalmente pressupõem um conhecimento integrado dos modelos organizacionais utilizados no projeto de agentes e organizações de agentes.

Neste capítulo, partindo da integração de modelos organizacionais realizada na Parte II, apresenta-se uma solução de interoperabilidade organizacional seguindo a linha da abordagem (4), a adaptação. A solução é uma infraestrutura denominada MAORI (Model-driven Architecture for ORganizational Interoperability). O objetivo principal da infraestrutura MAORI é mostrar concretamente como a integração de modelos organizacionais realizada nos capítulos anteriores pode ser utilizada como componente de uma solução de interoperabilidade 
organizacional.

Com relação à escolha da adaptação, em oposição às outras abordagens de interoperabilidade, observa-se o seguinte. Como mencionado na subseção 1.1.3, a padronização requer consenso entre vários grupos de pesquisa e desenvolvimento em uma área. Dessa forma, utilizar a integração realizada para propor um padrão de modelagem organizacional não é realista no escopo de uma tese de doutorado. Com relação à segunda abordagem, a delegação do raciocínio organizacional a componentes da infraestrutura que implementa uma organização elimina a autonomia organizacional dos agentes. Além disso, nota-se que esta solução não pressupõe a integração de modelos organizacionais que norteia este trabalho. Por fim, a criação de uma arquitetura de agente ou infraestrutura organizacional universal é possível. Neste sentido, a idéia seria criar uma arquitetura de agente ou infraestrutura organizacional diretamente a partir do metamodelo integrado do capítulo anterior. Estando baseados em uma visão unificada dos modelos organizacionais, o agente poderia ser capaz de especializar o seu "raciocínio organizacional" a modelos particulares, ou a infraestrutura poderia prover suporte direto aos vários modelos organizacionais subsumidos pela integração. No entanto, comparada com a adaptação, esta abordagem requer um tempo de desenvolvimento maior do que o tempo disponível nesta pesquisa, o que leva a deixar esta possibilidade como trabalho futuro.

O capítulo divide-se em quatro seções principais. Na seção 7.1, apresentase uma visão geral da abordagem proposta. Em seguida, nas seções 7.2 e 7.3, detalham-se a estrutura interna e funcionamento de MAORI. Na seção 7.4, são apresentadas algumas considerações finais. Uma versão resumida deste capítulo foi publicada em (COUTINHO et al., 2009).

\subsection{Visão Geral}

A infraestrutura MAORI consiste em uma solução por adaptação para o problema de interoperabilidade organizacional. Antes de detalhá-la, convém discutir de modo mais concreto o problema de interoperabilidade organizacional e a idéia geral da abordagem por adaptação. Na discussão a seguir, adota-se a arquitetura geral de SMA-COs exibida na figura 2.9.

Na figura 7.1(a), nota-se a presença de dois agentes heterogêneos ${ }^{1}$ em relação a uma organização de agentes. A organização é implementada em uma infraestru-

\footnotetext{
${ }^{1}$ Neste capítulo, o adjetivo "heterogêneo" é utilizado no sentido de "projetados tendo por base modelos organizacionais distintos".
} 


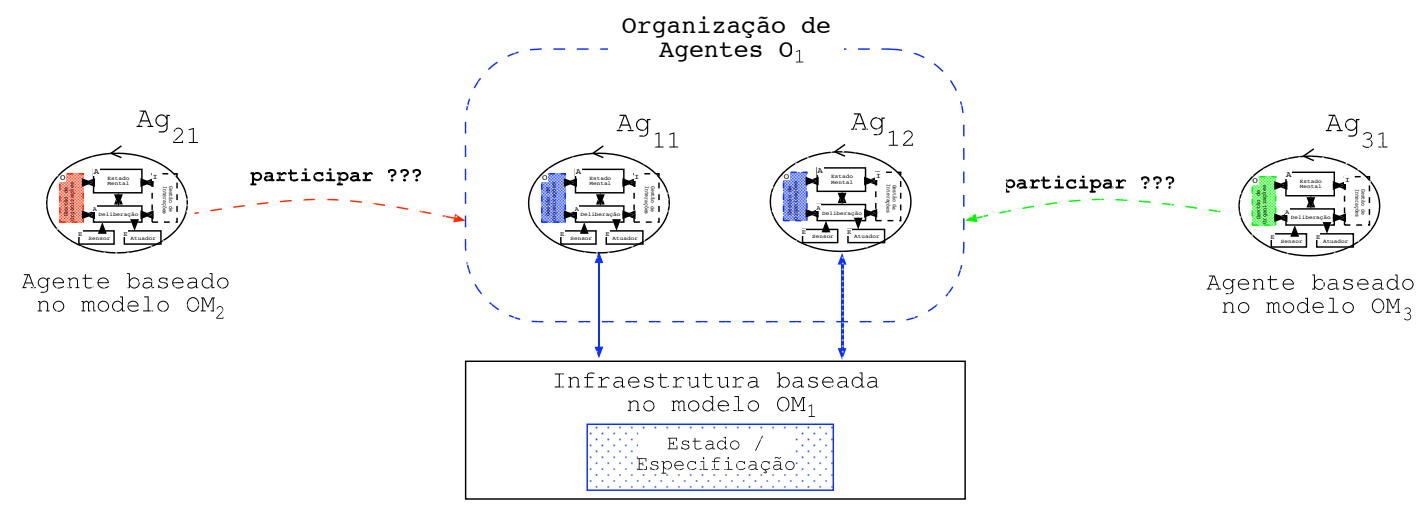

(a) O problema: agentes heterogêneos.

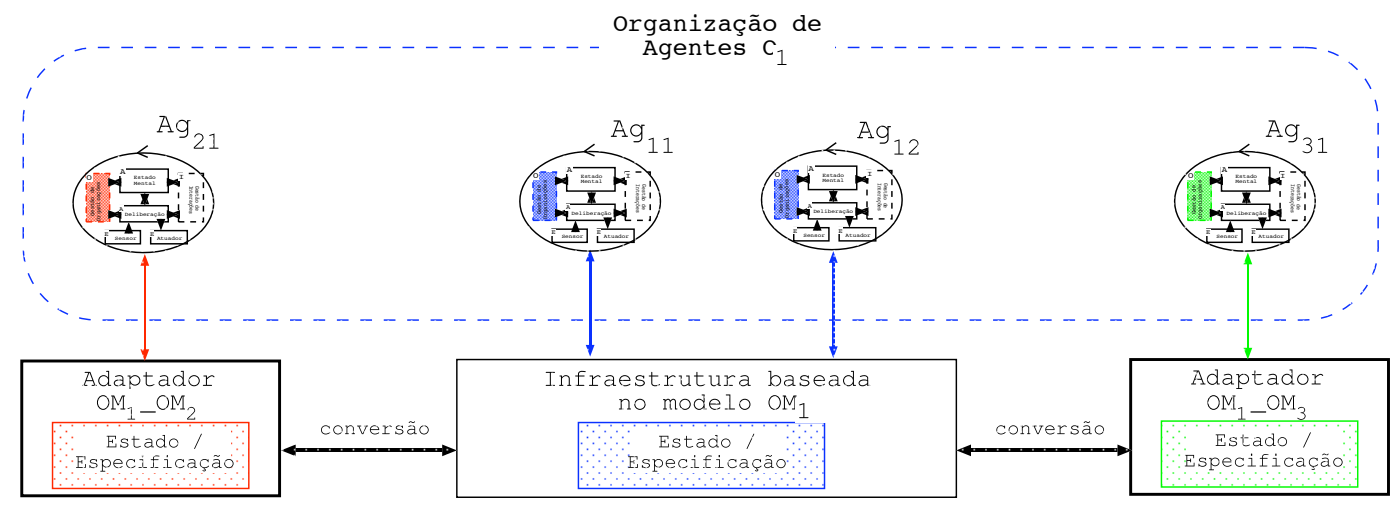

(b) Uma solução: a criação de adaptadores.

Figura 7.1: Interoperabilidade organizacional.

tura organizacional que tem por base o modelo organizacional $O M_{1}$. Os agentes heterogêneos são os agentes $A g_{21}$ e $A g_{31}$ que foram projetados para operar em infraestruturas que utilizam os modelos $O M_{2}$ e $O M_{3}$, diferentes de $O M_{1}$. Neste contexto, o problema de interoperabilidade organizacional surge quando se deseja que $A g_{21}$ ou $A g_{31}$ participem da organização de agentes.

Na figura 7.1(b), ilustra-se a idéia geral da solução por adaptação para o problema de interoperabilidade organizacional. Nesta abordagem, a participação de agentes heterogêneos é possibilitada por adaptadores. Cada adaptador tem como função converter tanto a especificação quanto o estado da organização do modelo $O M_{1}$ para um modelo organizacional destino. No caso do agente $A g_{21} \mathrm{o}$ modelo destino é $\mathrm{OM}_{2}$; no caso do $\mathrm{Ag}_{31}, \mathrm{OM}_{3}$.

Além de realizar esta conversão, o adaptador tem ainda duas outras funções: interligar os agentes à infraestrutura da organização de agentes e permitir a comunicação do agente heterogêneo com os outros agentes da organização. No primeiro caso, o adaptador deve compatibilizar não apenas o estado e especificação orga- 
nizacional, mas também a interface de acesso à infraestrutura organizacional. Sem isso, o agente heterogêneo fica sem poder disparar eventos organizacionais. No segundo caso, o adaptador deve fazer uma ponte entre a infraestrutura de comunicação da organização de agentes e a infraestrutura utilizada pelo agente heterogêneo, caso sejam diferentes. Sem isso, o agente fica sem poder trocar mensagens com os outros agentes da organização que podem estar situados em um espaço de comunicação diferente.

Como discutido na subseção 1.1.3, a conversão entre modelos organizacionais pode ser feita de duas maneiras. A primeira é converter diretamente de um modelo organizacional para o outro. A segunda consiste em fazer a conversão por intermédio de uma integração dos modelos. No caso de MAORI, cuja proposta é aplicar a integração de modelos organizacionais realizada na Parte II, adota-se a segunda abordagem.

\subsection{Estrutura Interna}

MAORI é estruturada em camadas. Destacam-se duas camadas principais: uma camada inferior, denominada camada de integração de modelos (camada M2M); e uma camada superior, denominada camada de interoperabilidade organizacional (camada ORI). Na figura 7.2, ilustra-se a divisão de MAORI nas camadas M2M e ORI, bem como os principais componentes que pertence a essas duas camadas.

\subsubsection{Camada de Integração de Modelos}

Na camada de integração de modelos (M2M), encontram-se dois tipos de componentes: metamodelos e transformações.

Os metamodelos designados por $M M_{1}, M M_{2}, \ldots, M M_{n}$ são representações da estrutura conceitual de modelos organizacionais $O M_{1}, O M_{2}, \ldots, O M_{n}$, respectivamente. O metamodelo $M M^{\text {int }}$ consiste na integração conceitual dos modelos organizacionais representados por $M M_{1}, M M_{2}, \ldots, M M_{n}$, conforme apresentado no capítulo 6.

As transformações são funções executáveis que implementam os mapeamentos de articulação entre o metamodelo integrado $M M^{\text {int }}$ e os metamodelos $M M_{1}$, $M M_{2}, \ldots, M M_{n}$ definidos durante a criação de $M M^{i n t}$. Cada mapeamento dá origem a duas transformações: uma transformação transf (from: $\left.M M_{i}\right): M M^{\text {int }}$, que converte especificações e estados organizacionais conforme $M M_{i}$ para uma 


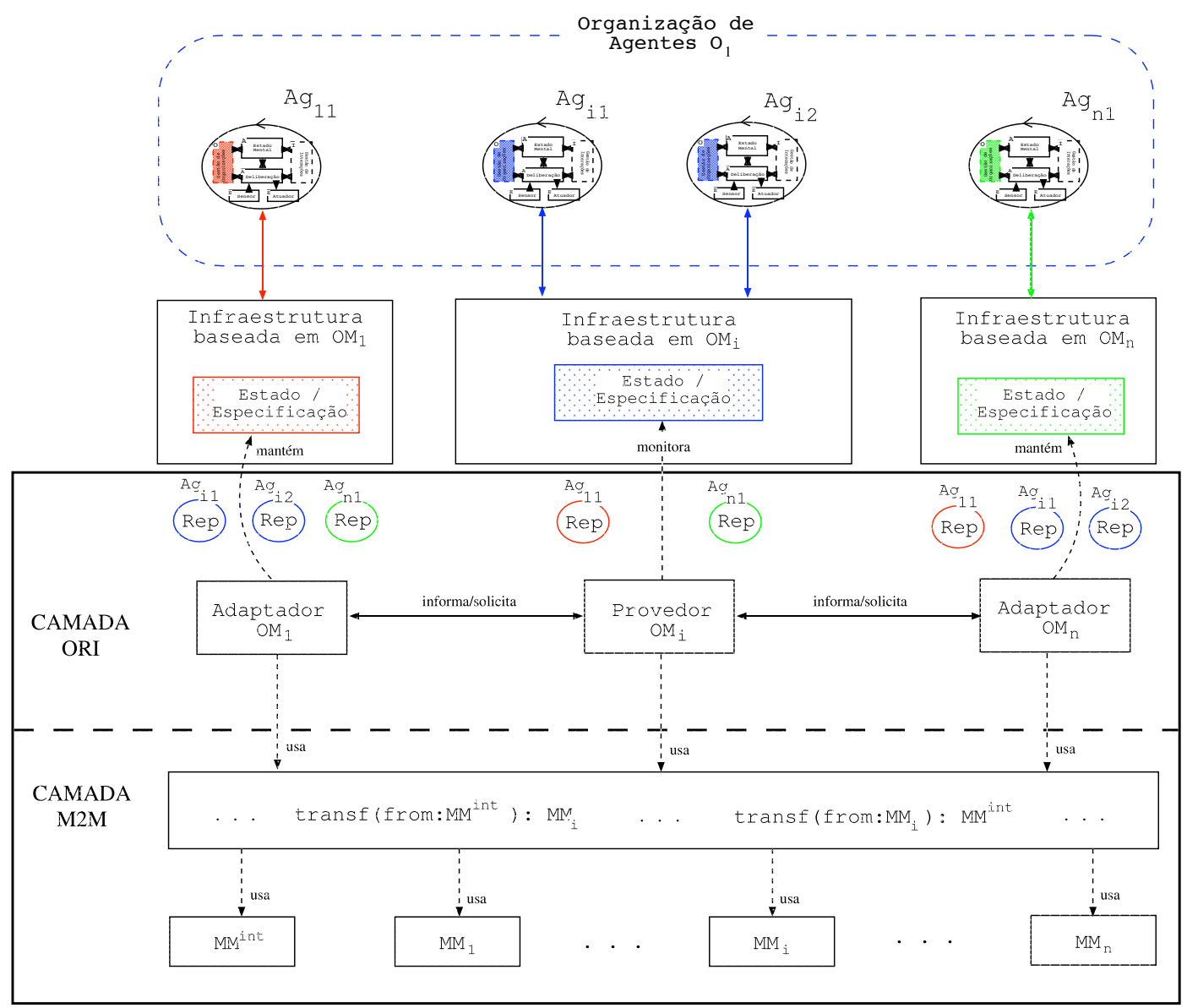

Figura 7.2: infraestrutura MAORI.

representação equivalente conforme $M M^{\text {int }}$; e a inversa transf $\left(\right.$ from: $\left.M M^{\text {int }}\right)$ : $M M_{i}$, que converte do metamodelo integrado $M M^{\text {int }}$ para um particular metamodelo $M M_{i}$.

Pela definição de integração conceitual, seção 3.2, observa-se que nas transformações transf $\left(\right.$ from: $\left.M M_{i}\right)$ : $M M^{\text {int }}$ não ocorrem perdas de informação. Já nas transformações inversas transf (from: $\left.M M_{i}\right): M M^{\text {int }}$, em geral, pode-se perder informação. Esta observação pode ser formulada de modo mais preciso da seguinte maneira. Dada a definição

$$
\operatorname{conv}_{i j}\left(\text { from }_{)}=_{\text {def }} \operatorname{transf}\left(\operatorname{transf}\left(\text { from }: M M_{i}\right): M M^{\text {int }}\right): M M_{j}\right.
$$

sempre se tem

$$
\text { spec }=\operatorname{conv}_{i i}(\text { spec })
$$

mas não há garantias de que

$$
s p e c=\operatorname{conv}_{j i}\left(\operatorname{conv}_{i j}(\text { spec })\right)
$$

para qualquer especificação spec escrita conforme um dado metamodelo $M M_{i}$. A condição $s p e c=\operatorname{conv}_{i i}(s p e c)$ especifica que transformar uma especificação 
para o metamodelo integrado e em seguida fazer o inverso, resulta na mesma especificação original. Por outro lado, partir de uma especificação escrita em um $M M_{i}$, converter esta especificação para um metamodelo diferente $M M_{j}$ por intermédio de $M M^{\text {int }}$, e em seguida fazer o caminho inverso, não necessariamente resulta na especificação original escrita conforme $M M_{i}$. Uma discussão mais detalhada sobre as implicações deste fato é apresentada nas considerações ao final deste capítulo.

Em suma, a função principal da camada de integração de modelos é prover transformações que possam ser combinadas para converter especificações e estados organizacionais entre modelos organizacionais.

\subsubsection{Camada de Interoperabilidade Organizacional}

A camada de interoperabilidade organizacional (ORI) funciona como uma extensão das infraestruturas organizacionais utilizadas na implementação de organizações de agentes. Buscando habilitar a participação de agentes heterogêneos em uma mesma organização, a camada ORI adiciona três componentes básicos às infraestruturas organizacionais: provedores organizacionais, adaptadores organizacionais e representantes de agentes.

\subsubsection{Provedores e adaptadores}

Provedores organizacionais são responsáveis por exportar a especificação e estado de uma organização de agentes. Neste caso, exportar significa converter a especificação e estados organizacionais expressos de acordo com um dado metamodelo $M M_{i}$ para o metamodelo integrado $M M^{\text {int }}$, utilizando transf $($ from: $\left.M M_{i}\right): M M^{i n t}$.

Adaptadores organizacionais são responsáveis por importar a especificação e estado organizacionais exportados pelos provedores, emulando a organização exportada em uma infraestrutura destino. A importação ocorre utilizando a transformação transf(from: $\left.M M^{\text {int }}\right): M M_{j}$, caso a infraestrutura destino seja baseada no modelo organizacional $O M_{j}$.

Deste modo, para cada organização formada por agentes heterogêneos deve existir um provedor organizacional. Conectados ao provedor, pode haver vários adaptadores organizacionais, um para cada infraestrutura organizacional na qual situam-se agentes heterogêneos que participam da organização. Para estabelecer conexões, os provedores e adaptadores devem compartilhar um meio de 


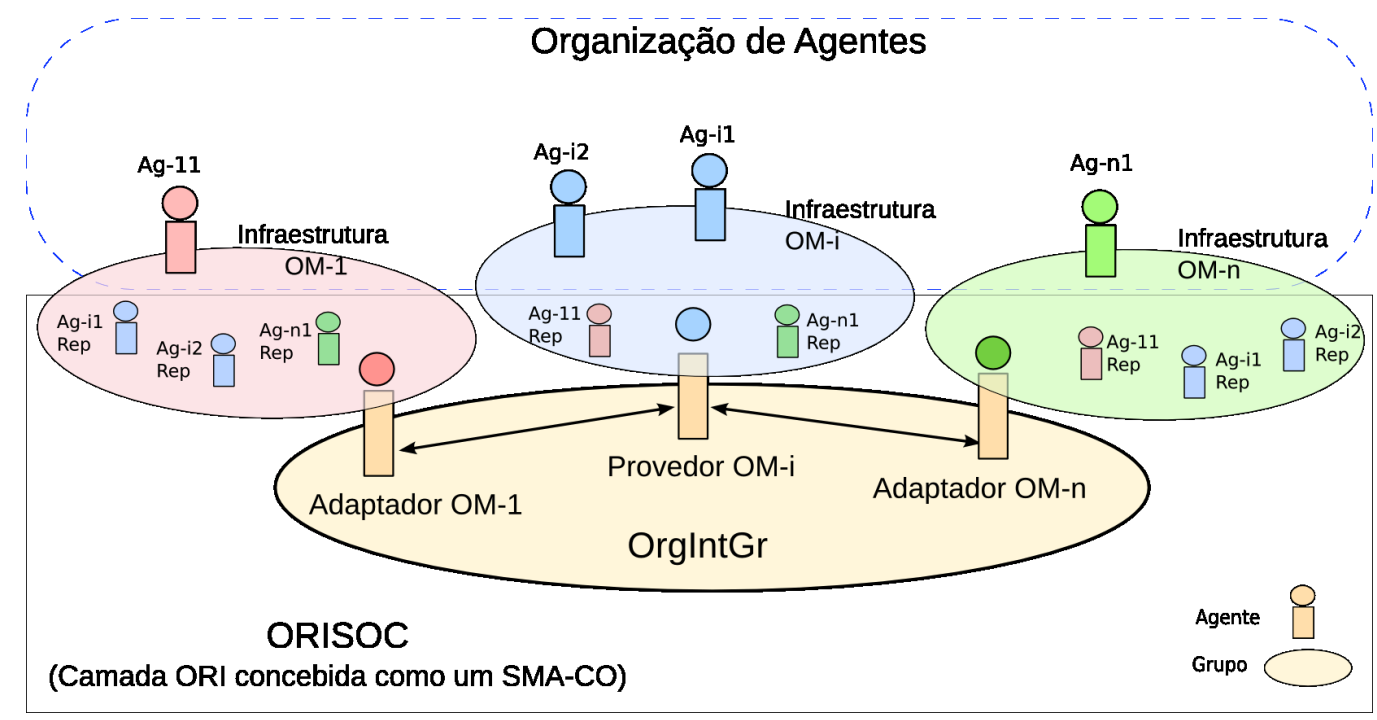

Figura 7.3: Sociedade de interoperabilidade organizacional ORISOC.

comunicação e protocolo de interação. Na seção 7.3, discute-se o protocolo de interação; já o meio de comunicação compartilhado é discutido a seguir.

\section{Sociedade de Interoperabilidade Organizacional}

De modo a permitir que se estabeleçam conexões, provedores e adaptadores organizacionais são concebidos como agentes que participam como membros de uma organização chamada de sociedade de interoperabilidade organizacional (ORISOC). Desta maneira, internamente, a própria camada ORI é concebida como um SMA-CO, como ilustrado na figura 7.3.

Concebida como um SMA-CO, a camada ORI pode ser modelada por meio de uma especificação organizacional. Utilizando o modelo MOISE+ (subseção 4.2.4), a especificação organizacional da camada ORI, restrita à dimensão estrutural, é apresentada na figura 7.4. Na figura, o grupo ORISOC representa a camada ORI. Compondo ORISOC, podem existir vários (sub)grupos OrgIntGr. Em cada OrgIntGr, definem-se dois papéis: OrgProvider e OrgAdapter. Dentro de um grupo OrgIntGr, no papel de OrgProvider, só pode haver um único agente, e este agente é um provedor organizacional. Já no papel de OrgAdapter, podem existir vários agentes, e estes agentes são adaptadores organizacionais. Por fim, agentes no papel de OrgProvider podem se comunicar com agentes no papel de OrgAdapter, e vice-versa. Deste modo, cada grupo OrgIntGr de ORISOC representa uma conexão que pode ser estabelecida entre um provedor e vários adaptadores organizacionais dentro da camada ORI para prover interoperabilidade organizacional.

A partir da representação da camada ORI por meio de uma especificação organizacional, o maior benefício é que se pode utilizar uma infraestrutura orga- 

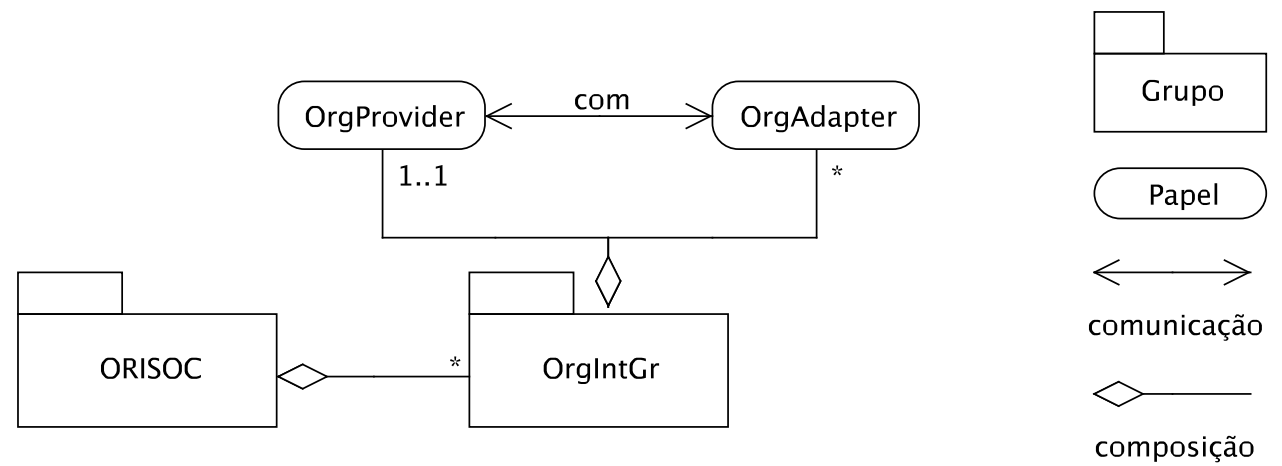

Figura 7.4: Especificação organizacional da camada ORI, em MOISE+.

nizacional para implementá-la. Seguindo este caminho, o meio de comunicação compartilhado entre provedores e adaptadores organizacionais será a infraestrutura de comunicação subjacente à infraestrutura organizacional utilizada. Por exemplo, observando que se utilizou MOISE+ para modelar a camada ORI, a escolha natural de infraestrutura organizacional é S-MOISE + , descrita na subseção 2.3.3.3. Utilizando S-MOISE+, a comunicação entre provedores e adaptadores pode ser realizada conforme ilustrado na figura 7.5. A figura é uma instanciação da arquitetura de S-MOISE+ (figura 2.7) na qual os agentes da camada de aplicação são provedores e adaptadores que compõem a camada ORI da infraestrutura MAORI.

Dado este meio de comunicação, uma conexão entre um provedor e vários adaptadores ocorre da seguinte maneira:

1. Um provedor obtém um OrgBox na infraestrutura S-MOISE+.

2. A partir do OrgBox, o provedor cria um grupo OrgIntGr e assume o papel OrgProvider.

3. Em seguida adaptadores obtêm componentes $\operatorname{OrgBox}$ e entram no grupo criado assumindo o papel de OrgAdapter.

4. Uma vez no grupo, provedores e adaptadores podem trocar mensagens utilizando a infraestrutura de comunicação subjacente a S-MOISE+.

Mais detalhes relativos a este protocolo são apresentados na seção 7.3.

\subsubsection{Representantes de Agentes}

Como o nome sugere, representantes de agentes são componentes da camada ORI que funcionam como representantes locais (proxies) de agentes situados em 


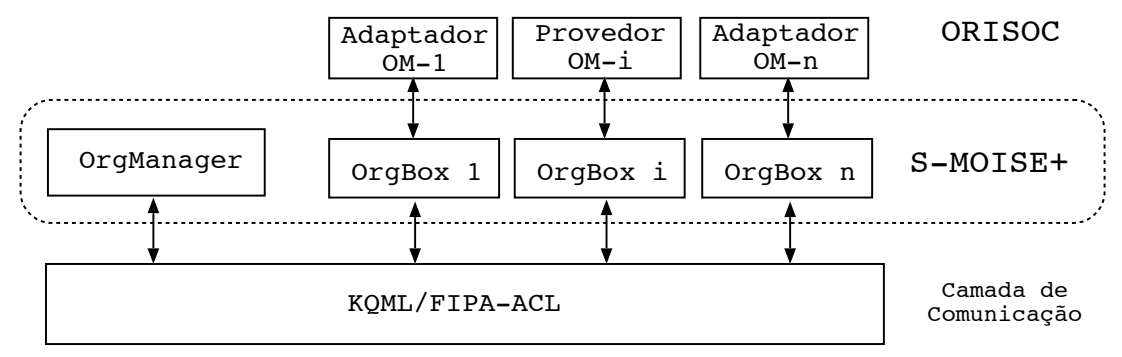

Figura 7.5: Conexão entre provedor e adaptadores por meio de S-MOISE+.

infraestruturas organizacionais remotas. O propósito básico destes componentes é possibilitar que agentes situados em diferentes infraestruturas organizacionais possam trocar mensagens.

Quando um agente entra em uma organização, em geral, espera-se que ele venha a trocar mensagens com outros agentes que fazem parte da mesma organização. Contudo, se o agente que deve receber a mensagem não estiver fisicamente localizado no mesmo espaço de comunicação, i.e., infraestrutura organizacional, há o problema de como fazer para que a mensagem chegue até o recipiente. Na camada ORI, isto é feito através dos representantes de agentes. Tanto o provedor quanto os adaptadores registram um representante para cada agente remoto, i.e., um agente que é parte da organização mas que está situado em um espaço de comunicação diferente. Estes representantes são vistos como agentes locais pelos outros agentes presentes no mesmo espaço de comunicação. Desta maneira, não importando onde estejam situados, os agentes têm uma visão de todos os agentes que atualmente fazem parte da organização, como ilustrado na figura 7.3 .

Caso um agente enderece uma mensagem a um representante de agente, a mensagem é roteada via provedor e adaptadores até chegar ao seu destinatário real, como apresentado a seguir.

\subsection{Funcionamento}

Nesta seção, descreve-se a dinâmica de funcionamento dos componentes de MAORI. São consideradas três situações: (1) o estabelecimento de conexão entre um provedor e vários adaptadores, (2) a propagação de eventos organizacionais entre provedor e adaptadores, e (3) o roteamento de mensagens entre agentes situados em diferentes infraestruturas. Estas situações resumem os aspectos principais do funcionamento de MAORI. 


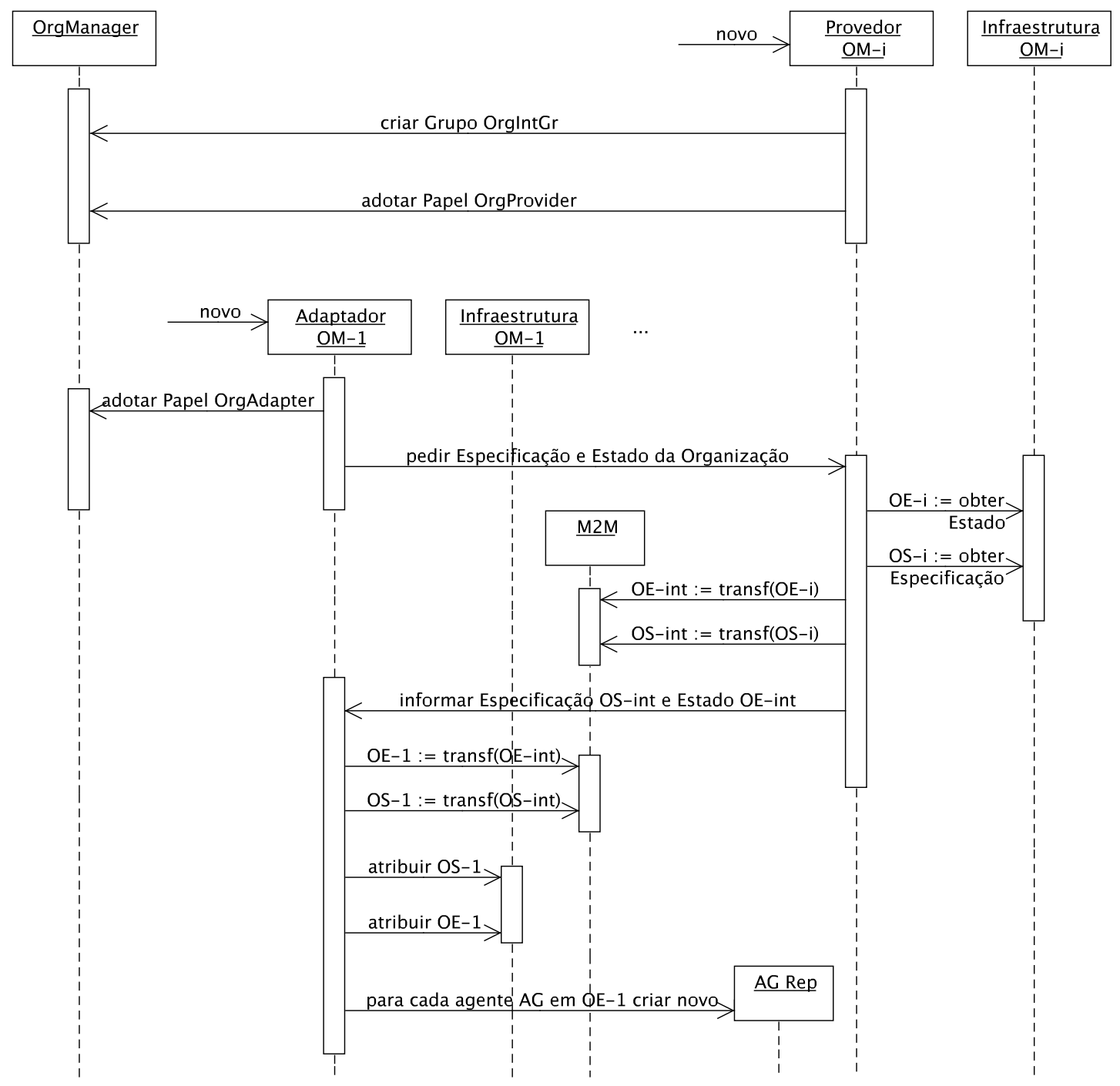

Figura 7.6: Protocolo de conexão entre provedor e adaptadores.

\subsubsection{Conexão entre Provedor e Adaptadores}

Para permitir a participação de agentes heterogêneos em uma mesma organização, o primeiro passo é instanciar um provedor organizacional encarregado de exportar a especificação e estado da organização de agentes. Em seguida, instanciam-se adaptadores organizacionais. Ao iniciar, cada adaptador entra em comunicação com o provedor e importa a especificação e estado da organização para a sua infraestrutura organizacional. Além disto, cada adaptador cria ainda representantes para cada agente presente no estado atual da organização. Este processo inicial de conexão entre um provedor e vários adaptadores é especificado pelo protocolo de conexão apresentado na figura 7.6.

No protocolo, nota-se a presença do componente OrgManager da infraestrutura S-MOISE+. Como mencionado anteriormente, a infraestrutura S-MOISE+ é utilizada como meio de comunicação entre provedores e adaptadores. Assim, as primeiras ações de um novo provedor organizacional são criar um grupo OrgIntGr 
e nele adotar o papel de OrgProvider. Em seguida, cada novo adaptador entra no grupo criado adotando o papel de OrgAdapter. Uma vez no grupo, os adaptadores passam a ter contato com o provedor via a infraestrutura de comunicação de S-MOISE+.

Estabelecida uma conexão, a primeira ação de cada adaptador é solicitar ao provedor a especificação e o estado atual da organização de agentes. O provedor obtém a especificação e estado junto a infraestrutura organizacional na qual ele foi criado. Em seguida, utilizando a transformação transf $\left(\right.$ from: $\left.M M_{i}\right): M M^{\text {int }}$ definidas na camada M2M, o provedor converte a especificação e estado organizacional para o formato do metamodelo integrado $M M^{\text {int }}$. O resultado é enviado para o adaptador que solicitou de início a especificação e estado da organização.

Ao receber a especificação e estado da organização no formato $M M^{\text {int }}$, cada adaptador ativa uma transformação transf(from: $\left.M M^{\text {int }}\right): M M_{j}$. Com isto, o adaptador passa a ter a especificação e estado da organização conforme o modelo organizacional $O M_{j}$ utilizado na infraestrutura que ele representa (na figura 7.6, ilustra-se o caso quando $j=1$ ). Por fim, para cada agente registrado no estado atual da organização, o adaptador inicia um representante de agente. Estes representantes ligarão os agentes que irão participar da organização por intermédio do adaptador aos outros agentes presentes na organização.

\subsubsection{Propagação de Eventos Organizacionais}

Com o passar do tempo, o estado de uma organização sofre mudanças causadas por eventos organizacionais disparados pelos agentes. Exemplos de eventos organizacionais são a criação de um grupo, a adoção de um papel por um agente em um grupo, a criação de um plano conjunto, etc. Para lidar com estes eventos, os adaptadores devem manter constante comunicação com o provedor ao qual estão conectados, e vice-versa. A forma geral dessa comunicação é especificada pelos protocolos de propagação de eventos organizacionais apresentados na figura 7.7.

Cada evento organizacional pode ser disparado tanto no lado do provedor como no lado de um adaptador. Por exemplo, uma requisição para adotar um papel pode ser feita tanto por um agente situado na infraestrutura monitorada por um provedor, quanto por um agente executando em um infraestrutura na qual o estado e especificação da organização foram importados por um adaptador. No primeiro caso, para manter seus estados em sincronia, provedor e adaptadores irão se comunicar como especificado pelo protocolo ilustrado na 7.7(a). No segundo caso, a comunicação ocorre seguindo o protocolo da figura 7.7(b). 


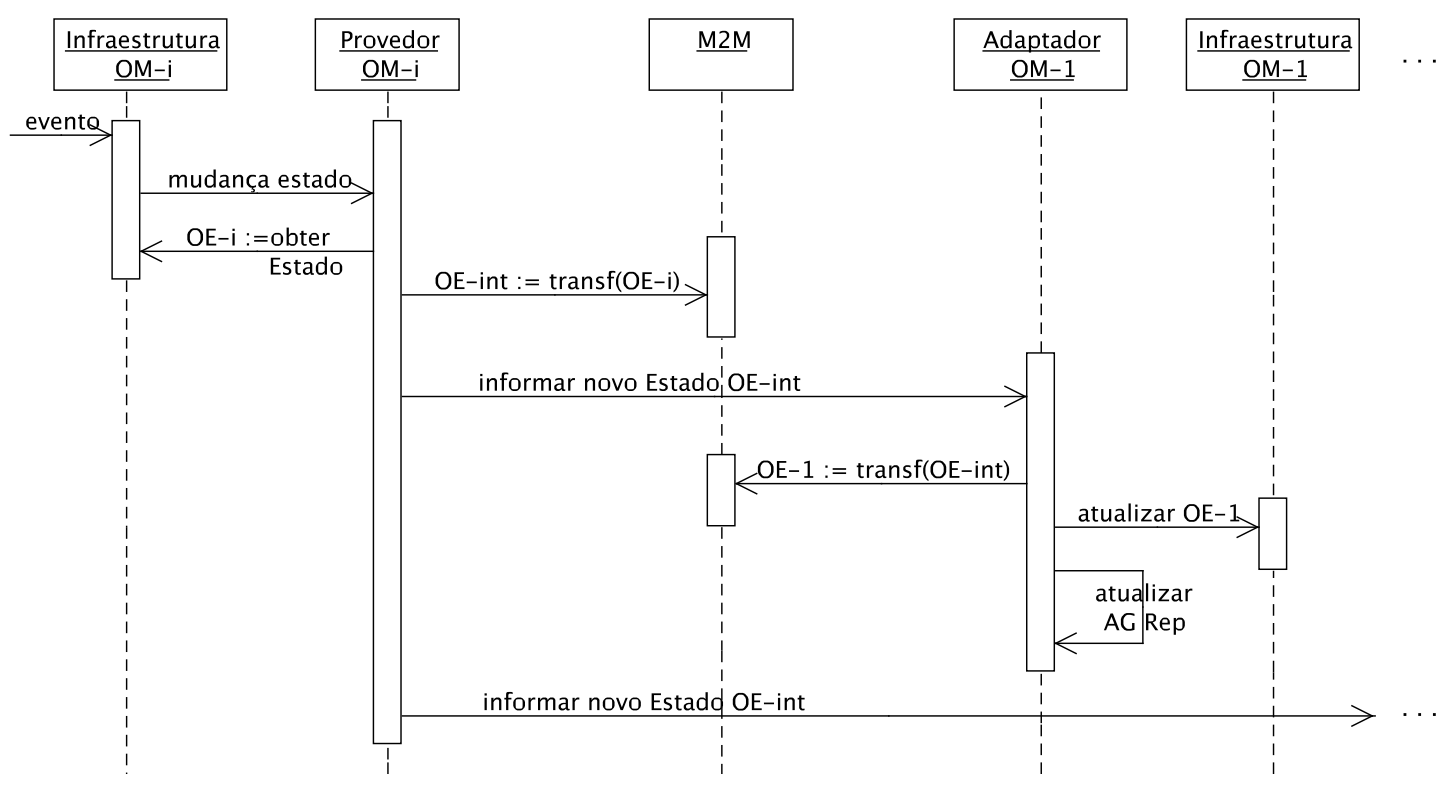

(a) Eventos no lado do provedor.

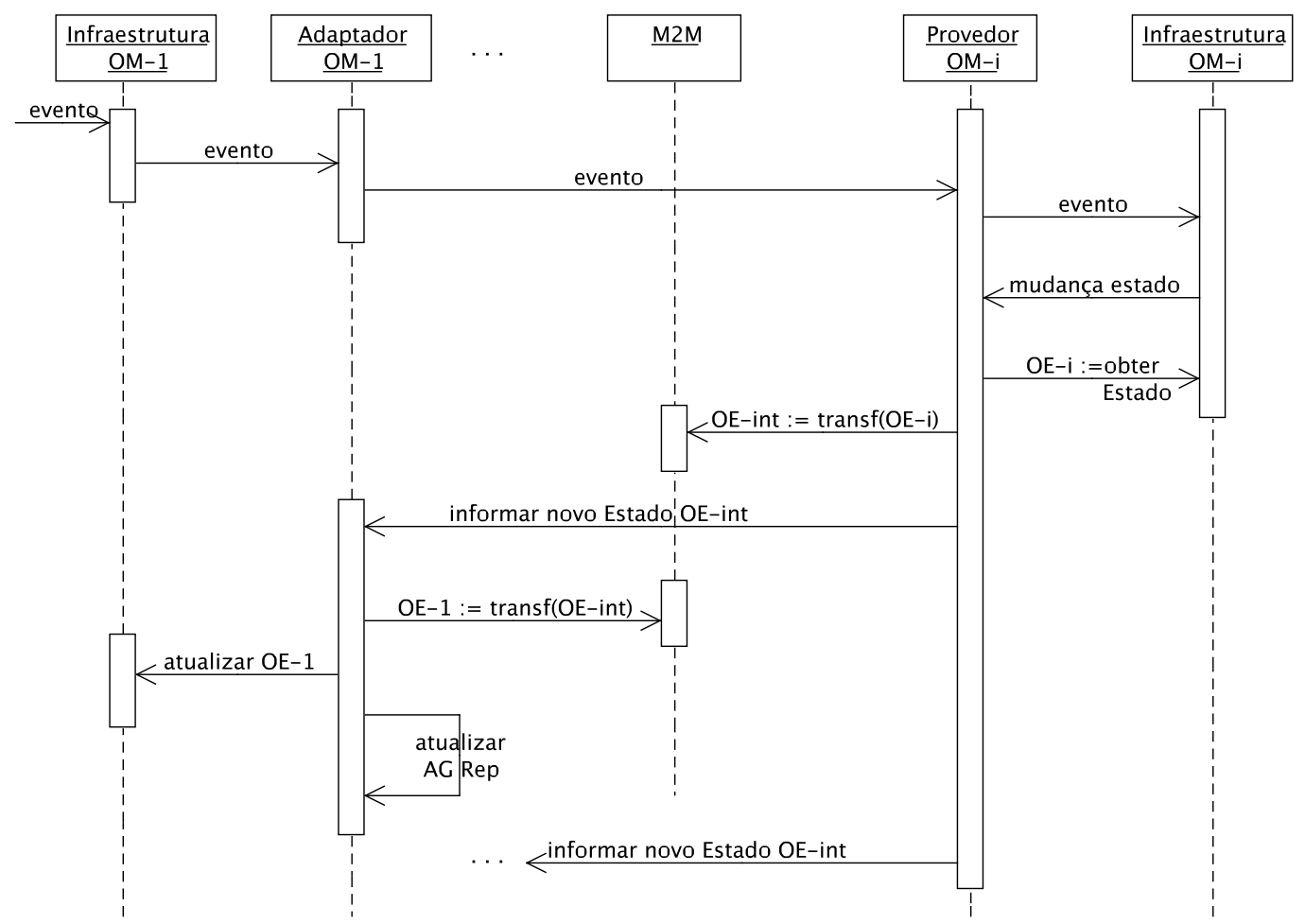

(b) Eventos no lado dos adaptadores.

Figura 7.7: Protocolos de propagação de eventos organizacionais. 
No lado do provedor, quando uma mudança no estado da organização é detectada, o provedor obtém o novo estado junto a infraestrutura organizacional, transforma-o para o formato do metamodelo integrado $M M^{i n t}$, e envia o novo estado convertido para cada adaptador atualmente presente no grupo OrgIntGr. Ao receber a mensagem com o novo estado, cada adaptador converte de $M M^{\text {int }}$ para o metamodelo de sua infraestrutura correspondente e, em seguida, atualiza o estado organizacional e eventualmente cria ou destrói representantes de agentes. Desta maneira, a mudança no estado organizacional causada por um evento, tal como a entrada de um novo agente em determinado papel, é propagada do provedor aos adaptadores.

No lado do adaptador, eventos organizacionais não causam diretamente mudanças no estado organizacional. O motivo é que os adaptadores mantém uma cópia traduzida do estado original presente no lado do provedor. Assim, o adaptador, ao perceber um evento, repassa-o ao provedor do grupo OrgIntGr do qual faz parte. Ao receber a mensagem de um adaptador informando sobre um evento organizacional, o provedor dispara o mesmo evento na sua infraestrutura correspondente. Caso ocorrido com sucesso, o evento causa uma mudança de estado que é propagada para todos os adaptadores seguindo a mesma sequência de mensagens descrita no protocolo representado na figura 7.7(a). Deste modo, eventos do lado de um adaptador primeiro são validados pelo provedor e em seguida quaisquer mudanças de estado ocorridas são propagadas para os adaptadores.

\subsubsection{Roteamento de Mensagens entre Agentes}

Para que uma organização heterogênea funcione de modo integrado, além da interoperabilidade organizacional que permite compatibilizar especificações e estados organizacionais entre diferentes modelos, também há a questão da interoperabilidade de comunicação entre os agentes participantes da organização. A este respeito, há três pontos a serem considerados:

- primeiro, a possibilidade dos agentes utilizarem diferentes linguagens de comunicação (e.g., KQML e FIPA-ACL);

- segundo, a possibilidade dos agentes interpretarem de modo diverso o conteúdo das mensagens trocadas entre eles (i.e., utilizando diferentes conceitualizações do domínio de aplicação da organização de agentes); e

- terceiro, a possibilidade dos agentes utilizarem diferentes infraestruturas de comunicação para enviar mensagens. 


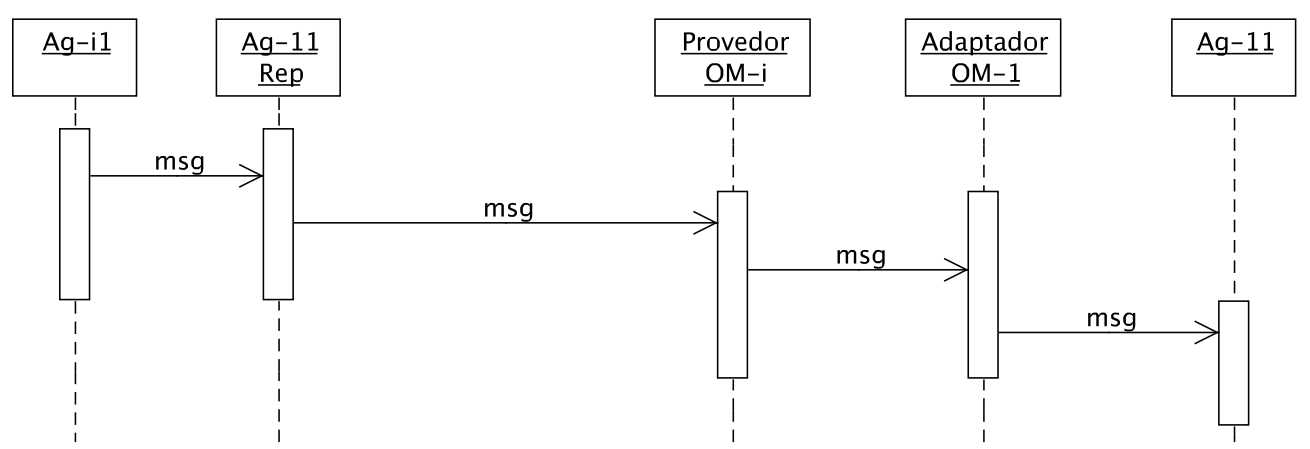

(a) Mensagens iniciadas no lado do provedor.

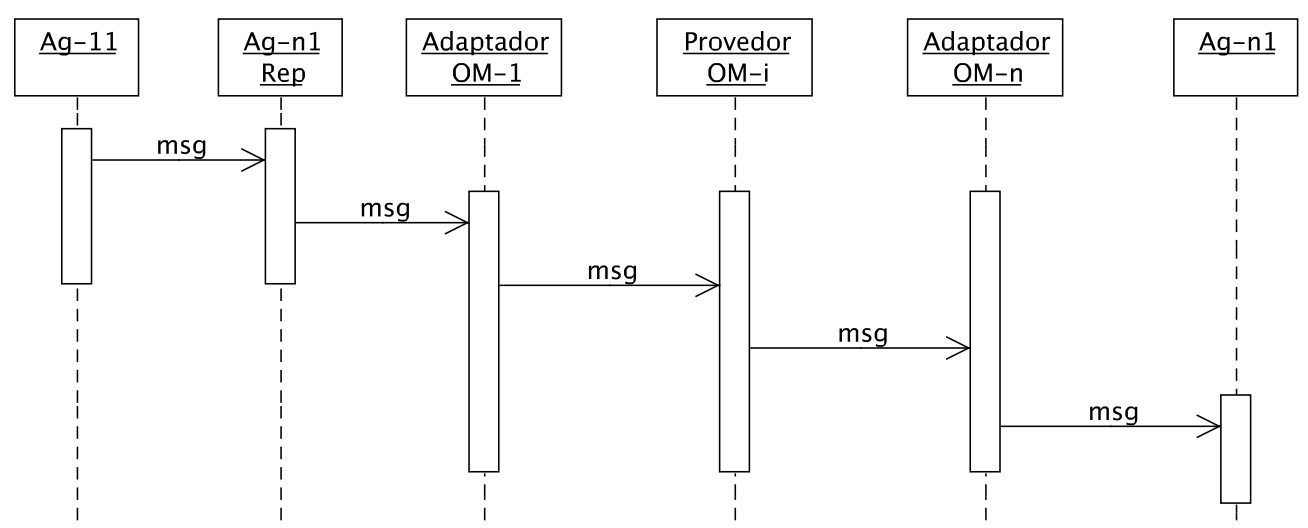

(b) Mensagens iniciadas no lado de um adaptador.

Figura 7.8: Protocolos de roteamento de mensagens entre agentes.

Foge ao escopo da infraestrutura MAORI solucionar todas estas questões. Assim, quanto ao primeiro e ao segundo pontos, assume-se que os agentes são homogêneos. Quanto ao terceiro ponto, ele é tratado explicitamente por meio dos representantes de agentes, como já mencionado.

A interação entre representantes de agentes, provedor, e adaptadores é ilustrada na figura 7.8. Como na propagação de eventos organizacionais, são considerados dois casos de roteamento de mensagens: mensagens que iniciam no lado do provedor e mensagens iniciadas no lado de um adaptador.

No primeiro caso, figura 7.8(a), um agente $A g_{i 1}$ envia uma mensagem destinada a um agente $A g_{11}$. A organização da qual os dois participam é originalmente implementada em uma infraestrutura baseada no modelo organizacional $O M_{i}$. $A g_{i 1}$ executa diretamente na mesma infraestrutura da organização e $A g_{11}$ está na organização por intermédio de um adaptador para o modelo organizacional $O M_{1}$ (cenário igual ao ilustrado na figura 7.3). Nestas condições, e assumindo que $A g_{i 1}$ tenha a permissão de enviar mensagens para $A g_{11}$, a mensagem enviada por $A g_{i 1}$ chega primeiro a um representante de $A g_{11}$ mantido pelo provedor $O M_{i}$. 
Recebendo a mensagem, o representante de $A g_{11}$ a repassa ao provedor. Sabendo tratar-se de uma mensagem para um agente que executa junto a um adaptador $O M_{1}$, o provedor encaminha a mensagem ao adaptador em questão. Por fim, o adaptador faz a mensagem chegar ao agente destinatário final $A g_{11}$.

No segundo caso, figura 7.8(b), tem-se a situação na qual um agente $A_{11}$ executando junto a um adaptador $O M_{1}$ deseja enviar uma mensagem a um agente $A g_{n 1}$ executando junto a um outro adaptador $O M_{n}$. Neste tipo de situação, a mensagem chega primeiro ao representante de $A g_{n 1}$ mantido pelo adaptador $O M_{1}$. Em seguida, o adaptador recebe a mensagem do representante. Como adaptadores não podem conversar diretamente entre si, restrição determinada pela especificação da figura 7.4, o adaptador $O M_{1}$ necessariamente repassa a mensagem ao provedor do grupo OrgIntGr do qual faz parte. Observando que a mensagem destina-se a um agente que executa junto a um adaptador $O M_{n}$, o provedor encaminha a mensagem ao adaptador adequado. Por fim, o adaptador $O M_{n}$ envia a mensagem ao agente destinatário final $A g_{n 1}$.

O motivo pelo qual não é permitida a comunicação direta entre adaptadores é que a visão que eles têm sobre a especificação e estado da organização pode ser incompleta. Por exemplo, no modelo organizacional MOISE+, pode-se especificar que certos papéis não têm permissão de comunicação com outros papéis. Já no modelo AGR, não há como expressar esta restrição. Assim, um adaptador do modelo MOISE+ para o modelo AGR não têm como decidir, sem consultar um provedor MOISE+, se um agente pode ou não se comunicar diretamente com outro.

\subsection{Considerações Finais}

Como discutido neste capítulo, na infraestrutura MAORI têm-se uma solução baseada em adaptação para o problema de interoperabilidade organizacional. Além de prover interoperabilidade organizacional, a solução permite que uma mesma organização seja distribuída ao longo de várias infraestruturas organizacionais heterogêneas.

Por ser baseada unicamente em adaptação, há entretanto algumas limitações práticas quanto à aplicação da infraestrutura MAORI. A principal delas é que a abordagem por adaptação requer que os modelos envolvidos apresentem compatibilidade conceitual, permitindo a definição de mapeamentos com pouca perda de informação. A este respeito, tendo por base os mapeamentos discutidos na Parte 
II ao se integrar os modelos AGR, STEAM, MOISE+ e ISLANDER, conclui-se que a perda de informação pode ser considerável ao se tentar expressar especificações escritas em um modelo organizacional em outro modelo. Por exemplo, o modelo AGR prevê apenas a modelagem estrutural de organização. Já STEAM e MOISE+, além da dimensão estrutural, provêem conceitos de modelagem funcional. Logo, converter especificações de AGR para STEAM ou MOISE+ é possível com perda mínima de informação. Mas o contrário, i.e., converter de STEAM ou MOISE+ para AGR acarreta perder as informações a respeito da dimensão funcional. Um outro exemplo, é converter entre MOISE+ e ISLANDER: em ISLANDER não é possível expressar a modelagem funcional de MOISE+, e em MOISE+ não é possível expressar a modelagem dialógica de ISLANDER.

Dada essa limitação inerente da abordagem de adaptação, um dos pressupostos básicos por trás da concepção da infraestrutura MAORI é que se possa realizar mapeamentos entre as estruturas conceituais dos modelos organizacionais envolvidos. Na prática, isto implica em restringir os modelos organizacionais a um núcleo comum. Considerando os modelos organizacionais integrados na Parte II, esse núcleo comum consiste em parte da dimensão estrutural, mais precisamente os conceitos básicos de definição de grupo e definição de papel. Ficam de fora a definição de relações entre papéis, terceiro conceito básico da dimensão estrutural, e as outras dimensões de modelagem organizacional. Apesar de ocorrer nos vários modelos organizacionais, a definição de relações entre papéis fica de fora porque em cada um deles ela se materializa em relações que têm significados completamente diferentes.

Uma maneira de minimizar essa limitação da abordagem por adaptação poderia ser estender MAORI com idéias de outras abordagens de interoperabilidade. Neste sentido, uma possível extensão é acrescentar aos representantes de agentes a capacidade de funcionarem como delegados, guiando os agentes heterogêneos quando necessário. Como discutido na subseção 1.1.3, na delegação, tem-se um componente que assume o "raciocínio organizacional" dos agentes que participam de uma organização. No caso dos representantes de agente em MAORI, eles poderiam assumir parte do raciocínio organizacional quando a adaptação entre modelos organizacionais levar a perda de informação. Por limitações de escopo e tempo, o desenvolvimento desta idéia é proposta como trabalho futuro.

A seguir, apresentam-se detalhes de implementação da infraestrutura MAORI, bem como um exemplo de seu uso. 


\section{Implementação e Testes}

Neste capítulo, discutem-se a implementação da infraestrutura MAORI e um exemplo de aplicação. A implementação (seção 8.1) divide-se em duas partes: a implementação da camada M2M, realizada de modo automático a partir dos metamodelos e mapeamentos entre metamodelos propostos na Parte II; e a implementação da camada ORI, realizada manualmente para as infraestruturas organizacionais MADKIT (baseada em AGR) e S-MOISE+ (baseada em MOISE+). A aplicação (seção 8.2) consiste em uma organização denominada Write Paper na qual agentes se reúnem para escrever um artigo. Para efeito de avaliação da infraestrutura, primeiro a aplicação foi implementada apenas na infraestrutura MADKIT (utilizando agentes AGR), e apenas na infraestrutura S-MOISE+ (utilizando agentes MOISE + ). Em seguida, foram realizados alguns experimentos nos quais os agentes AGR e MOISE+ desenvolvidos, sem quaisquer modificações, são combinados em uma organização heterogênea por intermédio de MAORI. Ao final (seção 8.3), discutem-se os resultados dos testes realizados.

\subsection{Implementação de MAORI}

A implementação de MAORI foi realizada em Java, visando a compatibilidade de código com as infraestruturas organizacionais disponíveis, que se encontram implementadas nesta linguagem.

\subsubsection{Camada de Integração de Modelos}

Na camada de integração de modelos (camada M2M), a implementação dos metamodelos e das transformações foi feita com o auxílio de ferramentas de geração automática de código. 


\begin{tabular}{|c|c|c|c|}
\hline \multicolumn{4}{|c|}{ 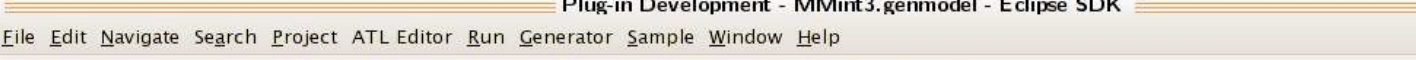 } \\
\hline 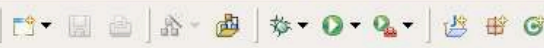 & 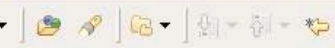 & & \\
\hline i- Navigator $\&$ Plug-ins & \multirow{2}{*}{$\begin{array}{l}\text { 圆 MMint3.gennode is } \\
\text { - 品 MMint3 }\end{array}$} & \multicolumn{2}{|r|}{ 口曰 } \\
\hline$\Leftrightarrow \Leftrightarrow \mid \mathbb{E} \Leftrightarrow$ & & & \\
\hline - cap4_orgmod & 坓 MMint3 & $\begin{array}{l}\text { Generate Model Code } \\
\text { Generate Edit Code }\end{array}$ & \\
\hline$\checkmark$ model & - 目 Organization & Generate Editor Code & \\
\hline 曷 agr.ecore & - 目 OSpec & Generate Iest Code & \\
\hline 国 agr.genmodel & $\Leftrightarrow \mathrm{sSpec}: \mathrm{SSpec}$ & Generate All & \\
\hline 䀝 islander.ecore & $\Leftrightarrow$ fSpec : FSpec & Open Ecore & \\
\hline 糔 islander.genmodel & $\Rightarrow$ nspec : NSpec & Open Germover & \\
\hline 曷 moiseplus.ecore & $\Leftrightarrow$ dSpec : DSpec & Pelindo & \\
\hline moiseplus.genmodel & '目 Sspec & $y$ Redo & \\
\hline 罚 opera.ecore & ' 目 GroupDef & of Cut & \\
\hline 曷 steam.ecore & - 目 GroupRef & Copy & \\
\hline steam.genmodel & - 目 RoleDef & Paste & \\
\hline 罚 taems.ecore & - 目 RoleRef & $X$ Delete & \\
\hline 貝 project & ·目 RoleRel & Set SDO Defaults & \\
\hline 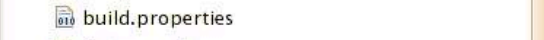 & ·目 FSpec & Run As & \\
\hline 2a. feature.xml & - 目 GoalDef & Debug As : & \\
\hline - E cap6_orgm $2 m$ & • 目 CoalDec & $\begin{array}{l}\text { Team } \\
\text { Compạre With }\end{array}$ & \\
\hline maps & ·目 CoalRel & $\begin{array}{l}\text { Compare With } \\
\text { Replace With }\end{array}$ & \\
\hline - model & - 目 HPlanDef & Refresh & \\
\hline 舅 MMint 1.ecore & $\begin{array}{l}\text { H MissionDef } \\
\text { D D pec }\end{array}$ & Show Properties View & \\
\hline 易 MMint2.ecore & - 目 DialogicalFramework & & \\
\hline 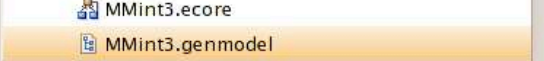 & - 目 Performativestructure & & \\
\hline 具 .project & 目 SceneNode & & \\
\hline 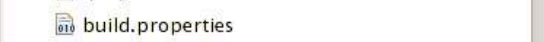 & - 目 TransitionNode & & \\
\hline
\end{tabular}

(a) Ativação da geração de código.

\begin{tabular}{|c|c|c|}
\hline E-Navigator $\& 3$ Plug-ins & 圆 MMint3.genmodel $\approx$ & 口曰 \\
\hline 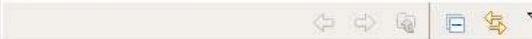 & - & - \\
\hline 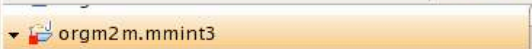 & - 曲 MMint3 & \\
\hline$\cdot \backsim$ bin & - 目 Organization & \\
\hline - 2 icons & - 目 OSpec & \\
\hline - $\because$ META-INF & $\Leftrightarrow$ sSpec : 55 pec & \\
\hline$\Rightarrow \operatorname{src}$ & $\Leftrightarrow$ fSpec : FSpec & \\
\hline$\Rightarrow \operatorname{orgm} 2 \mathrm{~m}$ & $\Leftrightarrow$ nSpec : NSpec & \\
\hline mmint 3 & $\square \mathrm{dspec}$ : DSpec & \\
\hline$-\backsim \mathrm{impl}$ & 1 Gspec & \\
\hline 』) AgentImpl.java & 1 GroupDef & \\
\hline 』 Deontic Rellmpl.java & Groupref & \\
\hline (1) DialogicalFrameworkImpl.java & , 目 RoleRef & \\
\hline (1) DSpecImpl.java & - 目 RoleRel & \\
\hline 』I FspecImpl.java & - 目 FSpec & \\
\hline (1) GoalDeclmpl.java & - 目 GoalDef & \\
\hline (1) GoalDefImpl.java & - 目 GoalDec & \\
\hline [1] GoalRellmpl.java & - 目 GoalRel & \\
\hline (1) GroupDefImpl.java & - 目 HPlanDef & \\
\hline (1) Grouplnstlmpl.java & - 目 MissionDef & \\
\hline (1) GroupRef Impl.java & 一目 DSpec & \\
\hline (1) HPlanDefImpl.java & - 目 DialogicalFramework & \\
\hline (1) MissionDefImpl.java & - 目 Performativestructure & \\
\hline (]) MissionInstImpl.java & · 目 SceneNode & \\
\hline (1) MMint3 Factorylmpl.java & - 目 TransitionNode & 7 \\
\hline
\end{tabular}

(b) Resultado da geração de código.

Figura 8.1: Implementação dos metamodelos da camada M2M. 


\section{Implementação dos metamodelos}

No caso da implementação dos metamodelos, utilizou-se a ferramenta EMF Eclipse Modeling Framework (STEINBERG et al., 2008). A utilização de EMF é consequência natural da escolha de Ecore e OCL (subseção 3.1.3) como linguagens para especificação da estrutura conceitual de modelos organizacionais. EMF é uma extensão do ambiente de desenvolvimento Eclipse $^{1}$ que habilita a geração automática de uma implementação em Java para as classes, relacionamentos e restrições contextuais de um metamodelo escrito em Ecore/OCL. A utilização de EMF é ilustrada na figura 8.1.

A título de exemplo, na figura 8.1(a) observa-se a ativação do processo de

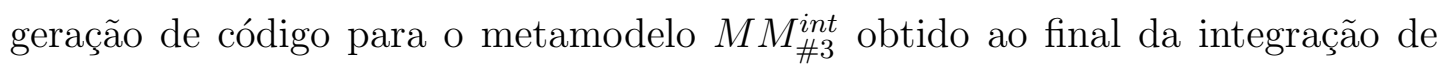
metamodelos do capítulo 6. O processo de geração é configurado pelo arquivo MMint3.genmodel e tem como entrada principal o arquivo MMint3.ecore que materializa o metamodelo $M M_{\# 3}^{\text {int }}$. Como resultado, tem-se a implementação em Java do metamodelo $M M_{\# 3}^{\text {int }}$ ilustrada na figura 8.1(b). Do mesmo modo, através dos outros arquivos com extensão . ecore e .genmodel exibidos no lado esquerdo da figura 8.1(a), os metamodelos dos outros modelos organizacionais do capítulo 4 foram implementados.

Os arquivos .ecore e .genmodel correspondentes aos modelos organizacionais discutidos no capítulo 4 estão disponíveis no anexo A. Os arquivos .ecore e . genmodel da integração de modelos organizacionais formam o anexo B. Por fim, as classes Java geradas encontram-se incorporadas à implementação de MAORI, disponível no anexo C.

\section{Implementação das transformações}

As transformações transf(from: $\left.M M_{i}\right): M M^{\text {int }}$ e transf(from: $\left.M M^{\text {int }}\right): M M_{i}$ foram codificadas de modo semi-automático. Neste caso, seguiram-se três etapas. Primeiro, utilizando uma extensão de Eclipse chamada MT4MDE - Mapping Tool for Model-Driven Engineering (LOPES; HAMMOUDI; ABDELOUAHAB, 2006), os mapeamentos definidos durante a integração de metamodelos foram descritos em modelos de mapeamento. A partir dos modelos de mapeamento, a ferramenta MT4MDE gerou implementações das transformações escritas em ATL - Atlas Transformation Language ${ }^{2}$. As transformações em ATL são executáveis, podendo

\footnotetext{
${ }^{1}$ http://www.eclipse.org/modeling/emf/, último acesso em 26/07/2009.

${ }^{2}$ Junto com EMF, a linguagem ATL (http://www.eclipse.org/m2m/atl/, último acesso em 26/07/2009) formam a base das ferramentas que possibilitam Engenharia dirigida por Modelos na plataforma Eclipe.
} 
Resource - AGR2OMint3.map - Eclipse Platform

File Edit Navigate Searrch project $\underline{R} u n$ Mapping Editor Window Help

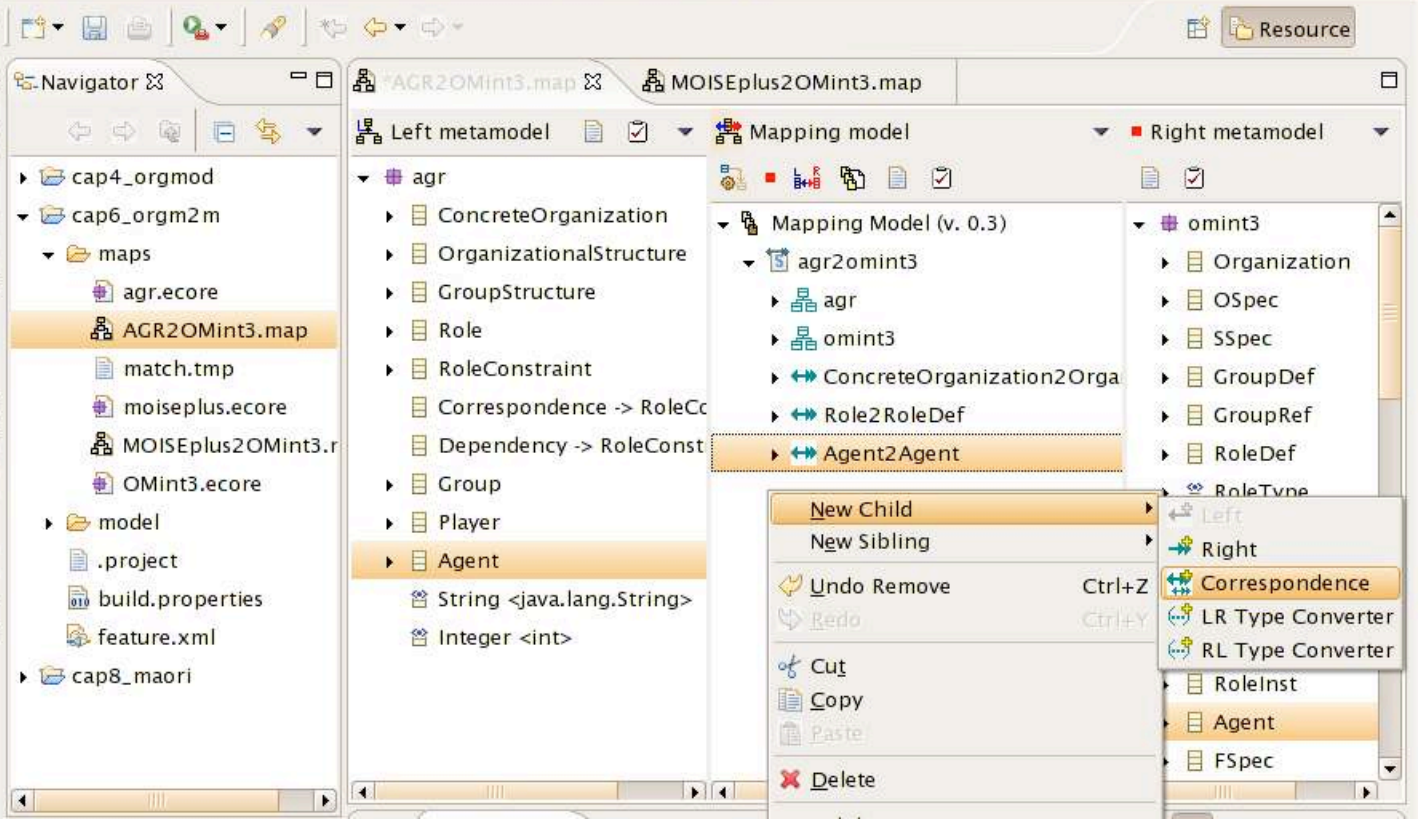

(a) Edição dos mapeamentos entre o metamodelo de AGR e $M M_{\# 3}^{\text {int }}$.

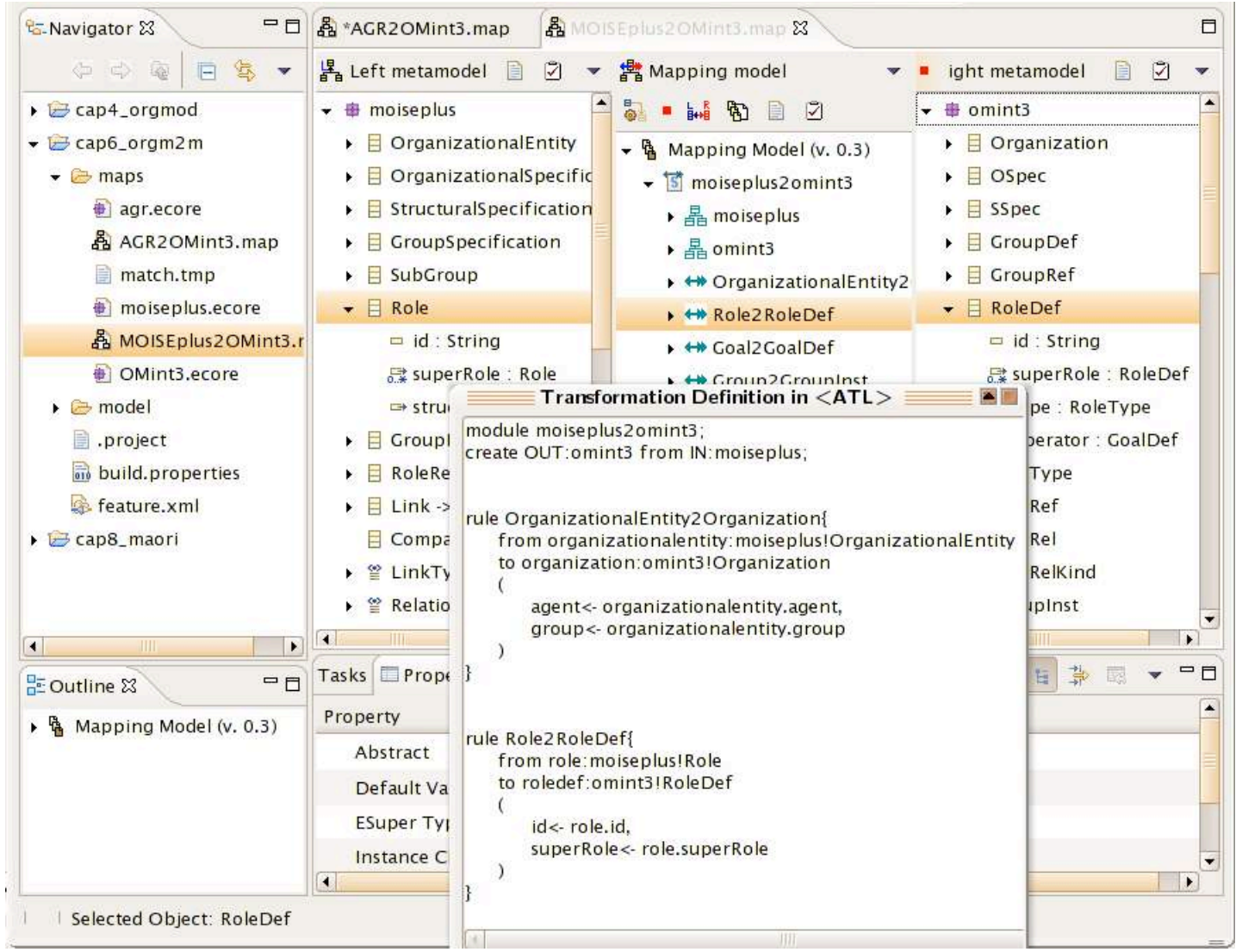

(a) Transformação ATL gerada a partir do modelo de mapeamento entre o metamodelo de MOISE+ e $M M_{\# 3}^{\text {int }}$.

Figura 8.2: Implementação das transformações da camada M2M. 
ser utilizadas diretamente no ambiente Eclipse para converter especificações dos modelos organizacionais para o metamodelo integrado, e vice-versa. Por fim, após verificado o funcionamento, as transformações em ATL foram manualmente traduzidas para uma implementação em Java. Este último passo foi realizado tanto por questões de compatibilidade com o código em Java das infraestruturas organizacionais, quanto por questões de eficiência, já que as transformações ATL necessitam de um módulo extra de interpretação.

Na figura 8.2, ilustram-se a definição de mapeamentos e geração de transformações em ATL por meio da ferramenta MT4MDE. Os modelos de mapeamentos criados estão disponíveis no anexo B. As transformações geradas encontram-se incorporadas à implementação de MAORI no anexo C.

Em resumo, na camada M2M foram gerados automaticamente classes Java que implementam os metamodelos e suas transformações. Tais classes são usadas como uma $\mathrm{API}^{3}$ para os provedores e adaptadores da camada ORI, descrita a seguir.

\subsubsection{Camada de Interoperabilidade Organizacional}

Na camada de interoperabilidade organizacional (camada ORI), os provedores e os adaptadores organizacionais são projetados como agentes que juntos compõem a organização ORISOC (Sociedade de Interoperabilidade Organizacional). Como discutido no capítulo anterior, a intenção deste projeto é possibilitar a implementação da camada ORI utilizando uma infraestrutura organizacional como meio de interconexão e comunicação entre provedores e adaptadores organizacionais.

\section{Implementação da especificação organizacional em S-MOISE+}

A especificação organizacional da camada ORI, exibida na figura 7.4, é escrita em MOISE+. Por este motivo, utilizou-se a infraestrutura organizacional S-MOISE+ em sua implementação. Neste caso, a implementação consiste na interpretação da especificação organizacional pela infraestrutura S-MOISE+, como ilustrado na figura 8.3. Como resultado da interpretação, um agente OrgManager é instanciado na camada organizacional de S-MOISE+ (figura 7.5). O objetivo desse agente OrgManager é controlar a criação de grupos, adoção de papéis e comunicação entre provedores e adaptadores conforme estabelecido pela especificação

\footnotetext{
${ }^{3}$ Application Programming Interface.
} 


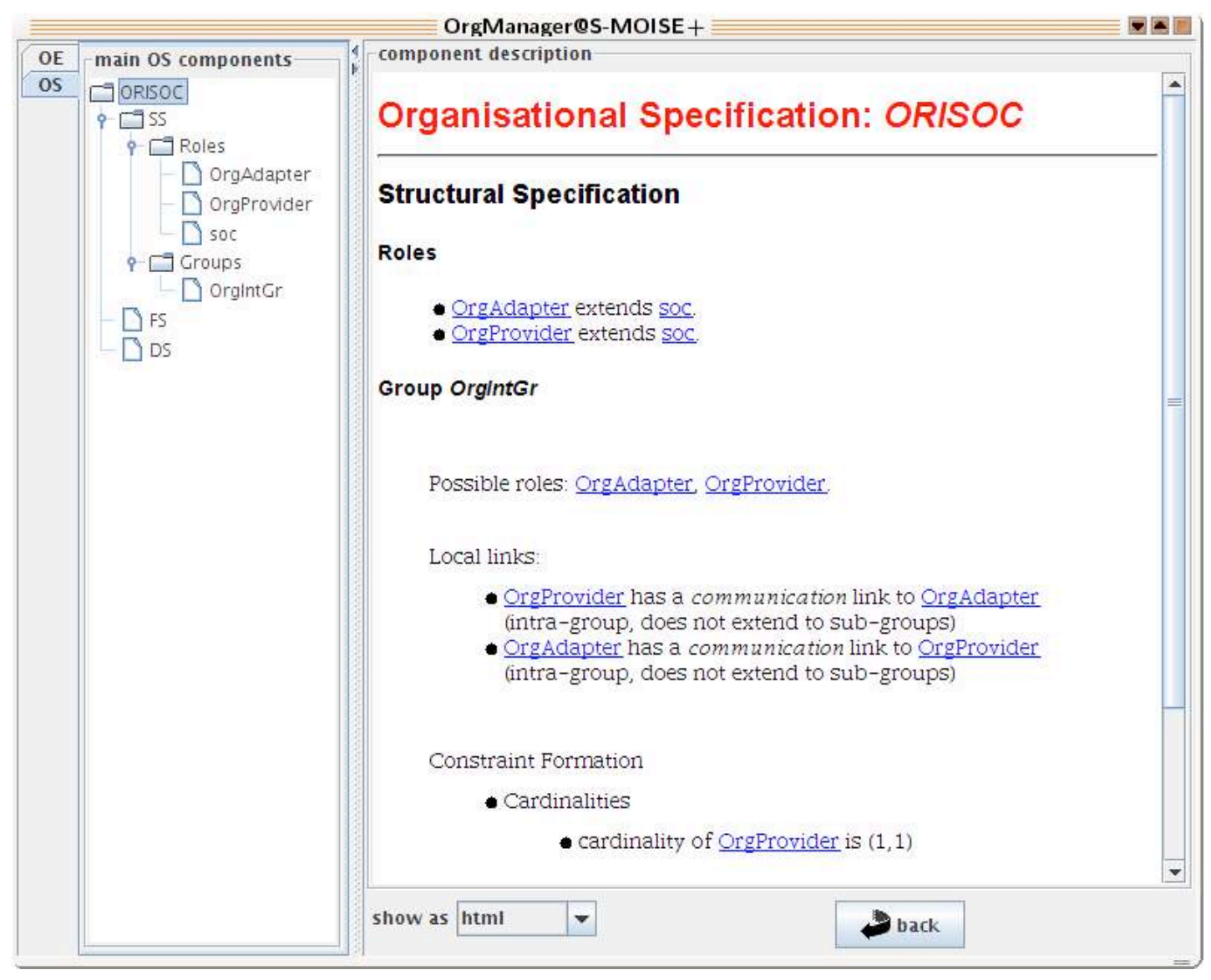

Figura 8.3: Implementação especificação organizacional da camada ORI utilizando S-MOISE+.

organizacional da camada ORI.

\section{Implementação dos provedores e adaptadores organizacionais}

Para cada infraestrutura organizacional suportada por MAORI, devem ser implementados um agente provedor e um agente adaptador. Por um lado, os provedores e adaptadores devem ser capazes de acessar a infraestrutura S-MOISE+ e entrar na organização ORISOC, seguindo o protocolo de conexão mostrado na figura 7.6. Por outro lado, cada provedor deve ser capaz de monitorar e reagir a mudanças de estados causadas por eventos organizacionais, como estabelecido nos protocolos de propagação de eventos exibidos na figura 7.7.

Visando a realização de testes da infraestrutura MAORI, os agentes provedores e os agentes adaptadores foram implementados para as infraestruturas MADKIT (subseção 2.3.3.1) e S-MOISE+ (subseção 2.3.3.3).

Na figura 8.4, ilustram-se o agente provedor para S-MOISE+ e o agente adaptador para MADKIT que foram implementados. Na mesma figura, em baixo, mostra-se também uma conexão estabelecida entre o provedor S-MOISE+ e o 


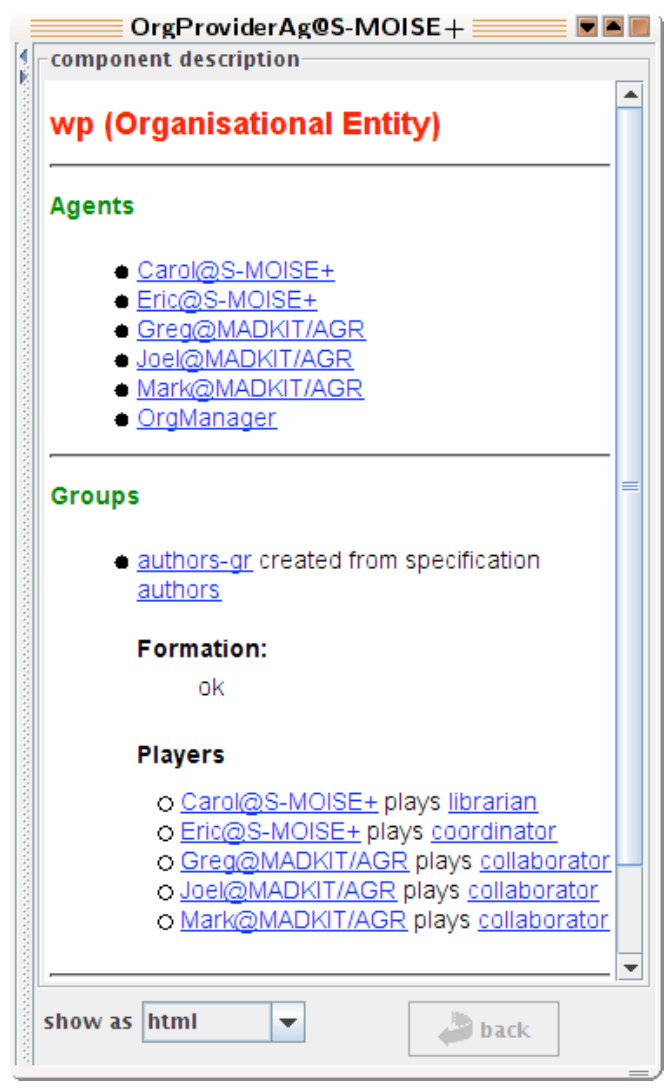

(a) Agente provedor S-MOISE+

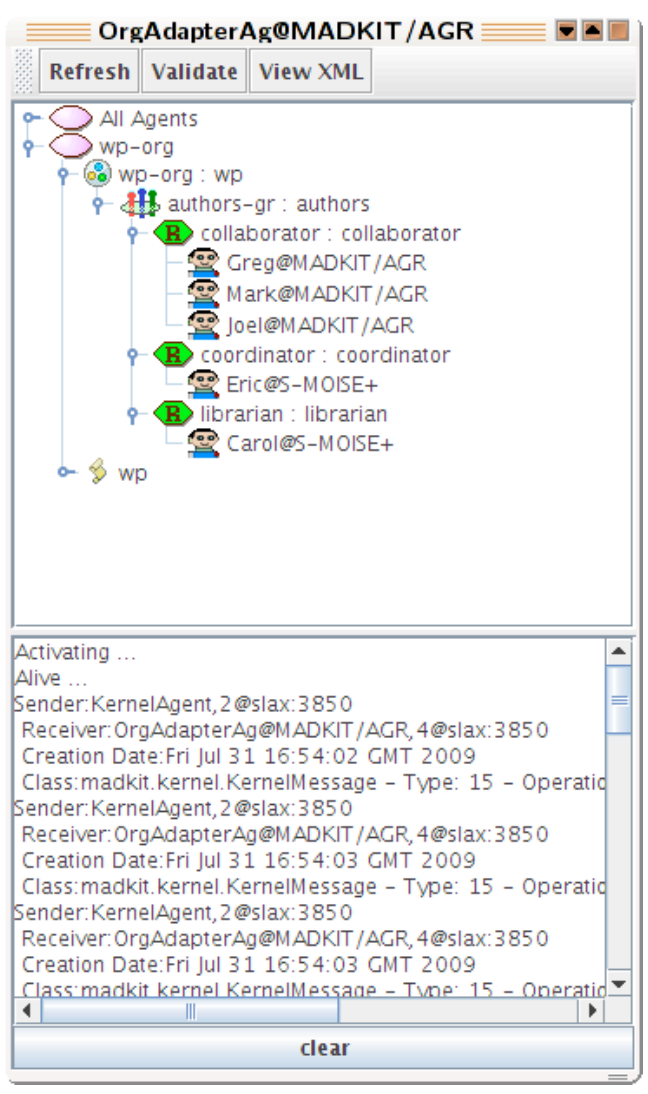

(b) Agente adaptador MADKIT

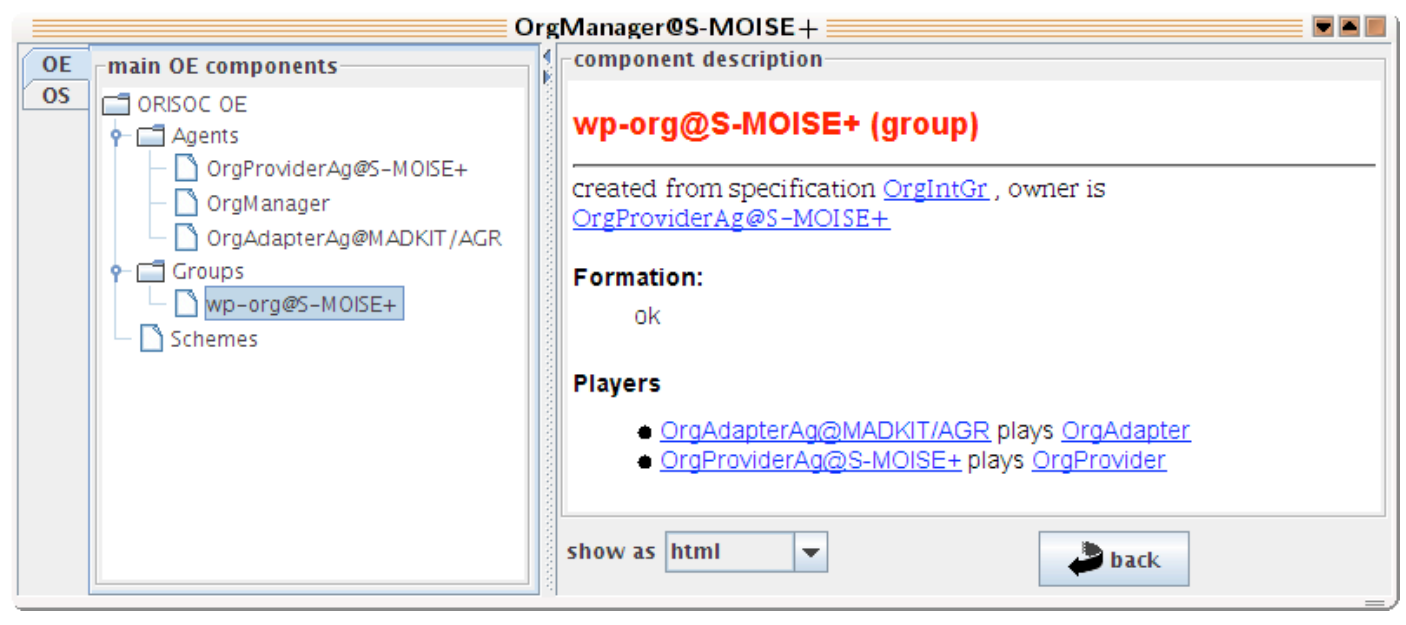

(c) Conexão entre o provedor S-MOISE+ e o adaptador MADKIT

Figura 8.4: Implementações do provedor S-MOISE+ e do adaptador MADKIT. 


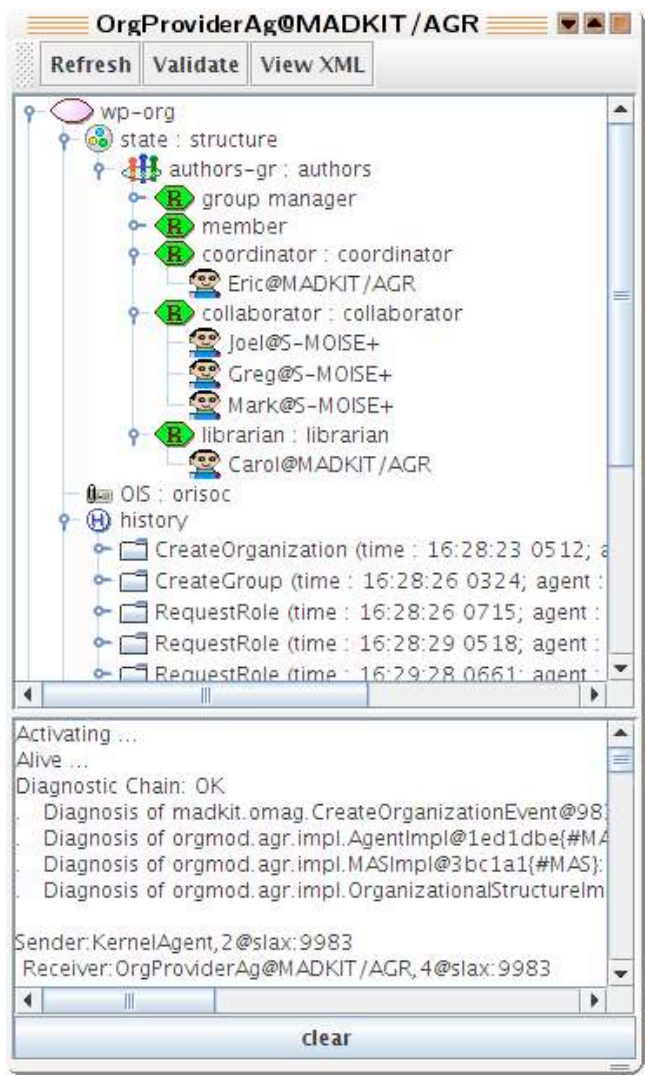

(a) Agente provedor MADKIT

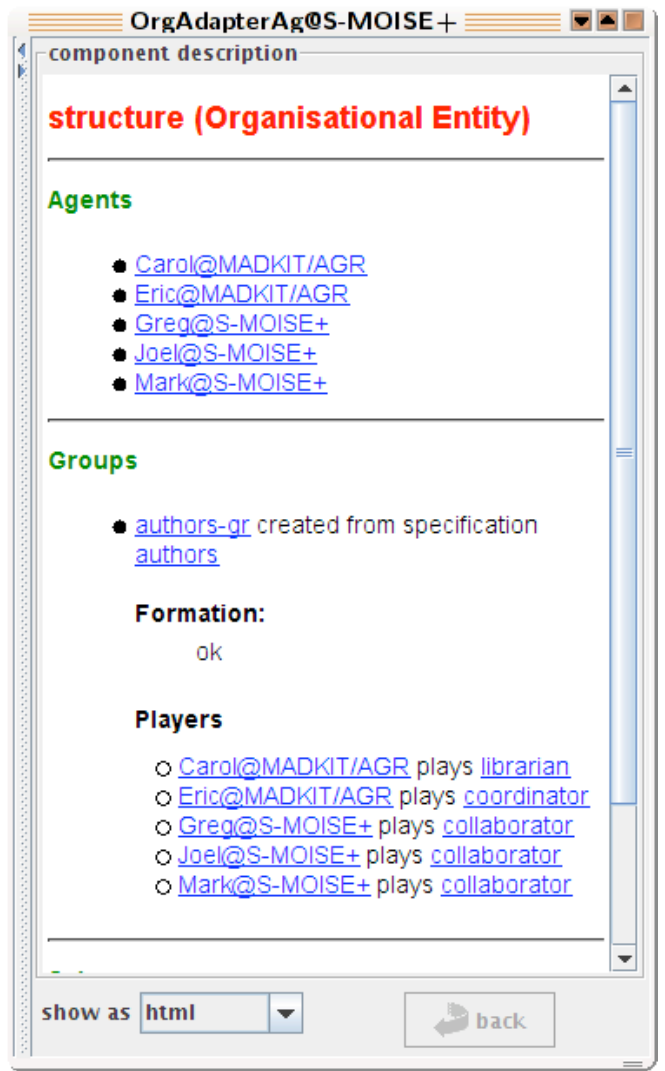

(b) Agente adaptador S-MOISE+

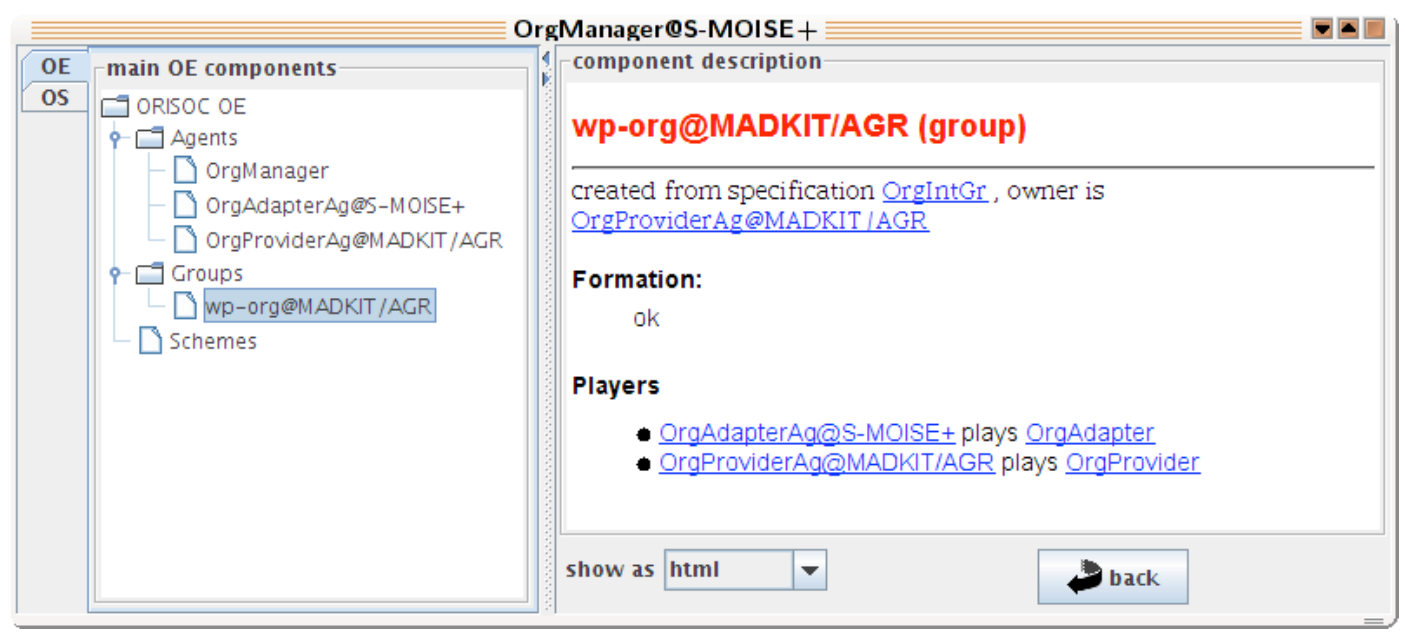

(c) Conexão entre o provedor MADKIT e o adaptador S-MOISE+

Figura 8.5: Implementações do provedor MADKIT e do adaptador S-MOISE+. 
adaptador MADKIT por meio de um grupo OrgIntGr criado na organização ORISOC. Neste exemplo, o grupo criado representa uma organização de nome wp-org, originalmente executando na infraestrutura S-MOISE+. A organização wp-org é exportada pelo agente provedor S-MOISE+ e importada pelo agente adaptador MADKIT. Como resultado, não apenas agentes que funcionam a partir do modelo MOISE+, mas também agentes que utilizam AGR podem participar da organização wp-org. Os detalhes sobre a organização wp-org são apresentados na próxima seção.

De modo complementar, na figura 8.5, apresentam-se o agente provedor para MADKIT e o agente adaptador para MOISE + que foram implementados. Como na outra figura, em baixo, tem-se um exemplo de conexão que o provedor MADKIT é capaz de estabelecer com o adaptador S-MOISE+. Neste caso, a organização $w p$-org originalmente executa na infraestrutura MADKIT, e é adaptada para a infraestrutura S-MOISE+.

A implementação dos agentes provedores e adaptadores das figuras 8.4 e 8.5 foi realizada manualmente, estendendo a implementação em Java das infraestruturas organizacionais correspondentes. O código completo da implementação da infraestrutura MAORI encontra-se no anexo C.

\subsection{Aplicação Write Paper}

A partir da implementação apresentada, foram realizados quatro experimentos com o objetivo de testar e avaliar o funcionamento da infraestrutura MAORI.

\subsubsection{Descrição da Aplicação}

Para a realização dos experimentos, utilizou-se como cenário uma aplicação na qual agentes formam uma organização com o objetivo de escrever um artigo. A aplicação é chamada Write Paper, sendo uma adaptação de um exemplo de mesmo nome constante no tutorial da infraestrutura S-MOISE $+{ }^{4}$. A aplicação Write Paper foi escolhida devido à sua simplicidade, tanto de entendimento quanto de implementação, o que permite a realização de experimentos que enfocam a dinâmica de funcionamento das camadas ORI e M2M que compõem a infraestrutura MAORI.

\footnotetext{
${ }^{4} \mathrm{O}$ tutorial encontra-se disponível em http: //moise. sourceforge.net/doc/tutorial.pdf, último acesso $31 / 07 / 2009$.
} 

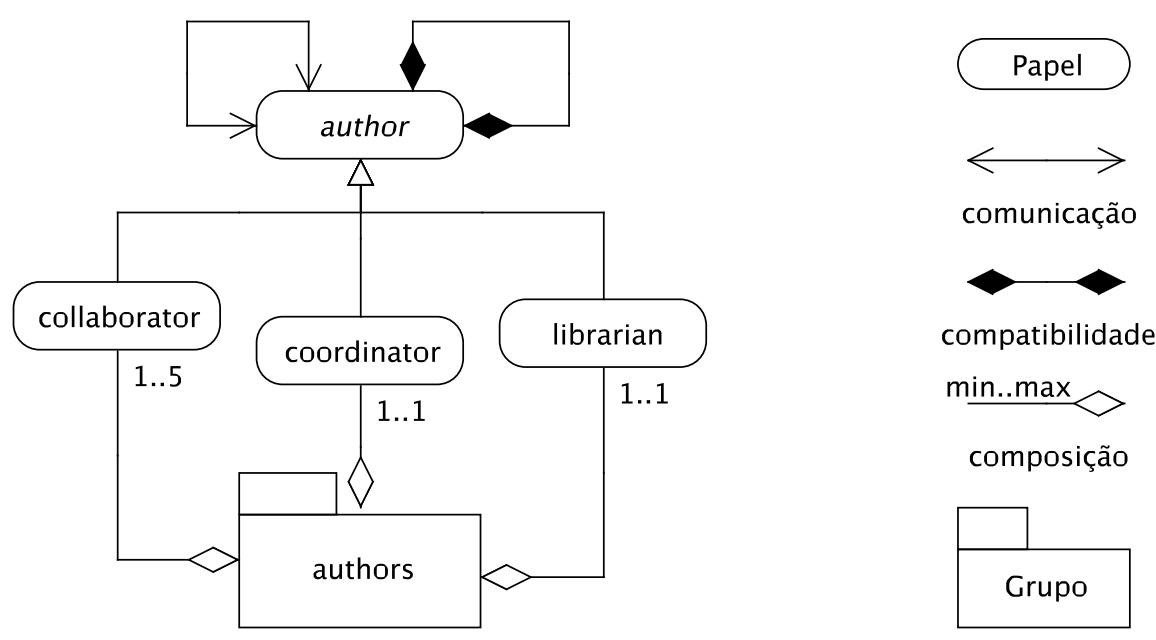

(a) Especificação escrita em MOISE+
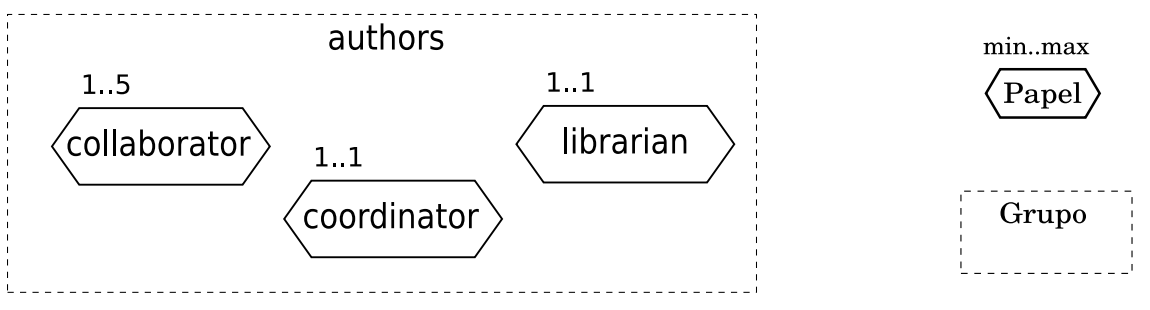

(b) Especificação escrita em AGR

Figura 8.6: Especificação da organização wp-org.

\subsubsection{Especificação Organizacional}

Na aplicação Write Paper, a escrita conjunta de um artigo ocorre em uma organização de agentes wp-org. A estrutura interna de wp-org é descrita por meio das especificações MOISE+ e AGR presentes na figura 8.6.

De acordo com as especificações, a organização wp-org consiste em um grupo de agentes chamado authors. No grupo authors, distinguem-se três papéis:

- o papel coordinator, desempenhado por um único agente encarregado de dividir o trabalho de escrita e delegar tarefas para os outros agentes;

- o papel collaborator, desempenhado por no mínimo 1 e no máximo 5 agentes encarregados de escrever uma parte do artigo determinada pelo coordinator;

- o papel librarian, desempenhado por apenas um agente encarregado de compilar as referências bibliográficas utilizadas pelos autores do artigo. 
Estes papéis são compatíveis, i.e., o mesmo agente pode desempenhar mais de um papel, caso queira ou seja necessário. Além disso, não há restrições de comunicação entre os papéis, i.e., todos os papéis podem se comunicar com todos os outros. Na especificação MOISE+ (figura 8.6(a)), estas informações são inferidas do fato de coordinator, collaborator e librarian serem definidos como especializações do papel abstrato author, e de haver relacionamentos de compatibilidade e de comunicação do papel author para ele mesmo. Na especificação AGR (figura 8.6(b)), as informações encontram-se implícitas tendo em vista que em AGR não há restrições de comunicação e papéis sempre são a priori compatíveis uns com os outros.

\subsubsection{Implementação dos agentes}

A partir das especificações organizacionais da figura 8.6, a organização wp-org foi implementada tanto na infraestrutura S-MOISE+, quanto na infraestrutura MADKIT. As figura 8.7 e 8.8 ilustram as implementações realizadas.

Com relação aos componentes da organização wp-org, foram implementados cinco agentes em cada infraestrutura organizacional:

- um agente capaz de desempenhar o papel coordinator, nomeado Eric;

- um agente capaz de desempenhar o papel librarian, nomeado Carol; e

- três agentes que desempenham o papel collaborator, nomeados Joel, Greg e Mark.

Durante o processo de escrita de um artigo, esses agentes coordenam as atividades e interagem conforme representado de modo esquemático na figura 8.9.

De acordo com a figura 8.9, a atividade na organização wp-org começa quando o agente Eric cria uma instância author-gr do grupo authors e nela assume o papel coordinator. Em seguida, Eric passa a definir o sumário do artigo a ser escrito enquanto, em paralelo, o agente Carol adota o papel librarian e os agentes Joel, Greg e Mark adotam o papel collaborator.

O sumário definido por Eric prevê um artigo com três seções, além da introdução e conclusão. Eric se encarrega de escrever a introdução e conclusão. Assim, ao terminar o sumário, Eric acessa a infraestrutura organizacional de modo a obter os identificadores de três agentes que assumiram o papel de collaborator (no caso, Joel, Greg e Mark), e o agente que assumiu o papel de librarian (no caso, Carol). 

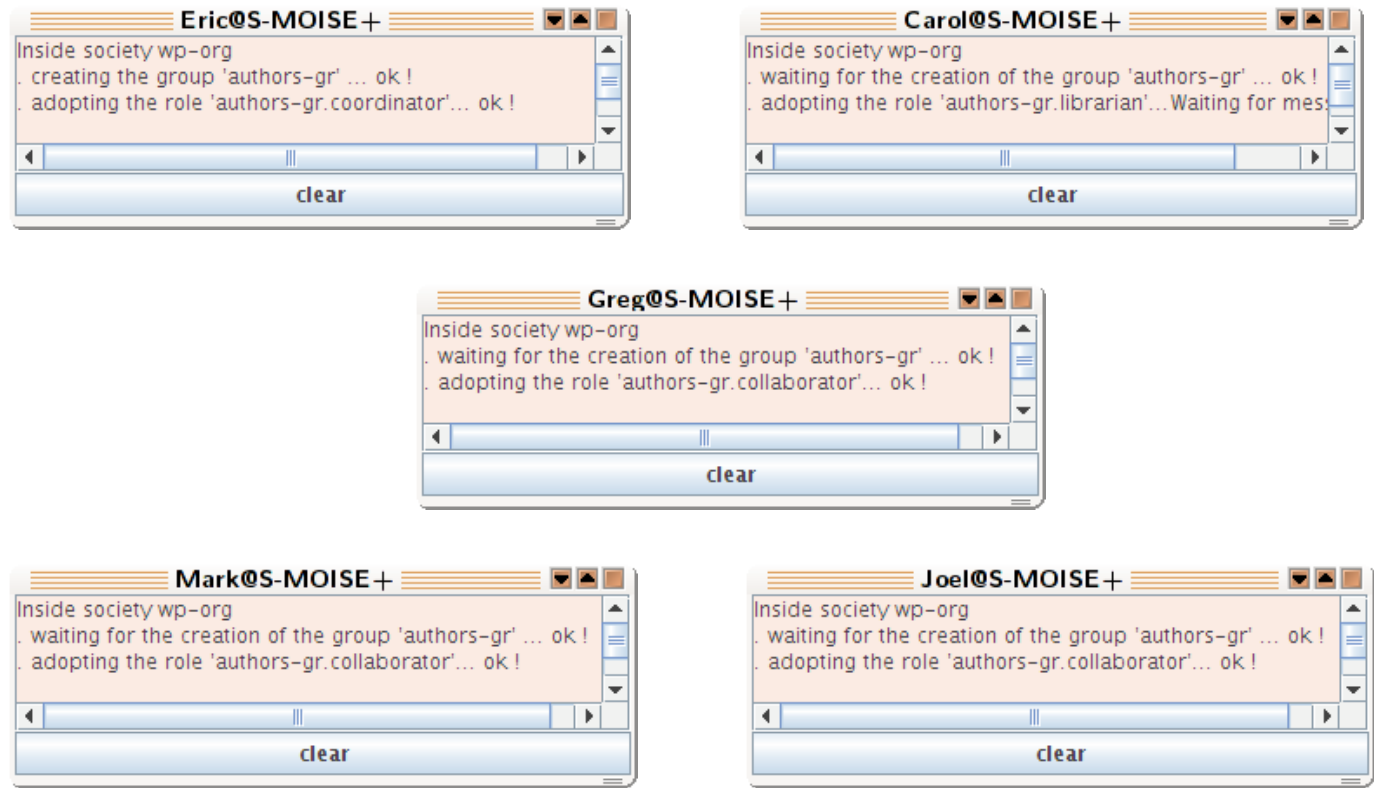

OrgManager@S-MOISE +
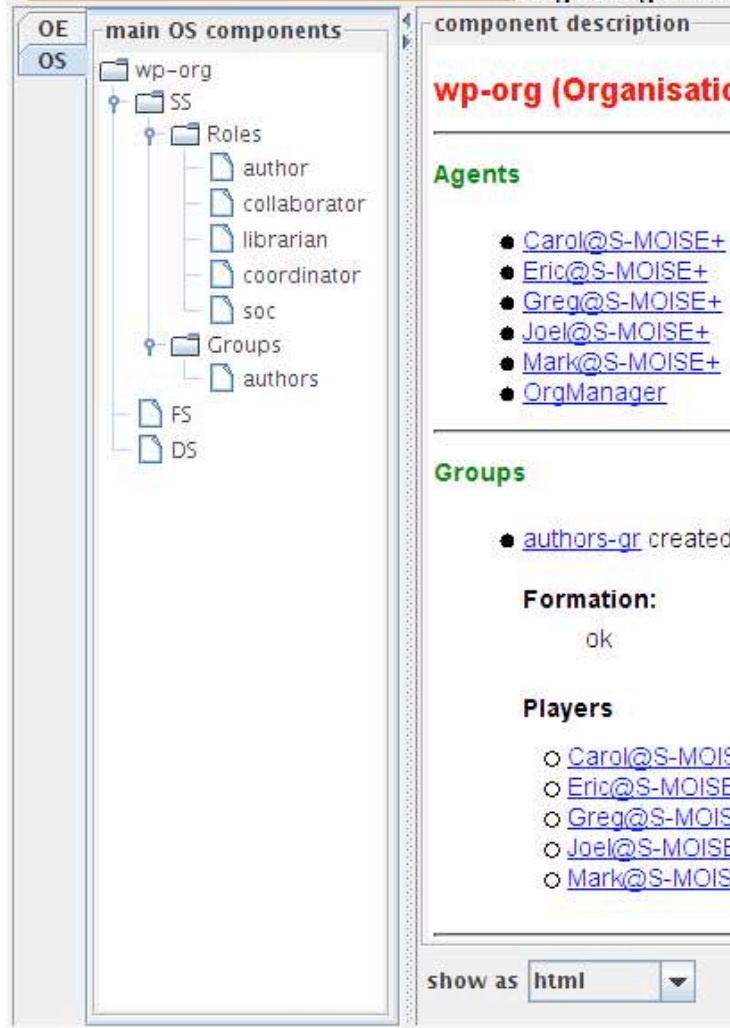

- Carol@S-MOISE+

- Eric@S-MOISE+

- GregQS-MOISE+

- Joel@S-MOISE+

- Mark@S-MOISE+

- orgmanager

Groups

- authors-gr created from specification authors

Formation:

ok

Players

OCarol@S-MOISE+plays librarian

o Eric@S-MOISE+ plays coordinator

o Greg(OS-MOISE+ plays collaborator

o Joel(CS-MOISE+ plays collaborator

- Mark@S-MOISE+ plays collaborator

show as html

Figura 8.7: Implementação da organização wp-org na infraestrutura S-MOISE+. 

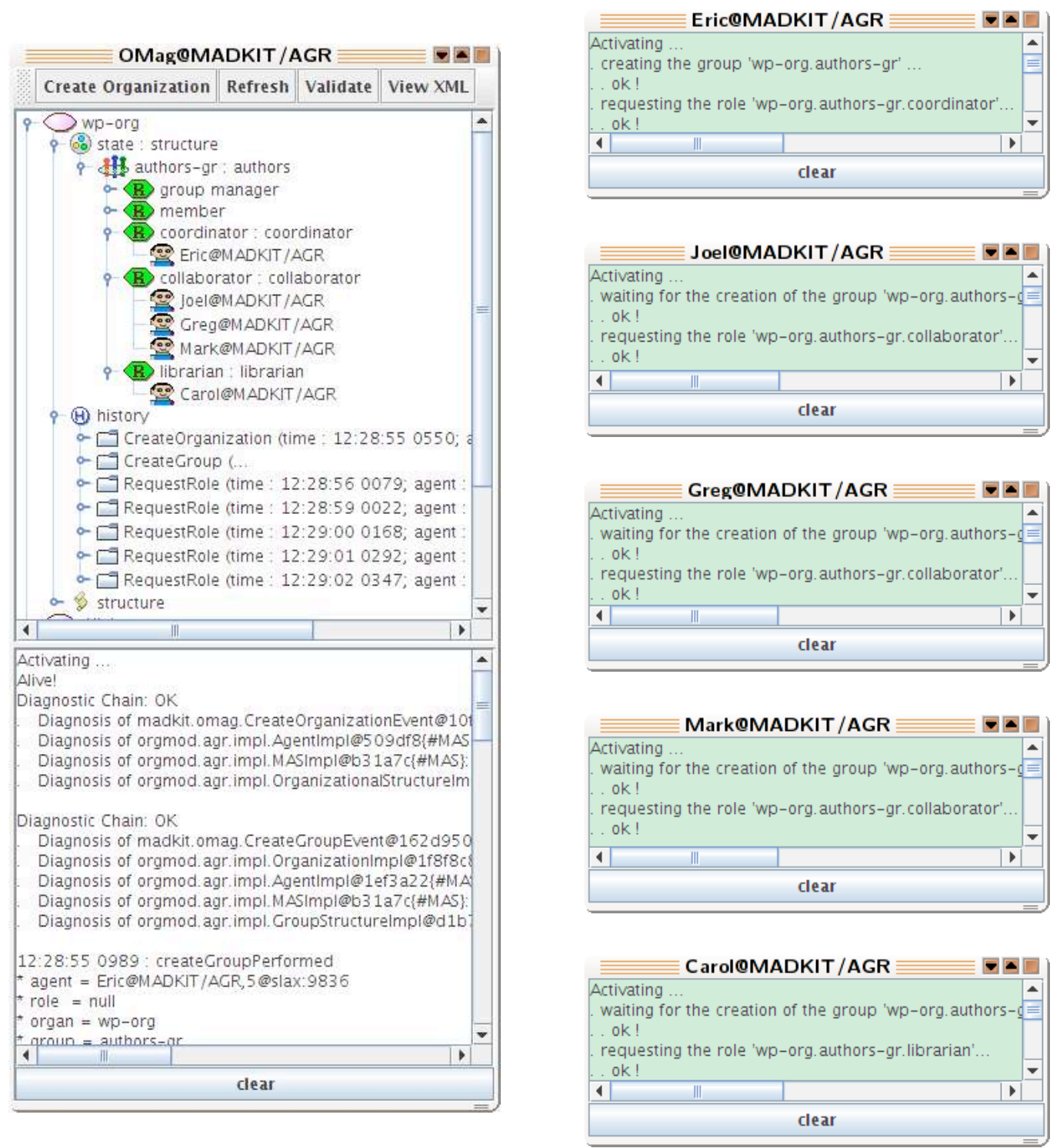

wp.madkit.Launcher

MODEL file:/mnt/ddh1/home/luciano/workspace/maori-rt/examples/writePaper/wp. madkit/wp-Iconf. agr

001: OMag@MADKIT/AGR = new madkit.omag. OMag0

002 : launchAgent(OMag@MADKIT/AGR "OMag@MADKIT/AGR", true)

003 : OMag@MADKIT/AGR.createOrganizationo

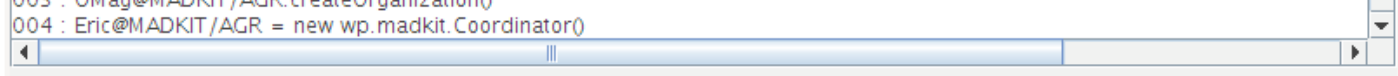

Save as... Clear output

Figura 8.8: Implementação da organização wp-org na infraestrutura MADKIT. 


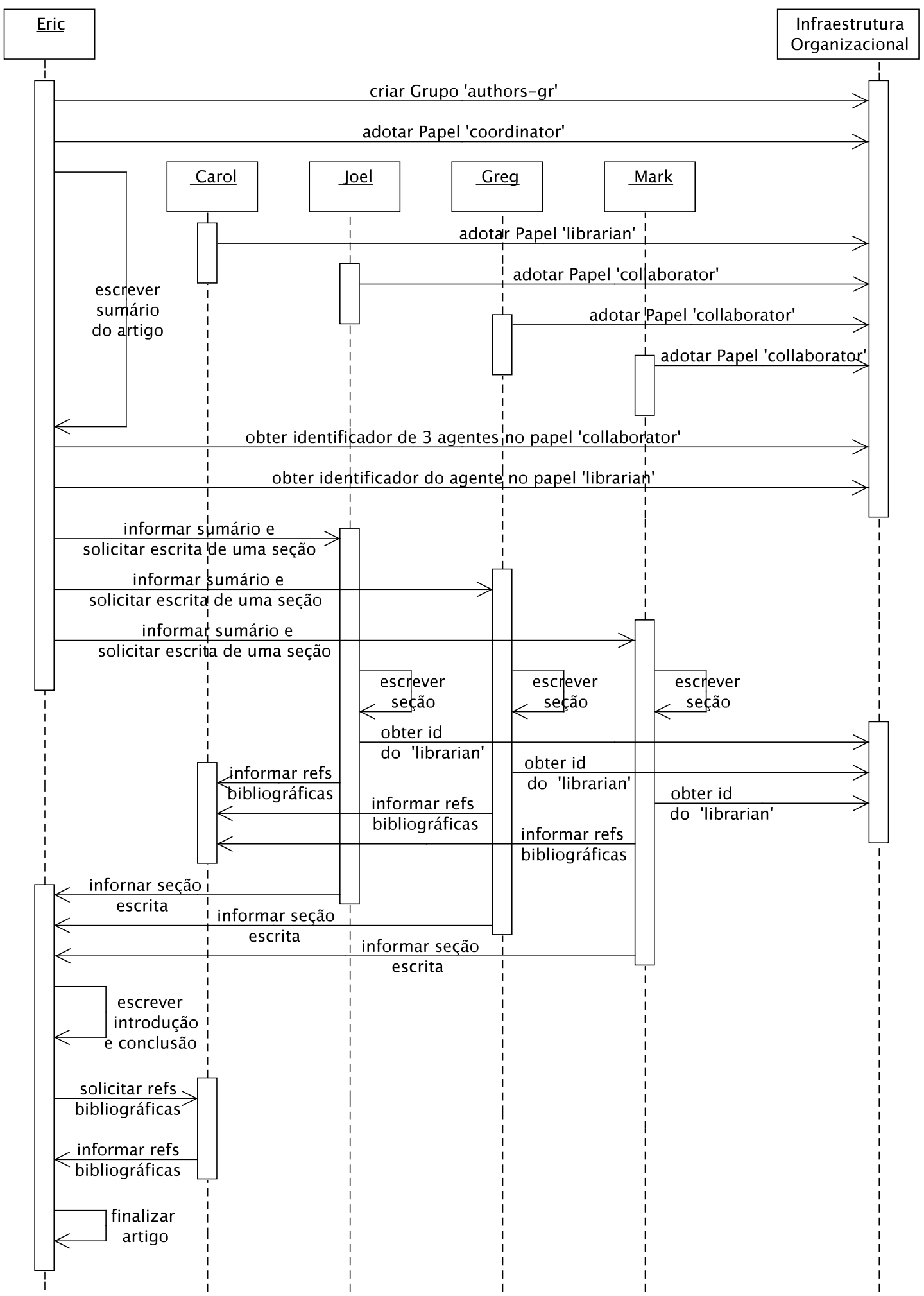

Figura 8.9: Especificação da atividade conjunta dos agentes que compõem a organização wp-org. 
Para os três agentes no papel collaborator, Eric envia o sumário e solicita a escrita de uma seção. Cada collaborator recebe o sumário e passa a escrever a seção solicitada. A escrita ocorre em paralelo, e nesse tempo Eric fica aguardando. Ao terminar a escrita da seção, cada collaborator, através da infraestrutura organizacional, descobre o identificador do agente librarian (Carol) e lhe envia as referências bibliográficas utilizadas na seção. Por fim, os agentes collaborator enviam a seção escrita para o agente Eric.

Ao receber o texto de todas as seções, Eric passa para a etapa final do processo de escrita do artigo: escrever a introdução e conclusão, solicitar e receber as referências bibliográficas compiladas pelo agente librarian, juntar todas as partes e finalizar o artigo.

Ressalta-se que tanto os agentes Eric, Carol, Joel, Greg e Mark que foram implementados para funcionar com a infraestrutura organizacional S-MOISE+ (figura 8.7), quanto os que funcionam com MADKIT (figura 8.8), coordenam as suas atividades e interagem conforme a descrição acima.

\subsubsection{Experimento 1}

No primeiro experimento realizado, testou-se o funcionamento conjunto dos agentes provedor S-MOISE+ e adaptador MADKIT (figura 8.4). Assim, este experimento ilustra como, através de MAORI, se possibilita que agentes que utilizam o modelo organizacional AGR possam fazer parte de uma organização cujo modelo subjacente é MOISE+.

Foram utilizados:

- a especificação MOISE+ de wp-org (figura 8.6(a));

- os agentes Eric e Carol implementados em S-MOISE+ (figura 8.7);

- os agentes Mark, Joel e Greg implementados em MADKIT (figura 8.8).

A execução do experimento é ilustrada na figura 8.10 e descrita a seguir.

Inicialmente, a organização wp-org é criada na infraestrutura S-MOISE+ a partir da especificação organizacional da figura 8.6(a) e do agente provedor SMOISE+. Seguindo o protocolo de conexão (figura 7.6), o agente provedor SMOISE+ cria uma instância do grupo OrgIntGr (figura 7.4) na organização ORISOC (camada ORI). Com isso, o estado e especificação da organização wp-org 


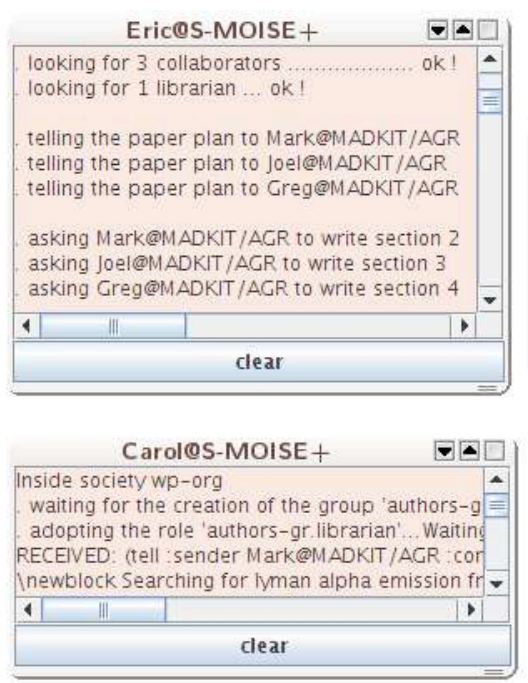

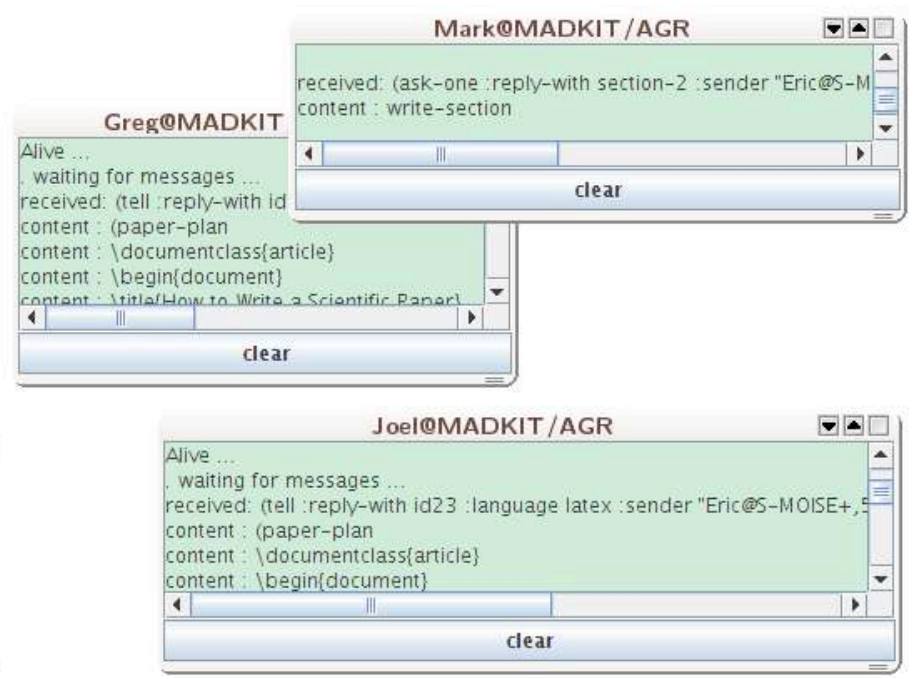

OrgProviderAg@S-MOISE+

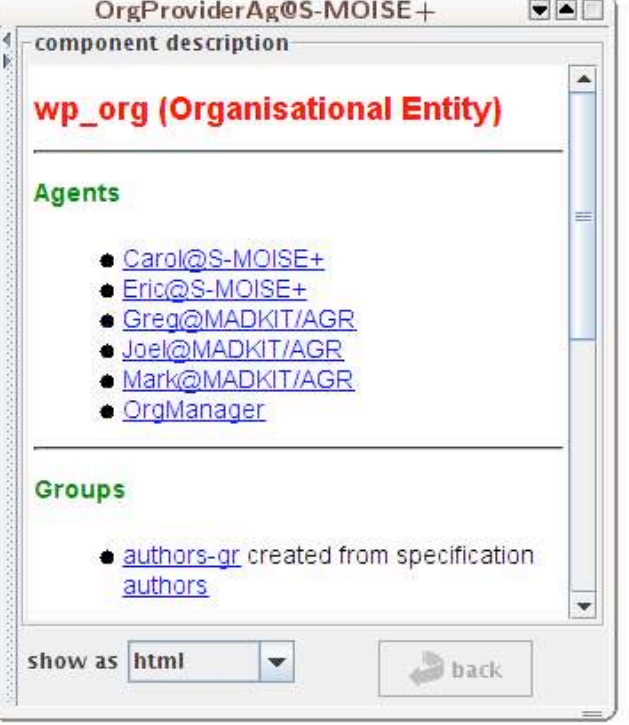

OrgAdapterAg@MADKIT / AGR

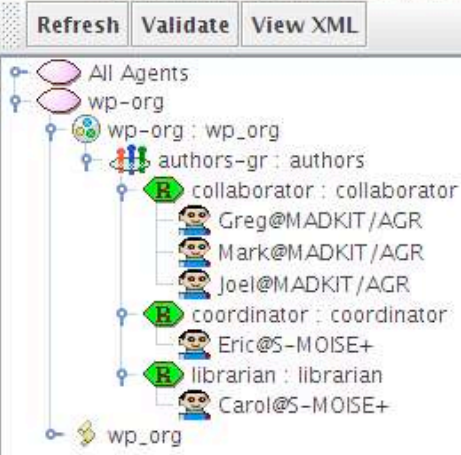

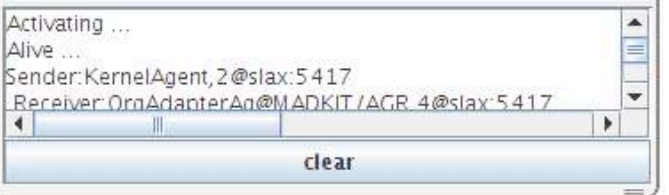

OrgManager@S-MOISE +

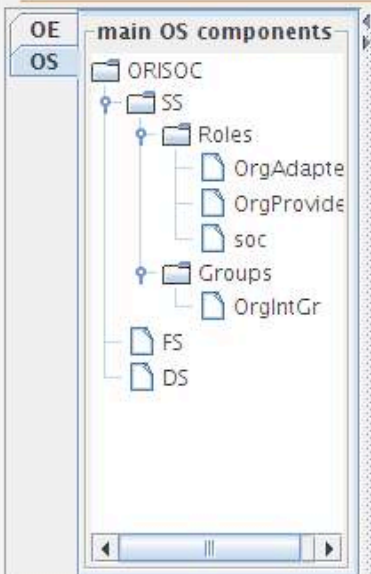

component description

\section{ORISOC (Organisational Entity)}

Agents

- OrgAdapterAg@MADKIT/AGR

- orgmanager

- OrgProviderAg(QS-MOISE+

Groups

- wp-org@S-MOISE+ created from specification orglntGr

Figura 8.10: Experimento 1 - Provedor S-MOISE+ e adaptador MADKIT; Eric e Carol em S-MOISE+; e Joel, Greg e Mark em MADKIT. 
passa a estar disponível a agentes adaptadores de outras infraestruturas organizacionais.

Em seguida, os agentes Eric e Carol são executados na infraestrutura SMOISE+. Seguindo o roteiro da figura 8.9, Eric cria uma instância do grupo authors, adota o papel de coordinator, e passa a escrever o sumário do artigo. Nesse meio tempo, percebendo que um grupo authors foi criado, Carol adota o papel de librarian. Ao terminar a escrita do sumário do artigo, Eric entra em estado de espera aguardando que três agentes entrem na organização wp-org assumindo o papel collaborator.

Enquanto Eric aguarda três colaboradores, o agente adaptador MADKIT é executado. Seguindo o protocolo de conexão (figura 7.6), o adaptador MADKIT importa o estado e especificação da organização wp-org para a infraestrutura MADKIT. Com isso, habilita-se a participação de agentes MADKIT na organização $w p$-org.

Após iniciar o adaptador MADKIT, os agentes Mark, Joel e Greg são executados na infraestrutura MADKIT. Logo que iniciam, Mark, Joel e Greg percebem a existência (de uma adaptação) da organização wp-org e imediatamente tentam adotar o papel collaborator. A requisição do papel é feita junto ao adaptador MADKIT. Para atender a requisição, o adaptador MADKIT contacta o provedor S-MOISE+, seguindo o protocolo de propagação de eventos organizacionais (figura 7.7(b)). Ao final da interação entre adaptador e provedor, os agentes Mark, Joel e Greg efetivamente passam a desempenhar o papel collaborator na organização wp-org.

A partir desse ponto, ocorre a cena mostrada na figura 8.10. Eric tem a disposição três agentes collaborator (Mark, Joel e Greg, executando na infraestrutura MADKIT) e um agente librarian (Carol, executando em S-MOISE+). Eric envia o sumário do artigo a Mark, Joel e Greg e requisita que eles escrevam respectivamente as seções 2,3 , e 4 . O envio é feito através dos representantes de Mark, Joel e Greg em S-MOISE+, e dos agentes provedor S-MOISE+ e adaptador MADKIT, conforme especificado no protocolo de roteamento de mensagens (figura 7.8(a)). Como se pode observar na figura 8.10, Mark, Joel e Greg efetivamente recebem as mensagens de Eric e passam a escrever as seções do artigo. Quanto terminam, as referências bibliográficas utilizada são enviadas para Carol, e o texto para Eric. O envio dessas últimas mensagens também ocorre conforme o protocolo de roteamento de mensagens (figura 7.8(b)). 


\subsubsection{Experimento 2}

No primeiro experimento, mostra-se na prática todos os aspectos do funcionamento conjunto do provedor S-MOISE+ e adaptador MADKIT, com uma exceção: a propagação de eventos organizacionais que ocorrem no lado do agente provedor (figura 7.7(a)). Para lidar com essa exceção, foi realizado uma variação do primeiro experimento na qual Eric e Carol são executados na infraestrutura MADKIT e Mark, Joel e Greg em S-MOISE+. Esse segundo experimento é ilustrado na figura 8.11.

No segundo experimento, a organização wp-org também é criada na infraestrutura S-MOISE+ a partir da especificação organizacional da figura 8.6(a) e do agente provedor S-MOISE+.

Após a criação de wp-org, os agentes Mark, Joel e Greg são executados. Ao serem executados, os agentes Mark, Joel e Greg entram em estado de espera. Isto ocorre porque não há ainda em wp-org uma instância do grupo authors no qual os agentes possam adotar o papel collaborator.

Enquanto Mark, Joel e Greg aguardam, o adaptador MADKIT é executado, importando a organização para a infraestrutura MADKIT. Logo em seguida, os agentes Eric e Carol são executados. Ao iniciar, Eric solicita a criação de uma instância do grupo authors junto ao adaptador MADKIT. O adaptador entra em interação com o provedor S-MOISE+ e, como resultado, o grupo é criado. A criação do grupo por Eric sinaliza o começo do processo de escrita do artigo.

Os agentes Mark, Joel e Greg requisitam então o papel collaborator no grupo recém criado. Como Mark, Joel e Greg executam na infraestrutura S-MOISE+, a adoção do papel collaborator é um evento organizacional que ocorre no lado do provedor S-MOISE+. Assim, o provedor S-MOISE+ interage com o adaptador MADKIT seguindo o protocolo de propagação de eventos organizacionais da figura 7.7(a), como se queria mostrar na prática com o experimento.

\subsubsection{Experimento 3}

De modo dual ao primeiro experimento, o terceiro experimento realizado consistiu em testar o funcionamento conjunto dos agentes provedor MADKIT e adaptador S-MOISE+ (figura 8.5). Ilustra-se assim como MAORI permite que uma organização cujo modelo subjacente é AGR possa funcionar com agentes externos que utilizam o modelo organizacional MOISE+. 


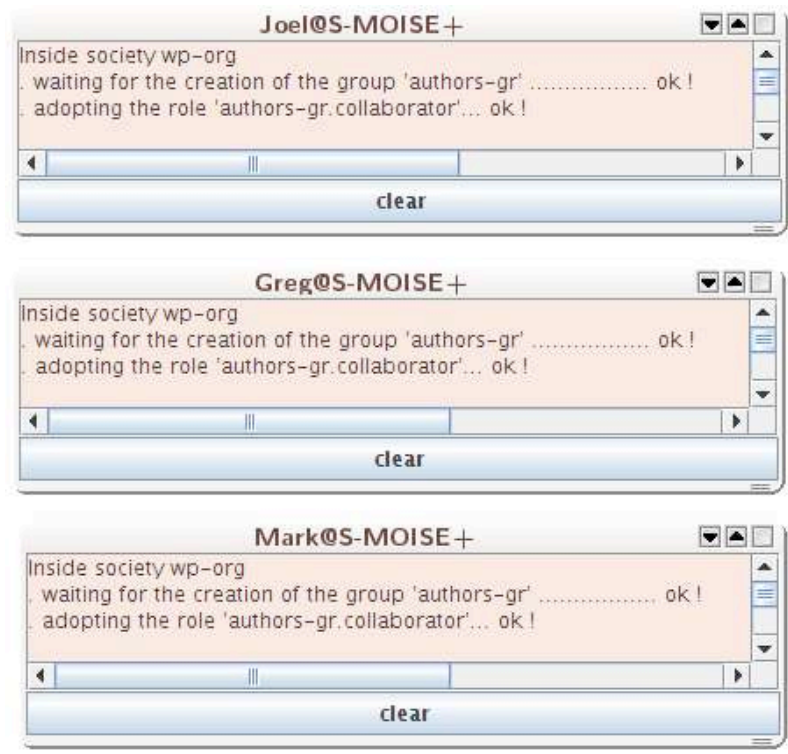

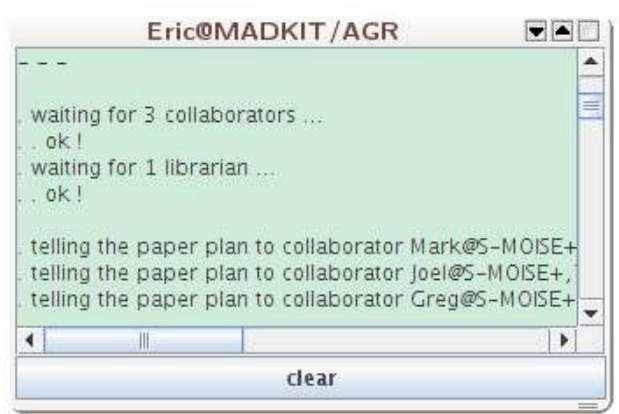

OrgProviderAgeS-MOISE +

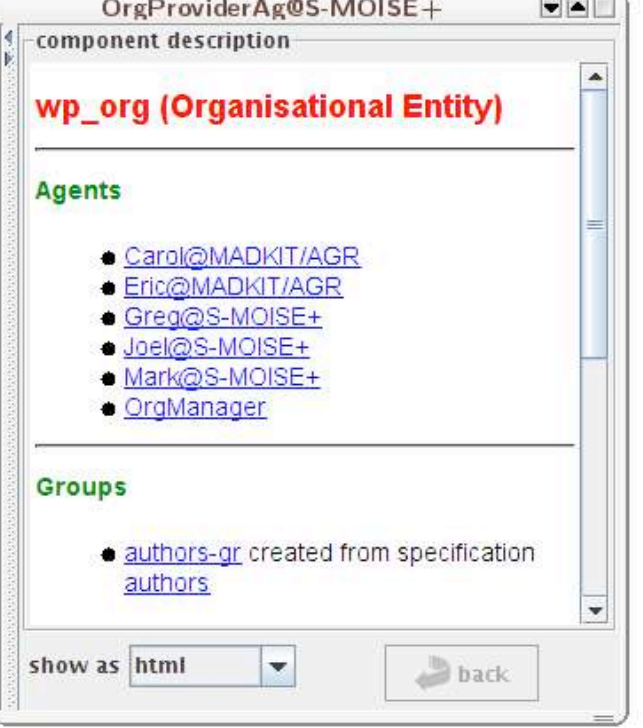
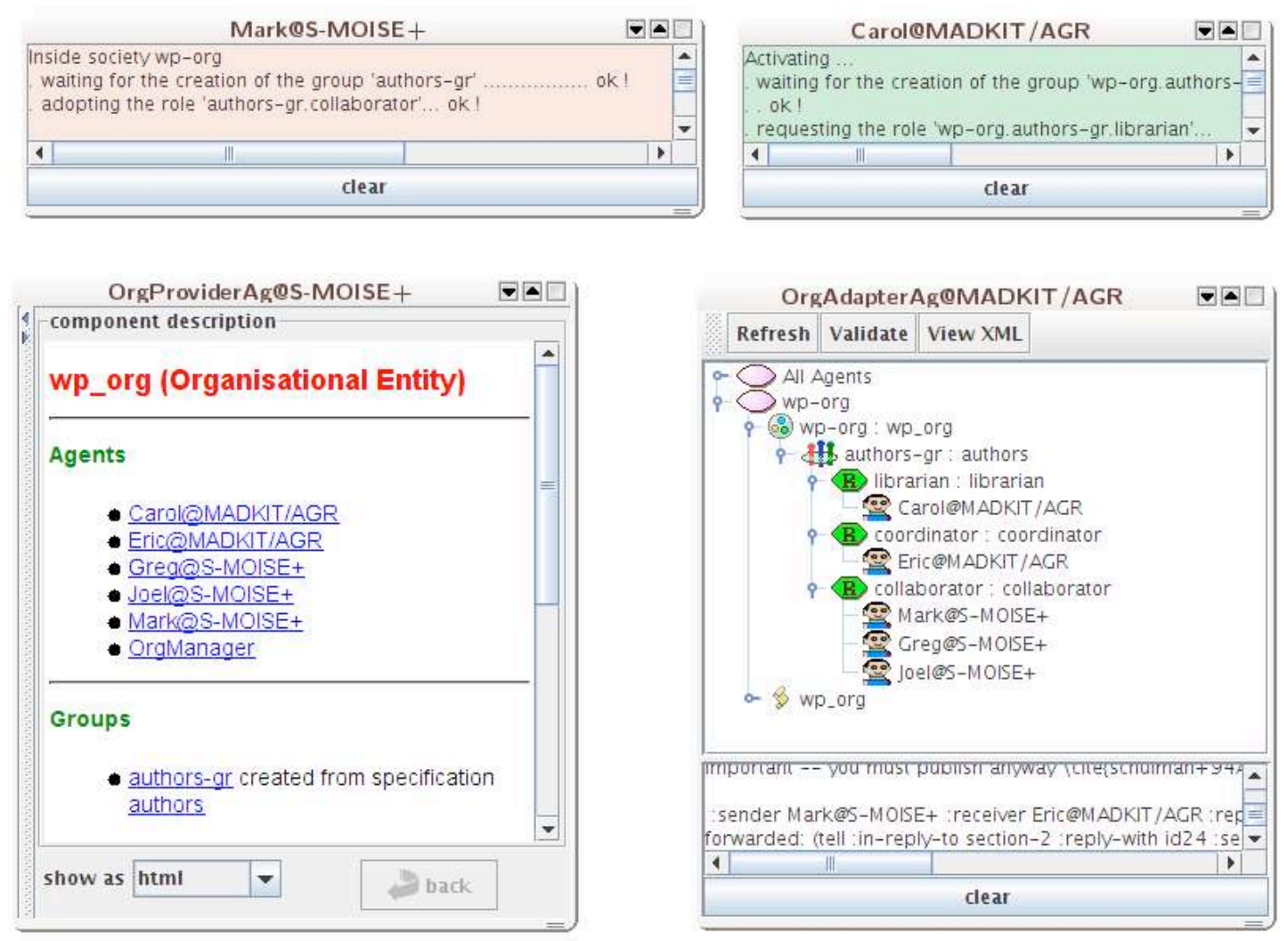

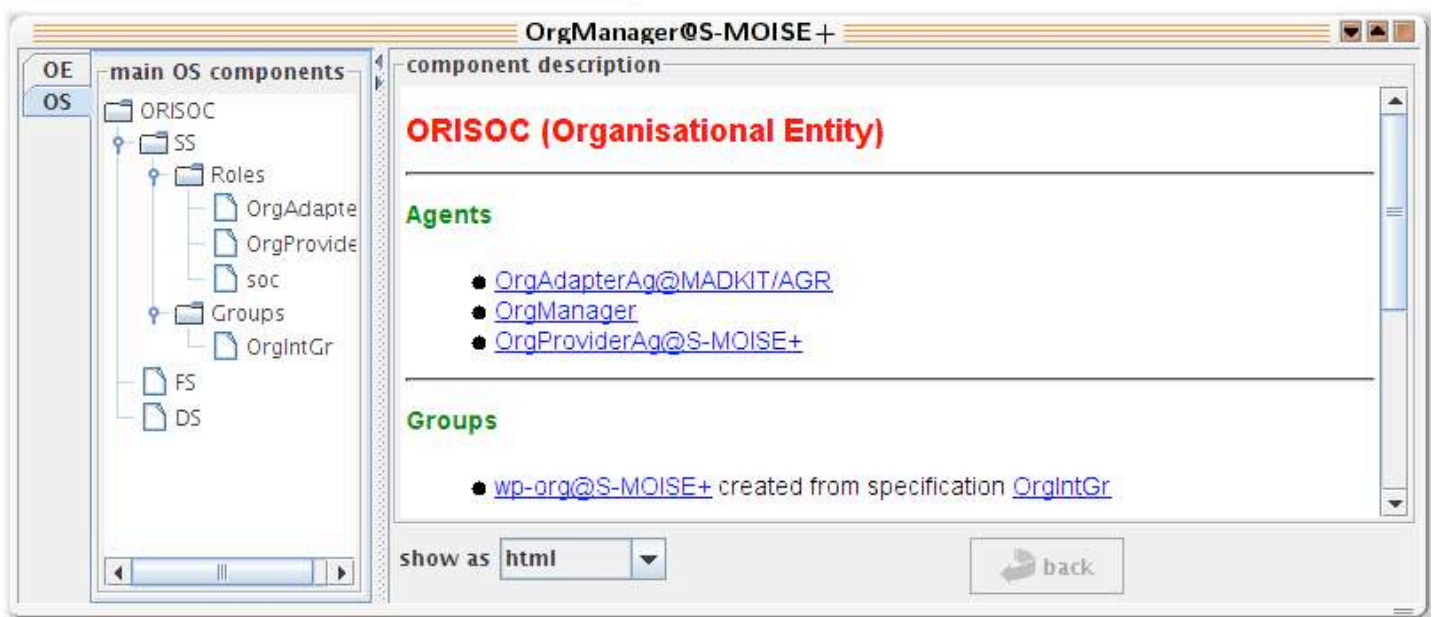

Figura 8.11: Experimento 2 - Provedor S-MOISE+ e adaptador MADKIT; Joel, Greg e Mark em S-MOISE+; e Eric e Carol em MADKIT. 
Foram então utilizados:

- a especificação AGR de wp-org (figura 8.6(b));

- os agentes Eric e Carol implementados em MADKIT (figura 8.8);

- os agentes Mark, Joel e Greg implementados em S-MOISE+ (figura 8.7).

A execução do experimento é ilustrada na figura 8.12 e sua descrição, mutatis mutantis, segue o mesmo padrão da descrição do experimento 1 .

\subsubsection{Experimento 4}

Da mesma forma que o segundo experimento foi realizado como uma variação do primeiro experimento, um quarto e último experimento foi realizado como uma variação do terceiro experimento. No quarto experimento, testou-se a interação entre os agentes provedor MADKIT e adaptador S-MOISE+ utilizando:

- a especificação AGR de wp-org (figura 8.6(b));

- os agentes Mark, Joel e Greg implementados em MADKIT (figura 8.8);

- os agentes Eric e Carol implementados em S-MOISE+ (figura 8.7).

A execução do experimento é ilustrada na figura 8.13 e sua descrição, mutatis mutantis, segue o mesmo padrão da descrição do experimento 2.

\subsection{Considerações Finais}

A partir da implementação de MAORI e dos experimentos realizados, fazem-se duas considerações finais: uma, quanto à efetividade da solução; a outra, quanto ao seu desempenho.

Quanto à efetividade, volta-se a observar que MAORI provê interoperabilidade organizacional quando se restringem os modelos organizacionais a um núcleo comum. Nos experimentos realizados neste capítulo, esta observação tem reflexo nas especificações da organização wp-org utilizadas (figuras 8.6(a) e 8.6(b)), que foram restritas à dimensão estrutural, comum aos modelos AGR e MOISE+.

Em face desta limitação, ressalta-se que MAORI foi projetada neste trabalho como uma possível solução de interoperabilidade organizacional que utiliza a integração de modelos organizacionais proposta na Parte II. Outras soluções de 


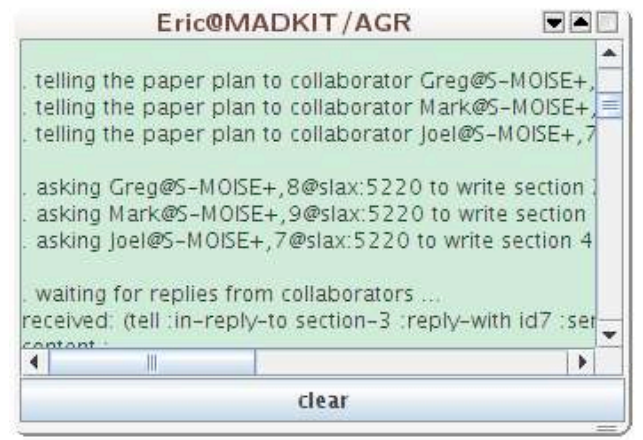

\begin{tabular}{|c|c|c|}
\hline & Carol@MADKIT/AGR & $\nabla \Delta \square$ \\
\hline \multicolumn{3}{|c|}{ 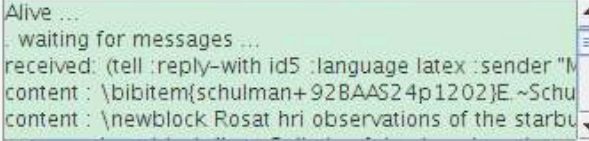 } \\
\hline 4 & IIII & - \\
\hline \multicolumn{3}{|c|}{ clear } \\
\hline
\end{tabular}

OrgProviderAg@MADKIT /AGR

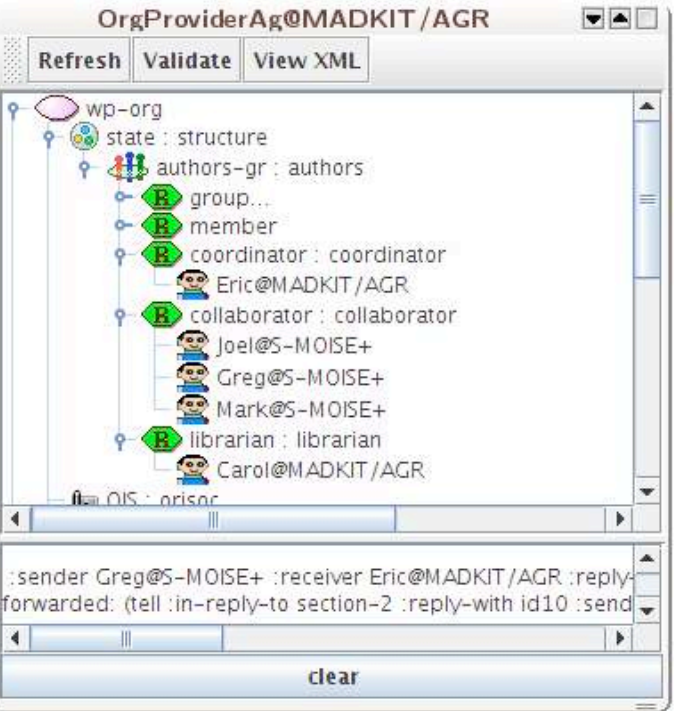

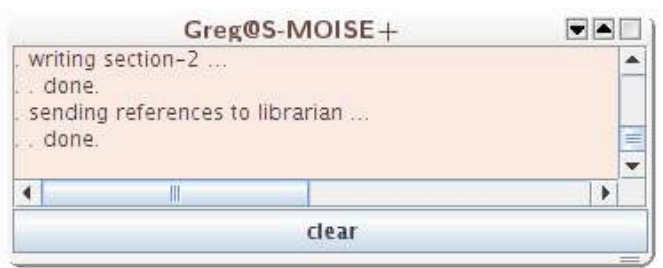
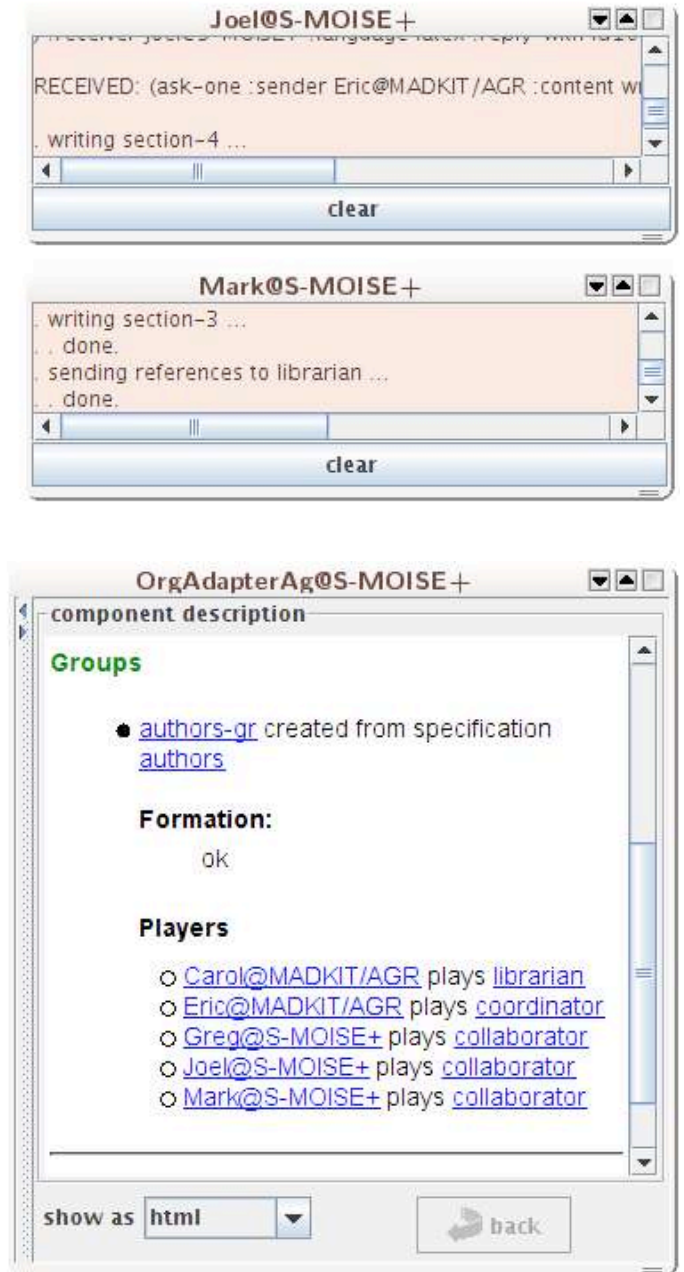

OrgManager@S-MOISE+

\begin{tabular}{|c|c|c|}
\hline OE & main OE components \\
\hline OS ORISOC OE \\
$\square$ Agents \\
$\square$ Groups \\
$\square$ Schemes \\
\\
\end{tabular}

\section{ORISOC (Organisational Entity)}

Agents

- OrgAdapterAg@S-MOISE+

- orgManager

- OrgProviderAg@MADKIT/AGR

Groups

- wp-org@MADKIT/AGR created from specification orgintGr

show as html

Figura 8.12: Experimento 3 - Provedor MADKIT e adaptador S-MOISE+; Eric e Carol em MADKIT; e Joel, Greg e Mark em S-MOISE+. 


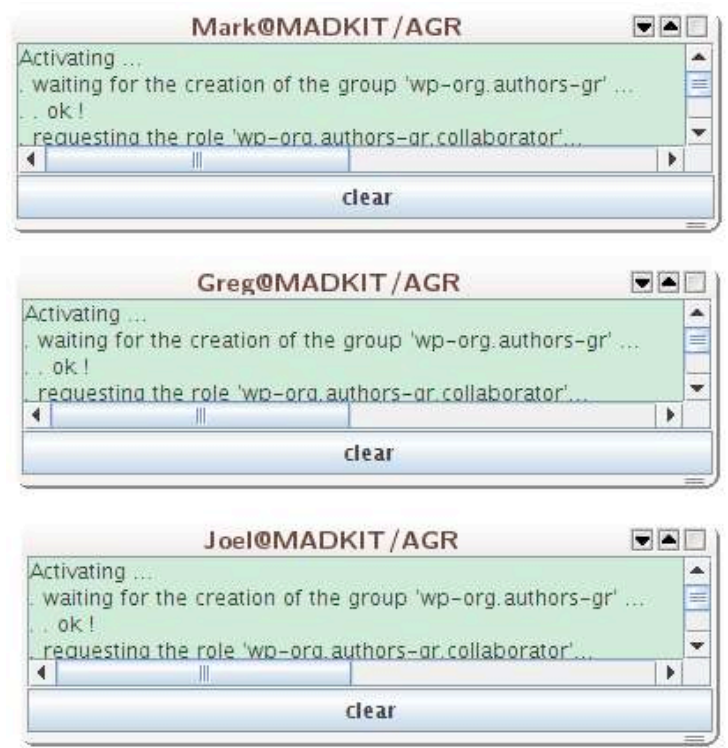
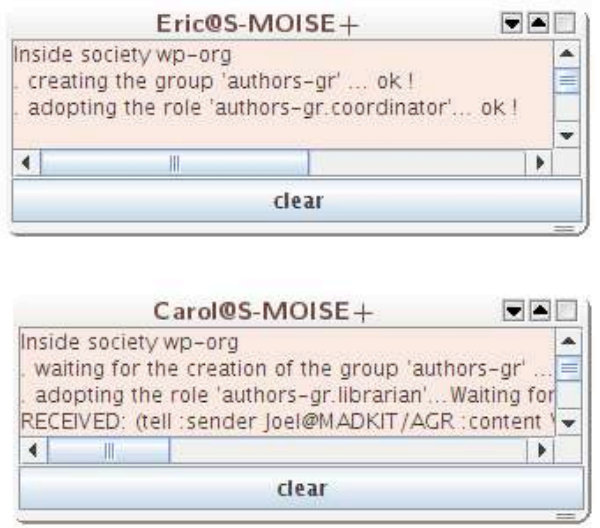

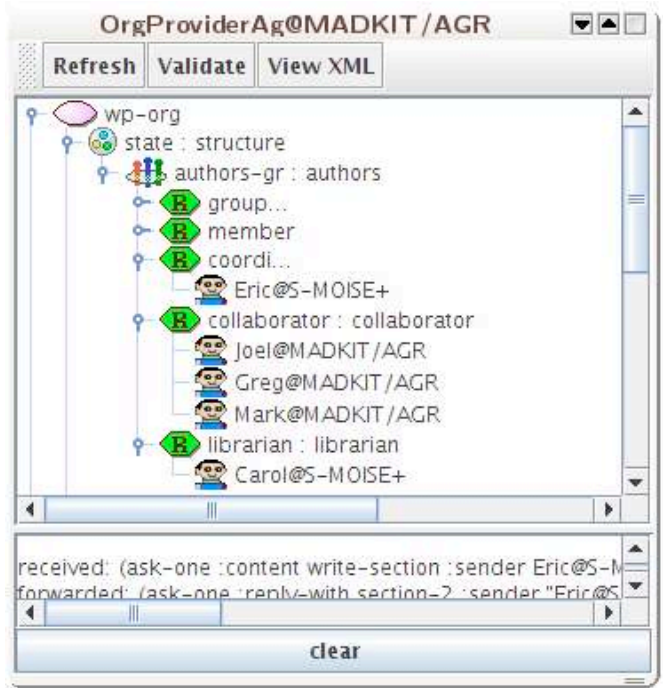

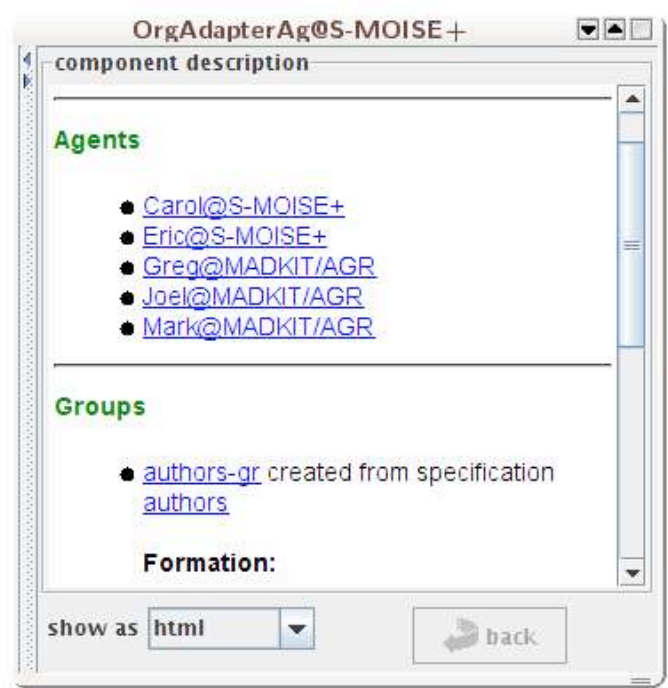

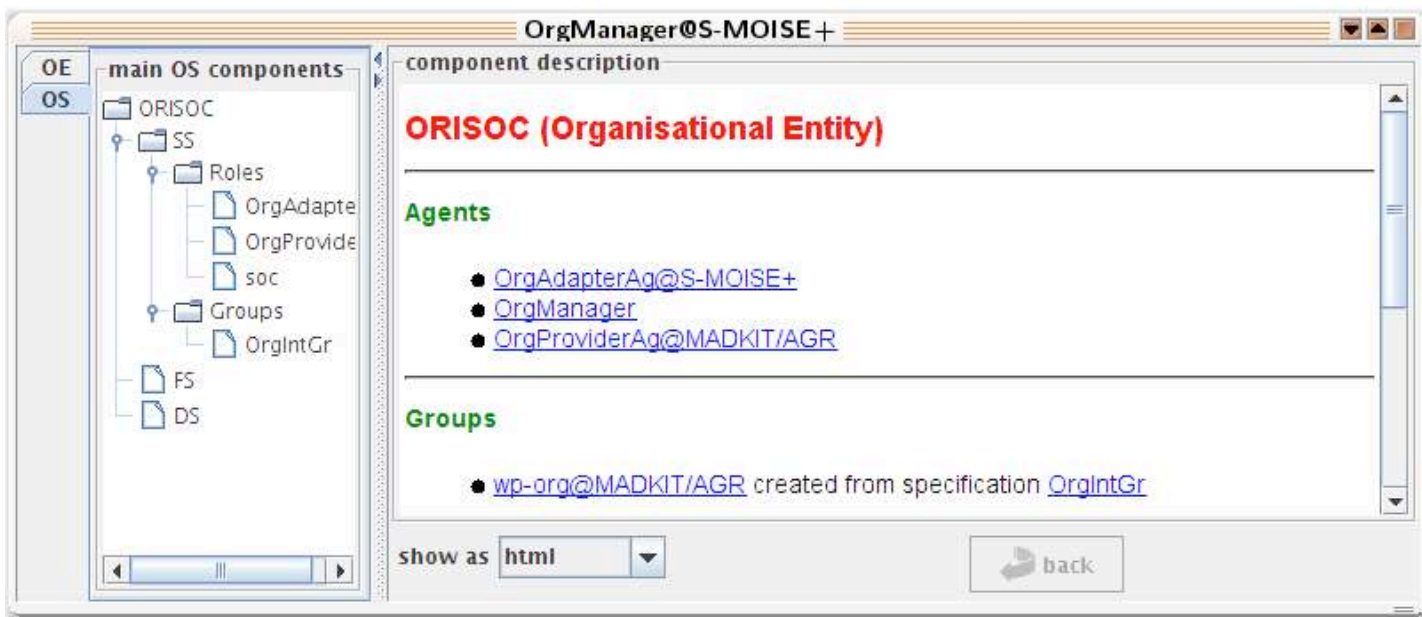

Figura 8.13: Experimento 4 - Provedor MADKIT e adaptador S-MOISE+; Joel, Greg e Mark em MADKIT; e Eric e Carol em S-MOISE+. 
interoperabilidade organizacional mais abrangentes podem também ser desenvolvidas a partir da integração de modelos organizacionais proposta.

Quanto ao desempenho, nota-se o seguinte. Para cada evento organizacional disparado pelos agentes, o estado da organização tem de ser atualizado. E isto sempre leva à ativação de transformações e a uma sequência de trocas de mensagens entre um provedor e vários adaptadores. Assim, caso ocorram muitos eventos organizacionais o tempo de resposta do sistema tende a aumentar. Um outro ponto problemático é a troca de mensagens entre os agentes. Neste caso, a cada troca de mensagem entre agentes situados em infraestruturas organizacionais distintas, a mensagem deve ser roteada através do provedor e adaptador(es). Entretanto, nota-se que os custos decorrentes da propagação de eventos organizacionais e do roteamento de mensagens são custos inerentes à própria natureza do problema sendo tratado, dado que se tem agentes situados em diferentes infraestruturas organizacionais. 


\section{Conclusões}

Neste trabalho, propôs-se um método para realizar sistematicamente a integração de modelos organizacionais, e especificou-se uma infraestrutura de interoperabilidade organizacional denominada MAORI, baseada na integração de modelos organizacionais. O método proposto foi aplicado para integrar os modelos organizacionais AGR, STEAM, MOISE+ e ISLANDER. O resultado da integração foi utilizado na implementação da infraestrutura MAORI no âmbito das infraestruturas organizacionais S-MOISE+ e MADKIT. Foram realizados alguns experimentos com a implementação de MAORI. Os resultados dos experimentos demonstram que, dentro dos limites inerentes à abordagem por adaptação adotada, MAORI efetivamente interconecta infraestruturas organizacionais distintas e permite que, em uma mesma organização de agentes, coexistam agentes desenvolvidos a partir de modelos organizacionais distintos. Assim, pode-se concluir que é possível integrar de modo consistente os modelos organizacionais, e que o resultado é aplicável na solução do problema de interoperabilidade organizacional.

A seguir, destacam-se as principais contribuições e possíveis extensões do trabalho realizado.

\subsection{Contribuições}

Na subseção 1.1.4, foram arroladas algumas questões que buscavam delimitar o escopo do trabalho de pesquisa. A seguir, retoma-se essas questões e apresentamse as respostas obtidas. As respostas destacam as principais contribuições desta tese.

- Como a estrutura conceitual dos modelos organizacionais existentes se relacionam? Há similaridades significativas ou todos apresentam uma visão radicalmente diferente e incompativel de como especificar organizações de agentes?

A resposta a esta questão encontra-se detalhada no capítulo 4. Após anali- 
sar uma parte significativa dos modelos organizacionais existentes, notou-se similaridade e complementaridade entre as estruturas conceituais dos modelos organizacionais analisados. De um ponto de vista amplo, os pontos comuns e complementares identificados foram classificados em cinco temas recorrentes de modelagem chamados de dimensões de modelagem organizacional: as dimensões funcional, estrutural, dialógica, normativa e ontológica.

Dos modelos analisados no capítulo 4, quase todos os modelos apresentam conceitos na dimensão estrutural, com exceção do modelo TAEMS. Também, quase todos os modelos promovem a modelagem funcional de organizações, com exceção de AGR e ISLANDER. Os modelos ISLANDER e OPERA apresentam estruturas conceituais bastante similares para modelagem dialógica de organizações. Conceitos normativos aparecem em MOISE+, ISLANDER e OPERA. Por fim, elementos para modelar explicitamente a linguagem de comunicação utilizada e ontologias do domínio de aplicação da organização são previstos tanto em ISLANDER como em OPERA. Essas observações foram resumidas na tabela 4.1.

De modo geral, as dimensões de modelagem organizacionais identificadas se devem ao fato de que organizações de agentes são sistemas projetados, e todo sistema projetado pode ser especificado destacando-se o seu comportamento funcional (dimensão funcional), a sua estrutura interna (dimensão estrutural) e o seu comportamento estrutural (dimensão dialógica). De modo particular, sendo concebidas como sistemas sociais, as organizações de agentes podem ainda ser modeladas quanto a aspectos normativos (dimensão normativa) e ontológicos (dimensão ontológica).

- Na hipótese de haver similaridades significativas, quais os conceitos de modelagem recorrentes nos modelos organizacionais?

Esta questão foi respondida no capítulo 5 na forma de padrões de modelagem organizacional, um para cada dimensão organizacional identificada. Resumidamente, o padrão da dimensão funcional é formado pelos conceitos recorrentes de definição meta, decomposição de uma meta em submetas, relacionamentos de ordem parcial ou influência entre metas, e definição de planos hierárquicos que agrupam a decomposição e relacionamentos entre metas. Por sua vez, o padrão da dimensão estrutural é composto pelos conceitos de definição de papel, relacionamentos entre papéis, e definição de grupo que envolvem tanto a definição de papéis quanto a definição de 
subgrupos. Já o padrão da dimensão dialógica é formado pelas noções de definição de diálogo, definição de cena que referencia definições de diálogo, relacionamentos entre cenas, e grafos de cenas que agrupam definições e relacionamento entre cenas. Quanto à dimensão normativa, o único conceito recorrente identificado foi a noção geral de norma. Por fim, a dimensão ontológica não foi analisada por se tratar de modelagem de domínio e não exatamente de modelagem organizacional.

- Levando em conta tanto os conceitos recorrentes quanto os conceitos particulares, é possível integrar os modelos organizacionais em um superconjunto consistente de conceitos, englobando a estrutura conceitual dos vários modelos organizacionais? Como metódica e tecnicamente realizar uma tal integração?

Esta questão foi respondida no capítulo 6. A resposta consistiu na definição e aplicação de um método sistemático para a integração incremental de modelos organizacionais. Pelo método, os modelos organizacionais são integrados realizando iterações. Em cada iteração acrescenta-se um modelo organizacional à integração de modelos obtida em uma iteração anterior, realizando-se três etapas: (1) a criação de um metamodelo $M M_{\#(i+1)}$ que represente o modelo organizacional a ser acrescentado a atual integração de modelos $M M_{\# i}^{i n t}$; (2) a identificação de correspondências semânticas entre $M M_{\#(i+1)}$ e $M M_{\# i}^{i n t}$, utilizando como heurística as dimensões e padrões de modelagem organizacionais propostas; (3) a geração de um novo metamodelo integrado $M M_{\#(i+1)}^{\text {int }}$, executando o algoritmo de junção descrito na subseção 3.2.3.4, passando como entrada os metamodelos $M M_{\#(i+1)}$ e $M M_{\# i}^{i n t}$, e as correspondências semânticas identificadas no passo anterior.

Ainda no capítulo 6, o método proposto foi aplicado para integrar os modelos organizacionais AGR, STEAM, MOISE+ e ISLANDER. Como resultado, obteve-se um metamodelo integrado $M M_{\# 3}^{\text {int }}$ capaz de expressar quaisquer especificações organizacionais escritas em AGR, STEAM, MOISE+ ou ISLANDER, bem como mapeamentos de correspondência semântica que relacionam as estruturas conceituais dos modelos particulares à estrutura conceitual de $M M_{\# 3}^{\text {int }}$.

- Na hipótese de se ter à disposição uma integração de modelos organizacionais, como efetivamente utilizá-la em uma solução de interoperabilidade organizacional?

Para responder a esta questão especificou-se (capítulo 7) e implementou-se 
(capítulo 8) a infraestrutura de interoperabilidade organizacional

MAORI, estruturada em duas camadas: a camada de integração de metamodelos (M2M) e a camada de interoperabilidade organizacional (ORI).

A integração de modelos organizacionais é utilizada para implementar os componentes da camada M2M. Na camada M2M, são implementados (a) um metamodelo $M M_{\#(n-1)}^{\text {int }}$ gerado a partir da integração de $n$ modelos organizacionais, (b) os metamodelos $M M_{1}, \ldots, M M_{n}$ que representam os $n$ modelos organizacionais subsumidos por $M M_{\#(n-1)}^{\text {int }}$, e (c) transformações que consistem em funções executáveis que podem ser utilizadas para converter especificações organizacionais entre modelos organizacionais. As transformações são definidas de acordo com os mapeamentos semânticos estabelecidos durante a geração de $M M_{\#(n-1)}^{\text {int }}$ a partir dos metamodelos $M M_{1}$, $\ldots, M M_{n}$.

Numa camada superior à camada M2M, os provedores e adaptadores organizacionais que compõem da camada ORI utilizam as transformações entre $M M_{\#(n-1)}^{i n t}$ e $M M_{1}, \ldots, M M_{n}$ para adaptar e compartilhar o estado e a especificação de uma organização de agentes entre várias infraestruturas organizacionais heterogêneas. Como resultado, torna-se possível a participação conjunta de agentes desenvolvidos a partir de modelos organizacionais distintos em uma mesma organização de agentes.

Além da infraestrutura MAORI, baseada em adaptação, a integração de modelos organizacionais proposta nesta tese pode ser utilizada como ponto de partida para uma padronização de modelos organizacionais ou a criação de agentes ou arquiteturas universais. Estas abordagens para prover interoperabilidade organizacional foram descritas na Introdução.

Adicionalmente, seis publicação foram produzidas durante o trabalho de pesquisa desenvolvido. As publicações são relacionadas abaixo, em ordem cronológica:

- "Modeling organization in MAS: a comparison of models" (COUTINHO; SICHMAN; BOISSIER, 2005);

- "Organizational modeling dimensions in multiagent systems" (COUTINHO; SICHMAN; BOISSIER, 2007);

- "Organizational interoperability in open multiagent systems - an approach based on metamodels and ontologies" (COUTINHO et al., 2007);

- "Model-driven integration of organizational models" (COUTINHO et al., 2008); 
- "Modelling dimensions for agent organizations" (COUTINHO; SICHMAN; BOISSIER, 2009);

- "A model-based architecture for organizational interoperability in open multiagent systems" (COUTINHO et al., 2009).

\subsection{Trabalhos Futuros}

No início e ao longo de todo este trabalho de pesquisa, várias escolhas tiveram de ser feitas para viabilizar a sua execução, devido a limitações de escopo e tempo. Por exemplo, dentre os modelos organizacionais existentes, seis foram escolhidos e analisados em detalhes; dentre os seis modelos analisados, a realização da integração de modelos organizacionais foi limitada a quatro (apenas os modelos que possuíam infraestruturas organizacionais que os implementam foram integrados); a implementação da camada ORI da infraestrutura MAORI foi realizada apenas para as infraestruturas S-MOISE e MADKIT, apesar de a camada M2M implementar os metamodelos e transformações dos quatro modelos que foram integrados; etc. Assim, há vários pontos nos quais os resultados obtidos nesta pesquisa podem ser estendidos, bem como novas linhas de pesquisas que podem ser exploradas. Como principais trabalhos futuros, apontam-se:

- Realizar uma análise detalhada de outros modelos organizacionais, tais como os modelos listados ao final da subseção 4.2.7. E, a partir desta análise, verificar se novas dimensões e padrões de modelagem organizacional podem ser identificadas, ou se os padrões que caracterizam as dimensões de modelagem já identificadas podem ser estendidos.

- Estender a integração de modelos organizacionais feita no capítulo 6, incluindo outros modelos, tais como TAEMS, OPERA, ODML, AUML, MASML, etc.

- No método de integração proposto no capítulo 6, a terceira etapa é completamente automática, sendo especificada pelo algoritmo de junção de metamodelos apresentado na subseção 3.2.3.4. Contudo, como mencionado no capítulo 6, a etapa de junção não foi realizada com o auxílio de um programa de computador, tendo sido realizada manualmente seguindo-se os passos do algoritmo utilizado. Assim, para facilitar o processo de estender e manter uma integração de vários modelos organizacionais, pode-se pensar em implementar o algoritmo de junção criando uma ferramenta de auxílio à integração de metamodelos. 
- Estender a infraestrutura MAORI, acrescentando aos representantes de agentes a capacidade de funcionarem como delegados, guiando os agentes heterogêneos quando necessário. Esta extensão de MAORI foi comentada ao final do capítulo 7 .

- Implementar a infraestrutura MAORI para outras infraestruturas organizacionais, tais como AMELI e TEAMCORE, e realizar novos experimentos em outros domínios de aplicação.

- Aplicar a integração de modelos organizacionais aqui proposta em outras soluções de interoperabilidade organizacional, além da adaptação. Por exemplo, utilizando-se a abordagem de universalidade discutida na subseção 1.1.3, uma idéia é projetar uma arquitetura de agente cujo "raciocínio organizacional" se dê a partir da integração de modelos organizacionais. Uma outra idéia é desenvolver uma infraestrutura organizacional a partir da integração. 


\section{Apêndice A - Meta-metamodelo de Ecore}

\section{Sintaxe}

Na figura A.1, encontra-se uma representação da estrutura conceitual da linguagem de meta-modelagem Ecore.

\section{Explicação preliminar}

O metamodelo da figura A.1 foi criado utilizando a própria linguagem que ele define, ou seja, de modo recursivo, tem-se um metamodelo de Ecore escrito em Ecore - o que é perfeitamente possível, uma vez que Ecore é uma linguagem aplicada à criação de metamodelos ${ }^{1}$. Assim, na leitura do (meta-)metamodelo de Ecore feita a seguir, serão utilizados inicialmente alguns termos tais como "classe", "atributo", "referência" e "generalização/especialização" que designam conceitos específicos de Ecore cujos significados só ficarão totalmente caracterizados ao final da explicação.

\section{Leitura do (meta-)metamodelo de Ecore}

Em Ecore, o conceito mais geral é a noção de elemento de modelagem (representada pela classe EModelElement ${ }^{2}$, figura A.1). Na "visão de mundo" (GUIZZARDI, 2007) de Ecore, tudo é encarado como um elemento de modelagem. Nada mais natural, tendo-se em vista a área de aplicação da linguagem que é a criação de metamodelos.

\footnotetext{
${ }^{1}$ Esta é uma prática tradicional na área de meta-modelagem. Quando uma linguagem de meta-modelagem tem a sua estrutura conceitual descrita por um metamodelo, este é designado como um meta-metamodelo. Caso o meta-metamodelo seja recursivo, i.e., escrito na própria linguagem cria-se uma arquitetura ou espaço de modelagem. Para mais detalhes, consultar (GASEVIC; DJURIC; DEVEDZIC, 2006, cap. 5).

${ }^{2}$ Palavras grafadas na fonte typewriter são utilizadas para designar elementos de modelagem presentes em um metamodelo sob discussão (no caso presente, o metamodelo da linguagem Ecore). Palavras grafadas em itálico (tais como elemento de modelagem) designão os conceitos de modelagem representados pelos elementos do metamodelo.
} 

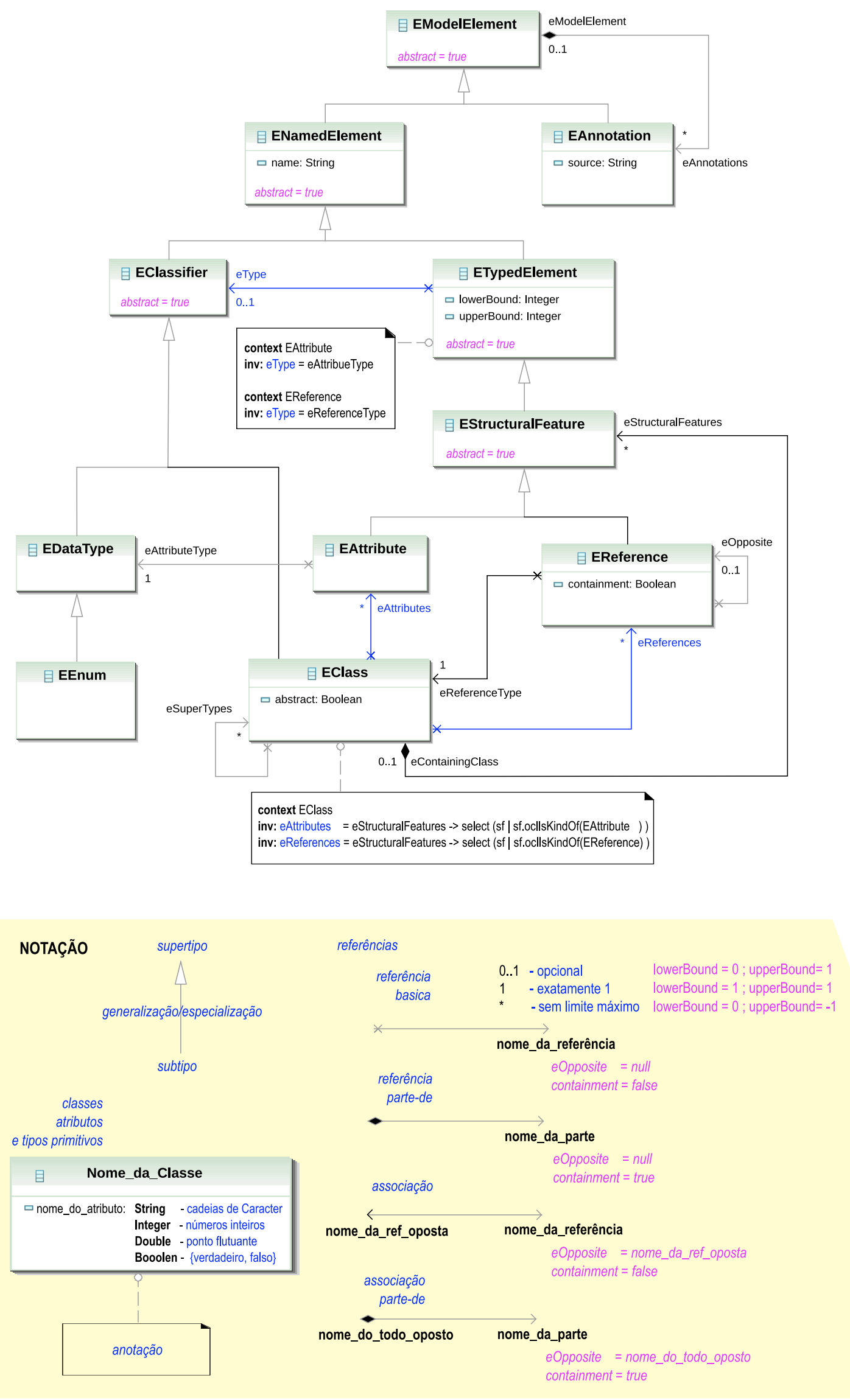

Figura A.1: Estrutura conceitual da linguagem de meta-modelagem Ecore. 
Em um primeiro nível, o conceito de elemento de modelagem se especializa em dois outros: o conceito de elemento nomeado (classe ENamedElement) e o conceito de anotação (classe EAnnotation). Um elemento nomeado é qualquer elemento de modelagem que se caracteriza por apresentar um nome (atributo name : String). Uma anotação, por sua vez, consiste em um elemento de modelagem que se caracterizam por um texto (atributo source : String) que se associa a elementos de modelagem com fins explicativos. Cada elemento de modelagem pode conter várias anotações (referência eAnnotations *); e cada anotação pode estar solta ou contida por no máximo um elemento de modelagem (referência eModelElement $0 . .1$ ).

Os elementos nomeados subdividem-se em classificadores (classe EClassifier) e elementos tipados (classe ETypedElement). A característica básica de classificadores é funcionar como tipos para elementos tipados. Cada elemento tipado opcionalmente pode referenciar no máximo um classificador como tipo (referência eType 0..1). Além disso, elementos tipados apresentam dois atributos: uma cardinalidade máxima (atributo upperBound : Integer) e uma cardinalidade mínima (atributo lowerBound : Integer). Respectivamente, estes atributos representam um número máximo e mínimo de instâncias do classificador que foi referenciado como tipo por um elemento tipado (via referência eType 0..1).

Quanto aos classificadores, há dois subtipos básicos: os tipos de dados e as classes. Um tipo de dados (classe EDataType) representa uma coleção de valores. Por padrão, há alguns tipos de dados primitivos tais como cadeias de caracteres (tipo String), números inteiros (tipo Integer), valores lógicos (tipo Boolean) e valores ponto flutuante (tipo Double). Além dos tipos primitivos, o conceito de tipo de dados se especializa em enumerações (classe EEnum). Enumerações são conjuntos de valores simbólicos definidos pelo usuário.

As classes (classe EClass), por outro lado, são classificadores que representam coleções de objetos (i.e., instâncias de uma classe) que possuem identidade e compartilham características estruturais (classe EStructuralFeature). O conceito de característica estrutural, por sua vez, é uma especialização de elemento tipado (classe ETypedElement).

Dentre as características estruturais compartilhadas por classes, há dois subtipos: atributos e referências. Um atributo (classe EAttribute) caracteriza-se por ter uma referência a um tipo de dados único (a referência eAttibuteType 1) e fazer parte da definição de uma classe (via referência eAttributes *).

Por sua vez, uma referência é similar a um atributo; ambos são carac- 
terísticas estruturais, logo, fazem parte da definição de uma classe e possuem uma referência a um classificador. A diferença básica está no fato de que referencias fazem parte de definição de classes via referência eReferences *, e o classificador que elas referenciam são classes (via referência eReferenceType 1) ao invés de tipos de dados. Além disso, referências podem se juntar aos pares formando referências opostas (por meio da referência eOpposite 0..1). A noção de referências opostas pode ser interpretada como uma associação no sentido de (BOOCH; RUMBAUGH; JACOBSON, 1999). As referências possuem ainda um atributo containment : Boolean que, quando verdadeiro, indica que as instâncias da classe referenciada são consideradas como sendo fisicamente contidas por instâncias da classe que as referencia (via referência eReferenceType 1). Em outras palavras, referências com containment = true caracterizam um relacionamento parte-de no sentido de (BOOCH; RUMBAUGH; JACOBSON, 1999).

Além de características estruturais, toda classe possui ainda uma referência eSuperTypes * que representa o relacionamento de generalização/especialização (ou super-tipo/sub-tipo) entre classes. O conceito de generalização/especialização, que vem sendo utilizado desde o início da discussão, significa que todas as instâncias da classe origem possuem todas as características (i.e., atributos, referências e super-tipos) da classe alvo, podendo, dessa forma, ser consideradas como instâncias indiretas da classe alvo, segundo o princípio da substituição (LISKOV, 1987). De modo inverso, uma classe origem é uma especialização de uma classe alvo no sentido de que pode acrescentar características extras às suas definições com relação à classe alvo.

Então, a partir do conceito de generalização, nota-se que os conceitos de classe, atributo, referência, tipo de dado e enumeração, todos eles são especializações do conceito de elemento nomeado. Logo, todos eles também possuem (ou herdam) o atributo nome (name : String) que caracteriza o conceito de elemento nomeado. Já os conceitos de atributo e referência, estes são especializações de característica estrutural; portanto herdam os atributos cardinalidade máxima (upperBound : Integer) e cardinalidade mínima (lowerBound : Integer), além da referência eType 0..1 que caracterizam o conceito abstrato de característica estrutural. No caso de atributos, a referência eType 0..1 se materializa na referência eAttributeType 1; no caso de referências, eType 0.1 se materializa na referência eReferenceType 1 .

Por fim, classes possuem um atributo abstract : Boolean que indica se a classe é abstrata ou não. Quando abstract = true (verdadeiro), a correspondente classe é abstrata. Uma classe abstrata significa uma classe que não 
admite instâncias diretas, mas apenas instâncias indiretas por meio de especializações. Uma classe concreta é o oposto de uma classe abstrata, i.e., tem o atributo abstract $=$ false, falso, e admite instâncias diretas.

\section{Anotações OCL}

Na figura A.1, há duas anotações escritas em OCL (OMG, 2006b). O objetivo de escrever anotações em OCL é expressar restrições contextuais que não são possíveis de representar apenas com os elementos de modelagem Ecore.

A primeira anotação está ligada à classe ETypedElement. Na anotação são estabelecidas duas condições invariantes que especificam o valor da referência eType 0..1 no contexto de EAttribute e EReference, ambas subclasses de ETypedElement. No contexto de EAttribute, especifica-se que o valor de eType deve ser o mesmo que o valor da referência eAttributeType 1. No contexto de EReference, determina-se que o valor de eType deve ser o valor da referência eReferenceType 1.

A segunda anotação está relacionada à classe EClass. Como na anotação anterior, nesta também são especificadas duas condições invariantes. A primeira invariante determina que o conteúdo da referência eAttributes *, no contexto de EClass, deve ser um subconjunto do conteúdo de eStructuralFeatures, uma outra referência em EClass. O subconjunto em questão é identificado como sendo o resultado da seleção dos objetos de tipo EAttribute dentre todos os objetos referenciados por eStructuralFeatures. De modo similar, a segunda invariante determina o conteúdo da referência eReferences *, identificado-o à seleção dos objetos de tipo EReference dentre todos os objetos referenciados por eStructuralFeatures.

\section{Em conclusão}

Ao se criar um metamodelo em Ecore, utilizam-se diretamente instâncias dos conceitos de classe, atributo, tipo de dados, enumeração, referência, generalização/especialização, e anotação.

Classes são utilizadas para representar explicitamente os conceitos primitivos de uma linguagem de modelagem. Atributos, tipos de dados e enumerações capturam propriedades ou características definidoras dos conceitos. Referências explicitam relacionamentos estruturais entre conceitos. Generalizações/especializações representam relações taxonômicas entre os conceitos de modelagem. Anotações 
consistem em itens de texto associados a elementos de modelagem com fins explicativos (ou para adicionar restrições contextuais extras escritas em OCL).

Esses conceitos, direta ou indiretamente, são especializações das noções abstratas de característica estrutural, elemento tipado, classificador, elemento nomeado e elemento de modelagem.

Tem-se um metamodelo Ecore bem formado ou válido quando, e somente quando, este foi criado preservando a estrutura e respeitando as restrições especificadas pelo (meta-)metamodelo de Ecore presente na figura A.1.

\section{Semântica}

Para fins de criação de metamodelos válidos, ou bem formados, a especificação da sintaxe de Ecore é suficiente. Por outro lado, para dar significado preciso a metamodelos válidos, i.e, para estabelecer como um metamodelo deve ser interpretado em relação à classe de modelos que ele próprio caracteriza como bem formados, há que se considerar a semântica de Ecore.

Por exemplo, no capítulo 3 é dito que o modelo representado na figura 3.3 é um modelo criado conforme o metamodelo da mLE mostrado na figura 3.2. Mas, neste caso, em que sentido deve-se interpretar a expressão "um modelo criado conforme o metamodelo"? Ou, de modo mais geral, o que significa a relação de conformidade ou validade entre modelos e metamodelos? Responder a esta questão implica em apresentar uma especificação da semântica de Ecore, enquanto linguagem de meta-modelagem.

\section{Semântica informal}

Em realidade, durante a descrição da sintaxe de Ecore feita na seção anterior, apresentou-se também uma descrição semântica dos conceitos subjacentes a metamodelos Ecore, porém de modo informal e intuitivo. Em retrospecto, têm-se as seguintes interpretações, onde os termos em negrito designam conceitos de Ecore, e os termos em itálico correspondem aos referentes dos conceitos:

- classes são utilizadas para representar explicitamente conceitos de modelagem; neste caso, conceitos de modelagem de uma dada linguagem são interpretados como coleções de objetos identificáveis no domínio de aplicação da linguagem; 
- atributos são utilizados para representar propriedades ou características básicas de conceitos de modelagem; neste caso, cada propriedade ou característica básica é interpretada como sendo um relacionamento entre objetos de uma dada coleção (conceito de modelagem) e valores de um particular domínio de valores, estes últimos representados ou por um tipo de dados ou por uma enumeração;

- referências são utilizadas para representar relacionamentos estruturais (dirigidos) entre dois conceitos de modelagem; neste caso, cada relacionamento estrutural é interpretado como uma coleção de ligações ou conexões existentes entre os objetos de duas coleções (conceitos de modelagem) relacionadas;

- generalizações/especializações são utilizadas para representar relacionamentos taxonômicos entre dois conceitos de modelagem; neste caso, um relacionamento taxonômico é interpretado como sendo o relacionamento entre uma sub-coleção de objetos (conceito mais especifico) e uma supercoleção que engloba todos os objetos sub-coleção (conceito mais geral).

A partir destas interpretações, em linhas gerais, a relação de conformidade entre (meta)modelos e (meta-)metamodelos pode ser analisada como se ilustra na figura A.2.

\section{Semântica formal}

Há várias maneiras de se especificar de modo mais preciso a semântica de Ecore. De um ponto de vista prático, Ecore é implementada pela plataforma de metamodelagem EMF (STEINBERG et al., 2008). Nesta implementação, há um modelo de transformação que especifica como metamodelos são traduzidos diretamente para uma representação em Java. Este tipo de descrição semântica, é chamado de semântica transformacional (CLARK; SAMMUT; WILLANS, 2008a).

De um ponto de vista mais teórico, há algumas alternativas de cunho matemático. Uma delas é representar os referentes dos metamodelos (i.e., coleções de objetos, valores, relações estruturais, relações taxonômicas, etc.) por meio de tipos algébricos (BORONAT; MESEGUER, 2007; OMG, 2006b). Uma outra possibilidade é utilização da teoria de tipos construtivos (POERnOMO, 2006). Por fim, um terceira abordagem consiste em representar a relação de conformidade entre modelos e metamodelos por meio de homomorfismos entre grafos (ou, grafos tipados)(DISKIN; KADISH, 2003). 


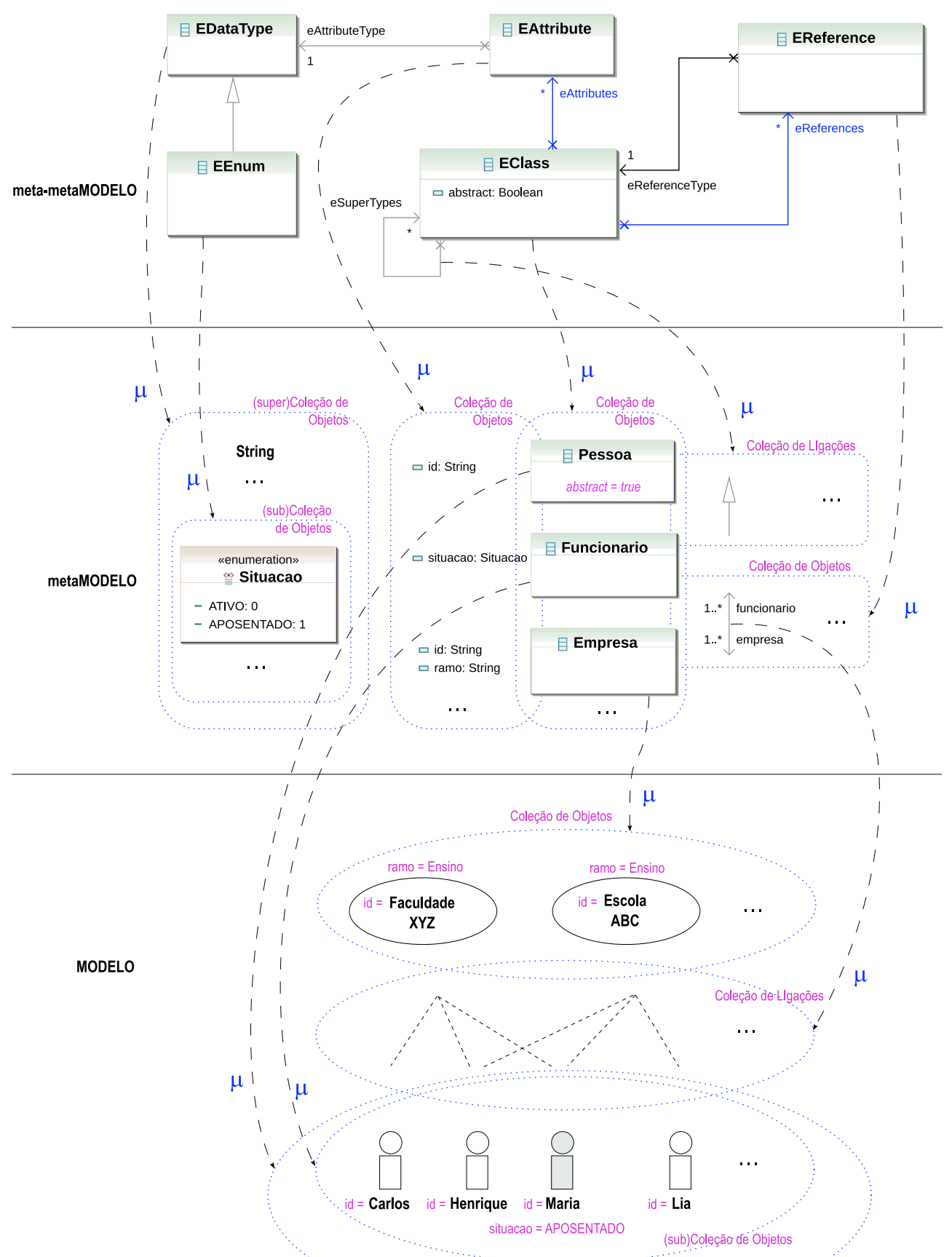

(super)Coleção de Objetos

Como:

tem-se:

IDEM

Como: i.e:

tem-se: (meta)modelo da mLE conforme (meta-)metamodelo de Ecore.

composição do modelo mLE, figura 3.3, respeita a interpretação do metamodelo mLE,

$$
\begin{aligned}
\{\text { FaculdadeXYZ, Escola }\} & \subseteq \boldsymbol{\mu}(\text { Empresa }) \\
\{\text { Carlos, Henrique, Maria, Lia }\} & \subseteq \boldsymbol{\mu}(\text { Funcionario }) \subseteq \boldsymbol{\mu}(\text { Pessoa }) \\
\{(\text { Carlos, FaculdadeXYZ }), \ldots,(\text { Lia, EscolaABC })\} & \subseteq \boldsymbol{\mu}(\text { funcionario }<-->\text { empresa })
\end{aligned}
$$

modelo da figura 3.3 conforme metamodelo da mLE.

$$
\text { \{Empresa, Funcionario, Pessoa }\} \subseteq \mu(\text { EClass })=\{\text { EClass, } \ldots\}
$$

composição do (meta)modelo mLE respeita a interpretação do (meta-)metamodelo Ecore,

Figura A.2: Conformidade entre (meta)modelos e (meta-)metamodelos. 


\title{
Anexo A - Metamodelos do Capítulo 4
}

\author{
Anexo em CD.
}


Anexo B - Metamodelos do Capítulo 6

Anexo em CD. 


\section{Anexo C - Implementação do Capítulo 8}

Anexo em CD. 


\section{Referências}

ACKOFF, R. L. Ackoff's best, His classic writings on management. New York, USA: John Wiley \& Sons, 1999.

BERNSTEIN, P. A. Applying model management to classical meta data problems. In: CIDR 2003, First Biennial Conference on Innovative Data Systems Research, Asilomar, CA, USA, January 5-8, Online proceedings. [S.l.: s.n.], 2003. p. 209-220.

BERTHET, S.; DEMAZEAU, Y.; BOISSIER, O. Knowing each other better. In: 11th International Workshop on Distributed Artificial Intelligence (IWDAI'92). Glen Arbor: [s.n.], 1992.

BéZIVIN, J.; GERBé, O. Towards a precise definition of the omg/mda framework. In: ASE '01: Proceedings of the 16th IEEE international conference on Automated software engineering. Washington: IEEE Computer Society, 2001. p. $273-280$.

BOISSIER, O. Modèles et architectures d'agents. In: BRIOT, J.-P.; DEMAZEAU, Y. (Ed.). Principes et architecture des systèmes multi-agents. Paris: Hermes, 2001. cap. 2.

BOISSIER, O.; HüBNER, J. F.; SICHMAN, J. S. Organisational oriented programming from closed to open organizations. In: O'HARE, G. M. P.; RICCI, A.; O'GRADY, M. J.; DIKENELLI, O. (Ed.). Engineering Societies in the Agents World VII, 7th International Workshop, ESAW 2006, Dublin, Ireland, September 6-8, 2006 Revised Selected and Invited Papers. Berlin: Springer, 2007. (LNCS, v. 4457), p. 86-105.

BOOCH, G. Object-oriented analysis and design with applications. Redwood City: Benjamin/Cummings, 1994.

BOOCH, G.; RUMBAUGH, J.; JACOBSON, I. The unified modeling language. Reading: Addison Wesley, 1999.

BORONAT, A.; MESEGUER, J. Algebraic Semantics of EMOF/OCL Metamodels. Urbana-Champaign, 2007.

BRIOT, J.-P.; DEMAZEAU, Y. (Ed.). Principes et architecture des systèmes multi-agents. Paris: Hermes, 2001.

BRUNET, G.; CHECHIK, M.; EASTERBROOK, S.; NEJATI, S.; NIU, N.; SABETZADEH, M. A manifesto for model merging. In: GaMMa '06: Proceedings of the 2006 international workshop on Global integrated model management. New York: ACM, 2006. p. 5-12. ISBN 1-59593-410-3. 
BUNEMAN, P.; DAVIDSON, S. B.; KOSKY, A. Theoretical aspects of schema merging. In: EDBT '92: Proceedings of the 3rd International Conference on Extending Database Technology. London: Springer, 1992. (LNCS, v. 580), p. 152-167. ISBN 3-540-55270-7.

BUNGE, M. Treatise on basic philosophy, Ontology II: A world of systems. Dordrecht: D. Reidel, 1979.

BéZIVIN, J. On the unification power of models. Software and System Modeling, v. 4, p. 171-188, 2005.

CADISH, B.; DISKIN, Z. Heterogeneous view integration via sketches and equations. In: RAS, Z.; MICHALEWICZ, M. (Ed.). ISMIS '96: Proceedings of the 9th International Symposium on Foundations of Intelligent Systems. London: Springer, 1996. (LNAI, v. 1079), p. 603-612. ISBN 3-540-61286-6.

CARABELEA, C.; BOISSIER, O.; FLOREA, A. Autonomy in multi-agent systems: a classification attempt. In: NICKLES, M.; ROVATSOS, M.; WEISS, G. (Ed.). Agents and Computational Autonomy: Potential, Risks, and Solutions. Berlin: Springer, 2004. (LNCS, v. 2969), p. $103-113$.

CASTELFRANCHI, C. Commitments: from individual intentions to groups and organizations. In: LESSER, V. R.; GASSER, L. (Ed.). Proceedings of the First International Conference on Multiagent Systems, June 12-14, 1995, San Francisco, California, USA. Cambridge: The MIT Press, 1995. p. 41-48.

CASTELFRANCHI, C. Modelling social action for AI agents. Artificial Intelligence, v. 103, p. 157-182, 1998.

CASTELFRANCHI, C. Engineering social order. In: OMICINI, A.; TOLKSDORF, R.; ZAMBONELLI, F. (Ed.). Engineering Societies in the Agents World: First International Workshop, ESAW 2000, Berlin, Germany, August 2000. Revised Papers. Berlin Heidelberg: Springer, 2000. (LNAI, v. 1972), p. 1-18.

CASTELFRANCHI, C.; MICELI, M.; CESTA, A. Dependence relations among autonomous agents. In: WERNER, E.; DEMAZEAU, Y. (Ed.). Decentralized AI 3. Amsterdan, NL: Elsevier, 1992. p. 215-227.

CAVEDON, L.; SONENBERG, L. On social commitment, roles and preferred goals. In: Proceedings of the 3rd International Conference on Multi Agent Systems. Washington, DC: IEEE Computer Society, 1998. p. 8-87.

CHAIB-DRAA, B.; DIGNUM, F. Trends in agent communication language. Computational Intelligence, v. 18, n. 2, p. 89-101, 2002.

CHAIB-DRAA, B.; MANDIAU, R.; MILLOT, P. Distributed artificial intelligence, an annotated bibliography. SIGART Bulletin, v. 3, n. 3, p. 20-37, 1992.

CHANDRASEKARAN, B.; JOSEPHSON, J. R.; BENJAMINS, V. R. What are ontologies, and why do we need them? IEEE Intelligent Systems, p. 20-26, January/February 1999.

CHEN, P. The entity-relationship model - toward a unified view of data. ACM Transactions on Database Systems, v. 1, n. 1, p. 9-36, 1976. 
CLARK, T.; EVANS, A.; KENT, S. Engineering modelling languages: A precise meta-modelling approach. In: FASE '02: Proceedings of the 5th International Conference on Fundamental Approaches to Software Engineering. London: Springer, 2002. (LNCS, v. 2306), p. 159-173. ISBN 3-540-43353-8.

CLARK, T.; SAMMUT, P.; WILLANS, J. Applied metamodelling - a foundation for language driven development. London: CETEVA, 2008.

CLARK, T.; SAMMUT, P.; WILLANS, J. Superlanguages - developing languages and applications with XML. London: CETEVA, 2008.

COUTINHO, L.; SICHMAN, J.; BOISSIER, O. Modeling organization in MAS: a comparison of models. In: 1st Workshop on Software Engineering for Agent-oriented Systems (SEAS05). Electronic Proceedings. Uberlândia, MG: SBC, 2005.

COUTINHO, L.; SICHMAN, J.; BOISSIER, O. Organizational modeling dimensions in multiagent systems. In: DIGNUM, V.; MATSON, E.; EDMONDS, B.; DIGNUM, F. (Ed.). Workshop on Agent Organizations: Models and Simulations (AOMS@IJCAI-07). Hyderabad: IJCAI, 2007.

COUTINHO, L.; SICHMAN, J.; BOISSIER, O. Modelling dimensions for agent organizations. In: DIGNUM, V. (Ed.). Handbook of research on multi-agent systems: semantics and dynamics of organizational models. Hershey: IGI Global, 2009. cap. II, p. 18-50.

COUTINHO, L. R.; BRANDãO, A. A. F.; SICHMAN, J. S.; BOISSIER, O. Organizational interoperability in open multiagent systems - an approach based on metamodels and ontologies. In: WOMSDE, II Wokshop on Ontologies and Metamodeling in Software and Data Engineering, 17 de outubro, João Pessoa, PB, Brasil. João Pessoa: SBC, 2007. p. 109-120.

COUTINHO, L. R.; BRANDãO, A. A. F.; SICHMAN, J. S.; BOISSIER, O. Model-driven integration of organizational models. In: LUCK, M.; GOMEZSANZ, J. (Ed.). Agent-Oriented Software Engineering IX, 9th International Workshop, AOSE 2008, Estoril, Portugal, May 12-13, Revised Selected Papers. Berlin: Springer, 2008. (LNCS, v. 5386), p. 1-15.

COUTINHO, L. R.; BRANDãO, A. A. F.; SICHMAN, J. S.; HüBNER, J. F.; BOISSIER, O. A model-based architecture for organizational interoperability in open multiagent systems. In: STATHIS, K.; SILVA, V. T. da; MATSON, E. (Ed.). Coordination, Organization, Institutions, and Norms in Agent Systems (COIN@IJCAI09). Pasadena, CA: IJCAI, 2009. p. 128-140.

COVRIGARU, A. A.; LINDSAY, R. K. Deterministic autonomous systems. AI Magazine, v. 12, n. 3, p. 110-117, Fall 1991.

CURY, A. Organização e métodos. São Paulo: Atlas S. A., 1990.

DAVIDSSON, P. Categories of artificial societies. In: OMICINI, A.; PETTA, P.; TOLKSDORF, R. (Ed.). Engineering Societies in the Agents World II: Second International Workshop, ESAW 2001, Prague, Czech Republic, July 7, 2001, Revised Papers. Berlin Heidelberg: Springer, 2001. (LNAI, v. 2203), p. 1-9. 
DECKER, K.; LESSER, V. Task environment centered design of organizations. In: AAAI Spring Symposium on Computational Organization Design. Menlo Park: AAAI, 1994.

DECKER, K. S. TAEMS: A framework for environment centered analysis \& design of coordination mechanisms. In: O'HARE, G.; JENNINGS, N. (Ed.). Foundations of distributed artificial intelligence. Malden: Wiley Inter-Science, 1996. cap. 16, p. 429-448.

DEMAZEAU, Y. From interactions to collective behaviour in agent-based systems. In: Proceedings of European Conference on Cognitive Science. Saint Malo: [s.n.], 1995. p. 117-132.

DIESTE, O.; JURISTO, N.; MORENO, A. M.; PAZOS, J.; SIERRA, A. Conceptual modeling in software engineering and knowledge engineering: Concepts, techniques and trends. In: CHANG, S. K. (Ed.). Handbook of Software Engineering and Knowledge Engineering. Singapore: World Scientific, 2002. I, p. 733-766.

DIGNUM, V. A model for organizational interaction: based on agents, founded in logic. Tese (Doutorado) — Utrecht University, 2004. SIKS Dissertation Series No. 2004-1.

DIGNUM, V. The role of organization in agent systems. In: DIGNUM, V. (Ed.). Handbook of research on multi-agent systems :semantics and dynamics of organizational models. Hershey: Information Science Reference, 2009. cap. I, p. $1-16$.

DIGNUM, V.; MEYER, J.-J.; WEIGAND, H.; DIGNUM, F. An organizationaloriented model for agent societies. In: Proceedings of International Workshop on Regulated Agent-Based Social Systems: Theories and Applications (RASTA'02), at AAMAS, Bologna, Italy, 16 July 2002. [s.n.], 2002. Disponível em: <http://www.cs.uu.nl/people/virginia/publications/vdignum-rasta.zip>.

DISKIN, Z.; DINGEL, J. A metamodel-independent framework for model transformation: Towards generic model management patterns in reverse engineering. In: FAVRE, J.-M.; GASEVIC, D.; LAEMMEL, R.; WINTER, A. (Ed.). 3rd International Workshop on Metamodels, Schemas, Grammars, and Ontologies. Berlin: Springer, 2007. (LNCS, v. 4364), p. 52-55.

DISKIN, Z.; DINGEL, J.; LIANG, H. Scenario integration via higher-order graphs. Kingston, 2006.

DISKIN, Z.; KADISH, B. Variable set semantics for keyed generalized sketches: formal semantics for object identity and abstract syntax for conceptual modeling. Data $\&$ Knowledge Engineering, v. 47, n. 1, p. 1-59, 2003.

DROGOUL, G.; CORBARA, B.; LALANDE, S. MANTA: new experimental results on the emergence of (artificial) ant societies. In: GILBERT, N.; CONTE, R. (Ed.). Artificial societies: the computer simulation of social life. London: UCL Press, 1995. p. 119-221.

DURFEE, E. H.; MONTGOMERY, T. A. A hierarchical protocol for coordinating multiagent behaviors. In: Proc. of AAAI-90, Eighth AAAI National Conference on AI,. Boston, MA: AAAI, 1990. p. 86-93. 
ESTEVA, M. Electronic Institutions: from specification to development. Tese (Doutorado) - Institut d'Investigació en Intel.ligència Artificial, Bellaterra, Catalonia, Spain, 2003.

ESTEVA, M.; CRUZ, D. de la; SIERRA, C. Islander: an electronic institutions editor. In: Proceedings of the First International Joint Conference on Autonomous Agents and MultiAgent Systems (AAMAS 2002). Bologna: ACM, 2002. p. $1045-1052$.

ESTEVA, M.; PADGET, J.; SIERRA, C. Formalizing a language for institutions and norms. In: MEYER, J.-J. C.; TAMBE, M. (Ed.). Intelligent Agents VIII: 8th International Workshop, ATAL 2001, Seattle, WA, USA, August 1-3. Revised Papers. Berlin Heidelberg: Springer, 2002. (LNAI, v. 2333), p. 348-366.

ESTEVA, M.; ROSELL, B.; RODRíGUEZ-AGUILAR, J. A.; ARCOS, J. L. AMELI: an agent-based middleware for electronic institutions. In: Third International Joint Conference on Autonomous Agents and Multiagent Systems (AAMAS'04), July 19 - 23. New York: IEEE Press, 2004. I, p. 236-243.

FABRO, M. D. D.; VALDURIEZ, P. Semi-automatic model integration using matching transformations and weaving models. In: SAC'07, Proceedings of the 2007 ACM symposium on Applied computing, Seoul, Korea, March 11 - 15. New York: ACM, 2007. p. 963-970.

FALLERI, J.-R.; HUCHARD, M.; LAFOURCADE, M.; NEBUT, C. Metamodel matching for automatic model transformation generation. In: MoDELS '08: Proceedings of the 11th international conference on Model Driven Engineering Languages and Systems. Berlin: Springer, 2008. p. 326-340. ISBN 978-3-540-87874-2.

FAVRE, J.-M. Foundations of meta-pyramids: Languages vs. metamodels - episode ii: Story of thotus the baboon1. In: BEZIVIN, J.; HECKEL, R. (Ed.). Language Engineering for Model-Driven Software Development. Dagstuhl: Internationales Begegnungs- und Forschungszentrum für Informatik (IBFI), 2005. (Dagstuhl Seminar Proceedings, 04101). ISSN 1862-4405. Disponível em: $<$ http://drops.dagstuhl.de/opus/volltexte/2005/21>.

FAVRE, J.-M. Megamodelling and etymology. In: CORDY, J. R.; LÄMMEL, R.; WINTER, A. (Ed.). Transformation Techniques in Software Engineering. Dagstuhl: Internationales Begegnungs- und Forschungszentrum für Informatik (IBFI), 2006. (Dagstuhl Seminar Proceedings, 05161). ISSN 1862-4405.

Disponível em: <http://drops.dagstuhl.de/opus/volltexte/2006/427>.

FEILER, P.; GABRIEL, R. P.; GOODENOUGH, J.; LINGER, R.; LONGSTAFF, T.; KAZMAN, R.; KLEIN, M.; NORTHROP, L.; SCHMIDT, D.; SULLIVAN, K.; WALLNAU, K. Ultra-Large-Scale Systems: The Software Challenge of the Future. Pittsburgh, PA, 2006.

FERBER, J.; GUTKNECHT, O. A meta-model for the analysis and design of organizations in multi-agent systems. In: Proceedings Third International Conference on Multi Agent Systems, July 03 - 07, Paris, France. New York: IEEE Press, 1998. p. 128-135. 
FERBER, J.; GUTKNECHT, O.; MICHEL, F. From agents to organizations: an organizational view of multi-agent systems. In: GIORGINI, P.; MüLLER, J. P.; ODELL, J. (Ed.). Agent-Oriented Software Engineering IV: 4th International Workshop, AOSE 2003, Melbourne, Australia, July 15, 2003, Revised Papers. Berlin: Springer, 2004. (LNCS, v. 2935), p. 214-230.

FERBER, J.; MICHEL, F.; BAEZ, J. AGRE: Integrating environments with organizations. In: WEYNS, D.; PARUNAK, H. V. D.; MICHEL, F. (Ed.). Environments for Multi-Agent Systems: First International Workshop, E4MAS 2004, New York, NY, July 19, 2004, Revised Selected Papers. Berlin: Springer, 2005. (LNCS, v. 3374), p. 48-56.

FININ, T.; LABROU, Y.; MAYFIELD, J. Kqml as an agent communication language. In: BRADSHAW, J. M. (Ed.). Software agents. Cambridge: MIT Press, 1997. p. 291-316.

FOWLER, M. Refactoring: Improving the Design of Existing Code. Reading: Addison Wesley, 1999.

FRANKLIN, S.; GRAESSER, A. Is it an agent, or just a program?: a taxonomy for autonomous agents. In: MüLLER, J. P.; WOOLDRIDGE, M.; JENNINGS, N. R. (Ed.). Intelligents Agents, III. Berlin: Springer, 1997. (LNAI, v. 1193), p. $21-36$.

GAMMA, E.; HELM, R.; JOHNSON, R.; VLISSIDES, J. Design Patterns: Elements of Reusable Object-Oriented Software. Reading: Addison Wesley, 1994.

GASEVIC, D.; DJURIC, D.; DEVEDZIC, V. Model driven architecture and ontology development. Berlin: Springer, 2006.

GASSER, L. Perspectives on organizations in multi-agent systems. In: LUCK, M.; MARíK, V.; STEPáNKOVá, O.; TRAPPL, R. (Ed.). Multi-Agent Systems and Applications: 9th ECCAI Advanced Course, ACAI 2001, and Agent Link's 3rd European Agent Systems Summer School, EASSS 2001; Prague, Czech Republic, July 2-13, 2001. Selected Tutorial Papers. Berlin Heidelberg: Springer, 2001. (LNAI, v. 2086), p. 1-16.

GERBé, O.; MINEAU, G. W.; KELLER, R. K. Conceptual graphs and metamodeling. In: DELUGACH, H. S.; STUMME, G. (Ed.). Proceedings of the 9th International Conference on Conceptual Structures: Broadening the Base. Berlin: Springer, 2001. (LNCS, v. 2120), p. 245-259.

GIAMPAPA, J. A.; PAOLUCCI, M.; SYCARA, K. Agent interoperation across multiagent system boundaries. In: Proceedings of the Fourth International Conference on Autonomous Agents (Agents 2000). New York: ACM, 2000. p. 179-186.

GOGUEN, J. A. Data, schema, ontology and logic integration. Journal of IGPL, v. 13, n. 6, p. 685-715, 2005.

GUIZZARDI, G. On ontology, ontologies, conceptualizations, modeling languages, and (meta)models. In: VASILECAS, O.; EDER, J.; CAPLINSKAS, A. (Ed.). Databases and Information Systems IV - Selected Papers from the Seventh International Baltic Conference DBESIS'2006. Amsterdam: IOS Press, 2007. p. 18-39. 
GUIZZARDI, G.; HERRE, H.; WAGNER, G. On the general ontological foundations of conceptual modeling. In: SPACCAPIETRA, S.; KAMBAYASHI, S. T. M. Y. (Ed.). ER '02: Proceedings of the 21st International Conference on Conceptual Modeling. London: Springer, 2002. (LNCS, v. 2503), p. 65-78. ISBN $3-540-44277-4$.

GUIZZARDI, G.; WAGNER, G.; GUARINO, N.; SINDEREN, M. van. An ontologically well-founded profile for UML conceptual models. In: PERSSON, A.; STIRNA, J. (Ed.). Advanced Information Systems Engineering, 16th International Conference, CAiSE 2004, Riga, Latvia, June 7-11, 2004, Proceedings. Berlin Heidelberg: Springer, 2004. (LNCS, v. 3084), p. 112-126.

GUTKNECHT, O. Proposition d'un modèle organisationnel générique de systèmes multi-agents: Examen de ses conséquences formelles, implémentatoires et méthodologiques. Tese (Doutorado) - Université des Sciences et Techniques du Languedoc, 2001.

GUTKNECHT, O.; FERBER, J. The MADKIT agent platform architecture. In: International Workshop on Infrastructure for Multi-Agent Systems: Infrastructure for Agents, Multi-Agent Systems, and Scalable Multi-Agent Systems. London: Springer, 2000. (LNCS, v. 1887), p. 48-55.

GâTEAU, B.; BOISSIER, O.; KHADRAOUI, D.; DUBOIS, E. Moiseinst: an organizational model for specifying rights and duties of autonomous agents. In: 1st International Workshop on Coordination and Organisation (CoOrg 2005) affiliated with the rth International Conference on Coordination Models and Languages, Namur - Belgium, April 20-23. [S.l.: s.n.], 2005.

HOPCROFT, J. E.; ULLMAN, J. D. Introduction to automata theory, languages, and computation. Reading: Addison Wesley, 1979.

HORLING, B.; LESSER, V. Quantitative organizational models for large-scale agent systems. In: Proceedings of the International Workshop on Massively Multi-Agent Systems, December 10-11, 2004, Kyoto Research Park. [S.l.: s.n.], 2004. p. 297-312.

HORLING, B.; LESSER, V. A survey of multi-agent organizational paradigms. The Knowledge Engineering Review, v. 19, n. 4, p. 281-316, 2005.

HüBNER, J. F. Um modelo de reorganização de sistemas multiagentes. Tese (Tese (Doutorado)) — Escola Politécnica da Universidade de São Paulo, 2003.

HüBNER, J. F.; SICHMAN, J. S.; BOISSIER, O. A model for the structural, functional, and deontic specification of organizations in multiagent systems. In: BITTENCOURT, G.; RAMALHO, G. L. (Ed.). Advances in Artificial Intelligence: 16th Brazilian Symposium on Artificial Intelligence, SBIA 2002 Porto de Galinhas/Recife, Brazil, November 11-14, 2002. Proceedings. Berlin Heidelberg: Springer, 2002. (LNAI, v. 2507), p. 118-128.

HüBNER, J. F.; SICHMAN, J. S.; BOISSIER, O. S-moise+: A middleware for developing organised multi-agent systems. In: BOISSIER, O.; DIGNUM, V.; MATSON, E.; SICHMAN, J. (Ed.). International Workshop on Organizations in Multi-Agent Systems: From Organizations to Organization Oriented Programming (OOOP 2005). [S.l.: s.n.], 2005. p. 107-120. 
JENNINGS, N. R. On agent-based software engineering. Artificial Intelligence, v. 117, n. 2, p. 277-296, 2000.

JENNINGS, N. R. An agent-based approach for building complex software systems. Communications of the ACM, v. 44, n. 4, p. 35-41, April 2001.

JENNINGS, N. R.; CAMPOS, J. R. Towards a social level characterization of socially responsible agents. IEE Proc. Softw. Eng., v. 144, n. 1, p. 11-25, 1997.

JOHNSON, S. Emergência: a vida integrada de formigas, cérebros, cidades e softwares. Rio de Janeiro: Jorge Zahar Ed., 2003.

JOUAULT, F.; BéZIVIN, J. KM3: A DSL for metamodel specification. In: Proceedings of 8th IFIP International Conference on Formal Methods for Open Object-Based Distributed Systems. Berlin: Springer, 2006. (LNCS, v. 4037), p. 171-185.

KALFOGLOU, Y.; SCHORLEMMER, M. Ontology mapping: the state of the art. The Knowledge Engineering Review, v. 18, n. 1, p. 1-31, 2003.

KARAGIANNIS, D.; KüHN, H. Metamodelling platforms. In: BAUKNECHT, K.; TJOA, A. M.; QUIRCHMAYR, G. (Ed.). EC-WEB '02: Proceedings of the Third International Conference on E-Commerce and Web Technologies. London: Springer, 2002. (LNCS, v. 2455), p. 182. ISBN 3-540-44137-9.

KATZAN, H. Systems Design and Documentation: An Introduction to the HIPO Method. New York: Van Nostrand Reinhold, 1976.

KELlY, S.; TOLVANEN, J.-P. Domain-Specific Modeling: Enabling Full Code Generation. Hoboken: Wiley-IEEE Computer Society Press, 2008.

KITIO, R.; BOISSIER, O.; HUBNER, J. F.; RICCI, A. Organisational artifacts and agents for open multi-agent organisations: giving the power back to the agents. In: SICHMAN, J. S.; PADGET, J. A.; OSSOWSKI, S.; NORIEGA, P. (Ed.). Coordination, Organizations, Institutions, and Norms in Agent Systems III, COIN 2007, International Workshops COIN@AAMAS 2007, Honolulu, HI, USA, May 14,2007, COIN@MALLOW 2007, Durham, UK, September 3-4, 200\%, Revised Selected Papers. Berlin: Springer, 2008. (LNAI, v. 4870), p. $171-186$.

KLEIN, M. Combining and relating ontologies: an analysis of problems and solutions. In: Proceedings of the IJCAI01 Workshop on Ontologies and Information Sharing. Washington: IJCAI, 2001. p. 53-62.

KLEPPE, A. Software Language Engineering: Creating Domain-Specific Languages Using Metamodels. Reading: Addison Wesley, 2008.

KNUTH, D. E. Backus normal form vs. backus naur form. Communications of the $A C M$, v. 7, n. 12, p. 735-736, 1964.

KOLP, M.; GIORGINI, P. A social ontology for information system development. DOCUMENT DE TRAVAIL WP30/02, ESPO/IAG Departement d'administration et de gestion, UCL. 2002. 
KURBEL, K.; LOUTCHKO, I. Towards multi-agent electronic marketplaces: what is there and what is missing? The Knowledge Engineering Review, v. 18, n. 1, p. 33-46, 2003.

KüHNE, T. Matters of (meta-)modeling. Software and System Modeling, v. 5, p. 369-385, 2006.

LABROU, Y.; FININ, T.; PENG, Y. Agent communication languages: the current landscape. IEEE Intelligent Systems, p. 45-52, March-April 1999.

LEMAîTRE, C.; EXCELENTE, C. B. Multi-agent organization approach. In: 2nd Iberoamerican Workshop on Distributed Artificial Intelligence and Multi-Agent Systems, Toledo, España, October 1-2. [S.l.: s.n.], 1998.

LESSER, V.; DECKER, K.; WAGNER, T.; CARVER, N.; GARVEY, A.; HORLING, B.; NEIMAN, D.; PODOROZHNY, P.; PRASAD, N. N.; RAJA, A.; VINCENT, R.; XUAN, P.; ZHANG, X. Q. Evolution of the GPGP/TAEMS domain-independent coordination framework. Autonomous Agents and Multi-Agent Systems, v. 9, p. 87-143, 2004.

LEVESQUE, H. J.; COHEN, P. R.; NUNES, J. H. T. On acting together. In: Proceedings of the 8th National Conference on Artificial Intelligence. Boston, Massachusetts, July 29 - August 3. Boston: AAAI Press / The MIT Press, 1990. p. $94-99$.

LISKOV, B. Keynote address - data abstraction and hierarchy. In: OOPSLA '87: Addendum to the proceedings on Object-oriented programming systems, languages and applications (Addendum). New York: ACM, 1987. p. 17-34. ISBN 0-89791-266-7.

LOPES, D.; HAMMOUDI, S.; ABDELOUAHAB, Z. Schema matching in the context of model driven engineering: From theory to practice. In: SOBH, T.; ELlEITHY, K. (Ed.). Advances in Systems, Computing Sciences and Software Engineering. [S.1.]: Springer, 2006. p. 219-227.

LUCK, M.; D'INVERNO, M. Autonomy: a nice idea in theory. In: CASTELFRANCHI, C.; LESPERANCE, Y. (Ed.). Intelligent Agents VII. Agent Theories Architectures and Languages: 7th International Workshop, ATAL 2000, Boston, MA, USA, July 2000. Proceedings. Berlin: Springer, 2001. (LNAI, v. 1986), p. $351-353$.

LUCK, M.; MARíK, V.; STEPáNKOVá, O.; TRAPPL, R. (Ed.). Multi-Agent Systems and Applications: 9th ECCAI Advanced Course, ACAI 2001, and Agent Link's 3rd European Agent Systems Summer School, EASSS 2001; Prague, Czech Republic, July 2-13, 2001. Selected Tutorial Papers, v. 2086 de LNAI, (LNAI, v. 2086). Berlin Heidelberg: Springer, 2001.

LUCK, M.; MCBURNEY, P.; PREIST, C. A manifesto for agent technology: towards next generation computing. Autonomous Agents and Multi-Agent Systems, v. 9, p. 203-252, 2004.

LUDEWIG, J. Models in software engineering ? an introduction. Software and System Modeling, v. 2, n. 1, p. 5-14, 2003. 
LYONS, D. M.; HENDRIKS, A. J. Reactive planning. In: SHAPHIRO, S. C. (Ed.). Encyclopedia of Artificial Intelligence. 2. ed. New York, USA: John Wiley \& Sons, 1992. p. 1171-1181. Disponível em: <citeseer.ist.psu.edu/lyons92reactive.html>.

MAGNIN, L.; PHAM, V. T.; DURY, A.; BESSON, N.; THIEFAINE, A. Our guest agents are welcome to your agent platforms. In: Proceedings of the ACM Symposium on Applied Computing 2002, Madrid, Spain, March 11 - 14. New York: ACM Press, 2002. p. 107-114.

MELLOR, S. J.; CLARK, A. N.; FUTAGAMI, T. Model-driven development. IEEE Software, v. 20, n. 5, p. 14-18, 2003.

MELNIK, S. Generic Model Management: Concepts And Algorithms. Secaucus: Springer, 2004. ISBN 3540219803.

MENEZES, P. B.; HAEUSLER, E. H. Teoria das categorias para a Ciência da Computação. Porto Alegre: Sagra Luzzatto, 2001.

MURATA, M.; LEE, D.; MANI, M.; KAWAGUCHI, K. Taxonomy of xml schema languages using formal language theory. ACM Trans. on Internet Technology, v. 5, n. 4, p. 1-45, 2005.

NEWELL, A. The knowledge level. Artificial Intelligence, v. 18, n. 1, p. 87-127, 1982.

NOY, N. F. Semantic integration: a survey of ontology-based approaches.

SIGMOD Record, ACM, New York, v. 33, n. 4, p. 65-70, 2004. ISSN 0163-5808.

OMG. Meta-Object Facility (2.0) Core Specification. 2006. OMG Document formal/2006-01-01.

OMG. Object Constraint Language, Version 2.0. 2006. último acesso: 30/05/2009. Disponível em: <http://www.omg.org/spec/OCL/2.0/>.

PARREIRAS, F. S.; STAAB, S.; WINTER, A. On marrying ontological and metamodeling technical spaces. In: ESEC-FSE companion '0\%: The 6th Joint Meeting on European software engineering conference and the ACM SIGSOFT symposium on the foundations of software engineering. New York: ACM, 2007. p. 439-448. ISBN 978-1-59593-812-1.

PARUNAK, H. V. D.; ODELL, J. J. Representing social structures in UML. In: WOOLDRIDGE, M. J.; WEIß, G.; CIANCARINI, P. (Ed.). Agent-Oriented Software Engineering II: Second International Workshop, AOSE 2001, Montreal, Canada, May 29, 2001. Revised Papers and Invited Contributions. Berlin Heidelberg: Springer, 2002. (LNCS, v. 2222), p. 1-16.

PITT, J.; MAMDANI, A.; CHARLTON, P. The open agent society and its enemies: a position statement \& programme of research. Telematics and Informatics, v. 18, n. 1, p. 67-87, 2001.

POERNOMO, I. The meta-object facility typed. In: SAC '06: Proceedings of the 2006 ACM symposium on Applied computing. New York: ACM, 2006. p. 1845-1849. ISBN 1-59593-108-2. 
POSLAD, S.; CHARLTON, P. Standardizing agent interoperability: the FIPA approach. In: AL., M. L. et (Ed.). ACAI 2001. Berlin: Springer, 2001. (LNAI, 2086), p. $98-117$.

POTTINGER, R.; BERNSTEIN, P. A. Merging models based on given correspondences. In: FREYTAG, J. C.; LOCKEMANN, P. C.; ABITEBOUL, S.; CAREY, M. J.; SELINGER, P. G.; HEUER, A. (Ed.). VLDB 2003, Proceedings of 29th International Conference on Very Large Data Bases, September 9-12, 2003, Berlin, Germany. San Francisco, CA: Morgan Kaufmann, 2003. p. 826-873.

PYNADATH, D. V.; TAMBE, M.; CHAUVAT, N.; CAVEDON, L. Toward team-oriented programming. In: JENNINGS, N. R.; LESPéRANCE, Y. (Ed.). Intelligent Agents VI: Agent Theories, Architectures, and Languages, 6th International Workshop, ATAL'99 Orlando, Florida, USA, July 15-17, 1999. Proceedings. Berlin: Springer, 2000. (LNAI, v. 1757), p. $233-247$.

RAHM, E.; BERNSTEIN, P. A. A survey of approaches to automatic schema matching. The VLDB Journal, Springer-Verlag New York, Inc., Secaucus, NJ, USA, v. 10, n. 4, p. 334-350, 2001. ISSN 1066-8888.

RICO, D. IDEF0 methodology. New York: J. Ross Publishing, 2004.

SABETZADEH, M.; EASTERBROOK, S. View merging in the presence of incompleteness and inconsistency. Requirements Engineering Journal, v. 11, n. 3, p. 174-193, 2006.

SANDHOLM, T. Distributed rational decision making. In: WEISS, G. (Ed.). Multiagent systems. Cambridge: MIT Press, 1999. p. 201-258.

SCHMIDT, D. C. Model-driven engineering. IEEE Computer, p. 25-31, February 2006 .

SCHMITT, I.; SAAKE, G. A comprehensive database schema integration method based on the theory of formal concepts. Acta Informatica, SpringerVerlag New York, Inc., Secaucus, NJ, USA, v. 41, n. 7, p. 475-524, 2005. ISSN 0001-5903.

SCOTT, W. R. Organizations: rational, natural and open systems. 4. ed. Upper Saddle River: Prentice Hall, 1998.

SEARLE, J. R. Mente, linguagem e sociedade: filosofia no mundo real. Rio de Janeiro: Rocco, 2000.

SEIDEWITZ, E. What models mean. IEEE Software, v. 20, n. 5, p. 26-32, 2003.

SELIC, B. The pragmatics of model-driven development. IEEE Software, v. 20, n. 5 , p. 19-25, 2003.

SHETH, A. P.; LARSON, J. A. Federated database systems for managing distributed, heterogeneous, and autonomous databases. ACM Computing Surveys, ACM, New York, v. 22, n. 3, p. 183-236, 1990. ISSN 0360-0300.

SHVAIKO, P.; EUZENAT, J. A survey of schema-based matching approaches. In: Journal on Data Semantics IV. Berlin: Springer, 2005, (LNCS, v. 3730). p. 146-171. 
SICHMAN, J. S.; DEMAZEAU, Y. A model for the decison phase of autonomous belief revision in open multi-agent systems. Journal of the Brazilian Computer Society, v. 3, n. 1, p. 40-50, 1996.

SICHMAN, J. S.; DEMAZEAU, Y. On social reasoning in multi-agent systems. Revista Iberoamericana de Inteligencia Artificial, v. 13, p. 68-84, 2001.

SIERRA, C. Agent-mediated electronic commerce. Autonomous Agents and Multi-Agent Systems, v. 9, p. 285-301, 2004.

SILVA, V.; CHOREN, R.; LUCENA, C. A UML based approach for modeling and implementing multi-agent systems. In: AAMAS (Ed.). Third International Joint Conference on Autonomous Agents and Multiagent Systems (AAMAS'04), July 19 - 23, 2004, New York City, NY, USA. New York: IEEE Press, 2004. p. 914-921.

SILVA, V.; GARCIA, A.; BRANDãO, A.; CHAVEZ, C.; LUCENA, C.; ALENCAR, P. Taming agents and objects in software engineering. In: GARCIA, A.; LUCENA, C.; ZAMBONELli, F.; OMICINI, A.; CASTRO, J. (Ed.). Software Engineering for Large-Scale Multi-Agent Systems: Research Issues and Practical Applications. Berlin Heidelberg: Springer, 2003. (LNCS, v. 2603), p. $1-26$.

SMITH, R. G. The contract net protocol: high-level communication and control in a distributed problem solver. IEEE Transactions on Computers, v. 29, n. 12, p. 1104-1113, 1980.

STACHOWIAK, H. Allgemeine Modelltheorie. Wien: Springer, 1973.

STEINBERG, D.; BUDINSKY, F.; PATERNOSTRO, M.; MERKS, E. EMF: Eclipse Modeling Framework. Reading: Addison-Wesley, 2008.

TAMBE, M. Towards flexible teamwork. Journal of Artificial Intelligence Research, v. 7, p. 83-124, 1997.

TAMBE, M.; ADIBI, J.; AL-ONAIZAN, Y.; ERDEM, A.; KAMINKA, G. A.; MARSELLA, S. C.; MUSLEA, I. Building agent teams using an explicit teamwork model and learning. Artificial Intelligence, v. 110, p. 215-239, 1999.

TAMBE, M.; PYNADATH, D. V. Towards heterogeneous agent teams. In: LUCK, M.; MARíK, V.; STEPáNKOVá, O.; TRAPPL, R. (Ed.). Multi-Agent Systems and Applications: 9th ECCAI Advanced Course, ACAI 2001, and Agent Link's 3rd European Agent Systems Summer School, EASSS 2001; Prague, Czech Republic, July 2-13, 2001. Selected Tutorial Papers. Berlin Heidelberg: Springer, 2001. (LNAI, v. 2086), p. 187-210.

TIMASHEFF, N. S. The basic concepts of sociology. The American Journal of Sociology, v. 58, n. 2, p. 176-186, 1952.

USCHOLD, M. Knowledge level modelling: concepts and terminology. The Knowledge Engineering Review, v. 13, n. 1, p. 5-29, 1998.

VINCENT, R.; HORLING, B.; LESSER, V. R. An agent infrastructure to build and evaluate multi-agent systems: The java agent framework and multi-agent system simulator. In: International Workshop on Infrastructure 
for Multi-Agent Systems: Infrastructure for Agents, Multi-Agent Systems, and Scalable Multi-Agent Systems. London: Springer, 2000. (LNCS, v. 1887), p. 102-127.

VáZQUEZ-SALCEDA, J.; DIGNUM, V.; DIGNUM, F. Organizing multiagent systems. Institute of Information and Computing Sciences, Utrecht University, 2004. Disponível em: <http://www.cs.uu.nl/research/techreps/UU-CS-2004015.html>. Acesso em: 07.12.2005.

WEGNER, P. Interoperability. ACM Computing Surveys, v. 28, n. 1, p. 285-287, 1996.

WELLMAN, M. P.; WURMAN, P. R.; OMALLEY, K.; BANGERA, R.; LIN, S. D.; REEVES, D.; WALSH, W. E. Designing the market game for a trading agent competition. IEEE Internet Computing, v. 5, n. 2, p. 43-51, 2001.

YOURDON, E. Análise estruturada moderna. Rio de Janeiro: Campus, 1992.

ZAMBONELLI, F.; JENNINGS, N. R.; WOOLDRIDGE, M. Organisational abstractions for the analysis and design of multi-agent systems. In:

CIANCARINI, P.; WOOLDRIDGE, M. (Ed.). Agent-Oriented Software Engineering: First International Workshop, AOSE 2000, Limerick, Ireland, June 10, 2000. Revised Papers. Berlin Heidelberg: Springer, 2001. (LNCS, v. 1957), p. 235-251.

ZAMBONELLI, F.; JENNINGS, N. R.; WOOLDRIDGE, M. Developing multiagent systems: the Gaia methodology. ACM Transactions on Software Engineering and Methodology, v. 12, n. 3, p. 317-370, 2003.

ZAMBONELLI, F.; OMICINI, A. Challenges and research directions in agent-oriented software engineering. Autonomous Agents and Multi-Agent Systems, v. 9, n. 3, p. 253-283, 2004.

ZAMBONELLI, F.; PARUNAK, H. V. D. Towards a paradigm change in computer science and software engineering: a synthesis. The Knowledge Engineering Review, v. 18, n. 4, p. 329-342, 2004. 